Carlos Elias da Silva Junior

\title{
ESTUDO EXPERIMENTAL DAS PRINCIPAIS CARACTERÍSTICAS DE UM DRESSADOR SINTERIZADO COM ÊNFASE NA DISSIPAÇÃO DE CALOR
}

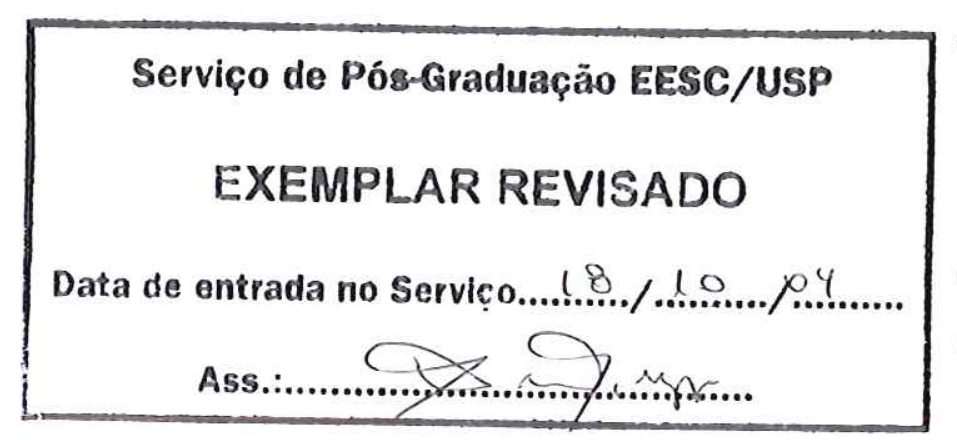

Tese apresentada à Escola de Engenharia de São Carlos, da Universidade de São Paulo, como parte dos requisitos para obtenção do título de Doutor em Engenharia Mecânica.

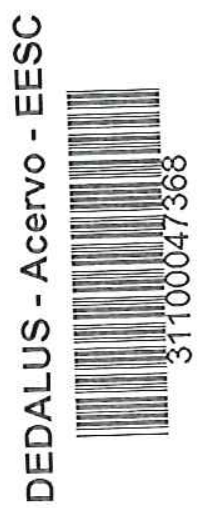

Orientador: Prof. Dr. Reginaldo Teixeira Coelho.

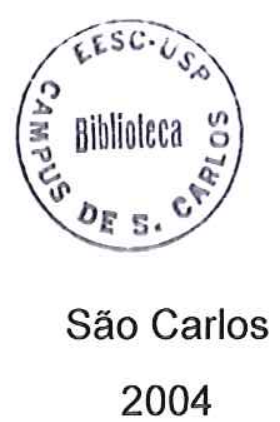


FOLHA DE JULGAMIENTO

Candidato: Engenheiro CARLOS ELIAS DA SILVA JUNIOR

Tese defendida e julgada em 07-04-2004 perante a Comissão Julgadora:

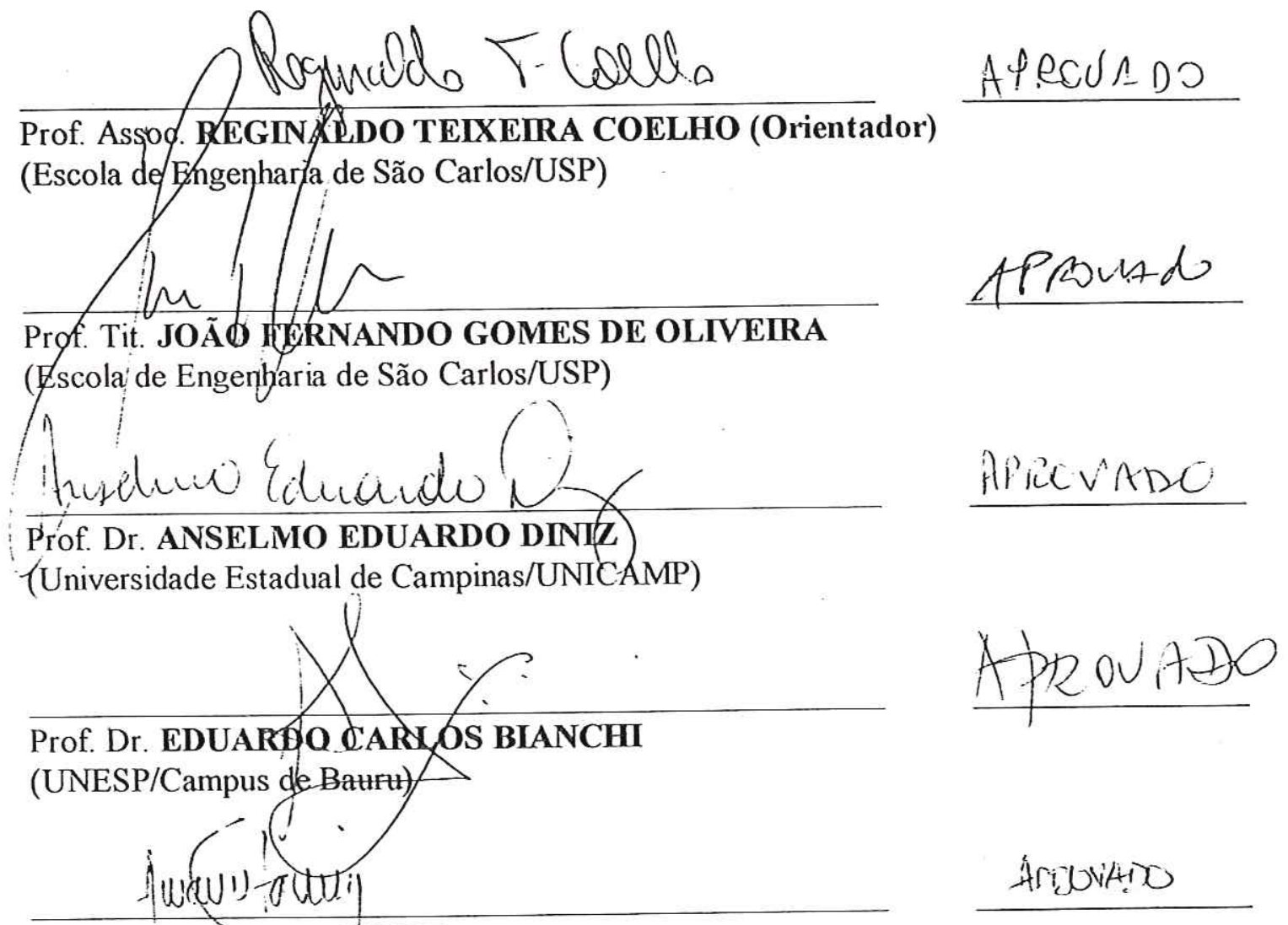

Prof. Dr. AMÁUR HASSUI

(Escola Politécnica/USP)

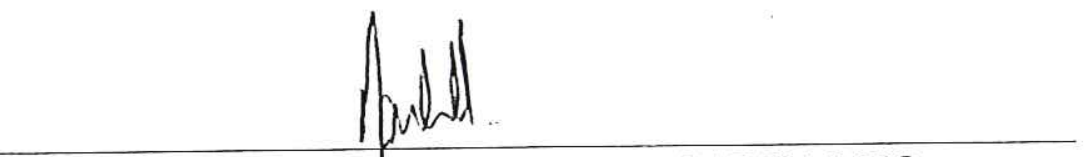

Prof. Associado JONAS DE CARVALHO

Coordenadorl do Programa de Pós-Graduação

em Engenharia Mecânica

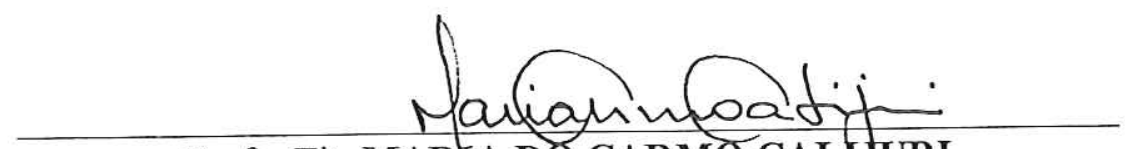

Profa. Tit. MAR IA DO CARMO CALIJURI

Presidente da Comissão de Pós-Graduação 
Às pessoas que foram meu suporte nesta jornada, Meus pais, Carlos e Romualda, Minhas irmãs Alda e Ana Carla, E você Dulce. 


\section{AgRADECIMENTOS}

Em primeiro lugar, agradeço a Deus, por tudo.

À minha família, por representar um porto seguro onde sempre consegui recuperar o ânimo nos momentos de dificuldade.

Ao Professor Reginaldo Teixeira Coelho pela orientação e compreensão.

Ao Professor João Fernando Gomes de Oliveira pelo auxílio na discussão dos resultados.

Ao Laboratório de Mecânica Aplicada e Computacional (LAMAC - EESC) por disponibilizar uma licença do software ANSYS ${ }^{\circledR}$ utilizado nas simulações.

Ao técnico mecânico Ronaldo de Oliveira Martins pelo inestimável auxílio na montagem do banco de ensaios e pelo companheirismo sempre presente.

Aos técnicos e funcionários do Lamafe (Adão Santo Bolzan, José Carlos Risardi, José Carlos Botelho) e da oficina mecânica da EESC - SEM (Adolfo e Marcelo), do Departamento de Engenharia de Materiais, Aeronáutica e Automobilística da EESC - SMM (Tico, Silvano, João, Pedro) e da oficina mecânica e vidraria do Departamento de Química - IQSC (Sr. Antônio e Edinho) por toda a ajuda prestada.

À pesquisadora $\mathrm{Dr}^{\mathrm{a}}$. Eliria Pallone pelas valiosas informações sobre o processo de sinterização, aos professores Walter Botta, Cláudio Kyminami e Maurizzio Ferrante pelas orientações e permissão para a utilização das instalações e equipamentos do DEMa, e aos alunos e funcionários do DEMa - UFSCar (Emerson, Heitor, Silma, Vânia, Walter Mariano, Sr. Cândido) por todo o apoio dispensado. 
Aos amigos Aldo, Alessandro, Carlos Magno (Dinho) e Fábio pelo grande auxílio no planejamento/execução dos ensaios.

A todos os demais integrantes do Laboratório OPF, Adriano Fagali, Aldo Ometto, Américo, César, Daniel, Douglas, Emanoel, Emílio, Eraldo, Gleisson, Guilherme, Hugo, Irene, Jalon, João Chagas, João Jorge, Leonardo, Lincoln, Marcelo Biffi, Marcelo del Guerra, Milton, Octaviano, Paulo Bellini, Ricardo, Salete, Tadeu, Tiago, Tobias e Vinícius pela agradável convivência.

A todos os colegas da Pós-Graduação e Graduação, professores e funcionários do Departamento de Engenharia Mecânica da EESC/USP.

À Ana Paula, funcionária da Secretaria de Pós-Gradução do Departamento de Engenharia Mecânica, por sua atenção e solicitude.

À Fapesp pela bolsa de estudos concedida e à empresa De Beers (Debid do Brasil Ltda.), na pessoa do Sr. Luis Carlos Caetano, pela doação dos diamantes utilizados no dressador.

À todas as pessoas que, de uma forma ou de outra, em maior ou menor grau, contribuíram para a realização deste trabalho. 


\section{RESUMO}

SILVA JUNIOR, C. E. (2004). Estudo experimental das principais características de dressadores sinterizados com ênfase na dissipação de calor. Tese (Doutorado) - Escola de Engenharia de São Carlos, Universidade de São Paulo, São Carlos, 2004.

No processo de retificação a dressagem desempenha um papel fundamental, uma vez que ela é responsável pela topografia da superfície de trabalho do rebolo, podendo afetar os resultados da retificação em termos da integridade superficial e precisão dimensional da peça, bem como a confiabilidade do processo. Portanto, como parte integrante da operação de retificação, a dressagem pode melhorar significativamente a qualidade das peças retificadas caso melhores dressadores sejam produzidos. Este trabalho tem o objetivo de estudar as principais características necessárias ao projeto de dressadores sinterizados que utilizam diamantes sintéticos de perfil constante e verificar experimentalmente a distribuição de temperaturas no dressador, obtidas através de ensaios práticos e simulação computacional pelo método dos elementos finitos. O modelo utilizado contém algumas limitações, porém os resultados obtidos mostraram que os níveis de temperaturas no dressador foram afetados pelos parâmetros de dressagem considerados no trabalho, a saber, a profundidade de dressagem $\left(\mathbf{a}_{\mathrm{d}}\right)$, o grau de recobrimento de dressagem $\left(\mathbf{U}_{\mathrm{d}}\right)$ e a vazão do fluido refrigerante $(\mathbf{Q})$. O desgaste do dressador foi afetado apenas pelos parâmetros de dressagem.

Palavras-chave: retificação, dressagem, diamante sintético, liga sinterizada, temperatura. 


\section{ABStRAct}

SILVA JUNIOR, C. E. (2004). Experimental study on the main characteristics of sintered dressing tools with emphasis on heat dissipation. $\mathrm{Ph}$. D. Thesis Escola de Engenharia de São Carlos, Universidade de São Paulo, São Carlos, 2004.

In grinding operations, dressing tools are of major importance, since they are responsible for the topography of the wheel working surface and, consequently, can affect the grinding results in terms of surface integrity, dimensional accuracy and process reliability. Therefore, as an important part of the grinding operation, dressing can significantly improve the quality of ground parts if better dressing tools are produced. This work studies the main needs for designing sintered dressing tools made with constant cross sectional synthetic diamonds. It also analyses the temperature distribution over a novel dressing tool design using experimental measurements to feed computacional simulation by the finite element method (FEM). The temperature model employed showed some limitations but the obtained results indicated that temperature levels over the dressing tool were affected by the dressing parameters considered in this work, namely the dressing depth of cut $\left(\mathbf{a}_{\mathrm{d}}\right)$, the dressing overlapping parameter $\left(U_{d}\right)$ and the flow rate $(\mathbf{Q})$. Additionally, one can say that the dressing tool wear was affected only by the dressing parameters.

Keywords: grinding, dressing, synthetic diamond, sintered bond, temperature. 


\section{LISTA DE FIGURAS}

FIGURA 1: SINAIS DE E.A. OBTIDOS NA DRESSAGEM DE REBOLOS COM PERFIL (A) UNIFORME E (B) IRREGULAR (INASAKI, 1985)

FIGURA 2: COMPORTAMENTO DO SINAL DE E.A. EM FUNÇÃO DA PROFUNDIDADE DE DRESSAGEM (INASAKI, 1985). 9

FIGURA 3: INFLUÊNCIA DO PASSO DE DRESSAGEM SOBRE A E.A., A RUGOSIDADE RA DA PEÇA E A POTÊNCIA DE RETIFICAÇÃO (INASAKI, 1985)...

FIGURA 4: COMPORTAMENTO dO SINAL DE E.A. DURANTE AS TRÊS FASES DE INTERAÇÃO ENTRE DRESSADOR E REBOLO (OLIVEIRA et al., 1994B).

FIGURA 5: EFEITO DA VELOCIDADE TRANSVERSAL E DO NÚMERO DE PASSES DE DRESSAGEM SOBRE O DIAMANTE DO DRESSADOR (SEN,2000).

FIGURA 6: O DRESSADOR COM PERFIL DE ATUAÇÃO CONSTANTE (VIGNA, 1997)

FIGURA 7: CINEMÁTICA DA OPERAÇÃO DE DRESSAGEM (SILVA JUNIOR, 1998). 21

FIGURA 8: (a) PRENSA UTILIZADA NA PRODUÇĀO DE SEGMENTOS DE FERRAMENTAS DE DIAMANTE ATRAVÉS DA PRENSAGEM À QUENTE DE PÓS METÁLICOS; (b) DIAGRAMA ESQUEMÁTICO DO PROCESSO (BAKON E SZYMANSKI, 1993).

FIGURA 9: PROPRIEDADES DOS MATERIAIS PARA FERRAMENTAS DE CORTE (CLARK E SEN, 1998) . . 40

FIGURA 10: CONDUTIVIDADE TÉRMICA À TEMPERATURA AMBIENTE DO DIAMANTE E DE OUTROS MATERIAIS (CLARK e SEN, 1998 ).

FIGURA 11: DIFERENTES DIAMANTES NATURAIS EMPREGADOS EM DIFERENTES TIPOS DE DRESSADORES (SEN, 2000).

FIGURA 12: BARRAS DE DIAMANTE SINTÉTICO MONOCRISTALINO E DE DIAMANTE SINTÉTICO PRODUZIDO PELO PROCESSO CVD E ALGUNS EXEMPLOS DE DRESSADORES FEITOS COM ELAS (SEN, 2000; PRICKEN, 1999).

FIGURA 13: ORIENTAÇÃO DA DIREÇÃO DE CORTE RELACIONADA À RESISTÊNCIA À ABRASÃO (SEN, 2000).

FIGURA 14: O FECHAMENTO DA ESPIRAL DE DRESSAGEM SOBRE A FACE DO REBOLO COM O DESGASTE GRADUAL DA PONTA DO DRESSADOR (SEN, 2000).

FIGURA 15: EFEITO DO USO DE DIAMANTES COM SECÇÃO TRANSVERSAL CONSTANTE SOBRE A ESPIRAL DA FACE DO REBOLO: (a) A ESPIRAL SOBRE A FACE DO REBOLO SE MANTÉM INALTERADA COM O DESGASTE DO DRESSADOR; (b) ESPIRAL FECHADA EM GRANDES REBOLOS UTILIZANDO UM DRESSADOR DO TIPO PLACA (SEN, 2000).

FIGURA 16: REPRESENTAÇÃO ESQUEMÁTICA DO DRESSADOR CONTENDO CANAIS INTERNOS PARA REFRIGERAÇÃO (KUCHER, 2003).

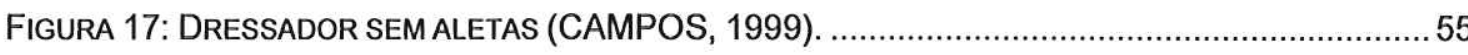

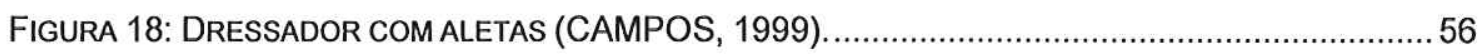


FIGURA 19: EXEMPLO DE UMA REDE DE ELEMENTOS FINITOS (ASSAN, 1999) ............................... 58

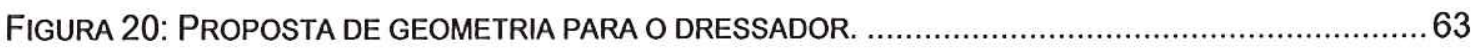

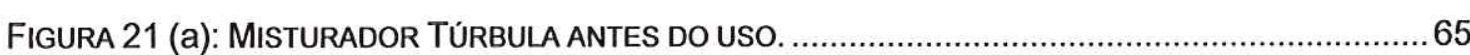

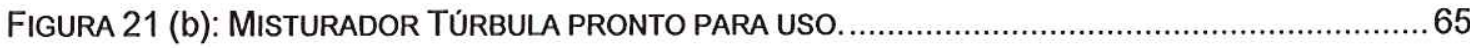

FIGURA 22: VISÃO GERAL DA BALANÇA UTILIZADA NO CÁLCULO DA DENSIDADE APARENTE....................70

FIGURA 23: SUPORTE PRESO SOB A BALANÇA E IMERSO EM ÁGUA DESTILADA. .................................. 70

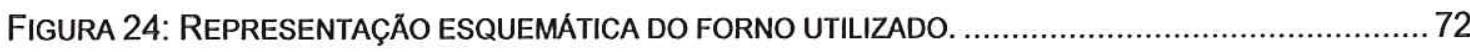

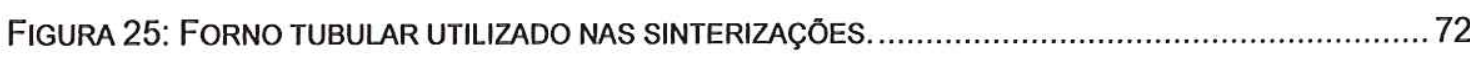

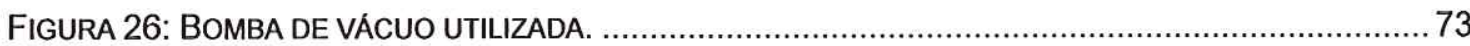

FIGURA 27: ENTRADA DO FORNO E EXTREMIDADE OPOSTA DO TUBO DE CERÂMICA COM O TAMPÃO ....75

FIGURA 28 (a): COMPONENTES PARA A SINTERIZAÇĀO UTILIZANDO ARGÔNIO...................................... 76

FIGURA 28 (b): COMPONENTES PARA A SINTERIZAÇÃO UTILIZANDO ARGÔNIO..................................... 76

FIGURA 29: DISPOSIÇÃO DOS COMPONENTES PARA A SINTERIZAÇÃO UTILIZANDO ARGÔNIO. ................77

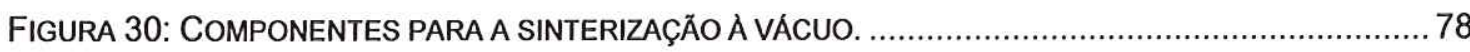

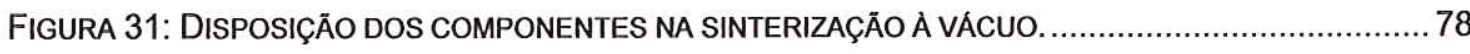

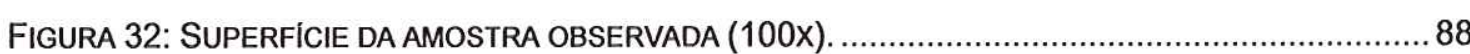

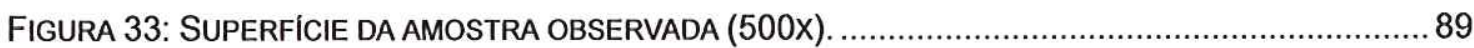

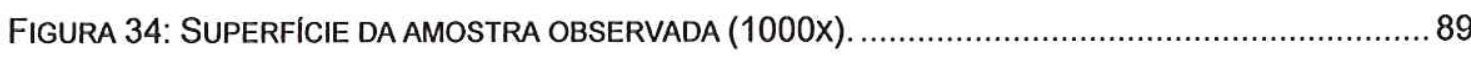

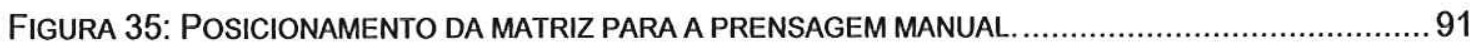

FIGURA 36: PRIMEIRA METADE DA MISTURA PRENSADA COM AS 4 BARRAS DE DIAMANTE CVDRESS ${ }^{\circledR}$

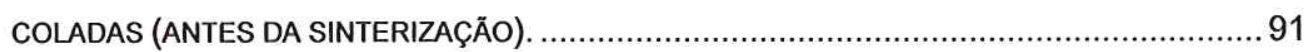

FIGURA 37: O PROTÓTIPO DE DRESSADOR OBTIDO (DRESSADOR ALETADO)................................... 92

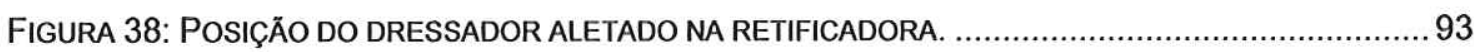

FIGURA 39: DETALHE DA FIXAÇÃO DO DRESSADOR ALETADO NA RETIFICADORA..................................93

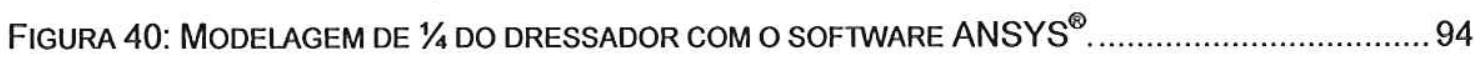

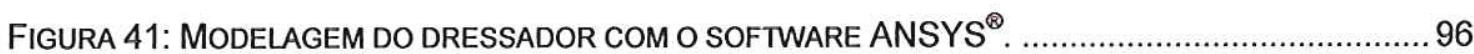

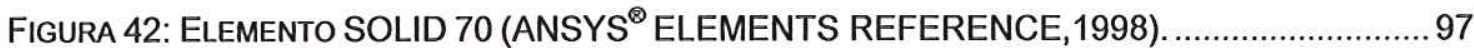

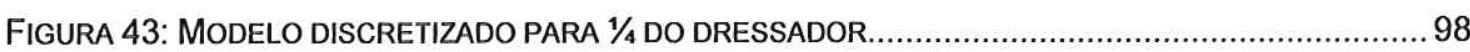

FIGURA 44: SIMULAÇÃO DA DISTRIBUIÇÃO DE TEMPERATURA PARA O DRESSADOR ALETADO UTILIZANDO

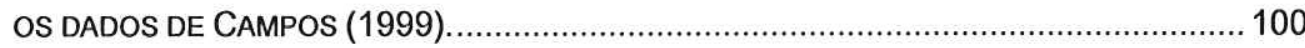

FIGURA 45: EXPERIMENTO DE CONDUÇÃO DE CALOR EM REGIME ESTACIONÁRIO (INCROPERA $\mathrm{e}$

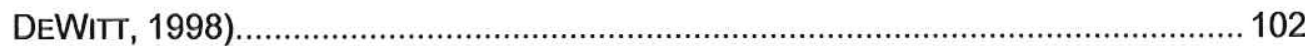

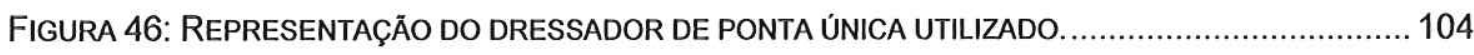

FIGURA 47: O DRESSADOR DE PONTA ÚNICA APÓS A PREPARAÇÃO PARA O ENSAIO DE ESTIMATIVA DO

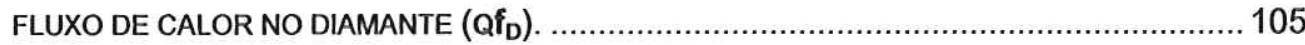

FIGURA 48: PROCEDIMENTO PARA A IMPRESSÃO NA SUPERFICIE DA CHAPA METÁLICA DA LARGURA DE

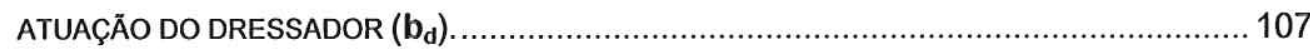

FIGURA 49: SISTEMA ORIGINAL DE REFRIGERAÇĀO DO DRESSADOR NA RETIFICADORA....................... 108

FIGURA 50: VISTA FRONTAL DO DISPOSITIVO DE REFRIGERAÇÃO DO DRESSADOR............................. 109 
FIGURA 51: VISTA POSTERIOR DO DISPOSITIVO DE REFRIGERAÇÃO DO DRESSADOR. 109

FIGURA 52: REGISTRO PARA O CONTROLE DE VAZÃO DO FLUIDO REFRIGERANTE E MANGUEIRAS DE ALIMENTAÇĀO DO DISPOSITIVO DE REFRIGERAÇÃO DO DRESSADOR.

FIGURA 53: DETALHE dO REGISTRO E dO POSICIONAMENTO dO SENSOR DE EMISSÃO ACÚSTICA. .... 111

FIGURA 54: DESENHO ESQUEMÁTICO DO POSICIONAMENTO DOS ORIFICIOS NO CORPO DO DRESSADOR PARA A INSERÇÃO DOS TERMOPARES. 112

FIGURA 55: DETALHE DA FIXAÇÃO DOS TERMOPARES NO DRESSADOR. 113

FIGURA 56: REPRESENTAÇÃO ESQUEMÁTICA DA PROTEÇÃO DOS FIOS DO TERMOPAR. 114

FIGURA 57: POSIÇÃO NA MÁQUINA DO DISPOSITIVO DE MEDIÇÃO DO DESGASTE DOS DIAMANTES....... 115

FIGURA 58: DETALHE DO DISPOSITIVO DE MEDIÇÃO DO DESGASTE DOS DIAMANTES.......................... 115

FIGURA 59: DETALHE DA APROXIMAÇÃO DO APALPADOR A SUPERFICIE DOS DIAMANTES. ..................116

FIGURA 60: SUPERFICIE RETIFICADA DE REFERÊNCIA UTILIZADA NA MEDIÇÃO DO DESGASTE RADIAL DOS DIAMANTES. 117

FIGURA 61: O BANCO DE ENSAIOS UTILIZADO NOS ENSAIOS. 120

FIGURA 62: CIRCUITO ELETRÔNICO UTILIZADO PARA A CONVERSÃO DO SINAL CAPTADO PELOS TERMOPARES (BRAGHINI JUNIOR, 2002). 121

FIGURA 63: RESPOSTA DOS 2 TERMOPARES UTILIZADOS NOS ENSAIOS. 123

FIGURA 64: TEMPOS DE RESPOSTA DOS TERMOPARES COM E SEM RESINA. 123

FIGURA 65: REFRATÔMETRO QUIMIS ${ }^{\circledR}$ UTILIZADO PARA MEDIR A CONCENTRAÇÃO DO FLUIDO REFRIGERANTE DURANTE OS ENSAIOS (www.quimis.com.br). 126

FIGURA 66: TEMPERATURAS OBTIDAS NO $3^{\circ}$ ENSAIO COM O DRESSADOR DE PONTA ÚNICA COM $\mathrm{Q}=3,2 \mathrm{l} / \mathrm{min}, \mathrm{U}_{\mathrm{d}}=12,6$ e $\mathrm{a}_{\mathrm{d}}=20 \mu \mathrm{m}$

FIGURA 67: TEMPERATURAS OBTIDAS NO $5^{\circ}$ ENSAIO COM O DRESSADOR DE PONTA ÚNICA COM $Q=3,2 \mathrm{l} / \mathrm{min}, U_{d}=23,2$ e $a_{d}=60 \mu \mathrm{m}$. 128

FIGURA 68: TEMPERATURAS OBTIDAS NO $3^{\circ}$ ENSAIO COM O DRESSADOR ALETADO COM $Q=3,2 \mathrm{l} / \mathrm{min}, \mathrm{U}_{\mathrm{d}}=12,6 \mathrm{e} \mathrm{a}_{\mathrm{d}}=20 \mu \mathrm{m}$. 130

FIGURA 69: TEMPERATURAS OBTIDAS NO $5^{\circ}$ ENSAIO COM O DRESSADOR ALETADO COM

$$
Q=3,2 \mathrm{l} / \mathrm{min}, \mathrm{U}_{\mathrm{d}}=23,2 \mathrm{e} \mathrm{a}_{\mathrm{d}}=60 \mu \mathrm{m} \text {. }
$$

FIGURA 70: TEMPERATURA MÉDIA VERSUS $a_{d} \operatorname{com} U_{d}=12,6$ e $Q=3,2 \mathrm{l} / \mathrm{min}$ (ENSAIOS 1,2 e 3 )...131

FIGURA 71: TEMPERATURA MÉDIA VERSUS $U_{d}$ COM $a_{d}=60 \mu \mathrm{m} \mathrm{e} Q=3,2 \mathrm{l} / \mathrm{min}$ (ENSAIOS 1, 4 e 5).. 132

FIGURA 72: TEMPERATURA MÉDIA VERSUS Q COM $\mathrm{a}_{\mathrm{d}}=60 \mu \mathrm{m}$ e $\mathrm{U}_{\mathrm{d}}=19,9$ (ENSAIOS 4, 6 e 7). ....... 134

FigurA 73: RESULTAdOS Do ÍNDICE ID COM Q = 3,2 I/min e $U_{d}=12,6$ (ENSAIOS 1, 2 e 3). ............ 136

FIGURA 74: RESULTADOS DO ÍNDICE ID COM $\mathrm{a}_{\mathrm{d}}=60 \mu \mathrm{m}$ e $\mathrm{Q}=3,2 \mathrm{l} / \mathrm{min}$ (ENSAIOS $1,4 \mathrm{e}$ )........... 137

FIGURA 75: RESULTADOS DO ÍNDICE ID COM $\mathrm{a}_{\mathrm{d}}=60 \mu \mathrm{m}$ e $\mathrm{U}_{\mathrm{d}}=19,9$ (ENSAIOS 4, 6 e 7)................. 138

FIGURA 76A: DISTRIBUIÇÃO DE TEMPERATURAS OBTIDAS NA SIMULAÇÃO COMPUTACIONAL PARA AS CONDIÇÖES DO $1^{\circ} \operatorname{ENSAIO}\left(Q=3,2 \mathrm{l} / \mathrm{min}, \mathrm{U}_{\mathrm{d}}=12,6\right.$ e $\left.\mathrm{a}_{\mathrm{d}}=60 \mu \mathrm{m}\right)$ SECÇÄO LONGITUDINAL. 
FIGURA 76B: DISTRIBUIÇÃO DE TEMPERATURAS OBTIDAS NA SIMULAÇÃO COMPUTACIONAL PARA AS CONDIÇÕES DO $1^{\circ}$ ENSAIO $\left(Q=3,2 \mathrm{l} / \mathrm{min}, U_{d}=12,6\right.$ e $\left.a_{d}=60 \mu \mathrm{m}\right)$ -

FERRAMENTA INTEIRA

FIGURA 77A: DISTRIBUIÇÃO DE TEMPERATURAS OBTIDAS NA SIMULAÇÃO COMPUTACIONAL PARA AS CONDIÇÕES DO $2^{\circ}$ ENSAIO $\left(Q=3,2 \mathrm{l} / \mathrm{min}, \mathrm{U}_{\mathrm{d}}=12,6\right.$ e $\left.\mathrm{a}_{\mathrm{d}}=40 \mu \mathrm{m}\right)$ SECÇÃO LONGITUDINAL.

FIGURA 77B: DISTRIBUIÇÃO DE TEMPERATURAS OBTIDAS NA SIMULAÇÃO COMPUTACIONAL PARA AS CONDIÇÕES DO $2^{\circ} \operatorname{ENSAIO}\left(Q=3,2 \mathrm{l} / \mathrm{min}, U_{d}=12,6\right.$ e $\left.a_{d}=40 \mu \mathrm{m}\right)$ FERRAMENTA INTEIRA

FIGURA 78A: DISTRIBUIÇÃO DE TEMPERATURAS OBTIDAS NA SIMULAÇÃO COMPUTACIONAL PARA AS CONDIÇŌES DO $3^{\circ}$ ENSAIO $\left(Q=3,2 \mathrm{l} / \mathrm{min}, \mathrm{U}_{0}=12,6\right.$ E $\left.\mathrm{A}_{\mathrm{D}}=20 \mu \mathrm{m}\right)$ SECÇÃO LONGITUDINAL.

FIGURA 78B: DISTRIBUIÇÃO DE TEMPERATURAS OBTIDAS NA SIMULAÇÃO COMPUTACIONAL PARA AS CONDIÇÕES DO $3^{\circ}$ ENSAIO $\left(Q=3,2 \mathrm{l} / \mathrm{min}, \mathrm{U}_{\mathrm{d}}=12,6\right.$ e $\left.\mathrm{a}_{\mathrm{d}}=20 \mu \mathrm{m}\right)$ FERRAMENTA INTEIRA.

FIGURA 79A: DISTRIBUIÇÃO DE TEMPERATURAS OBTIDAS NA SIMULAÇÃO COMPUTACIONAL PARA AS CONDIÇÕES DO $4^{\circ}$ ENSAIO $\left(Q=3,2 \mathrm{l} / \mathrm{min}, U_{d}=19,9\right.$ e $\left.a_{d}=60 \mu \mathrm{m}\right)$ SECÇÃO LONGITUDINAL.

FIGURA 79B: DISTRIBUIÇÃO DE TEMPERATURAS OBTIDAS NA SIMULAÇÃO COMPUTACIONAL PARA AS CONDIÇÖES DO $4^{\circ}$ ENSAIO $\left(Q=3,2 \mathrm{l} / \mathrm{min}, \mathrm{U}_{\mathrm{d}}=19,9\right.$ e $\left.\mathrm{a}_{\mathrm{d}}=60 \mu \mathrm{m}\right)$ FERRAMENTA INTEIRA

FIGURA 80A: DISTRIBUIÇÃO DE TEMPERATURAS OBTIDAS NA SIMULAÇÃO COMPUTACIONAL PARA AS CONDIÇŌES DO $5^{\circ}$ ENSAIO $\left(Q=3,2 \mathrm{l} / \mathrm{min}, \mathrm{U}_{\mathrm{d}}=23,2\right.$ e $\left.\mathrm{a}_{\mathrm{d}}=60 \mu \mathrm{m}\right)$ SECÇÃO LONGITUDINAL.

FIGURA 80B: DISTRIBUIÇÃO DE TEMPERATURAS OBTIDAS NA SIMULAÇÃO COMPUTACIONAL PARA AS CONDIÇÕES DO $5^{\circ}$ ENSAIO $\left(Q=3,2 \mathrm{l} / \mathrm{min}, \mathrm{U}_{\mathrm{d}}=23,2\right.$ e $\left.\mathrm{a}_{\mathrm{d}}=60 \mu \mathrm{m}\right)$ FERRAMENTA INTEIRA

FIGURA 81A: DISTRIBUIÇÃO DE TEMPERATURAS OBTIDAS NA SIMULAÇÃO COMPUTACIONAL PARA AS CONDIÇÕES DO $6^{\circ}$ ENSAIO $\left(Q=4,1 \mathrm{l} / \mathrm{min}, U_{d}=19,9\right.$ e $\left.a_{d}=60 \mu \mathrm{m}\right)$ SECÇÃO LONGITUDINAL.

FIGURA 81B: DISTRIBUIÇÃO DE TEMPERATURAS OBTIDAS NA SIMULAÇÃO COMPUTACIONAL PARA AS CONDIÇŌES DO $6^{\circ}$ ENSAIO $\left(Q=4,1 \mathrm{l} / \mathrm{min}, \mathrm{U}_{\mathrm{d}}=19,9\right.$ e $\left.\mathrm{a}_{\mathrm{d}}=60 \mu \mathrm{m}\right)$ FERRAMENTA INTEIRA.

FIGURA 82A: DISTRIBUIÇÃO DE TEMPERATURAS OBTIDAS NA SIMULAÇÃO COMPUTACIONAL PARA AS CONDIÇÕES DO $7^{\circ}$ ENSAIO $\left(Q=13,3 \mathrm{l} / \mathrm{min}, U_{d}=19,9\right.$ e $\left.a_{d}=60 \mu \mathrm{m}\right)$ SECÇÃO LONGITUDINAL. 146

FIGURA 82B: DISTRIBUIÇÃO DE TEMPERATURAS OBTIDAS NA SIMULAÇÃO COMPUTACIONAL PARA AS CONDIÇÕES DO $7^{\circ} \operatorname{ENSAIO}\left(Q=13,3 \mathrm{l} / \mathrm{min}, U_{d}=19,9\right.$ e $\left.a_{d}=60 \mu \mathrm{m}\right)$ - 
FIGURA 83: DISTRIBUIÇÃO DE TEMPERATURAS OBTIDAS NA SIMULAÇÃO COMPUTACIONAL PARA UMA CONDIÇĀO DE 100\% DE AUMENTO NO FLUXO DE CALOR (SECÇÃO LONGITUDINAL). ........ 150

FIGURA 84: DISTRIBUIÇÃO DE TEMPERATURAS OBTIDAS NA SIMULAÇÃO COMPUTACIONAL PARA UMA CONDIÇÃO DE $100 \%$ DE AUMENTO NAS TEMPERATURAS T1 E T2 (SECÇÃO LONGITUDINAL).

FIGURA 85: DISTRIBUIÇÃO DE TEMPERATURAS OBTIDAS NA SIMULAÇÃO COMPUTACIONAL PARA UMA CONDIÇÃO DE $100 \%$ DE AUMENTO SIMULTÂNEO PARA AS TEMPERATURAS MEDIDAS E PARA O FLUXO DE CALOR (SECÇÃO LONGITUDINAL).

FIGURA 86: DISTRIBUIÇÃO DE TEMPERATURAS OBTIDAS NA SIMULAÇÃO COMPUTACIONAL PARA UMA CONDIÇÃO DE $100 \%$ DE AUMENTO NAS TEMPERATURAS MEDIDAS (SECÇÃO LONGITUDINAL).

FIGURA 87: DISTRIBUIÇÃO DE TEMPERATURAS OBTIDAS NA SIMULAÇÃO COMPUTACIONAL PARA UMA CONDIÇÄO DE AUMENTO SIMULTÂNEO DE 500\% NO FLUXO DE CALOR E DE $100 \%$ NAS TEMPERATURAS MEDIDAS E NO GRADIENTE ENTRE ESSAS TEMPERATURAS (SECÇÃO LONGITUDINAL). 154

FIGURA 88: SUPERFICIE DO DRESSADOR APÓS OS ENSAIOS (VISTA COM O DRESSADOR INCLINADO). 155

FIGURA 89: SUPERFÍCIE DO DRESSADOR APÓS OS ENSAIOS (VISTA DE TOPO)................................. 156

FIGURA 90: SUPERFICIE DO PRIMEIRO DIAMANTE A CONTACTAR O REBOLO (VISTA DE TOPO) ............ 156

FIGURA 91: SUPERFICIE DO SEGUNDO DIAMANTE A CONTACTAR O REBOLO (VISTA DE TOPO)..............157

FIGURA 92: SUPERFÍCIE DO TERCEIRO DIAMANTE A CONTACTAR O REBOLO (VISTA DE TOPO) ............ 157

FIGURA 93: SUPERFICIE DO QUARTO DIAMANTE A CONTACTAR O REBOLO (VISTA DE TOPO)................ 158

FIGURA 94: PoSSIVEL EVOLUÇÃO DO DESGASTE DOS DIAMANTES DO DRESSADOR. ........................... 159

FIGURA B1: TEMPERATURAS OBTIDAS NO $1^{\circ}$ ENSAIO COM O DRESSADOR DE PONTA ÚNICA. ...............178

FIGURA B2: TEMPERATURAS OBTIDAS NO $2^{\circ}$ ENSAIO COM O DRESSADOR DE PONTA ÚNICA. .............179

FIGURA B3: TEMPERATURAS OBTIDAS NO $3^{\circ}$ ENSAIO COM O DRESSADOR DE PONTA ÚNICA. ............... 179

FIGURA B4: TEMPERATURAS OBTIDAS NO $4^{\circ}$ ENSAIO COM O DRESSADOR DE PONTA ÚNICA. .............. 180

FIGURA B5: TEMPERATURAS OBTIDAS NO $5^{\circ}$ ENSAIO COM O DRESSADOR DE PONTA ÚNICA. ...............180

FIGURA B6: TEMPERATURAS OBTIDAS NO $6^{\circ}$ ENSAIO COM O DRESSADOR DE PONTA ÚNICA. ...............181

FIGURA B7: TEMPERATURAS OBTIDAS NO $7^{\circ}$ ENSAIO COM O DRESSADOR DE PONTA ÚNICA. ............... 181

FIGURA C1: TEMPERATURAS OBTIDAS NO $1^{\circ}$ ENSAIO COM O DRESSADOR ALETADO. ......................... 182

FIGURA C2: TEMPERATURAS OBTIDAS NO $2^{\circ}$ ENSAIO COM O DRESSADOR ALETADO. .......................... 183

FIGURA C3: TEMPERATURAS OBTIDAS NO $3^{\circ}$ ENSAIO COM O DRESSADOR ALETADO. ........................... 183

FIGURA C4: TEMPERATURAS OBTIDAS NO $4^{\circ}$ ENSAIO COM O DRESSADOR ALETADO. .......................... 184

FIGURA C5: TEMPERATURAS OBTIDAS NO $5^{\circ}$ ENSAIO COM O DRESSADOR ALETADO. ......................... 184

FIGURA C6: TEMPERATURAS OBTIDAS NO 6 ${ }^{\circ}$ ENSAIO COM O DRESSADOR ALETADO. ............................. 185

FIGURA C7: TEMPERATURAS OBTIDAS NO 7 ENSAIO COM O DRESSADOR ALETADO. .......................... 185 


\section{LISTA DE TABELAS}

TABELA 1: EFEITO DA DENSIDADE VERDE E DA TEMPERATURA DE SINTERIZAÇÃO SOBRE A DENSIDADE DO MATERIAL SINTERIZADO (HIRSCHHORN, 1991).

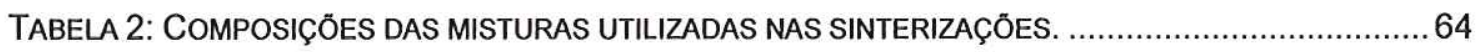

TABELA 3: COMPOSIÇÃO DO ARGÔNIO UTILIZADO NAS SINTERIZAÇÕES. .............................................. 73

TABELA 4: CONDIÇÕES DE SINTERIZAÇÃO PARA AS PEÇAS 1, 2, 3 E 4 …………………………...... 79

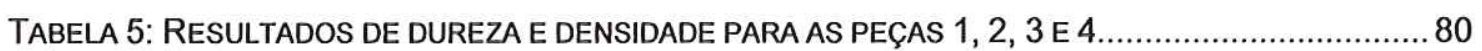

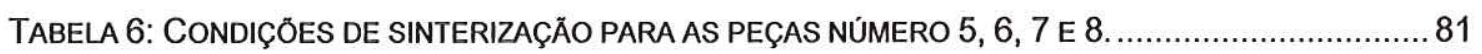

TABELA 7: RESULTADOS DE DUREZA E DENSIDADE PARA AS PEÇAS NÚMERO 5, 6, 7 E $8 \ldots \ldots \ldots \ldots \ldots \ldots . . . . . . . . .11$

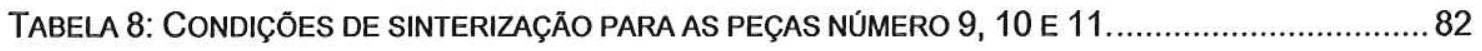

TABELA 9: RESULTADOS DE DUREZA E DENSIDADE PARA AS PEÇAS NÚMERO 9, 10 E $11 \ldots \ldots \ldots \ldots \ldots \ldots . . . . . . . . . . .22$

TABELA 10: CONDIÇŐES DE SINTERIZAÇÃO PARA AS PEÇAS DE NÚMERO 12 A 17................................ 83

TABELA 11: RESULTADOS DE DUREZA E DENSIDADE PARA AS PEÇAS DE NÚMERO 12 A $17 \ldots \ldots \ldots \ldots \ldots . . . . . . .83$

TABELA 12: CONDIÇŐES DE SINTERIZAÇĀO PARA AS PEÇAS DE NÚMERO 18 A 25 ................................ 85

TABELA 13: RESULTADOS DE DUREZA E DENSIDADE PARA AS PEÇAS DE NÚMERO 18 A $25 \ldots \ldots \ldots \ldots \ldots . . . . . . . .85$

TABELA 14: RESUMO DAS CONDIÇŌES DE SINTERIZAÇÃO EMPREGADAS PARA TODAS AS PEÇAS. ......... 86

TABELA 15: RESUMO DOS RESULTADOS DE DUREZA E DENSIDADE PARA TODAS AS PEÇAS. .................. 87

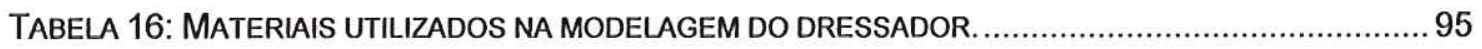

TABELA 17: PROPRIEDADES FÍSICAS DOS MATERIAIS UTILIZADOS NA CONFECÇÃO DO DRESSADOR. .... 95

TABELA 18: VALORES DOS COEFICIENTES UTILIZADOS NA SIMULAÇÃO (CAMPOS, 1999)................. 100

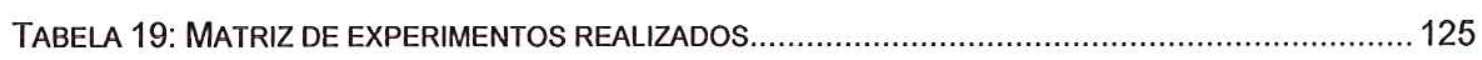

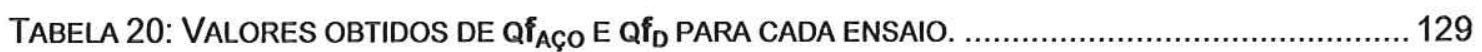

TABELA 21: QUANTIDADE TOTAL DE PASSES DE DRESSAGEM EM CADA ENSAIO................................. 135

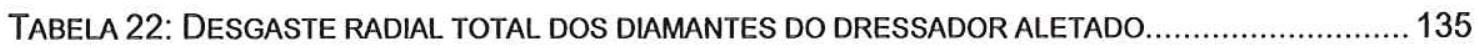

TABELA 23: VALORES DO COEFICIENTE DE CONVECÇÃO ( $\left.h_{\text {MÉOIO }}\right)$ OBTIDOS NAS SIMULAÇÕES. .............. 148 


\section{LISTA DE AbReVIaturas e Siglas}

$\begin{array}{ll}\text { AA } & \text { Absorção de Água } \\ \text { APDL } & \text { Ansys Parametric Design Language } \\ \text { CVD } & \text { Chemical Vapour Deposition } \\ \text { DEMa } & \text { Departamento de Engenharia de Materiais da UFSCar } \\ \text { EESC } & \text { Escola de Engenharia de São Carlos - USP } \\ \text { E.A. } & \text { Emissão Acústica } \\ \text { FEM } & \text { Método dos Elementos Finitos } \\ \text { M.E.V. } & \text { Microscópio Eletrônico de Varredura } \\ \text { PA } & \text { Porosidade Aparente } \\ \text { PCD } & \text { Diamante policristalino } \\ \text { PI } & \text { Peso Imerso } \\ \text { PS } & \text { Peso Seco } \\ \text { PU } & \text { Peso Úmido } \\ \text { RMS } & \text { Root Mean Square } \\ \text { UFSCar } & \text { Universidade Federal de São Carlos }\end{array}$




\section{LISTA DE SímBolos}

$a_{d}[\mu m]$

$\mathrm{a}_{\operatorname{dlim}}[\mu \mathrm{m}]$

$b_{d}[\mathrm{~mm}]$

$\mathrm{DA}\left[\mathrm{g} / \mathrm{cm}^{3}\right]$

$\mathrm{h}\left[\mathrm{W} / \mathrm{m}^{2} . \mathrm{K}\right]$

$\mathrm{h}_{\text {médio }}\left[\mathrm{W} / \mathrm{m}^{2} . \mathrm{K}\right]$

ID $\left[\mathrm{cm}^{3} / \mathrm{mm}\right]$

$\mathrm{K}$

$\mathrm{k}[\mathrm{W} / \mathrm{m} . \mathrm{K}]$

mbar

$\mathrm{MPa}$

$\mathrm{Q}[1 / \mathrm{min}]$

q $[\mathrm{W} / \mathrm{m}]$

$\mathrm{q}_{\mathrm{f}}\left[\mathrm{W} / \mathrm{m}^{2}\right]$

qf $\left[\mathrm{W} / \mathrm{m}^{2}\right]$

$\mathrm{S}_{\mathrm{d}}[\mathrm{mm} / \mathrm{volta}]$

$\mathrm{T} 1[\mathrm{~K}]$

$\mathrm{T} 2[\mathrm{~K}]$

TP1 [K]

TP2 [K]

$U_{d}$

$\mathrm{V}_{\mathrm{s}}[\mathrm{m} / \mathrm{s}]$
Profundidade de dressagem

Profundidade limite de dressagem

Largura de atuação do dressador

Densidade aparente

Coeficiente de transferência de calor por convecção

Coeficiente médio de transferência de calor por convecção

Índice de desgaste do dressador

Agressividade do rebolo

Condutividade Térmica

Mili-bar

Mega-Pascal

Vazão do fluido refrigerante

Fluxo de calor por unidade de comprimento

Fluxo de calor por área

Fluxo de calor por área dos diamantes

Passo de dressagem

Temperatura obtida pela simulação no ponto do termopar 1

Temperatura obtida pela simulação no ponto do termopar 2

Temperatura medida durante os ensaios com o termopar 1

Temperatura medida durante os ensaios com o termopar 2

Grau de recobrimento de dressagem

Velocidade periférica do rebolo 


\section{SUMÁRIO}

AGRADECIMENTOS

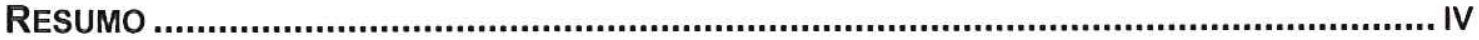

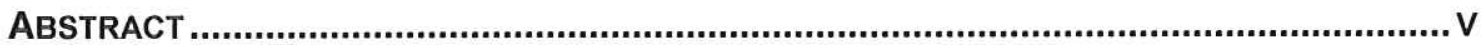

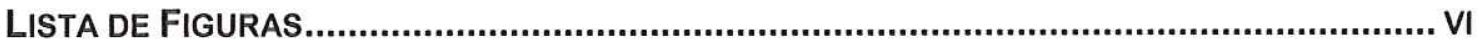

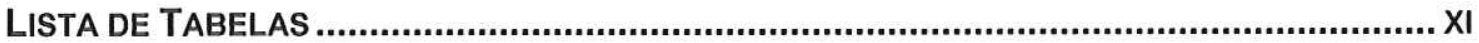

LISTA DE ABREVIATURAS E SIGLAS .......................................................................... XII

LISTA DE SÍmBOLOS ...............................................................................................III

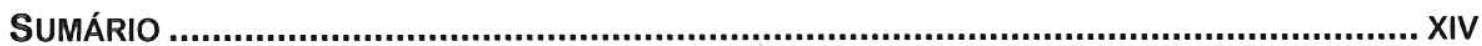

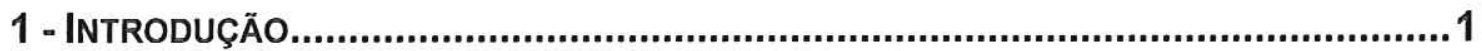

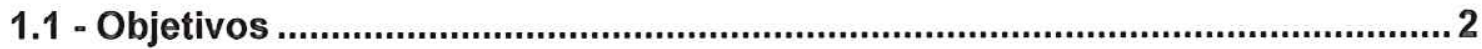

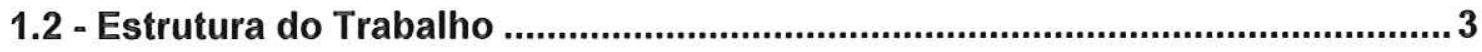

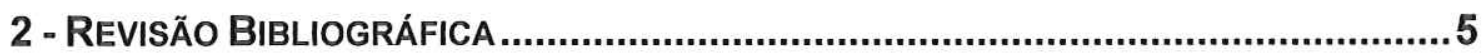

2.1 - O Processo de Dressagem de Rebolos de Óxido de Alumínio ........................5

2.1.1 - Avaliação da Dressagem de Rebolos .....................................................

2.1.1.1 - Utilização da Emissão Acústica........................................................

2.1.1.2- Rugosidade da Peça Retificada .................................................. 12

2.1.1.3 - Agressividade da Superfície de Trabalho do Rebolo ....................... 13

2.1.2 - Os Efeitos das Variáveis do Rebolo sobre o Desgaste dos Diamantes do

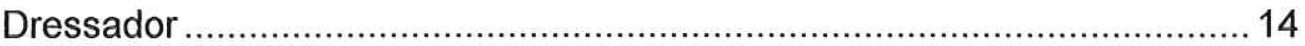

2.1.2.1 - Abrasividade dos Grãos Abrasivos Convencionais.......................... 14

2.1.2.2 - O Tamanho do Grão Abrasivo.................................................... 15

2.1.2.3 - A Dureza do Ligante do Rebolo..................................................... 15 
2.1.2.4 - O Balanceamento do Rebolo 16

2.1.3 - Os Efeitos das Variáveis do Processo sobre o Desgaste dos Diamantes do

Dressador 16

2.1.3.1 - A Profundidade de Dressagem e o Avanço de Dressagem ............ 16

2.1.3.2 - A Velocidade do Rebolo e a Rigidez da Retificadora..................... 19

2.1.4 - Vantagens dos Dressadores com Perfil de Atuação Constante ................. 19

2.2 - Cinemática da Operação de Dressagem ........................................................20

2.3 - A Fabricação de Dressadores Estáticos Sinterizados ....................................22

2.3.1 - Ferramentas Produzidas com Diamantes Brasados................................2 23

2.3.2 - Ferramentas Produzidas pela Metalurgia do Pó...................................... 24

2.3.2.1 - Ferramentas Produzidas pelo Processo de Infiltração.................... 25

2.3.2.2 - Ferramentas Produzidas pelo Processo de Prensagem à Quente .. 26

2.3.2.3 - Ferramentas Produzidas pelo Processo de Prensagem à Frio e Posterior Sinterização.................................................................... 28

2.3.3 - Ferramentas de Diamantes Produzidas Através da Eletrodeposição ........29

2.4 - Principais Características dos Dressadores Estáticos Sinterizados ............. 30

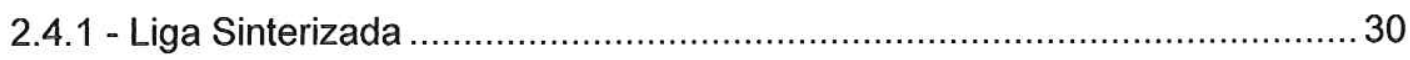

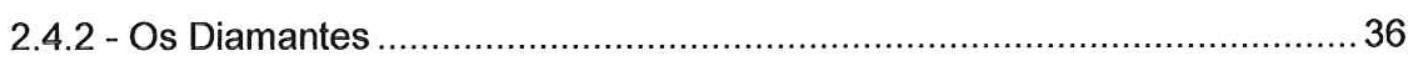

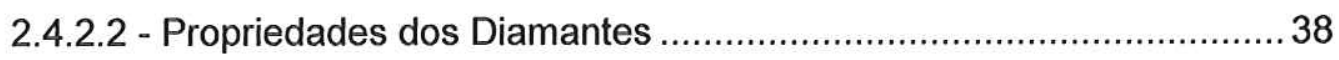

2.4.2.2.1 - Propriedades Mecânicas ...................................................................... 38

2.4.2.2.2 - Propriedades Térmicas ........................................................................ 40

2.4.2.2.3 - Propriedades Químicas................................................................. 42

2.4.2.3 - Tipos de Diamantes Utilizados em Dressadores ......................... 42

2.4.2.3.1 - Diamante Natural Industrial Monocristalino ..................................... 43

2.4.2.3.2 - Diamante Sintético Monocristalino ..................................................... 44

2.4.2.3.3 - Diamante Policristalino (PCD - Polycristalline Diamond) .......... 44

2.4.2.3.4 - Diamante Produzido pelo Processo CVD ....................................... 45

2.4.2.4 - Seleção dos Diamantes do Dressador ............................................. 46

2.4.2.4.1 - Orientação do Cristal de Diamante ..................................................... 47

2.4.2.4.2 - Manutenção da Forma da Ponta do Diamante do

Dressador 49

2.4.2.4.3 - Taxa de Desgaste Invariável ........................................................... 52

2.4.2.4.4 - Eficiente Dissipação de Calor ............................................................. 52 


\section{6 - Simulação da Dissipação de Calor Utilizando o Método dos Elementos}

Finitos 56

2.6.1 - O Método dos Elementos Finitos ……................................................ 56

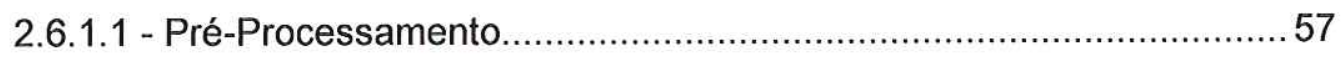

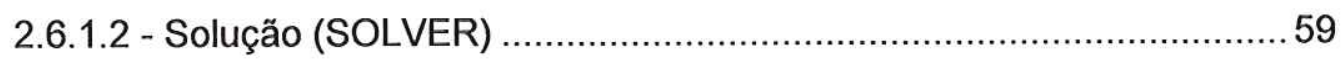

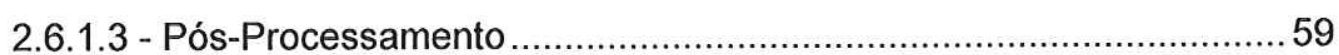

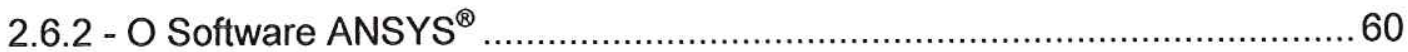

3 - PROCEDIMENTO EXPERIMENTAL .................................................................61

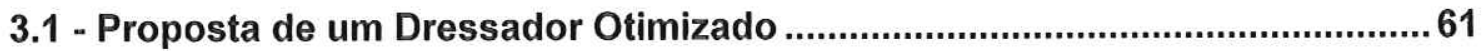

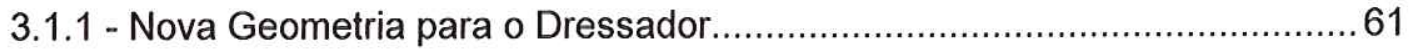

3.1.2 - Procedimentos para Obtenção da Liga Sinterizada ..............................63

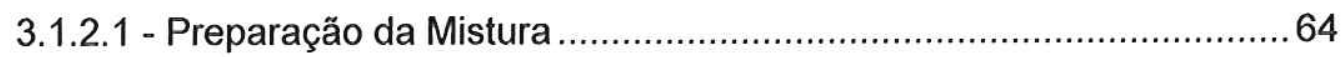

3.1.2.2 - Cálculo da Densidade Teórica e da Massa da Mistura....................66 66

3.1.2.3- Cálculo da Densidade Aparente .......................................................68 68

3.1.3 - Utilização do Forno .............................................................................. 71

3.1.3.1 - Atmosferas Protetoras Utilizadas .............................................. 73

3.1.3.1.1 - Sinterização com Argônio .................................................................... 74

3.1.3.1.2 - Sinterização com Vácuo ..................................................................... 77

3.1.4 - Resultados de Dureza e Densidade Aparente da Liga Sinterizada ........... 79

3.1.5 - Observação da Liga Escolhida em Microscópio Eletrônico de Varredura.. 87

3.3 - Simulações em Elementos Finitos com o Dressador Proposto ...................... 94

3.3.1 - Modelagem do Dressador Utilizando o Software ANSYS ${ }^{\circledR}$........................ 94

3.3.1.1 - Escolha dos Elementos no ANSYS ${ }^{\circledR}$............................................. 97

3.3.1.2 - Carregamentos e Condiçőes de Contorno ................................... 98

3.4 - Sistema de Avaliação do Fluxo de Calor Através do Dressador.

3.4.1 - Ensaios para a Estimativa do Fluxo de Calor Através do Diamante (qf $\left.f_{D}\right) 101$

3.5 - Ensaios de Avaliação do Dressador Proposto 106

3.5.1 - Medição da Largura de Atuação do Dressador $\left(b_{d}\right)$ 106 
3.5.2 - Novo Dispositivo de Refrigeração do Dressador

3.5.2.1 - Troca da Alimentação do Dispositivo de Refrigeração do

Dressador 110

3.5.3 - Colocação dos Termopares no Dressador

3.5.3.1 - Proteção dos Termopares

3.5.4 - Dispositivo para Medição do Desgaste Radial dos Diamantes

3.5.5 - Medição do Desgaste Radial dos Diamantes

3.5.6 - Índice de Desgaste do Dressador (ID) 118

3.5.7 - Cálculo do Volume de Rebolo Gasto

3.6 - Banco de Ensaios

3.6.1 - Sistema de Aquisição da Temperatura

3.6.2 - Calibração dos Termopares

3.6.3 - Tempo de Resposta dos Termopares .

3.6.4 - Ensaios Realizados

4.2 - Medição de Temperatura no Dressador Aletado

4.2.1 - Resultados de temperatura Variando-se a Profundidade de Dressagem $a_{d}$

(Ensaios 1, 2 e 3).

4.2.2 - Resultados de temperatura Variando-se o Grau de Recobrimento $U_{d}$

(ensaios 1,4 e 5 )

4.2.3 - Resultados de temperatura Variando-se a Vazão do Fluido Refrigerante $Q$

(ensaios 4, 6 e 7 )

4.3 - Medição do Desgaste do Dressador

4.3.1 - Resultados do Índice ID Variando-se a Profundidade de Dressagem $a_{d}$ (ensaios 1, 2 e 3)

4.3.2 - Resultados do Índice ID Variando-se o Grau de Recobrimento $U_{d}$

(ensaios 1,4 e 5 )

4.3.3 - Resultados do Índice ID Variando-se a Vazão do Fluido Refrigerante $Q$ (ensaios 4, 6 e 7 ) 
4.4 - Resultados Obtidos com a Simulação por Elementos Finitos 139

4.4.1 - Resultados para o Coeficiente de Convecção $\left(\mathrm{h}_{\text {médio }}\right)$ 148

4.4.2 - Estudo da Sensibilidade do Modelo de Elementos Finitos Adotado 149

4.5 - Aspecto Visual do Dressador após os Ensaios 155

5 - CONCLUSÕES 160

6 - SugestöEs PARA TRABALHos Futuros 162

7 - REFERÊNCIAS BIBLIOGRÁFICAS 163

APÊNDICE A

APÊNDICE B 178

APÊNDICE C 182 


\section{1 - INTRODUÇÃO}

Os benefícios surgidos da criação de novas tecnologias de fabricação somente podem ser plenamente alcançados quando os processos são conhecidos e dominados pois, em última análise, são eles que transformam a matéria-prima em produto final.

A retificação de precisão tem como objetivo principal a obtenção e manutenção de tolerâncias dimensionais e geométricas reduzidas no componente usinado, em conjunto com um elevado acabamento superficial. Uma longa vida do rebolo também é desejável para melhores resultados na operação. Inevitavelmente, no entanto, com o decorrer da operação haverá perda de agressividade (capacidade do rebolo de remover material da peça) da superfície de trabalho do rebolo. Um rebolo gasto produz, entre outros efeitos, mais calor devido à elevação do atrito, o que pode prejudicar a resistência mecânica e a integridade superficial do componente retificado. Sendo assim, a operação de afiação do rebolo, denominada dressagem, é parte integrante do processo de retificação (OLIVEIRA et al., 1992b), (BIANCHI et al., 1991).

Uma vez que a operação de dressagem modifica a topografia da superfície de trabalho do rebolo, o seu estudo e conhecimento é fundamental para se conseguir um maior controle sobre o desempenho da retificação (OLIVEIRA e SILVA, 1990).

As condições de dressagem exercem uma grande influência no desempenho da operação de retificação. Oliveira (1988) cita que as forças de 
retificação podem variar cerca de $500 \%$, apenas com a variação das condições de dressagem em um mesmo tipo de operação.

A busca de maior conhecimento a respeito da influência das condições de dressagem na retificação esbarra num fator de grande importância, representado pela geometria do dressador, o qual muitas vezes não é considerado (OLIVEIRA, 1988). Na operação de dressagem gera-se uma grande quantidade de calor, devido ao contato de natureza abrasiva na interface dressador/rebolo. Este calor deve ser prontamente retirado para evitar danos aos componentes do dressador, a saber o(s) diamante(s), à liga e, por conseguinte, ao rebolo.

Além do fluido de corte, a função de retirada do calor é desempenhada pelos próprios diamantes e também pela liga que constitui o "corpo" do dressador, isto é, pelo material que sustenta e posiciona o(s) diamante(s) do mesmo. Assim, esta liga deve possuir, como qualidades preferenciais, uma boa condutividade térmica, tenacidade, dureza, resistência à abrasão e, se possivel, facilidade de obtenção.

A escassez de informações, tanto dos fabricantes quanto da literatura técnica, principalmente no que diz respeito aos materiais utilizados, representa uma grande dificuldade para a fabricação de bons dressadores.

Portanto, como parte da operação de retificação, a dressagem pode ser melhorada se dressadores mais adequados forem empregados. Além disso, existe uma preocupação econômica, pois as ferramentas de diamante ainda possuem um custo relativamente alto e sua limitação de uso está na temperatura de trabalho, que deve ficar abaixo de cerca de $700{ }^{\circ} \mathrm{C}$ para evitar a grafitização do diamante.

\section{1 - Objetivos}

Considerando esta limitação térmica do uso da ferramenta de dressagem e buscando ampliar a sua vida útil, este trabalho objetiva: 
1. Medir a temperatura em um dressador de diamante ponta única e estimar o fluxo de calor em diversas condições de dressagem e de refrigeração do dressador;

2. Aplicar os dados obtidos em uma simulação através de elementos finitos para um dressador proposto, do tipo placa, de forma a otimizar a dissipação de calor;

3. Construir e testar um protótipo do dressador proposto utilizando-se uma nova forma geométrica (superfície aletada), sinterizando-se uma liga metálica de alta condutividade térmica e empregando-se diamantes sintéticos policristalinos produzidos pela técnica de Deposição Química de Vapor (Chemical Vapour Deposition - CVD);

4. Medir durante os ensaios experimentais o índice de desgaste do dressador proposto, avaliando-se sua eficácia.

Dentro de seus limites, este trabalho proporciona uma contribuição inédita ao trabalho pioneiro realizado por CAMPOS (1999), ampliando o campo de informações disponíveis sobre o assunto, uma vez que trabalhos abordando a temperatura gerada no dressador durante a dressagem de rebolos convencionais praticamente inexistem na literatura.

\section{2 - Estrutura do Trabalho}

O presente trabalho é dividido em Revisão Bibliográfica (capítulo 2), Procedimento Experimental (capítulo 3), e Resultados e Discussões (capitulo 4).

A Revisão Bibliográfica aborda alguns aspectos relacionados com a dressagem de rebolos de Óxido de Alumínio (mecanismo, variáveis presentes e métodos de avaliação da operação), características funcionais dos dressadores, tipos e características dos diamantes empregados nos dressadores de ponta única e multi-pontas, a fabricação de dressadores destacando o processo de Sinterização, considerações sobre a forma geométrica dos dressadores, efeitos das variáveis do rebolo e da retificadora sobre o desgaste dos diamantes do dressador e vantagens dos dressadores 
com perfil de atuação constante. Relativo à simulação computacional, discorreu-se sobre o Método dos Elementos Finitos.

O capítulo sobre Procedimento Experimental destaca todos os procedimentos realizados, além da máquina, equipamentos, e metodologia aplicados na realização dos ensaios experimentais. Ao final, o capítulo referente aos Resultados e Discussões apresenta uma análise dos resultados obtidos, a partir dos quais foram elaboradas algumas conclusões. 


\section{2 - REVISÃo BIBLIOGRÁFICA}

\section{1 - O Processo de Dressagem de Rebolos de Óxido de Alumínio}

Os rebolos convencionais inevitavelmente desgastam-se e necessitam ter seus perfis e/ou arestas cortantes renovadas periodicamente através da dressagem e do perfilamento, utilizando dressadores de diamante. Para atender as necessidades de dressagem dos vários tipos de rebolos convencionais, vários tipos diferentes de dressadores estão disponíveis no mercado.

Segundo Sen (2000), a compatibilidade da qualidade do diamante do dressador em termos de sua aplicabilidade para uma operação específica, vida do dressador e repetibilidade de desempenho provavelmente nem sempre se manteve em nível de igualdade com os avanços tecnológicos ocorridos na indústria de retificadoras nos anos 90 , envolvendo máquinas totalmente automatizadas e projetadas para produzir peças de alta qualidade, tanto em pequenos lotes como em grandes volumes de produção (ou seja, máquinas que apresentem flexibilidade de aplicação).

Enquanto essas máquinas foram projetadas para fabricar produtos com qualidade consistente, ao dressador faltou o correspondente diamante planejado segundo conceitos de engenharia, que fosse compatível com as exigências das modernas retificadoras. Portanto, é necessário considerar o dressador em termos do campo de aplicação, e também determinar se a introdução de novos tipos de diamante para o dressador, especificamente do 
diamante sintético na forma de barras, pode atender as necessidades básicas e específicas da dressagem no contexto da indústria moderna (SEN, 2000).

Em um rebolo abrasivo a geometria da face dressada determina a sua eficiência no processo de retificação, ou seja, a taxa de remoção de material, sua eficiência entre os intervalos de dressagem e o acabamento e as tolerâncias dimensionais e geométricas obtidas no componente retificado. Em uma situação de produção, o ajuste dos parâmetros de dressagem está naturalmente ligado à repetibilidade e à consistência da operação de dressagem. Para satisfazer esta necessidade, juntamente com outros fatores de influência no custo, a vida da ferramenta contribui para as implicações econômicas do set-up de produção (SEN, 2000).

Os principais elementos envolvidos na dressagem de rebolos convencionais são: o rebolo, a retificadora e o dressador. Cada um desses elementos possui suas próprias características.

O diamante do dressador, por exemplo, possui algumas peculiaridades como formato, tamanho, qualidade do cristal, etc., as quais the conferem sua característica particular. Estas características podem variar entres cristais diferentes, mas são fixas ou estáticas para um diamante em particular. $\mathrm{Na}$ dressagem do rebolo, estas características influenciam a qualidade da dressagem e o desgaste do diamante (WILKS e WILKS, 1991).

\subsection{1 - AvaliaçÃo da Dressagem de Rebolos}

Dentre os métodos empregados para realizar a avaliação da dressagem de um rebolo, podem ser citados:

\subsubsection{1 - UTILIZAÇÃO DA EMISSÃO ACÚSTICA}

A emissão acústica (E.A.) pode ser entendida como ondas de tensão geradas nos materiais durante os processos dinâmicos (LIPTAI et al., 1972). Assim, quando o material é submetido a um estímulo externo qualquer (por exemplo a formação do cavaco, o atrito entre a peça e a ferramenta ou mesmo 
o simples contato entre a ferramenta e a peça) ocorrem deformações e o correspondente rearranjo da estrutura cristalina do material. Isto libera uma quantidade de energia suficiente para produzir ondas de tensão que se propagam na superfície do material. Sua freqüência varia de $50 \mathrm{kHz}$ a 1000 $\mathrm{kHz}$, a qual está acima do campo dos ruídos provenientes de fontes externas ao próprio processo de retificação. Portanto, trata-se de um método muito sensível e adequado para monitorar o processo de retificação (OLIVEIRA, 1999).

$\mathrm{Na}$ retificação as fontes de E.A. no processo são principalmente as fraturas do ligante e do grão, as trincas no grão e o atrito entre o grão abrasivo e a peça, todos elas diretamente relacionadas ao processo de formação do cavaco e de desgaste do rebolo (MALKIN, 1989).

Dornfeld e Cai (1984) foram pioneiros na investigação do potencial de utilização da análise do sinal de E.A. para o monitoramento do processo de retificação. Concluíram que o sinal de E.A. é capaz de detectar com precisão o empastamento da superfície do rebolo, o contato peça/rebolo e o centelhamento (ou "spark-out"), sendo que em todos os casos a sensibilidade do sinal de E.A. superou a da medição de força.

$\mathrm{Na}$ dressagem do rebolo os choques entre os grãos abrasivos e o diamante do dressador criam fortes ondas de tensão, as quais viajam ao longo do dressador e das peças da máquina em uma banda larga de freqüências. $A$ energia dessas ondas pode ser detectada por um sensor de E.A. Alguns trabalhos de pesquisa têm mostrado que o nível RMS de E.A. é proporcional aos principais parâmetros de dressagem (OLIVEIRA, 1999), (MARINELLI FILHO, 1997), (INASAKI, 1985).

O sensor de emissão acústica possibilita a detecção da posição relativa do dressador e do rebolo (OLIVEIRA et al., 1994a), (VIEIRA JUNIOR, 1996), (DORNFELD, 1992). Além disso, oferece valiosas informações a respeito da uniformidade do contato entre dressador e rebolo durante a dressagem (ARONSON, 1994).

Inasaki (1985) e Marinelli Filho (1997) realizaram estudos para verificar a influência dos parâmetros de dressagem sobre o sinal de Emissão Acústica e encontraram uma relação direta da profundidade de dressagem $\left(\mathbf{a}_{\mathbf{d}}\right)$ e do passo 
de dressagem $\left(\mathbf{S}_{\mathbf{d}}\right)$ com a amplitude do sinal de emissão acústica. Confirmaram portanto a possibilidade do emprego da E.A. no monitoramento da operação de dressagem.

Inasaki (1985) identificou que o uso da E.A. na dressagem poderia trazer informações importantes sobre a topografia do rebolo. Considerando que durante o processo de retificação o desgaste irregular do rebolo provoca alterações no seu perfil, ele propôs o uso da E.A. para verificar o perfil do rebolo. Assim, a região da superfície do rebolo onde o desgaste foi mais acentuado origina um sinal de E.A. com menor intensidade durante a dressagem, enquanto que na porção onde o desgaste foi menor, 0 correspondente sinal é mais intenso. A figura 1 apresenta um exemplo esquemático desse tipo de verificação, mostrando um rebolo com perfil uniforme e o correspondente sinal de E.A. obtido na dressagem desse rebolo (a) e um outro rebolo com perfil irregular junto ao seu respectivo sinal de E.A. na dressagem (b).

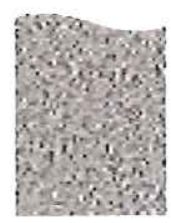

(a)

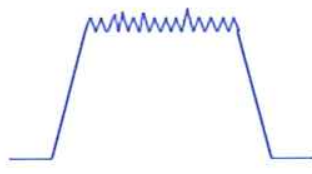

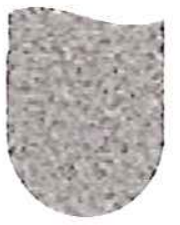

(b)

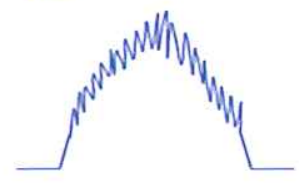

Figura 1: Sinais de E.A. obtidos na dressagem de rebolos com perfil (a) uniforme e (b) irregular (INASAKI, 1985).

Entretanto, Inasaki (1985) verificou que, durante a dressagem, a variação na intensidade do sinal de E.A. pode ser causada também por alterações na dureza ou na estrutura do rebolo. Ele também notou que a distribuição dos grãos abrasivos na superfície do rebolo pode ser avaliada 
através dos picos que ocorrem no sinal de E.A. durante a dressagem, visto que cada choque entre o dressador (de ponta única) e um grão abrasivo provoca uma elevação do sinal de E.A. Assim, mostrou ser possível calcular a distância média entre grãos na superfície do rebolo, constatando que para rebolos de dureza $Q$ com granulometria 60 , esta distância é da ordem de 0,90 a $0,95 \mathrm{~mm}$.

Ele constatou ainda que existe uma tendência do sinal de E.A. se estabilizar em um determinado nível, mesmo com o aumento da profundidade de dressagem $\left(\mathbf{a}_{\mathbf{d}}\right)$. Isto ocorre devido a uma saturação do sinal (figura 2). Dentro deste contexto, é importante o conceito de Profundidade Limite de Dressagem ( $\mathbf{a}_{\text {dlim }}$ ) estabelecido por Coelho (1991), segundo o qual o valor da profundidade de dressagem deve ser suficiente para promover somente o arrancamento dos grãos desgastados e a fratura dos grãos com boa ancoragem na liga, e não a liberação de grãos ainda inteiros.

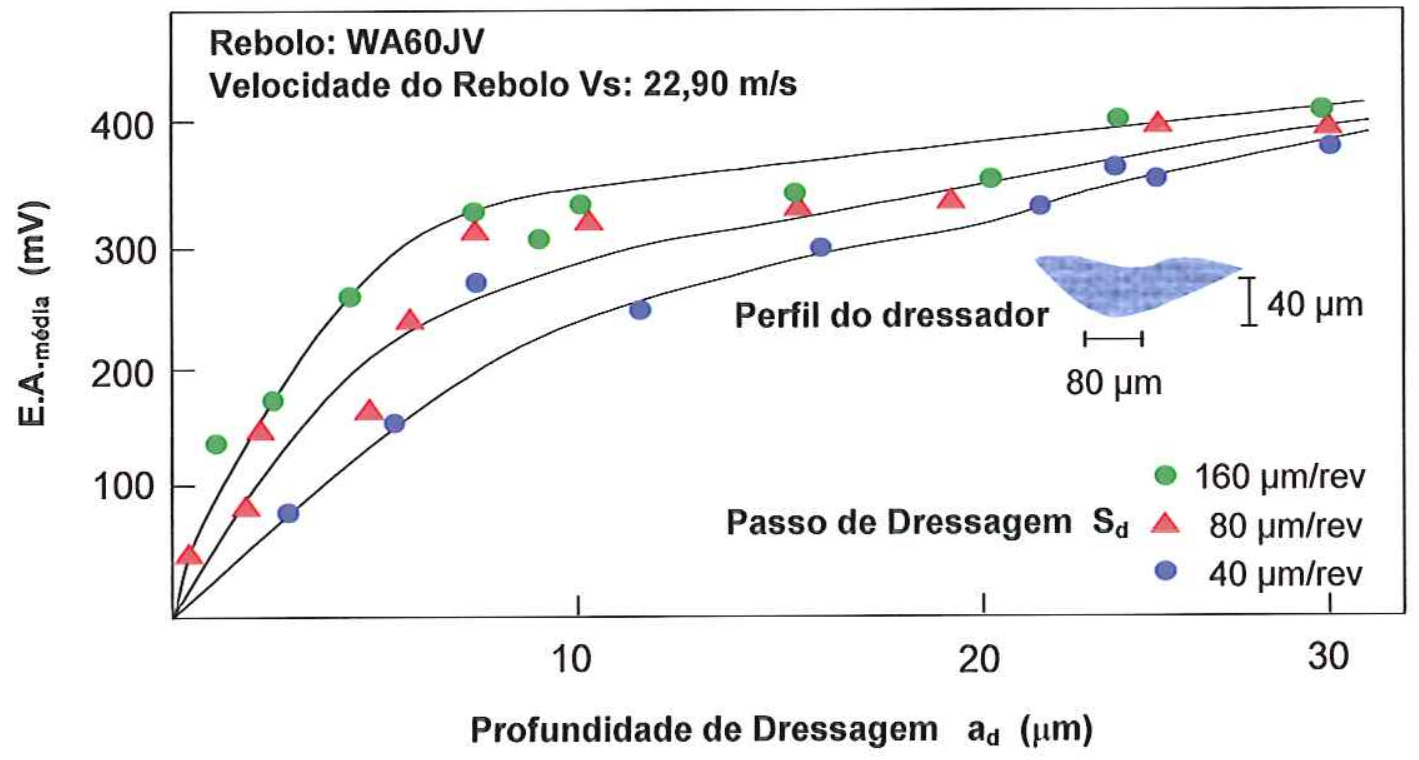

Figura 2: Comportamento do sinal de E.A. em função da profundidade de dressagem (INASAKI, 1985).

Inasaki (1985) também estudou o comportamento do sinal de E.A. durante a dressagem em função do Passo de Dressagem $\left(\mathbf{S}_{\mathbf{d}}\right)$, constatando uma relação direta entre $\mathbf{S}_{\mathbf{d}}$ e E.A., conforme mostra a figura 3 , onde observa- 
se que a rugosidade $(\mathrm{R} a)$ da peça obtida em relação à $\mathbf{S}_{\mathbf{d}}$ apresenta um comportamento semelhante ao do sinal acústico. Isto indica a possibilidade de predizer o acabamento superficial das peças através do controle da E.A. na operação de dressagem. Oliveira (1988) confirma essa possibilidade citando que um aumento no passo de dressagem faz crescer a agressividade do rebolo, diminuindo o grau de recobrimento de dressagem $\left(\mathbf{U}_{d}\right)$. O parâmetro $\mathbf{U}_{d}$ é definido como a razão entre a largura de dressagem $\left(\mathbf{b}_{\mathbf{d}}\right)$ e o passo de dressagem $\left(\mathbf{S}_{\mathbf{d}}\right)$.

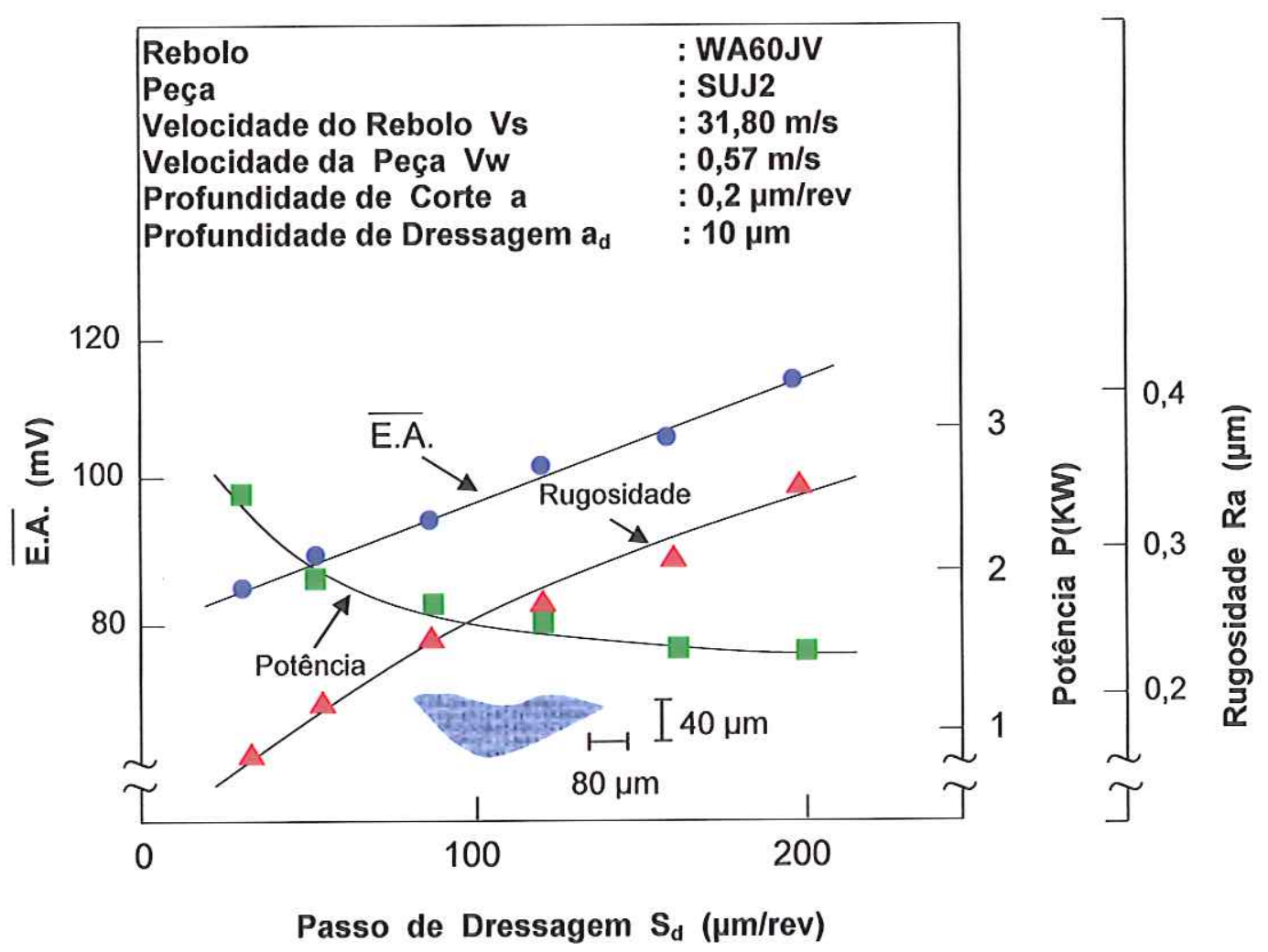

Figura 3: Influência do passo de dressagem sobre a E.A., a rugosidade Ra da peça e a potência de retificação (INASAKI, 1985).

Outro trabalho sobre as condições de desgaste do rebolo utilizando técnicas de E.A. e dressagem foi conduzido por OLIVEIRA et al. (1994b). O objetivo do trabalho foi identificar o momento em que ocorre o contato entre o dressador e o rebolo, a partir de diferentes posições da superfície de corte do 
mesmo. Para isto, partiram do princípio de que a interação entre o dressador e o rebolo passa por três fases:

a) Uma fase de turbulência, em que ainda não há contato e surge um leve sinal de E.A. devido às ondas de choque geradas pela interação entre o fluxo turbulento da camada de ar + refrigerante que rodeia o rebolo e as partículas abrasivas do mesmo (região $A$ );

b) Uma fase de contato elástico (posição virtual), na qual começam a ocorrer choques entre o dressador e as partes mais altas dos grãos abrasivos do rebolo, sem que a superfície do mesmo seja afetada, uma vez que nesta fase ocorrem apenas deformações elásticas, especialmente no ligante (região B);

c) Uma fase de contato friável, na qual começam a ocorrer fraturas dos grãos abrasivos do rebolo e, portanto, desgaste volumétrico do mesmo (região $\mathrm{C}$ ).

A E.A. na fase de contato elástico é afetada pela dureza do rebolo e pela geometria do dressador, não sendo influenciada pela velocidade de aproximação do rebolo em relação ao dressador. Sinais mais intensos de E.A. ocorrem para rebolos mais duros e dressadores desgastados, isto é, com maior área de contato. A figura 4 mostra uma representação esquemática dessas fases e a intensidade do sinal de E.A. obtido em cada uma delas. Assim, caso em alguma posição o instante de contato seja diferente, isto é, caso demore algum tempo a mais para o sinal de E.A. acusar o contato, significa que houve desgaste do rebolo.

O método proposto por OLIVEIRA et al. (1994b) também possibilita identificar a ocorrência de dilatações térmicas na máquina que provoquem o afastamento do cabeçote do rebolo de sua posição nominal. 


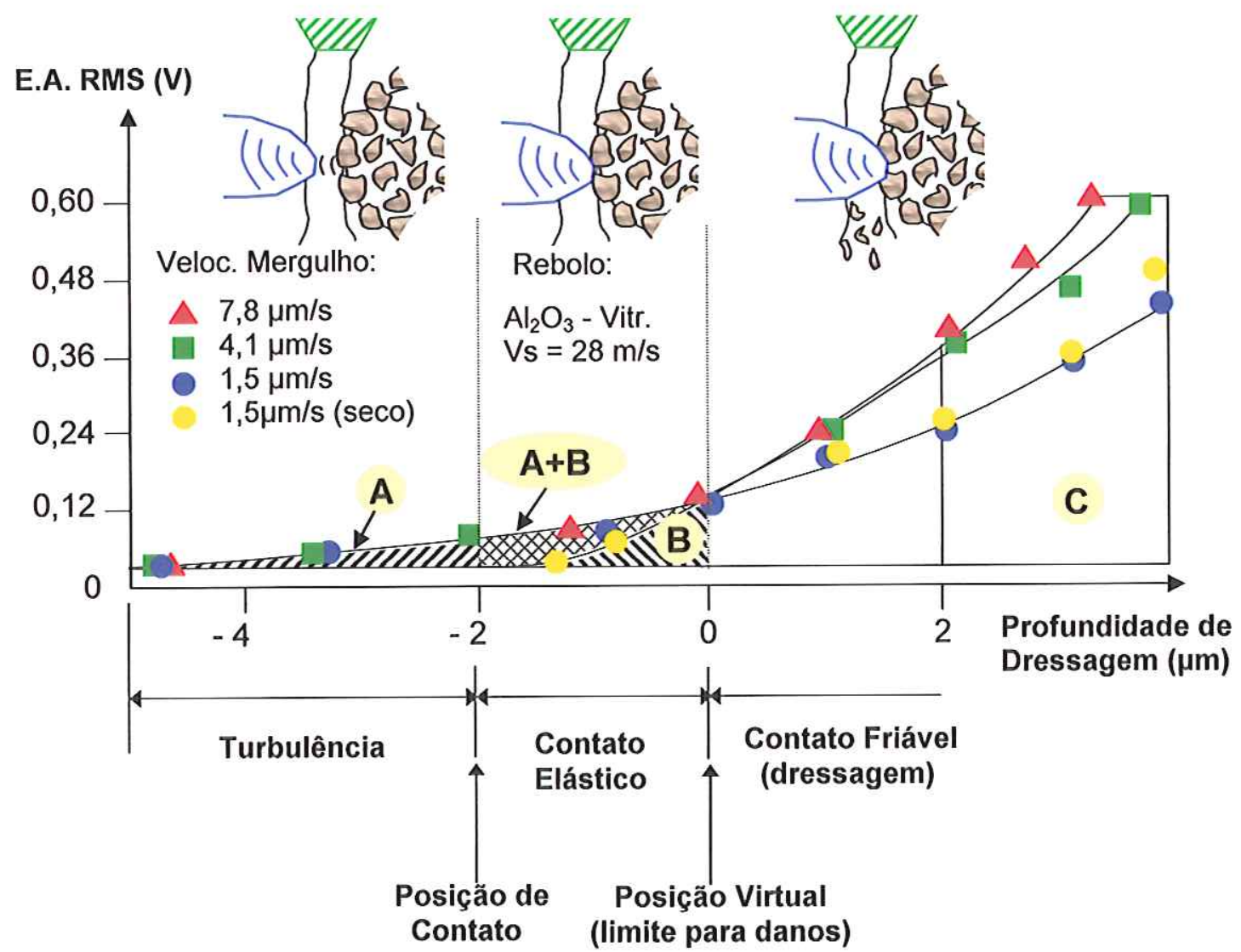

Figura 4: Comportamento do sinal de E.A. durante as três fases de interação entre dressador e rebolo (OLIVEIRA et al., 1994b).

OLIVEIRA et al. (1995) sugerem ainda que o sinal de E.A. seja utilizado para detectar o contato entre o dressador e o rebolo nos casos em que se deseja realizar um novo set-up da posição de dressagem, quer seja devido a uma troca de rebolo ou então à necessidade de se alterar o posicionamento do dressador.

\subsubsection{2- RugosidAdE dA PEÇA RETIFICADA}

A rugosidade superficial da peça retificada está relacionada com a remoção de metal, a qual, por sua vez, depende dos parâmetros de dressagem empregados na operação. Com relação ao dressador, um fator determinante na geração da rugosidade da peça é a geometria do diamante. Caso o 
desgaste do dressador provoque uma variação no perfil do diamante, a rugosidade da peça deverá apresentar variações. Este é o caso do dressador de ponta única fabricado com diamantes naturais, o qual apresenta uma variação do perfil do diamante de acordo com o seu grau de desgaste. Nesta situação a tendência da rugosidade é diminuir ao longo do tempo devido à geração de uma superfície plana na ponta do diamante, o que provoca um aumento da largura de dressagem $\left(\mathbf{b}_{\mathbf{d}}\right)$ e, conseqüentemente, do grau de recobrimento $\left(\mathbf{U}_{\mathrm{d}}\right)$. Em dressagens grossas, em que o valor do grau de recobrimento é pequeno e o número de arestas atuantes da superfície do rebolo é reduzido, ocorre um aumento na profundidade dos sulcos gerados na peça, originando valores mais elevados de rugosidade. Se a dressagem for fina, isto é, com valores maiores de grau de recobrimento, um número significativamente maior de arestas atuantes divide os esforços e cada grão abrasivo penetra menos na peça, reduzindo assim os valores de rugosidade (ROWE et al., 1993), (OLIVEIRA et al., 1992b), (CHEN e ROWE, 1996).

Caso o desgaste não altere a geometria do diamante do dressador, a rugosidade obtida na peça não deve apresentar uma variação significativa. Portanto, o emprego de dressadores com perfil de atuação constante deve originar rugosidades uniformes ao longo de sua utilização.

\subsubsection{3 - AgRESSIVIDADE DA SUPERFICIE DE TRABALHO DO REBOLO}

A agressividade corresponde à capacidade do rebolo de remover material em uma operação de retificação. A agressividade da superfície de trabalho do rebolo está diretamente ligada à determinação: das forças de retificação, da geração de calor, da integridade superficial da peça, etc.

Nakayama et al. (1980) foram pioneiros na elaboração de um método (conhecido por Método da Esfera Retificada ou também por Método da Balança de Nakayama) para a quantificação de um parâmetro (designado pela letra K), o qual pode ser definido como sendo a relação entre a taxa (ou velocidade) de remoção de material e a pressão necessária para se efetuar esta remoção.

Semelhante a este é o Método do Disco Retificado (COELHO, 1991). Este método consiste em manter um disco, confeccionado com o mesmo 
material da peça a ser retificada, pressionado contra o rebolo com uma força constante. O valor do deslocamento do disco, que representa a penetração no rebolo, é registrado, ponto a ponto, em função do tempo. Com esses dados é construída uma curva cujo eixo vertical mostra os valores da derivada do deslocamento em relação ao tempo (ou seja, a velocidade), e no eixo horizontal a relação entre a força normal e a área de contato entre o disco e o rebolo, no instante da medição do deslocamento. A tangente desta curva representa numericamente a agressividade (K) do rebolo (COELHO, 1991).

\subsection{2 - Os Efeitos das VARIÁveis do Rebolo sobre o Desgaste dos} DIAMANTES DO DRESSADOR

\subsubsection{1 - ABRASIVIDADE dos GRÃOS ABRASIVOS CONVENCIONAIS}

O Óxido de Alumínio e o Carbeto de Silício são os dois principais materiais classificados como abrasivos convencionais. Diferentes tipos de grãos abrasivos afetam o desgaste do diamante do dressador de maneiras diferentes. Grãos com baixa friabilidade (a friabilidade corresponde à capacidade do grão fraturar sob uma determinada força ou impacto) e uma alta resistência à fratura, como por exemplo o Carbeto de Silício, são conhecidos por ser mais abrasivos do que o Óxido de Alumínio. O Óxido de Alumínio Branco, cuja pureza está acima de $99 \%$, é muito friável, enquanto que o Óxido de Alumínio Marrom, com pureza de $95 \%$ e contendo uma pequena quantidade de Óxido de Titânio, possui alta tenacidade. Na dressagem, o desgaste do diamante mostrará uma correlação com as características dos tipos de grãos. Grãos com alta resistência à fratura afetarão o desgaste do diamante do dressador de duas maneiras: primeiramente, como resultado dos impactos mais severos, a abrasão do diamante será mais rápida. Além disso, a temperatura gerada também será maior, quando uma certa porcentagem do diamante poderá se perder devido à grafitização (NUSBAUM, 1988). 


\subsubsection{2 - O TAMANHO DO GRÃO ABRASIVO}

Os rebolos convencionais contendo grãos abrasivos grosseiros (de maior granulometria) são utilizados para a retificação de desbaste a fim de conseguir primordialmente remoção de material, enquanto que os rebolos de grãos finos são empregados para obter alta qualidade de acabamento do componente, assim como a necessária tolerância dimensional e geométrica. $\mathrm{O}$ desgaste dos diamantes de um dressador pode variar em intensidade quando se empregam rebolos de mesmo tipo de grão mas com granulometrias diferentes.

O diamante, embora seja o material de maior dureza conhecido, é frágil, e a maior força de impacto produzida pelos grãos maiores (de maior massa), comparada com a menor força dos menores grãos, produzirá microlascamentos mais agressivos do diamante, resultando num desgaste mais rápido. Esta condição pode piorar se a forma geométrica e o tamanho da ponta do diamante (e portanto sua resistência) não forem compatíveis com o tamanho dos grãos do rebolo, com sua resistência à fratura e com a resistência do ligante na qual os grãos são mantidos no rebolo, resultando em forças de impacto altas que podem acelerar o microlascamento da ponta do diamante (TAEYAERTS, 1968).

\subsubsection{3 - A DUREZA DO LIGANTE DO REBOLO}

A dureza do ligante que sustenta os grãos no rebolo varia desde o relativamente macio até o muito duro, sendo que existem diferentes tipos de ligantes para diversas aplicações. A capacidade de retenção do grão pelo ligante aumenta com o aumento da dureza do ligante. Durante a dressagem a porcentagem de expulsão dos grãos de rebolos com ligante macio será maior do que a dos rebolos de ligante duro. No caso destes, a diminuição proporcional na expulsão dos grãos irá aumentar o número de impactos entre os grãos e o dressador, acelerando o desgaste do diamante (VIEIRA JUNIOR e OLIVEIRA, 2000). 


\subsubsection{4 - O BALANCEAMENTO DO REBOLO}

Existem várias razões para um rebolo montado girar desbalanceado e produzir vibração. Estas causas podem ser uma concentração inconsistente dos grãos no rebolo, geometria não concêntrica do rebolo devido à existência de folga entre o eixo da máquina e o orifício do rebolo ou vibração sendo transmitida através do eixo da máquina. Como o diamante é um material frágil, durante a dressagem a vibração do rebolo pode influenciar o seu desgaste através do microlascamento mais rápido. A vibração em rebolos de grandes dimensões é mais prejudicial à vida do dressador. Por isso, um balanceamento dinâmico periódico à medida que o rebolo diminui o seu diâmetro é importante para otimizar a vida do dressador (TAEYAERTS, 1968).

2.1.3 - Os Efeitos das Variáveis do Processo sobre o Desgaste dos DIAMANTES DO DRESSADOR

\subsubsection{1 - A Profundidade de Dressagem e o Avanço de Dressagem}

Segundo SEN (2000) na prática, a profundidade de dressagem irá variar dependendo do objetivo da operação. Assim, por exemplo:

a) Perfilando um rebolo recentemente montado:

$\mathrm{Na}$ correção da excentricidade da periferia de um rebolo recentemente montado e na geração de perfis retos, curvos ou angulares, o diamante do dressador corta os grãos e o ligante, na medida em que a profundidade de dressagem foi ajustada visando a remoção de material e neste processo o desgaste do diamante pode ser razoavelmente alto.

b) Restauração periódica do perfil e reafiação da superfície de trabalho do rebolo:

A profundidade de dressagem é normalmente pequena e depende do tipo de grão, do seu tamanho e do grau de cegamento dos grãos. Para grãos com elevada resistência à fratura, como o Carbeto de Silício, uma profundidade 
de dressagem inadequada, principalmente para um diamante com uma grande área de contato, resultará em atrito entre o diamante e o grão cego, sendo improvável desta forma fraturar os grãos de maneira eficiente.

c) Reafiando a superfície de trabalho do rebolo através da remoção de uma camada de grãos empastados:

Uma elevada profundidade de dressagem, cortando os grãos e o ligante a fim de remover uma espessa camada empastada da superfície do rebolo irá impor maiores forças de impacto sobre a ponta do diamante, acelerando o seu desgaste.

O deslocamento transversal de um dressador faz com que o material seja removido da superfície do rebolo até a profundidade ajustada pela penetração do diamante, à uma taxa definida pela velocidade de deslocamento do dressador fixada na máquina. A rotação do rebolo, a velocidade de deslocamento transversal do dressador, a granulometria do rebolo e a forma e tamanho do diamante do dressador determinam a topografia da face de trabalho do rebolo. O ajuste destes parâmetros controla o número de cortes feitos pelo diamante por grão (ou por número de grãos), o acabamento resultante sobre a face do rebolo e, por conseguinte, o acabamento sobre a peça retificada.

A profundidade de penetração e o avanço transversal do dressador são dependentes um do outro na dinâmica da operação de dressagem. Uma vez ajustado, o fator profundidade de dressagem torna-se estático e seu efeito sobre a dressagem do rebolo e sobre a vida do dressador torna-se uma função do avanço transversal (SEN, 2000).

Um exemplo do efeito da taxa de avanço transversal é mostrada esquematicamente na figura 5. Este exemplo assume que os grãos sobre a face plana de um rebolo estejam posicionados lado a lado em uma linha reta ao longo da trajetória do diamante, e que este tenha uma ponta fina compatível com a granulometria do rebolo. A taxa de avanço transversal de um único passe de dressagem pode ser ajustada para impactar uma única vez cada grão que esteja na trajetória do diamante, ou cada grão secundário, ou cada grão terciário, e assim por diante. 


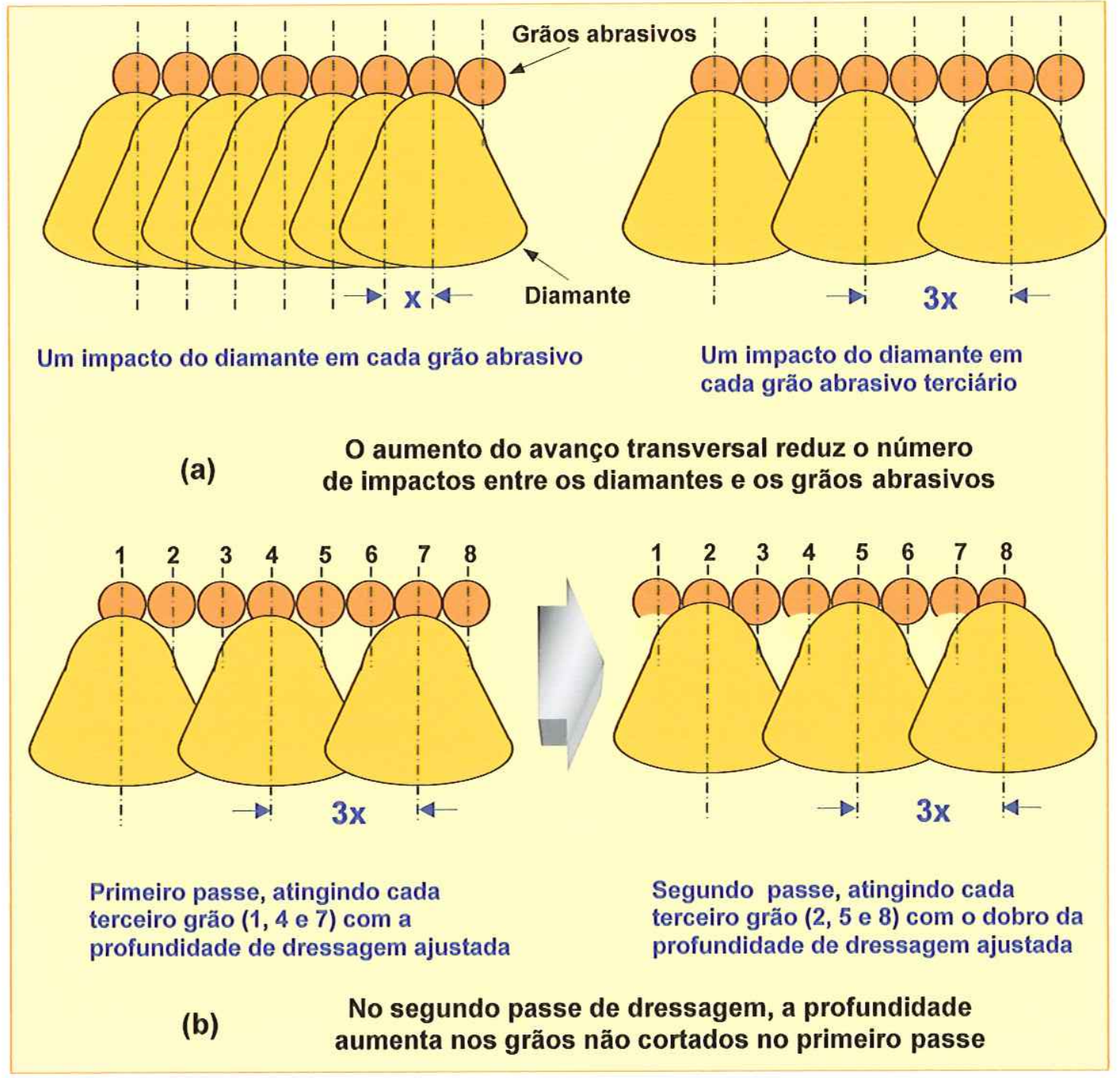

Figura 5: Efeito da velocidade transversal e do número de passes de dressagem sobre o diamante do dressador (SEN,2000).

Diminuindo o número de impactos entre o diamante e os grãos, esperase aumentar a vida do diamante, como mostrado no desenho esquemático da figura 5 (a). Entretanto, como mostrado na figura 5 (b), se o avanço transversal é ajustado para impactar cada grão terciário e mais do que um passe de dressagem é dado, com uma nova profundidade em cada passe, então no passe secundário e nos subseqüentes a ponta do diamante irá impactar os grãos que não foram cortados nos passes anteriores com duas vezes a profundidade ajustada, ou mais. Isto irá aumentar o desgaste do diamante de modo imprevisível. 


\subsubsection{2 - A VELOCIDADE DO REBOLO E A RIGIDEZ DA RETIFICADORA}

Em uma situação de produção, tanto a dressagem do rebolo como a retificação da peça são executadas com a mesma velocidade de corte do rebolo. Na dressagem e na retificação, à medida que o diâmetro do rebolo diminui, a velocidade periférica de corte também diminui (a menos que a retificadora tenha algum dispositivo de compensação da velocidade do rebolo) e, consequentemente, a força de impacto produzida pelos grãos do rebolo sobre o dressador se reduz (menor energia cinética). Além disso, com a redução do diâmetro do rebolo, o volume de material removido pelo dressador por volta do rebolo também diminui. Assim, estes dois fatores têm um efeito positivo sobre a vida do diamante do dressador.

Buscando evitar qualquer outra forma de desgaste do dressador do que o desgaste abrasivo normal, é importante minimizar a vibração no ponto de contato entre o dressador e o rebolo. Além da vibração que pode ser causada por um desbalanceamento do rebolo, é importante ter uma rigidez adequada da retificadora, começando do eixo porta-rebolo e passando pela fixação da retificadora no solo, pelos suportes da máquina, pelo suporte do dressador, até chegar à ponta do diamante em contato com o rebolo, com todos estes elementos formando um ciclo completo para o ajuste da operação de dressagem (SEN, 2000).

2.1.4 - Vantagens dos Dressadores com Perfil de Atuaçäo Constante

A figura 6 apresenta a concepção geral deste dressador, o qual apresenta as seguintes vantagens, comparados aos dressadores de ponta única:

- Desgaste uniforme da parte ativa;

- Não necessitam de rotação após um período de utilização;

- Regulagem simples e única do dispositivo de dressagem. 


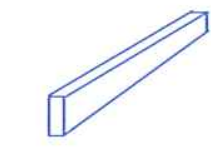

CRISTAL DE DIAMANTE

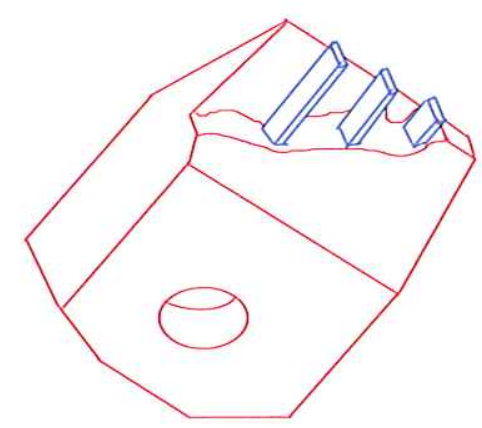

Figura 6: O dressador com perfil de atuação constante (VIGNA, 1997).

Este tipo de dressador apresenta as seguintes características, as quais podem resolver alguns dos problemas dos dressadores que empregam diamantes naturais (MARINELLI FILHO, 1997):

- A geometria dos diamantes utilizados e o seu posicionamento em relação ao rebolo asseguram uma área de contato constante entre os dois durante toda a vida do dressador.

- A possibilidade de maior área de contato aliada ao número maior de diamantes, comparado ao dressador de ponta única, provavelmente proporcionará uma redução no desgaste do mesmo.

- Os diamantes utilizados são artificiais, o que assegura um padrão de qualidade difícil de se obter com os diamantes naturais, pois elimina-se a influência negativa de fatores como inclusões, anisotropia, trincas, etc.

\section{2 - Cinemática da Operação de Dressagem}

O desgaste de um dressador pode ser melhor visualizado quando se considera o desgaste do diamante do dressador de ponta única, comumente fabricado com uma pedra de diamante natural.

O mecanismo cinemático da operação de dressagem consiste em se deslocar o dressador transversalmente ao rebolo, com este em movimento de rotação (OLIVEIRA et al., 1990). A penetração do dressador a uma determinada profundidade de dressagem $\left(\mathbf{a}_{\mathbf{d}}\right)$ implica uma largura de atuação de dressagem $\left(\mathbf{b}_{\mathbf{d}}\right)$, e este valor pode ser determinado medindo-se a ponta do 
dressador com um projetor de perfis, conforme é apresentado na figura 7 (SILVA JUNIOR e COELHO, 1998), (OLIVEIRA, 1992).

$$
\mathrm{U}_{\mathrm{d}}=\frac{\mathrm{b}_{\mathrm{d}}}{\mathrm{S}_{\mathrm{d}}}
$$
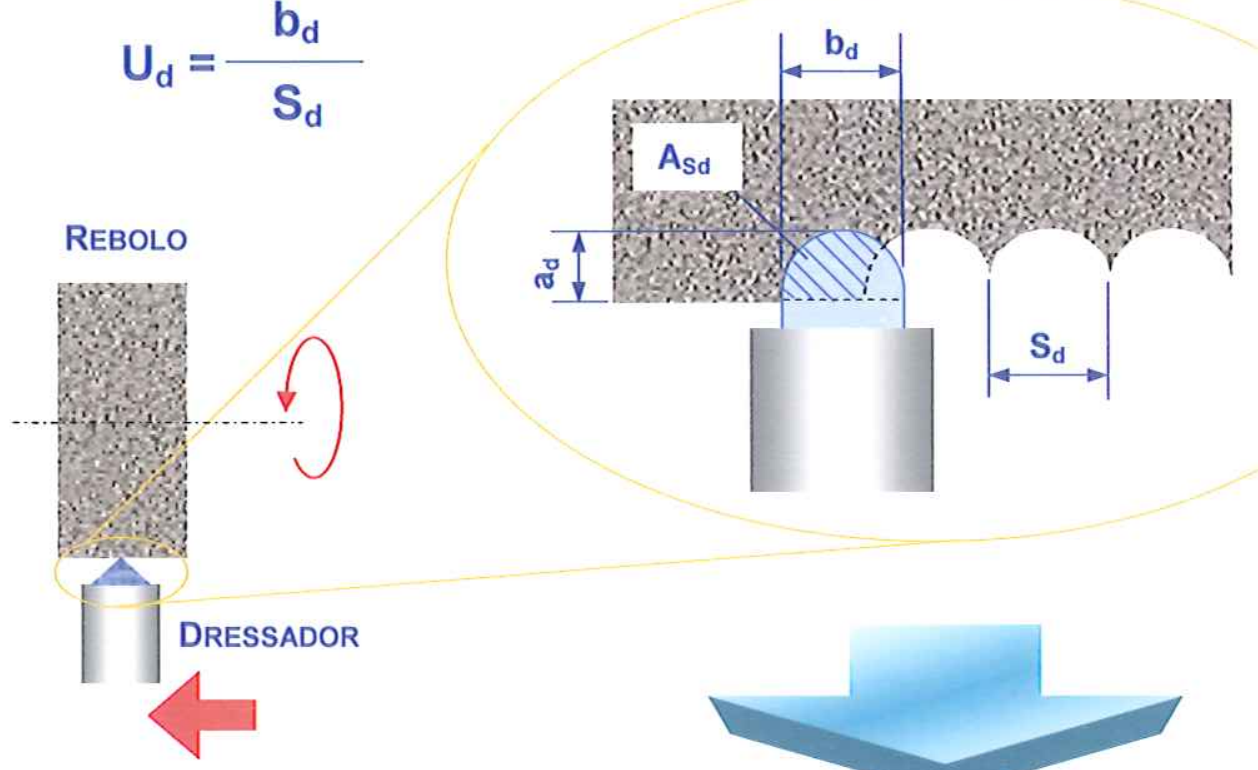

DRESSADOR
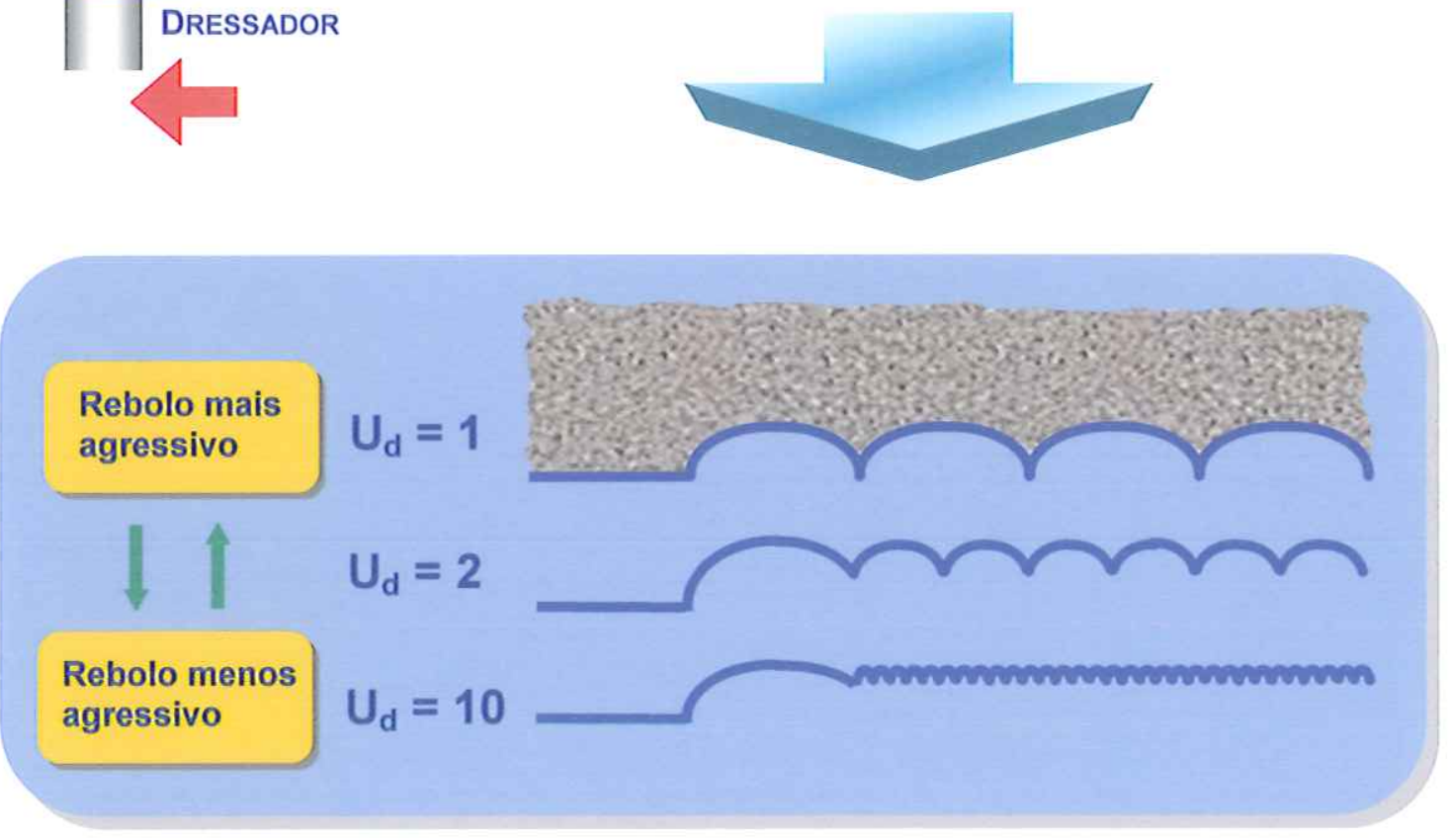

Figura 7: Cinemática da operação de dressagem (SILVA JUNIOR, 1998).

A operação de dressagem provoca o corte e a fratura dos grãos abrasivos pelo dressador, além de gerar uma "rosca" na superfície do rebolo. Desta operação surgem dois efeitos (OLIVEIRA, 1988), (OLIVEIRA et al., 1992a), (COELHO e OLIVEIRA, 1991), (OLIVEIRA e PURQUERIO, 1989), (BIANCHI, 1990), (VERKERK e PEKELHARING, 1979): 
a) Macroefeito: a sua formação é função do formato do dressador, da profundidade de penetração deste e do passo de dressagem em que é realizada a operação. Este fenômeno determina a posição em que as arestas dos grãos abrasivos estão localizadas na superfície do rebolo. Pode-se dizer também que o macroefeito corresponde à rosca formada na superfície do rebolo após a passagem do dressador.

b) Microefeito: é formado pelo arrancamento dos grãos desgastados (com baixa ancoragem na liga), e pela fratura dos grãos que não se desgastaram por completo, em que novas arestas de corte são geradas pelo dressador. A agressividade das arestas depende das condições de dressagem e da friabilidade do grão abrasivo (capacidade de formar novas arestas cortantes quando fraturado). O fenômeno do microefeito está portanto relacionado com o tipo de aresta que é formada nos grãos abrasivos durante a operação de dressagem, podendo tornar o rebolo mais agressivo.

Uma vez que o dressador passa com velocidade constante pelo rebolo, se o dressador se desgasta, ocorre uma interferência de um passo sobre o outro. O desgaste do dressador provoca um aumento do grau de recobrimento de dressagem $\left(\mathbf{U}_{\mathrm{d}}\right)$, diminuindo a agressividade da superfície de trabalho do rebolo.

Além da menor agressividade da rosca, o dressador gasto provoca uma menor agressividade do grão, pois pode não promover a quebra ou arrancamento deste com a mesma facilidade que um dressador novo. Esta menor agressividade do rebolo pode provocar o aumento das forças de corte e a perda mais rápida de afiação dos grãos, levando à queima da peça retificada (MARINELLI FILHO et al., 1998), (FELIPE JUNIOR, 1996).

\section{3 - A Fabricação de Dressadores Estáticos Sinterizados}

Apesar do registro mais antigo do uso do diamante datar de 300-350 A.C., é apenas nos meados do século 19 que se iniciou a produção industrial de ferramentas de diamante e os projetos que conduziram às aplicações 
atuais. Devido ao alto custo e às dimensões relativamente pequenas do diamante, geralmente é necessário que eles sejam montados em suportes ou sinterizados em segmentos abrasivos ou ainda suspensos em fluidos, etc, para viabilizar economicamente o seu uso (BAKON e SZYMANSKI, 1993).

$O$ projeto e as dimensões de uma determinada ferramenta dependem diretamente da natureza da operação de usinagem, das características do material da peça, e das exigências de acabamento superficial. Em termos da quantidade de diamante empregado, as ferramentas podem ser divididas nas variedades ponta-única ou multi-pontas. Nas ferramentas multi-pontas os diamantes podem ou não estar orientados relativamente uns aos outros e em relação à superfície da peça. Os diamantes podem ser moldados (cortados em formas especiais) ou podem ser usados no seu estado natural (WILKS e WILKS, 1991).

Os métodos de fabricação das ferramentas diamantadas incluem (BAKON e SZYMANSKI, 1993):

- ferramentas com diamantes brasados;

- ferramentas produzidas pelos métodos da Metalurgia do Pó;

- ferramentas com diamantes ligados através da eletrodeposição.

\subsection{1 - FerRamentas Produzidas com Diamantes Brasados}

A brasagem como método de montagem dos diamantes é empregada nas ferramentas que utilizam diamantes monocristalinos e PCD (Polycristalline Diamond). Esta técnica causa um aquecimento relativamente rápido do diamante a uma temperatura alta, o que carrega o risco do cristal trincar ou sofrer oxidação superficial. $\mathrm{O}$ calor é aplicado utilizando-se um maçarico ou uma resistência elétrica ou ainda bobinas de indução, sendo este último geralmente o melhor. A vantagem desta última é que a temperatura pode ser controlada de maneira mais precisa, além de requerer pouca habilidade e treinamento do operador. No primeiro caso, a brasagem geralmente é feita com um maçarico de oxi-acetileno, embora outros gases também forneçam resultados satisfatórios. 
A principal recomendação de precaução na realização da brasagem diz respeito ao fato de que o calor deve sempre ser aplicado à haste ou suporte da ferramenta, nunca diretamente sobre o diamante, a fim de minimizar a possibilidade de avaria térmica ao mesmo. Para reduzir o risco do diamante danificar-se no processo, utilizam-se soldas com pontos de fusão menores do que $1070 \mathrm{~K}\left(797^{\circ} \mathrm{C}\right)$. As soldas para diamantes mais populares são aquelas baseadas na Prata, pois suportam bem as condições de uso da ferramenta e, ao mesmo tempo, apresentam "molhabilidade" e boa ligação tanto com o diamante quanto com a haste de aço da ferramenta. A brasagem também envolve o uso de fluxos, por exemplo, uma mistura de Borax e Ácido Bórico (ou óxido de Boro) e fluoretos (BAKON e SZYMANSKI, 1993), (WILKS e WILKS, 1991).

Mais sensíveis às temperaturas elevadas, quando comparados ao diamante natural, são as ferramentas que utilizam o PCD, principalmente se elas possuem um substrato de Carbeto de Tungstênio, tais como os utilizados nas ferramentas de corte. A temperatura elevada pode trincar o diamante devido à diferença na expansão térmica dos dois materiais. Esses materiais somente podem ser mantidos em temperaturas acima de $870 \mathrm{~K}\left(597^{\circ} \mathrm{C}\right)$ por não mais do que uns poucos segundos (SPEAR e DISMUKES, 1993).

\subsection{2 - Ferramentas Produzidas pela Metalurgia do Pó}

Existem três tecnologias básicas empregadas na fabricação das ferramentas diamantadas utilizando processos da Metalurgia do Pó:

- Infiltração;

- Prensagem à quente;

- Prensagem a frio e posterior sinterização.

Os processos acima também podem ser empregados para preparar semi-produtos para a fabricação das ferramentas, na forma de compactos onde o diamante é sustentado pelo pó metálico sinterizado. Esses compactos são então brasados à haste da ferramenta. 
Em termos de estrutura da camada de diamante, as ferramentas com ligantes metálicos sinterizados dividem-se em duas categorias: as de superfície revestida com diamante e as impregnadas com diamante. As ferramentas revestidas são fabricadas em moldes onde os cristais de diamante são mantidos em posições rigidamente pré-determinadas, sendo que, na seqüência, o molde é preenchido com o material do ligante e todo o conjunto é então sinterizado. As técnicas de infiltração e de prensagem à quente são especialmente úteis para este objetivo.

As ferramentas impregnadas, por outro lado, são feitas através da sinterização da mistura do ligante e de finas partículas de diamante, sendo que estas partículas encontram-se dispersas por toda a camada do ligante. Portanto, nas ferramentas revestidas existe uma única camada de diamantes maiores enquanto que nas ferramentas impregnadas, as partículas de diamante são muito menores, podendo ser incorporadas em uma camada de, teoricamente, qualquer altura ou profundidade. (BAKON e SZYMANSKI, 1993), (WILKS e WILKS, 1991).

\subsubsection{1 - FERRAMENTAS PROduZidAs PELO PROCESSO dE INFILTRAÇÃo}

O processo de Infiltração consiste de um tratamento pós-sinterização realizado no compacto poroso obtido da prensagem da mistura de pós metálicos com os diamantes.

Neste processo, primeiramente é feita uma estrutura porosa, denominada esqueleto, geralmente a partir dos pós de Carbetos (de Tungstênio, Molibdênio, Titânio, Cromo) e de pós metálicos (Tungstênio, Cromo, Molibdênio), assim como de pós de metais fáceis de sinterizar (Cobalto, Ferro, Níquel, Bronze, Cobre). A fim de se obter um empacotamento suficientemente denso, o pó no molde pode ser vibrado.

O material que vai atuar como ligante, que possui um ponto de fusão relativamente baixo, fica contido em um pequeno reservatório com uma saída para a superfície do compacto poroso contido na matriz de tal modo que, sob fusão, esta liga é sugada por uma ação de capilaridade e se espalha por todo o compactado, preenchendo os seus poros e unindo todo o conjunto. A 
pressão pode ou não ser empregada na seqüência desse processo de infiltração, dependendo do tipo de ferramenta e das propriedades desejadas. Os agentes infiltrantes geralmente são ligas de Cobre, como, por exemplo, Cu$\mathrm{Ni}-\mathrm{Zn}, \mathrm{Cu}-\mathrm{Ni}, \mathrm{Cu}-\mathrm{Sn}, \mathrm{Cu}-\mathrm{Mn}-\mathrm{Ni}, \mathrm{Cu}-\mathrm{Ag}$. O tratamento térmico ocorre em fornos com atmosfera protetora, ou o aquecimento por indução é utilizado a uma temperatura na faixa de $1250-1500 \mathrm{~K}\left(977-1227^{\circ} \mathrm{C}\right)$. A temperatura máxima de sinterização deve ser no mínimo $100 \mathrm{~K}$ maior do que o ponto de fusão da liga utilizada para a infiltração. Esta liga irá fluir mais facilmente e preencher mais completamente os poros intergranulares se forem empregados fluxos (GOETZEL, 1984).

No caso dos ligantes baseados no Tungstênio (ou em seu Carbeto), quanto maior o ponto de fusão da liga infiltrante, maior a resistência do produto final à abrasão (BAKON e SZYMANSKI, 1993). A qualidade do ligante também é influenciada pelo tamanho, forma e estrutura superficial das partículas constituintes do esqueleto poroso. Assim, partículas com formas regulares e superfícies lisas proporcionam melhor contato com a liga infiltrante, produzindo ligações mais fortes (GERMAN, 1994).

\subsubsection{2 - Ferramentas Produzidas pelo Processo de Prensagem à}

\section{QUENTE}

O processo de prensagem à quente consiste em aquecer uma mistura de ligante metálico impregnada com diamante acompanhada de prensagem. Os moldes cuidadosamente preenchidos são inicialmente prensados à frio e então aquecidos em fornos especiais até a temperatura de sinterização. Em muitos casos utiliza-se atmosferas protetoras. Os agentes ligantes são incluídos com a mistura do pó a qual, após a compactação no molde, é prensada após a sinterização ou aquecida simultaneamente à prensagem até a temperatura de sinterização. Estas duas técnicas produzem diferentes propriedades físicas a partir da mesma matriz de pó metálico, sendo possível obter-se um bom controle de qualidade. Trata-se da técnica mais utilizada comercialmente para a produção de ferramentas de corte diamantadas (GERMAN, 1994). O trabalho desenvolvido por Paloschi Junior e Coelho (2000) 
mostrou que é possível a produção de dressadores sinterizados utilizando-se este método.

A prensagem à quente até cerca de $1150 \mathrm{~K}\left(877^{\circ} \mathrm{C}\right)$ pode ser executada em moldes de aço. Para temperaturas maiores deve-se empregar moldes de grafite (os mais utilizados), de cerâmica ou de ligas especiais resistentes ao calor.

A figura 8 mostra um equipamento para fabricar elementos da ferramenta de diamante através do processo de prensagem à quente. $A$ máquina controla automaticamente o tempo e a temperatura de sinterização. $O$ aquecimento pode ser feito através de resistência ou por indução elétrica. No primeiro caso, o aquecimento ocorre no momento em que o circuito elétrico é fechado quando as metades do molde entram em contato (BAKON e SZYMANSKI, 1993).
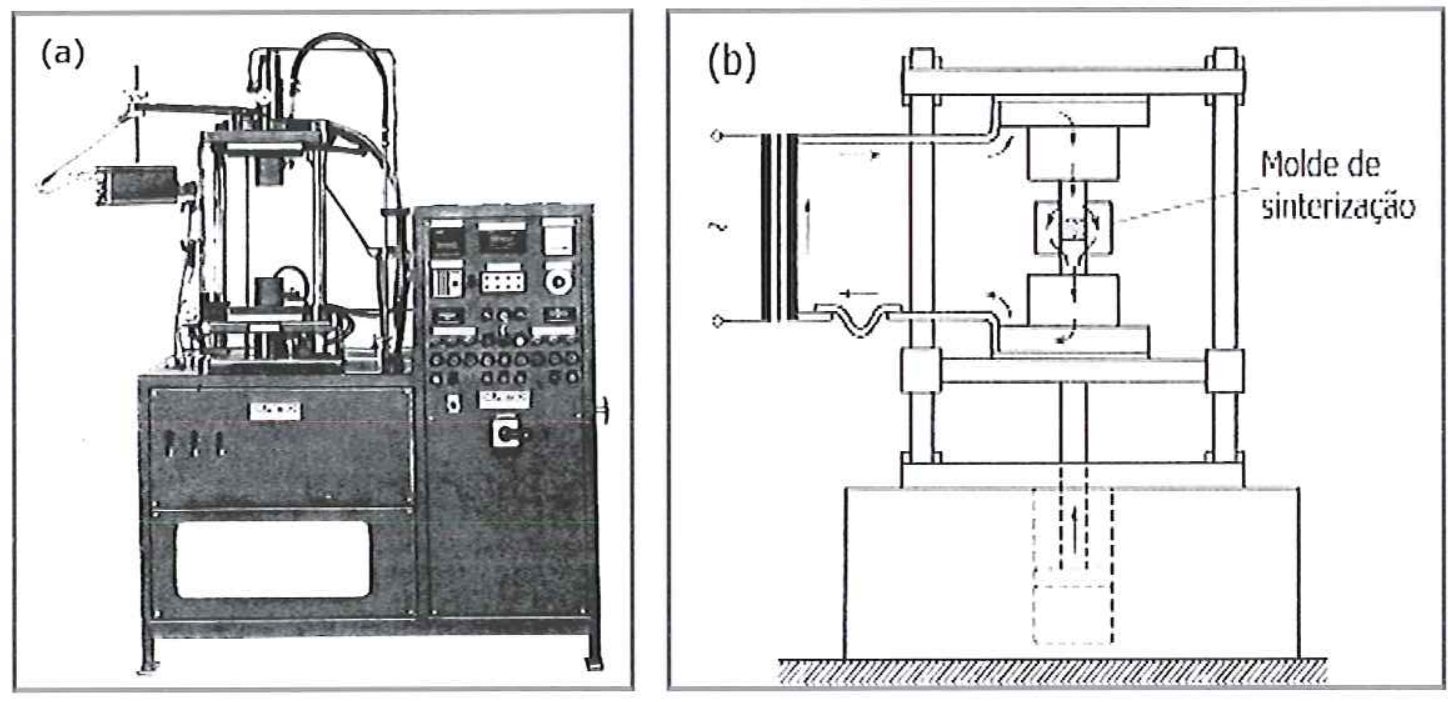

Figura 8: (a) Prensa utilizada na produção de segmentos de ferramentas de diamante através da prensagem à quente de pós metálicos;

(b) Diagrama esquemático do processo (BAKON e SZYMANSKI, 1993). 


\subsubsection{3 - Ferramentas Produzidas pelo Processo de Prensagem À} FrIo e POSTERIor SinterizaçÃo

A prensagem a frio e posterior sinterização utiliza pós auto-ligantes, os quais geralmente são fornecidos com um ligante orgânico que torna-se volátil nas temperaturas de fabricação, mas serve para dar resistência temporária (ou resistência verde) para os compactos.

Os pós adquirem as formas das ferramentas através da prensagem em moldes, sendo então removidos para serem inseridos em fornos de atmosfera controlada para a sinterização. No processo de prensagem à frio a prensagem mecânica é comparativamente mais rápida. O emprego de Hidrogênio ou de outros gases redutores garante um ambiente pobre em Oxigênio, condição importante para minimizar a oxidação, principalmente quando se utiliza diamantes pequenos e composições de matriz metálica que exigem elevadas temperaturas de sinterização (BAKON e SZYMANSKI, 1993). Ao final, a pastilha obtida é soldada em um suporte adaptado para a forma particular do dressador empregado pela retificadora.

Neste método, várias composições de ligantes (ou de misturas de pós) foram desenvolvidas, não existindo uma formulação universal para emprego geral. Na prática, cada fabricante de ferramenta emprega o seu próprio conjunto de composições e de condições de sinterização, todas minuciosamente testadas. Os constituintes dos ligantes metálicos de uso mais difundido são baseados no Cobre e suas ligas, no Ferro, Cobalto, bem como nos Carbetos e pós metálicos de alto ponto de fusão. As temperaturas máximas de sinterização para os ligantes baseados no Bronze estão na faixa de 1000 - $1250 \mathrm{~K}\left(727-977^{\circ} \mathrm{C}\right)$, enquanto que para aqueles com altos teores de carbetos e de Tungstênio, estão na faixa de 1200 - $1550 \mathrm{~K}\left(927-1277^{\circ} \mathrm{C}\right)$.

A pressão máxima de compactação depende da resistência do molde. $O$ diamante e a matriz metálica são prensados à frio em moldes de aço utilizando pressões variando de 0,3 a $7 \mathrm{tf} / \mathrm{cm}^{2}$ (BAKON e SZYMANSKI, 1993). 


\subsection{3 - Ferramentas de Diamantes Produzidas Através da} ELETRODEPosıçÄo

A ferramenta produzida por este processo consiste de um núcleo metálico com partículas de diamante aderidas à sua face de corte. O processo se resume basicamente em depositar partículas de diamante sobre a face de trabalho da ferramenta mergulhada em um banho eletrolítico. Sob a influência da corrente elétrica o metal contido no banho se deposita sobre a ferramenta, recobrindo os cristais de diamante. Desta forma, elas são ligados à superfície da ferramenta.

O metal mais freqüentemente utilizado é o Níquel, embora as composições dos banhos estejam relacionadas aos aditivos químicos empregados. Esses aditivos determinam a qualidade da eletrodeposição, por isso as informações relacionadas aos seus tipos e quantidades geralmente são protegidas por patentes.

A principal característica das ferramentas eletrodepositadas é a existência de apenas uma camada de diamantes. Consequentemente, elas possuem um número relativamente grande de pontas de diamante por unidade de área da face de trabalho. Outro benefício é seu baixo custo, uma vez que não necessitam de moldes para sua produção. A principal desvantagem é a curta vida útil da ferramenta, que chega ao fim quando algum ponto da face de trabalho apresentar-se desgastado (BAKON e SZYMANSKI, 1993). 


\section{4 - Principais Características dos Dressadores Estáticos}

\section{Sinterizados}

\subsection{1 - LIGA SINTERIZADA}

O campo de aplicação do diamante para o emprego como ferramenta é parcialmente determinado pelas propriedades físico-químicas da liga utilizada para a sua sustentação, e dentre estas, acima de tudo pela resistência ao calor, aos esforços químicos e mecânicos, bem como à sua resistência ao desgaste (BAKON e SZYMANSKI, 1993).

$\mathrm{Na}$ dressagem há uma grande quantidade de calor sendo gerado na operação, devido ao contato de natureza abrasiva na interface dressador/rebolo. Este calor deve ser prontamente retirado para evitar danos ao diamante do dressador, pois quando o diamante é submetido a temperaturas acima de $700{ }^{\circ} \mathrm{C}$, na presença de Oxigênio, mesmo por curtos períodos de tempo, a sua superfície tende a se converter de volta em grafite, a forma alotrópica mais estável nessas condições. Este processo de quebra da estrutura do diamante é conhecido como grafitização. Os cristais de diamante contendo inclusões de elementos metálicos são especialmente susceptíveis a ela.

No projeto de uma ferramenta diamantada de dressagem a distribuição de temperatura é indubitavelmente um dos aspectos mais importantes, estando fortemente relacionada à liga sinterizada utilizada no corpo da ferramenta (COELHO, 1999). Este material ligante deve ser capaz de manter os diamantes em suas posições e ao mesmo tempo oferecer a possibilidade de conduzir rapidamente o calor para fora dos diamantes.

Durante a dressagem, excetuando-se a ação do fluido refrigerante, a função de retirada do calor da região de corte é desempenhada primordialmente pelos próprios diamantes que compõem o dressador, visto que são os melhores condutores de calor; entretanto, esta função também deve ser desempenhada pela liga que compöe o "corpo" do dressador, ou seja, pelo material que sustenta e posiciona os diamantes do mesmo. Assim, esta liga deve possuir necessariamente uma boa condutividade térmica, o que explica a 
tradicional utilização de materiais baseados no Cobre/Bronze na formulação destas ligas. Além disso, a liga deve apresentar uma boa adesão à superfície dos diamantes, possibilitando uma boa ancoragem dos mesmos, assim como resistência mecânica, para suportar os esforços da dressagem, dureza e resistência à abrasão, para não se desgastar muito facilmente e continuar a sustentar os diamantes até que estes cheguem ao fim e finalmente, se possível, facilidade de obtenção.

Todas estas características, ou pelo menos as principais, devem ser oferecidas pela mistura dos pós metálicos utilizados como matéria-prima para a obtenção da liga sinterizada. Simultaneamente, é preciso considerar as variáveis de importância presentes no processo de sinterização: a pressão de compactação da mistura, o tempo, a temperatura e a atmosfera de aquecimento, todas exercendo influência nas propriedades finais da liga.

O calor também pode representar um problema devido à diferença no coeficiente de expansão térmica entre a liga sinterizada e o diamante, para o qual o valor é bem menor do que os dos metais presentes na liga (WILKS e WILKS, 1991).

A Metalurgia do Pó tem sido utilizada comercialmente por mais de 60 anos para produzir uma ampla gama de produtos como componentes estruturais, mancais auto-lubrificantes, ferramentas de corte, etc. Ela compreende a produção de metais na forma de pó e a transformação desses pós em objetos úteis pelo processo conhecido como Sinterização. O processo envolve comprimir o pó, normalmente em um reservatório, a fim de produzir um corpo compacto que tenha coesão suficiente para permitir o seu manuseio seguro, e a seguir, aquecer esse corpo, geralmente em uma atmosfera protetora, a uma temperatura abaixo do ponto de fusão do componente principal da mistura. Durante esse processo as partículas individuais do pó se unem e conferem resistência suficiente ao material para a aplicação pretendida. Esta etapa de aquecimento em particular é conhecida como sinterização.

Existem muitas maneiras pelas quais os metais podem ser produzidos na forma de pós: reações químicas e decomposição, atomização de metais 
fundidos, decomposição eletrolítica, processamento mecânico de materiais sólidos (HIRSCHHORN, 1991).

A qualidade do pó metálico é função do processo de fabricação, sendo que um mesmo pó metálico pode ser obtido por mais de um método (CHIAVERINI, 1992).

A sustentação e o posicionamento dos diamantes nos dressadores com perfil de atuação constante é tradicionalmente feita por uma liga sinterizada.

O procedimento básico na fabricação de peças da Metalurgia do Pó é:

1. Misturar o pó ou os pós metálicos;

2. Descarregar a mistura dentro de um molde ou matriz e aplicar pressão. Isto proporciona o que é chamado de corpo compactado, o qual apenas necessita ter coesão suficiente para ser manuseado com segurança e transferido ao próximo estágio. Esses são chamados de compactados verde, significando não sinterizado, daí os termos densidade verde e resistência verde;

3. Aquecer o corpo compactado, geralmente em uma atmosfera protetora, a uma temperatura abaixo do ponto de fusão do constituinte principal, de modo que as partículas do pó unam-se umas às outras e confiram resistência suficiente ao objeto para a utilização pretendida (CLAPP, 1995).

Em certos casos especiais os estágios 2 e 3 são combinados, isto é, a compactação é feita a uma temperatura elevada de tal modo que a sinterização ocorre durante o processo. Isto é chamado Compactação à Quente ou Sinterização por Pressão.

Os pós misturados são prensados em uma matriz rígida de aço ou de carbeto sob pressões de 150-900 MPa. Neste estágio os compactos mantém as suas formas devido à soldagem à frio dos grãos do pó dentro da massa. Os compactos devem ser suficientemente fortes para resistir à expulsão da matriz e o subseqüente manuseio antes da sinterização.

A compactação é uma operação crítica no processo uma vez que a forma final e as propriedades mecânicas são determinadas essencialmente pelo nível e uniformidade da densidade obtida nesta etapa. Os pós sob pressão 
não se comportam como líquidos, a pressão não é transmitida uniformemente e ocorre muito pouco escoamento lateral dentro da matriz.

De um modo geral a diminuição do tamanho da partícula do pó torna a sinterização mais efetiva. Isto porque, em termos de transporte de material, quando utiliza-se um tamanho menor de partícula, ocorre um maior contato entre elas e, por isso, forma-se um maior número de pescoços que irão proporcionar mais caminhos para a difusão volumétrica. Além disso, o tamanho de partícula pode ter grande influência sobre as transformações que ocorrem durante a sinterização, como na formação de ligas e no crescimento de grão.

O emprego de partículas cujas formas promovam um maior contato físico entre elas e um aumento da área superficial interna da massa sob sinterização facilita o processo. Assim, as formas mais favoráveis ao processo são as que apresentam menor esfericidade e com os maiores níveis de rugosidade superficial.

À primeira vista, um menor valor de densidade verde seria mais favorável para a sinterização pois se obteria uma maior área superficial interna e, como resultado, uma maior força motriz. Entretanto, na prática verifica-se que o aumento da densidade verde provoca o aumento da densidade do compacto sinterizado, como ilustrado na tabela 1 (HIRSCHHORN, 1991). Percebe-se também que quanto mais elevada for a temperatura de sinterização, maior será a densidade final.

As discussões sobre os mecanismos de difusão e de formação de liga mostram que a sinterização é extremamente dependente da temperatura. $A$ tabela 1 contém alguns dados reais que também demonstram isto.

Segundo Hirschhorn (1991), o aumento da temperatura de sinterização causa um grande aumento da velocidade e da dimensão de qualquer alteração que possa ocorrer. Além disso, as pesquisas indicam que o mecanismo preciso de transporte de material que determina a velocidade da sinterização varia com a alteração da temperatura. Percebe-se então que a temperatura de sinterização é um dos principais e mais importantes fatores do processo. 
Tabela 1: Efeito da densidade verde e da temperatura de sinterização sobre a densidade do material sinterizado (HIRSCHHORN, 1991).

\begin{tabular}{|c|c|c|c|c|}
\hline MATERIAL & $\begin{array}{c}\text { PRESSÃO dE } \\
\text { COMPACTAÇÃO } \\
\left(\mathbf{t} / \mathrm{cm}^{2}\right)\end{array}$ & $\begin{array}{c}\text { DENSIDADE } \\
\text { VERDE } \\
\left(\mathrm{g} / \mathrm{cm}^{3}\right)\end{array}$ & $\begin{array}{c}\text { TEMPERATURA DE } \\
\text { SINTERIZAÇĀO } \\
\left({ }^{\circ} \mathrm{C}\right)\end{array}$ & $\begin{array}{c}\text { DENSIDADE } \\
\text { SINTERIZADA } \\
\left(\mathrm{g} / \mathrm{cm}^{3}\right)\end{array}$ \\
\hline \multirow[t]{6}{*}{ Cobalto } & 2,8 & 5,07 & 700 & 5,16 \\
\hline & 5,6 & 6,03 & 700 & 6,05 \\
\hline & 8,5 & 6,61 & 700 & 6,02 \\
\hline & 2,8 & 5,07 & 1100 & 8,34 \\
\hline & 5,6 & 6,03 & 1100 & 8,36 \\
\hline & 8,5 & 6,61 & 1100 & 8,38 \\
\hline \multirow[t]{2}{*}{ FERRO } & 4,2 & 6,72 & 1120 & 6,73 \\
\hline & 7,0 & 7,23 & 1120 & 7,25 \\
\hline \multirow[t]{4}{*}{ MOLIBDÊNIO } & 5,1 & - & 1200 & 8,00 \\
\hline & 7,0 & - & 1200 & 8,60 \\
\hline & 5,1 & - & 1700 & 9,80 \\
\hline & 7,0 & - & 1700 & 10,00 \\
\hline
\end{tabular}

Embora o grau de sinterização aumente com o aumento do tempo, sob uma mesma temperatura, este efeito é pequeno quando comparado ao efeito do aumento da temperatura. Isto porque, na prática, as principais alterações acontecem no estágio inicial do processo. Hirschhorn (1991) comenta que seriam necessárias dezenas ou centenas de horas para produzir as mesmas modificações que poderiam ser obtidas com um aumento de cerca de $100{ }^{\circ} \mathrm{F}$ $\left(56{ }^{\circ} \mathrm{C}\right)$ na temperatura de sinterização. Isto dá uma boa idéia a respeito da dependência do fenômeno em relação à temperatura empregada.

O conhecimento da prática de sinterização é muito importante, uma vez que esta operação é responsável pelas propriedades finais das peças produzidas.

Existem diversos tipos de fornos empregados na Metalurgia do Pó. As fontes de aquecimento são gás combustível ou eletricidade. Os fornos à gás possibilitam temperaturas de até $1200{ }^{\circ} \mathrm{C}$. Entretanto, acima de $1080{ }^{\circ} \mathrm{C}$ o calor 
perdido nas chaminés torna-se muito grande, limitando a sua utilização acima desta temperatura (CHIAVERINI, 1992).

Geralmente o tipo de forno mais favorável é um aquecido eletricamente, pelo qual os compactos passam sobre uma correia de malha trançada.

Segundo NAYAR (1984), as atmosferas empregadas na sinterização devem desempenhar várias funções, dentre as quais pode-se citar:

- Evitar a entrada de ar no forno;

- Facilitar a retirada de lubrificantes ou cera dos compactados;

- Reduzir os óxidos superficiais das partículas do pó;

- Controlar o teor de Carbono na superfície e no interior das peças;

- Remover Carbono em aplicações especiais;

- Transmitir ou remover calor de forma eficiente e uniforme.

As atmosferas representam um fator fundamental para quase todos os processos de sinterização. Na prática, o Hidrogênio seco, a Amônia dissociada e os hidrocarbonetos parcialmente queimados são os mais utilizados, embora o Hidrogênio normalmente seja excluído devido ao seu alto custo. O Hidrogênio é uma atmosfera altamente redutora, sendo utilizado para a sinterização de carbetos e de materiais magnéticos. Entretanto, por ser inflamável, exige extrema precaução no seu manuseio (CHIAVERINI, 1992), (HALE, 1984), (HIGGINS, 1974).

As atmosferas mais amplamente utilizadas, principalmente por causa de seu baixo custo, são produzidas pela combustão parcial de hidrocarbonetos. Pela variação da relação ar/gás, uma ampla faixa de composições é obtida. $O$ gás queimado contém vapor d'água, por isso, para um desempenho satisfatório quando aplicado a componentes de Ferro, deve-se secá-lo.

O vácuo pode ser considerado como um caso especial de atmosfera controlada, e é, provavelmente, a melhor do ponto de vista científico. O gás no interior do compacto é prontamente removido e rapidamente metais como Alumínio, Berílio, Nióbio e Tântalo, cujos óxidos não são removidos, mesmo pelas melhores atmosferas redutoras, podem ser sinterizados. Entretanto, a sinterização à vácuo é muito cara e por esta razão é difícil encontrar a sua aplicação na produção de peças mecânicas onde outros tipos de atmosferas 
dão resultados satisfatórios. Além do alto custo do equipamento e das baixas taxas de produção, o processo é difícil, quase impossível, de se fazer contínuo e automatizado. Por outro lado, para certas aplicações especiais, a sinterização à vácuo está se tornando padrão. Um exemplo é a sinterização de aços rápidos e metais altamente ligados. Além disso, devido ao seu baixo potencial de oxidação, o vácuo apresenta um desempenho superior ao Hidrogênio na sinterização de carbetos de Titânio, Tântalo e Nióbio, os quais são sensíveis à oxidação (POWDER MANUFACTURE..., 1999), (HALE, 1984).

\subsection{2 - Os DiAMANTES}

\subsubsection{1 - CARACTERÍSTICAS FUNDAMENTAIS DOS DIAMANTES UTILIZADOS NA} FABRICAÇÃO DE DRESSADORES

A história da síntese do diamante tem início em 1797 quando SmithsonTennant descobriram que o diamante é composto unicamente de carbono. Desde então, leigos e cientistas têm tentado converter o carbono sem valor no precioso diamante. Por volta de 1800 os cientistas concluíram que esta transformação necessitava de altas pressões, mas somente com o trabalho de Leipunskii em 1939 e os trabalhos de Libjeblad e de Berman e Simon, ambos em 1955, foi possível obter uma idéia razoável das pressões exigidas. As primeiras tentativas de Hannay em 1880 resultaram no que se confirmou depois serem ainda fragmentos de diamantes naturais e não de diamante sintético (FIELD, 1979).

Bridgman, considerado o pai da tecnologia de alta pressão tentou por muitos anos produzir o diamante sintético. Muitas das suas tentativas se resumiam a comprimir o grafite a pressões cada vez maiores, mas no final o resultado foi sempre o mesmo: o grafite inicial permanecia inalterado.

O primeiro cálculo da linha de equilíbrio grafite-diamante provou para os cientistas, no início dos anos 50, que Bridgman muitas vezes comprimiu o grafite em pressões dentro da região estável do diamante, sem, no entanto, os obter. Concluíram assim que o problema estava relacionado com a cinética da reação. Este problema foi primeiramente resolvido por uma equipe de cientistas 
trabalhando no laboratório ASEA em Estocolmo, Suécia, em 1953 (DAVIES, 1984). Entretanto, os resultados somente foram publicados muito mais tarde. Independentemente disto, a equipe da General Electric composta por Bundy, Hall, Strong e Wentorf conseguiu produzir diamantes sintéticos em 1955 (SPEAR e DISMUKES,1993).

Ambas as equipes utilizaram um solvente/catalisador do carbono para superar a grande barreira cinética e agir como um agente de transporte para o carbono. Isto já havia sido sugerido primeiramente por Leipunskii em 1939. Logo depois a De Beers também conseguiu produzir diamantes em seu laboratório de pesquisas na África do Sul, sendo atualmente a controladora mundial desse mercado.

Quando os diamantes são aquecidos a elevadas temperaturas, as mudanças que ocorrem dependem muito do ambiente em volta do diamante. Se oxigênio, ou outros agentes ativos, estiverem presentes, uma cobertura escura pode se formar sobre a superfície do diamante acima de aproximadamente $900 \mathrm{~K}\left(627^{\circ} \mathrm{C}\right)$.

A estrutura do diamante pode se transformar em grafite mesmo sob condições quimicamente inertes, desde que a temperatura seja suficientemente alta. Se os diamantes (naturais puros e sintéticos de boa qualidade) são aquecidos em uma atmosfera inerte, o início da grafitização pode ser detectado a aproximadamente $1800 \mathrm{~K}\left(1527^{\circ} \mathrm{C}\right)$ e a velocidade de grafitização aumenta rapidamente até aproximadamente $2400 \mathrm{~K}\left(2127^{\circ} \mathrm{C}\right)$ (WILKS e WILKS, 1991), (BAKON e SZYMANSKI, 1993).

O processo de quebra da estrutura do diamante (grafitização) tem início na interface diamante-ambiente (aqui ambiente significa a porção exterior ao cristal ou inclusões dentro do cristal). As primeiras áreas a grafitizar são as arestas e os cantos. Nesta transformação os átomos de Carbono são deslocados e as ligações interatômicas mudam o seu caráter e orientação. As formas mais termicamente estáveis são os cristais puros livres de impurezas. A presença destas impurezas afeta negativamente a estabilidade da estrutura do diamante, não importando se ocorreram naturalmente ou se foram incorporadas durante a síntese. 
A temperatura de início da grafitização diminui proporcionalmente ao número de inclusões existentes. Cristais contendo inclusões de elementos metálicos são especialmente susceptíveis à grafitização. Os elementos que reagem quimicamente com o Carbono ou que o dissolvem rapidamente, como o Oxigênio, o Ferro ou o Níquel, atuam como catalisadores da grafitização (BAKON e SZYMANSKI, 1993).

\subsubsection{2 - PROPRIEDADES DOS DIAMANTES}

Duas das principais propriedades do diamante são sua extrema dureza e sua alta condutividade térmica. Materiais com alta dureza geralmente são frágeis. Neste aspecto o diamante não é exceção, pois um golpe bem orientado pode partí-lo ao longo de um plano (111) com um pequeno gasto de energia. Entretanto, a alta condutividade térmica é uma vantagem, uma vez que ela reduz a possibilidade de choques térmicos que causam danos, um problema que ocorre com muitos outros materiais frágeis (FIELD, 1979).

Estudos da fratura e das propriedades de resistência do diamante são inerentemente difíceis. Com a maioria dos outros materiais é possível ter um controle razoável sobre o tamanho da amostra, da sua forma e pureza. As amostras de diamante, ao contrário, são invariavelmente pequenas, irregulares, podem conter tensões internas e a existência de defeitos e impurezas nas amostras exige uma investigação separada. A estas outras desvantagens pode ser adicionada aquela do alto custo: os testes de resistência invariavelmente significam avaria ou ruptura da amostra.

\subsubsection{1 - Propriedades Mecânicas}

O diamante é o mineral mais duro e o mais resistente à abrasão de todos os conhecidos. Ao mesmo tempo ele possui o mais alto valor para o Módulo de Elasticidade. Os valores das propriedades mecânicas apresentam ampla variação, dependendo acima de tudo da estrutura interna dos cristais e da sua morfologia. Como regra geral, as inclusões na rede cristalina de 
elementos diferentes do Carbono enfraquecem os cristais do diamante (FIELD, 1979) .

Os átomos de Carbono na estrutura cristalina possuem diferentes arranjos em planos diferentes, e estes são responsáveis pela anisotropia nas propriedades mecânicas dos diamantes. A densidade de átomos mais alta encontra-se no plano (111). Esta diferenciação direcional da densidade atômica é responsável pela variação do comportamento da clivagem em direções diferentes. $O$ fato dos diamantes clivarem preferencialmente no plano (111) e a sua relativamente baixa resistência à flexão devem ser considerados na fabricação e no uso das ferramentas de diamante.

Uma técnica totalmente diferente para enfrentar o problema do trincamento do diamante foi a introdução dos novos materiais policristalinos para ferramentas, os quais consistem de pó de diamante sinterizado, juntamente com um agente ligante, em condiçōes de elevadas pressão e temperatura. Sendo policristalino, este material compacto é mais tenaz e menos susceptivel à fratura do que o material monocristalino; por outro lado, não é possível polir uma aresta em uma ferramenta de acabamento de modo tão perfeito quanto no material monocristalino.

Esses novos materiais diferem consideravelmente do diamante monocristalino: a condutividade térmica será menor do que para um cristal monocristalino e assim a ferramenta atuará mais quente, enquanto que a matriz será mais susceptível à deterioração em altas temperaturas (FIELD, 1979).

A figura 9 fornece uma indicação da posição relativa de alguns materiais ultra-duros com relação à resistência ao desgaste e à tenacidade. 


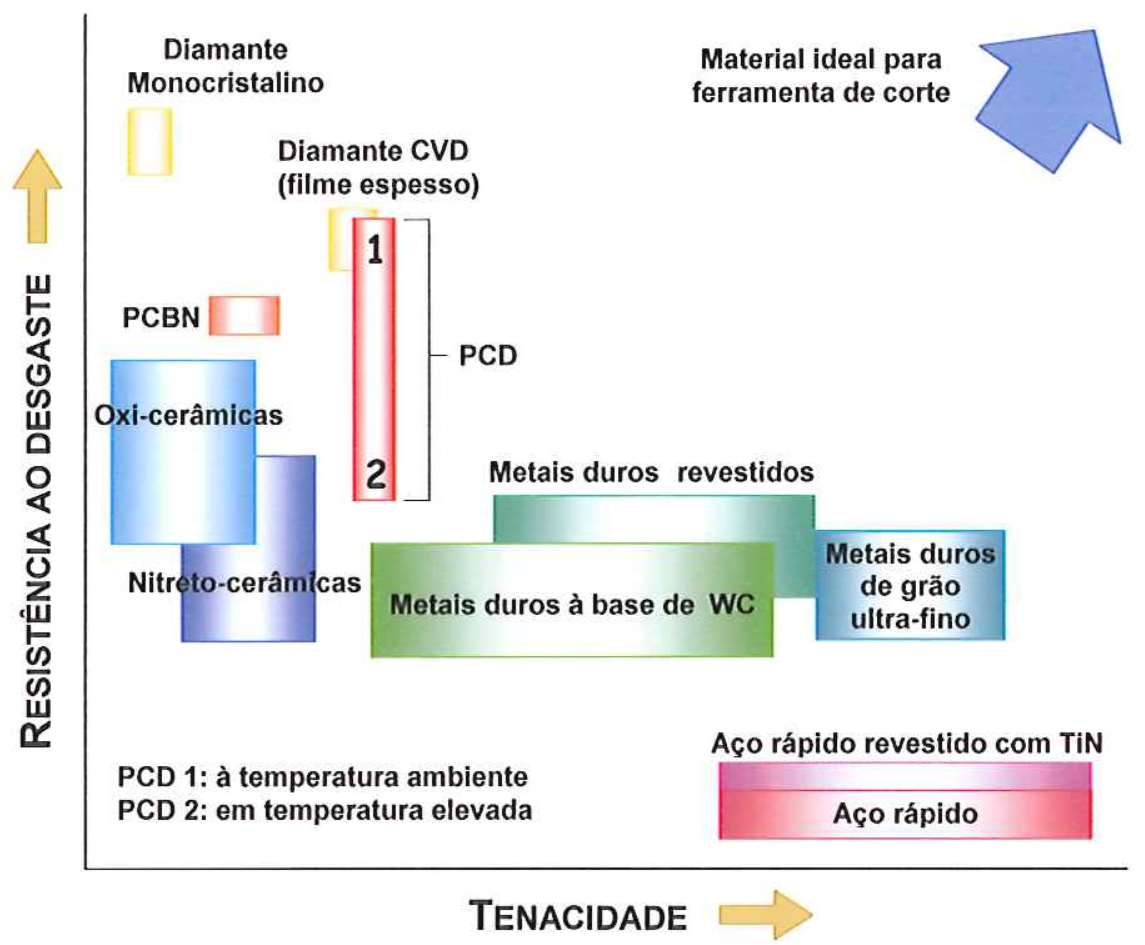

Figura 9: Propriedades dos materiais para ferramentas de corte (CLARK e SEN,1998).

Nota-se que o diamante monocristalino possui uma resistência ao desgaste maior do que o PCD, cujos valores de resistência diminuem quando a temperatura ultrapassa $700{ }^{\circ} \mathrm{C}$. Isto se deve à presença, na estrutura do diamante PCD, do Cobalto, o qual promove a conversão do diamante para o grafite a uma temperatura mais baixa do que ocorreria na ausência desse elemento (CLARK e SEN, 1998).

\subsubsection{2 - Propriedades Térmicas}

À temperatura ambiente, o diamante é o melhor condutor de calor de todos os materiais conhecidos. Como exemplo, a condutividade térmica do diamante à temperatura ambiente é várias vezes maior do que a do Cobre. Por esta razão os diamantes são empregados em alguns dispositivos eletrônicos como elementos de dissipação do calor. $O$ valor preciso da condutividade 
térmica do diamante depende da sua estrutura cristalina, sendo que os melhores valores são encontrados nos cristais mais puros, com a concentração mais baixa de Nitrogênio (WILKS e WILKS, 1991).

O gráfico da figura 10 compara os valores de condutividade térmica correspondentes ao diamante com os de outros materiais para ferramentas.

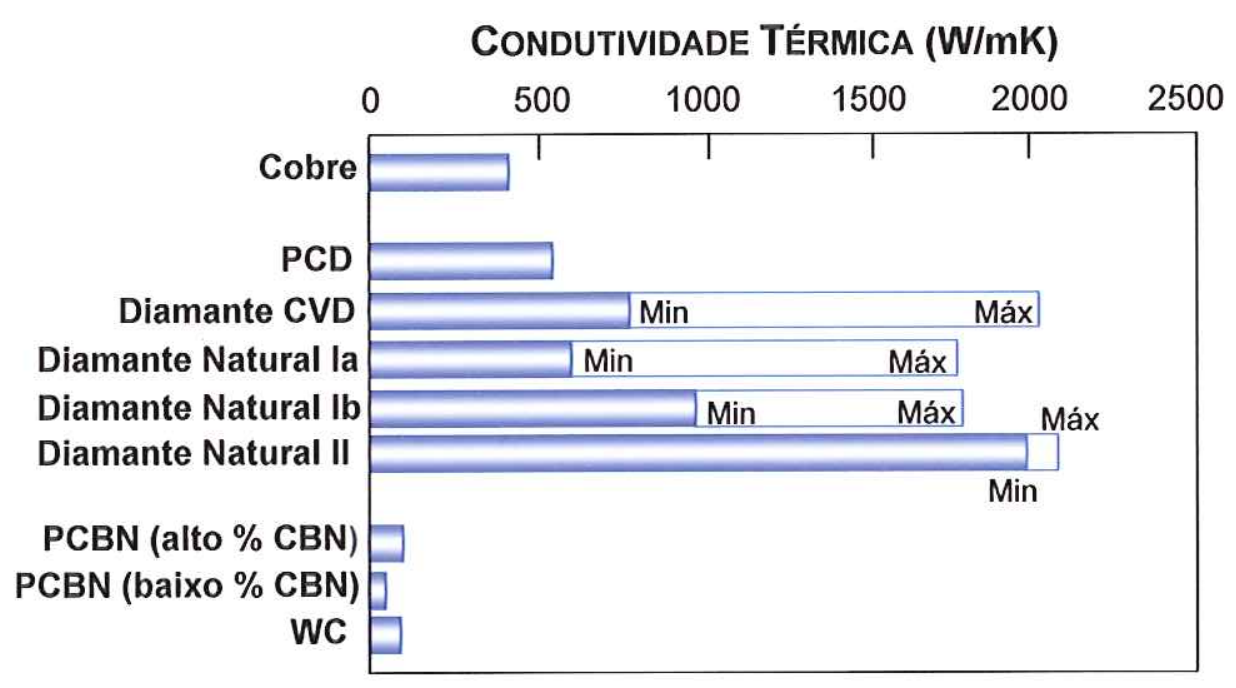

Figura 10: Condutividade térmica à temperatura ambiente do diamante e de outros materiais (CLARK e SEN, 1998).

As inclusões presentes no diamante possuem valores de coeficientes de expansão térmica diferentes da estrutura cristalina e o aquecimento, neste caso, irá causar tensões no cristal, podendo, em casos extremos, causar a fratura do diamante. Alterações no estado dos cristais como resultado do aquecimento são observadas principalmente nos diamantes sintéticos. Por exemplo, o aquecimento do diamante sintético a $1473 \mathrm{~K}\left(1200{ }^{\circ} \mathrm{C}\right)$ provoca uma mudança na densidade, sendo que as maiores alterações ocorrem nos diamantes policristalinos (BAKON e SZYMANSKI, 1993). 


\subsubsection{3 - Propriedades Químicas}

Uma característica do diamante que o diferencia do grafite é que ele não reage com os ácidos comuns, mesmo em temperaturas elevadas. Esta característica permite separá-los quimicamente. Tratado por uma mistura de ácido crômico quente ou por uma mistura de ácidos sulfúrico e nítrico, o grafite oxida levemente enquanto o diamante é quimicamente inerte. Por outro lado, o diamante oxida (grafitiza) relativamente rápido em altas temperaturas na presença de uma atmosfera de Oxigênio ou ao ar.

O diamante também pode reagir quimicamente com os metais e formar carbetos, ou pode se dissolver no metal. Os metais com os quais o diamante forma carbetos em altas temperaturas são o Tungstênio, Titânio, Tântalo e Zircônio, enquanto aqueles que dissolvem o diamante são o Ferro, Cobalto, Níquel, Manganês e Cromo. O fato de que o diamante se dissolve e/ou reage com o Ferro ou suas ligas (aço) acima de $950 \mathrm{~K}\left(677^{\circ} \mathrm{C}\right)$ torna as ferramentas diamantadas inadequadas para a maioria das operações de usinagem em metais ferrosos, incluindo os aços rápido e endurecido (BAKON e SZYMANSKI, 1993).

\subsubsection{3 - TIPOS DE DIAMANTES UTILIZADOS EM DRESSADORES}

A fim de alcançar o desempenho esperado do dressador, é necessário considerar quais tipos de diamante estão disponíveis para aplicação nos dressadores, mesmo porque o diamante é o principal componente do dressador, pois é ele quem efetivamente realiza o arrancamento do material do rebolo durante a dressagem (NUSSBAUM, 1988).

Atualmente existem alguns tipos de diamantes sintéticos disponíveis comercialmente para a aplicação em dressadores, sendo que os maiores fabricantes mundiais como De Beers Industrial Diamond Division, General Electric Company e Sumitomo, possuem linhas específicas de produtos para esta aplicação. 


\subsubsection{1 - Diamante Natural Industrial Monocristalino}

O diamante industrial natural tem sido usado em dressadores de ponta única, multi-pontas, perfilados, etc., empregando diferentes formas e tamanhos do diamante. Alguns exemplos são mostrados na figura 11, juntamente com suas aplicações. Para uma operação de dressagem com ponta única a escolha geralmente é para um cristal natural (PRICKEN, 1999).

Os tipos disponíveis variam, desde um cristal com apenas uma ponta utilizável até um com seis pontas reafiáveis, no caso de um octaedro. Sendo um produto natural, o preço e a disponibilidade podem variar. Dressadores do tipo placa, contendo um número múltiplo de diamantes foram desenvolvidos especialmente para a aplicação em rebolos de grande diâmetro, nos quais o uso de um dressador de ponta única não é econômico, principalmente devido à vida curta do dressador (BAKON e SZYMANSKI, 1993), (WILKS e WILKS, 1991).

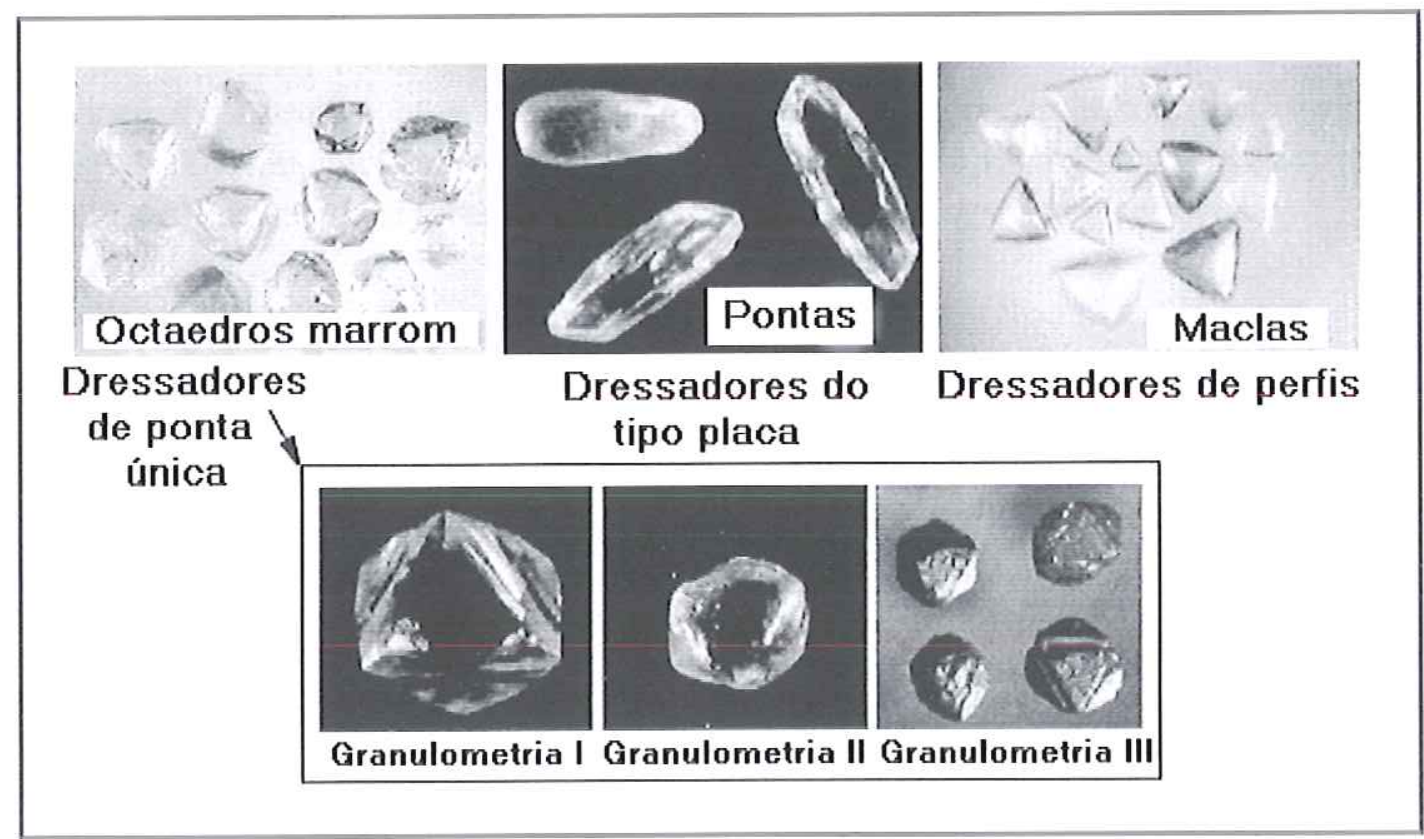

Figura 11: Diferentes diamantes naturais empregados em diferentes tipos de dressadores (SEN, 2000). 


\subsubsection{2 - Diamante Sintético Monocristalino}

Nos anos 90 as pequenas "barras" de diamante sintético monocristalino produzidas por um processo de síntese a alta pressão e alta temperatura (HP/HT) foram introduzidas para o emprego em dressadores (SPEAR e DISMUKES, 1993).

O conceito do diamante em forma de barra, com uma geometria do corpo com ângulo de $90^{\circ}$, representou uma inovação no projeto do dressador, trazendo a vantagem de que a forma da ponta do diamante é mantida durante toda a sua vida útil. Entretanto, mais importante ainda é que, sendo um produto planejado segundo conceitos de engenharia, as barras de diamante sintético possuem propriedades de qualidade repetíveis, as quais tornam a seleção do diamante do dressador uma tarefa lógica e compatível para uma aplicação específica (SEN, 2000).

A De Beers possui uma linha de diamantes denominada MONODRESS ${ }^{\circledR}$, utilizando a tecnologia de síntese de diamantes monocristalinos, os quais são cortados à laser na forma de bastões de até 7,0 $\mathrm{mm}$ de comprimento com seção transversal quadrada ou retangular. Isto permite uma grande variedade de opções na fabricação de dressadores, uma vez que as quatro faces destes diamantes podem ser identificadas e posicionadas em relação à direção da operação de dressagem. (DE BEERS ...), (DE HEUS, 1997).

Atualmente o diamante sintético monocristalino já é identificado por padrões internacionais, sendo produzido em tamanhos maiores do que os encontrados na natureza, o que abriu a possibilidade para novas aplicações (SUSSMANN et al., 1999).

\subsubsection{3 - Diamante Policristalino (PCD - Polycristalline Diamond)}

A General Electric Company possui a linha denominada FORMSET ${ }^{\circledR}$, que se baseia na síntese de diamantes sintéticos policristalinos. Este tipo de diamante é constituído por cristais orientados de forma aleatória, fortemente 
ligados através de altas pressões e temperaturas, originando estruturas cristalinas muito densas.

A principal diferença dos diamantes policristalinos em relação aos monocristalinos é que as suas propriedades são distribuídas uniformemente em todas as direções, enquanto que os diamantes monocristalinos devem ser utilizados segundo as orientações do fabricante, com relação às direções de dressagem. Além disso, os diamantes policristalinos podem ser fabricados em várias formas geométricas diferentes (prismática, triangular, cilíndrica, retangular), que favorecem a posterior colocação no suporte da ferramenta (BRYANT, 1999), (GENERAL ELECTRIC...).

Portanto, pode-se dizer que os dressadores que empregam diamantes policristalinos possibilitam uma manufatura e, principalmente, uma utilização mais simples, o que pode ser uma vantagem no caso de mão-de-obra pouco experiente ou na automação do processo de retificação.

\subsubsection{4 - Diamante Produzido pelo Processo CVD}

O diamante CVD (de Chemical Vapour Deposition ou Deposição Química de Vapor) também é uma forma de diamante policristalino (PCD), sendo quase uma fase do diamante puro, não contendo ligante metálico (o chamado binder), fato que o diferencia do diamante PCD. Por isso, é mais estável em altas temperaturas e todos os seus planos possuem a mesma dureza e resistência à abrasão (SUSSMANN et al., 1999), (COLLINS, 1999).

A atual tecnologia de produção do diamante pelo processo CVD possibilita a produção de peças relativamente maiores e de alta qualidade, nas quais a pureza e a microestrutura são rigidamente controladas. Isto removeu um dos principais obstáculos para a ampliação do emprego do diamante, que era a ausência de uma fonte de diamantes de maior tamanho com pureza controlada. Todo este desenvolvimento vem possibilitando a aplicação do diamante CVD em diversas áreas de alta tecnologia dentro da engenharia, da física e da medicina (SUSSMANN et al., 1999), (BARANAUSKAS, 2000). 
A figura 12 mostra várias barras de diamante sintético monocristalino e CVD e alguns tipos de dressadores feitos com elas.

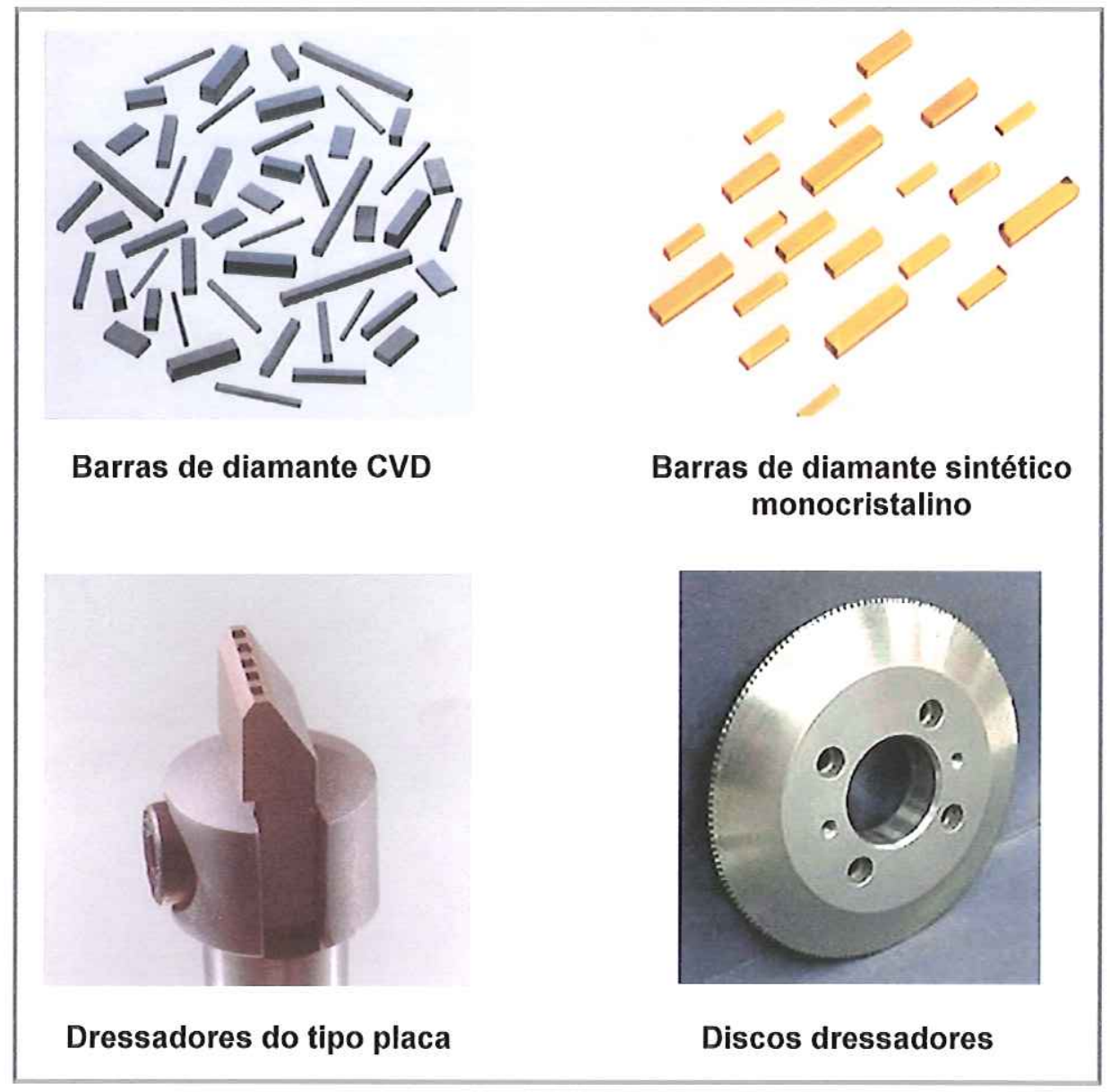

Figura 12: Barras de diamante sintético monocristalino e de diamante sintético produzido pelo processo CVD e alguns exemplos de dressadores feitos com elas (SEN, 2000; PRICKEN, 1999).

\subsubsection{4 - SELEÇÃo dOS DIAMANTES dO DRESSADOR}

Os diamantes para o emprego em ferramentas de ponta única podem ser empregados no estado como são fornecidos ou então os cristais brutos são apropriadamente moldados para apresentarem as características geométricas de projeto, como raio de ponta e ângulos entre as faces, ou ainda eles podem ser ovalizados, perfurados, cortados em placas, etc.

Este trabalho é necessário no caso dos diamantes naturais ou em ferramentas que empreguem o diamante PCD, e deve ser realizado 
anteriormente à sua montagem em ferramentas como dressadores, indentadores para testes de dureza, pontas de instrumentos de calibração, matrizes de estiramento, etc. Isto vale também para os diamantes a serem utilizados em produtos de joalheria. Para a maioria das aplicações da engenharia os métodos de preparo do diamante são semelhantes.

A anisotropia da dureza do diamante faz com que, antes de qualquer operação mecânica de preparo para uso, seja necessário realizar um exame completo da sua morfologia e da sua estrutura interna, como uma base para se decidir o melhor curso da ação de corte, incluindo as direções de polimento. Entretanto, estes problemas de orientação não existem com o diamante PCD, cujas propriedades mecânicas são isotrópicas, característica que dificulta muito o preparo desse tipo de diamante (KRAR e RATTERMAN, 1990).

A remoção de partes redundantes ou defeituosas do cristal é feita através da clivagem ou do corte com serra. O cristal de diamante para ser clivado é primeiro colado em uma haste especial, e, na seqüência, o local onde a clivagem será iniciada é selecionado e marcado com o emprego de outro diamante ou de um feixe de laser. A clivagem é efetuada com uma cunha de aço, a qual é golpeada com uma haste. O operador deve possuir amplo conhecimento da estrutura cristalina do diamante, além de excelente visão e habilidade manual, pois qualquer erro durante esta delicada operação pode causar o estilhaçamento do cristal (WILKS e WILKS, 1991).

Para facilitar a seleção de um diamante para dressador, baseado no desempenho para uma condição definida do rebolo, os tópicos seguintes analisam as alterações nas variáveis estáticas e a sua influência sobre o desempenho da dressagem.

\subsubsection{1 - Orientação do Cristal de Diamante}

A necessidade de orientação dos dressadores de diamante natural na direção dura do cristal é bem conhecida para os fabricantes e usuários dessas ferramentas. Esta é uma escolha baseada na qualidade e uniformidade da forma do cristal. No caso dos dressadores do tipo placa, empregando barras ou 
pontas de diamante natural, as exigências de orientação não podem ser aceitas justamente porque esses cristais, independentemente da sua orientação cristalográfica, são escolhidos devido à sua forma elongada (SEN, 2000).

No caso de dressadores que empregam barras de diamante sintético monocristalino, geralmente se escolhe a direção dura de orientação do cristal para o trabalho. Por outro lado, as barras de diamante produzidas pelo processo CVD consistem de uma massa de partículas de diamante fortemente ligadas, o que as isenta de variações na resistência à abrasão em relação à orientação cristalográfica (BAKON e SZYMANSKI, 1993).

A figura 13 ilustra a orientação e a relacionada resistência à abrasão dos três tipos de diamante para dressador.

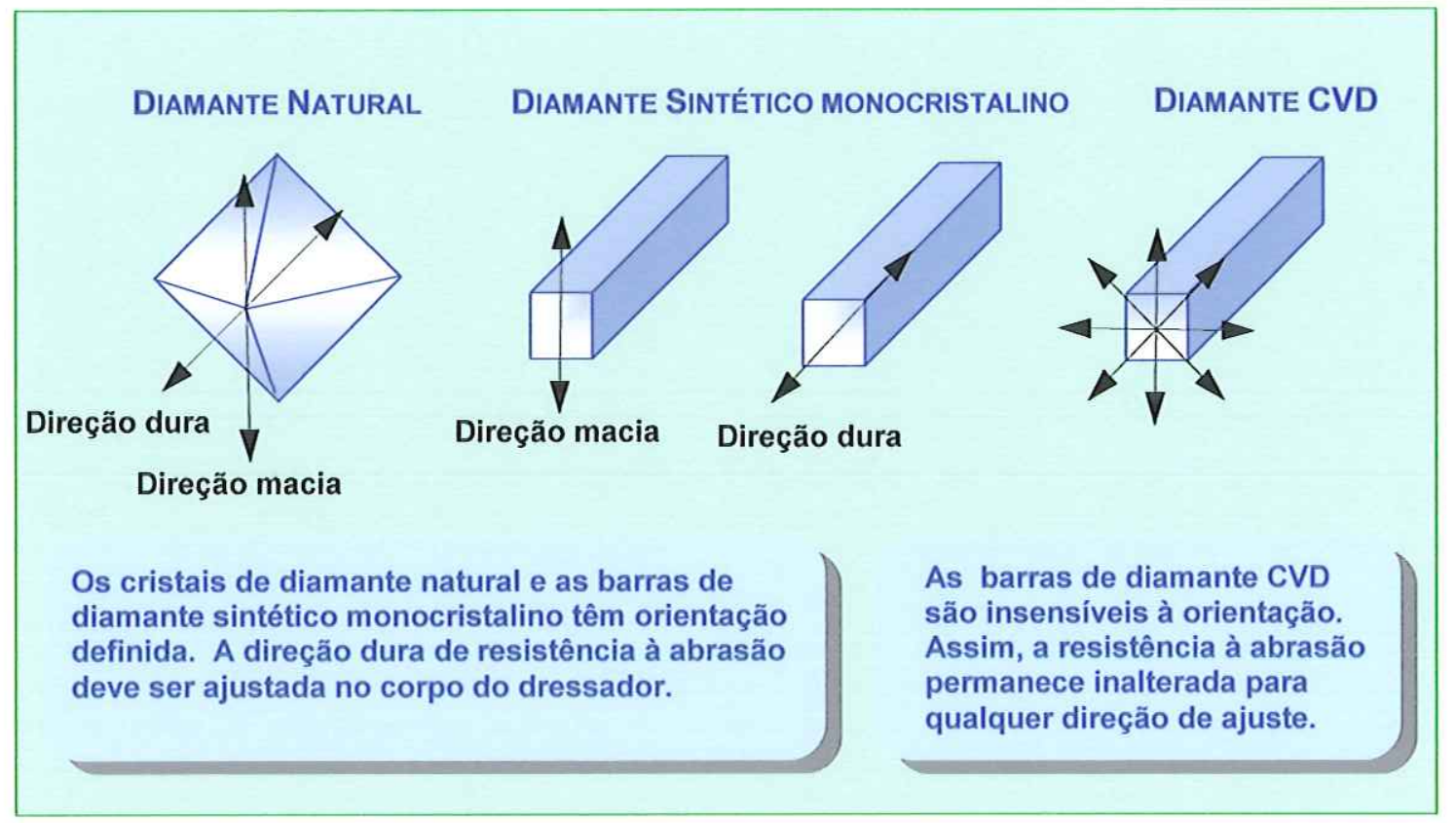

Figura 13: Orientação da direção de corte relacionada à resistência à abrasão (SEN, 2000).

Após estas considerações pode-se dizer que as barras de diamante sintético são as mais adequadas para os dressadores do tipo placa devido à sua secção transversal uniforme e à sua disponibilidade em vários tamanhos. 
Outro ponto a considerar é que, com o uso das barras de diamante, a vida ótima do dressador pode ser obtida a partir do seu ajuste original no corpo do dressador, devido ao fato de que quase todo o seu comprimento pode ser utilizado. Entretanto, no caso de um dressador de diamante natural de ponta única, por exemplo um octaedro com todas as suas seis pontas utilizáveis, embora a vida ótima para cada uma das seis pontas possa ser obtida, isto requer que o diamante seja reajustado seis vezes. Isto irá contribuir para o aumento dos custos de produção, pois haverá uma perda de produção enquanto o dressador está sendo girado e, obviamente, com a área plana de desgaste se tornando maior, ocorrerá uma indesejável variação na qualidade da dressagem, trazendo conseqüências sobre a qualidade do componente retificado (SEN, 2000).

\subsubsection{2 - Manutenção da Forma da Ponta do Diamante do}

\section{Dressador}

Nas aplicações gerais, normalmente a ponta do diamante natural do dressador não é renovada freqüentemente e o dressador continua a ser utilizado com uma área plana de desgaste que aumenta progressivamente em tamanho. O efeito disto pode ser visto na figura 14. 


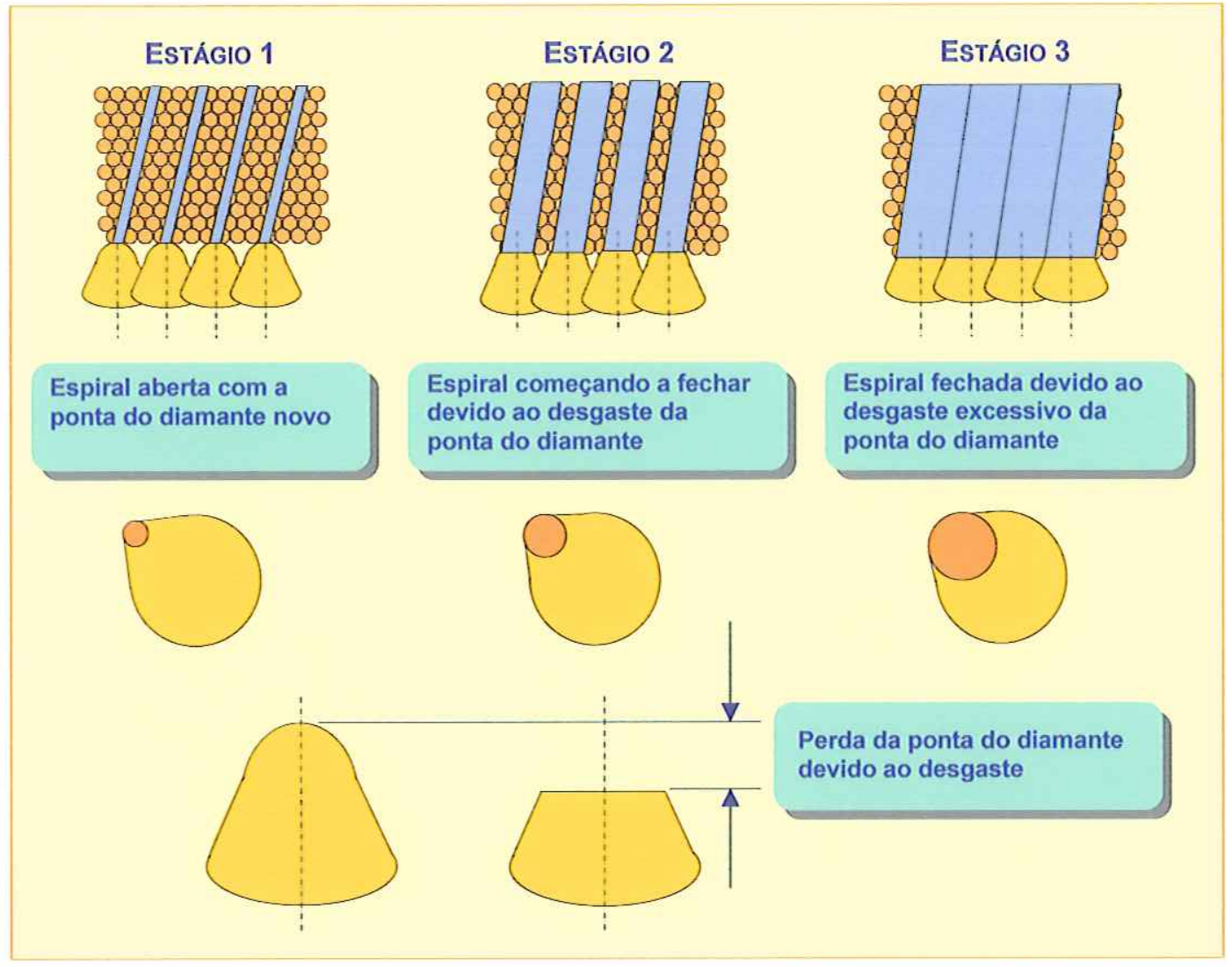

Figura 14: O fechamento da espiral de dressagem sobre a face do rebolo com o desgaste gradual da ponta do dressador (SEN, 2000).

Tomando como exemplo um caso no qual um dressador novo é escolhido para produzir um padrão de dressagem espiral aberto. À medida que a ponta do diamante gradualmente se desgasta com os periódicos passes de dressagem, a largura das espirais aumenta, fechando portanto o espaço entre as espirais. Uma vez que a largura de desgaste da ponta de diamante coincide com o valor de seu avanço transversal, as espirais aproximam-se completamente e o rebolo perde a sua capacidade de corte original. Vale lembrar que com o aumento da área plana de desgaste do dressador de ponta única, com o conseqüente aumento na área de contato com o rebolo, mais calor será gerado, podendo causar grafitização da ponta do diamante e acelerado desgaste. O pior defeito do aumento gradual da área plana de desgaste é a não uniformidade da dressagem periódica (SEN, 2000). 
Como uma superfície de rebolo aberta é obtida não somente através de uma velocidade transversal maior, mas também pelo corte levemente mais profundo dos grãos, isto é, com uma penetração maior, a solução para o problema acima é empregar um diamante com largura constante no dressador.

Através do projeto, as barras de diamante sintético têm uma secção transversal constante em várias dimensões, e uma vez que o tamanho apropriado tenha sido escolhido (isto é, uma largura do diamante compatível com a granulometria do rebolo e com outros parâmetros de dressagem), ambos os princípios da dressagem de corte em espiral e de maior penetração podem ser aplicados. O diagrama da figura 15 (a) mostra que a espiral sobre a face do rebolo permanece inalterada devido à secção transversal constante do diamante. A espiral pode ser mais fechada através de um menor avanço transversal, ou alternativamente, para rebolos de grande diâmetro, um dressador do tipo placa pode ser mais adequado, como mostrado na figura 15 (b) (SEN, 2000).

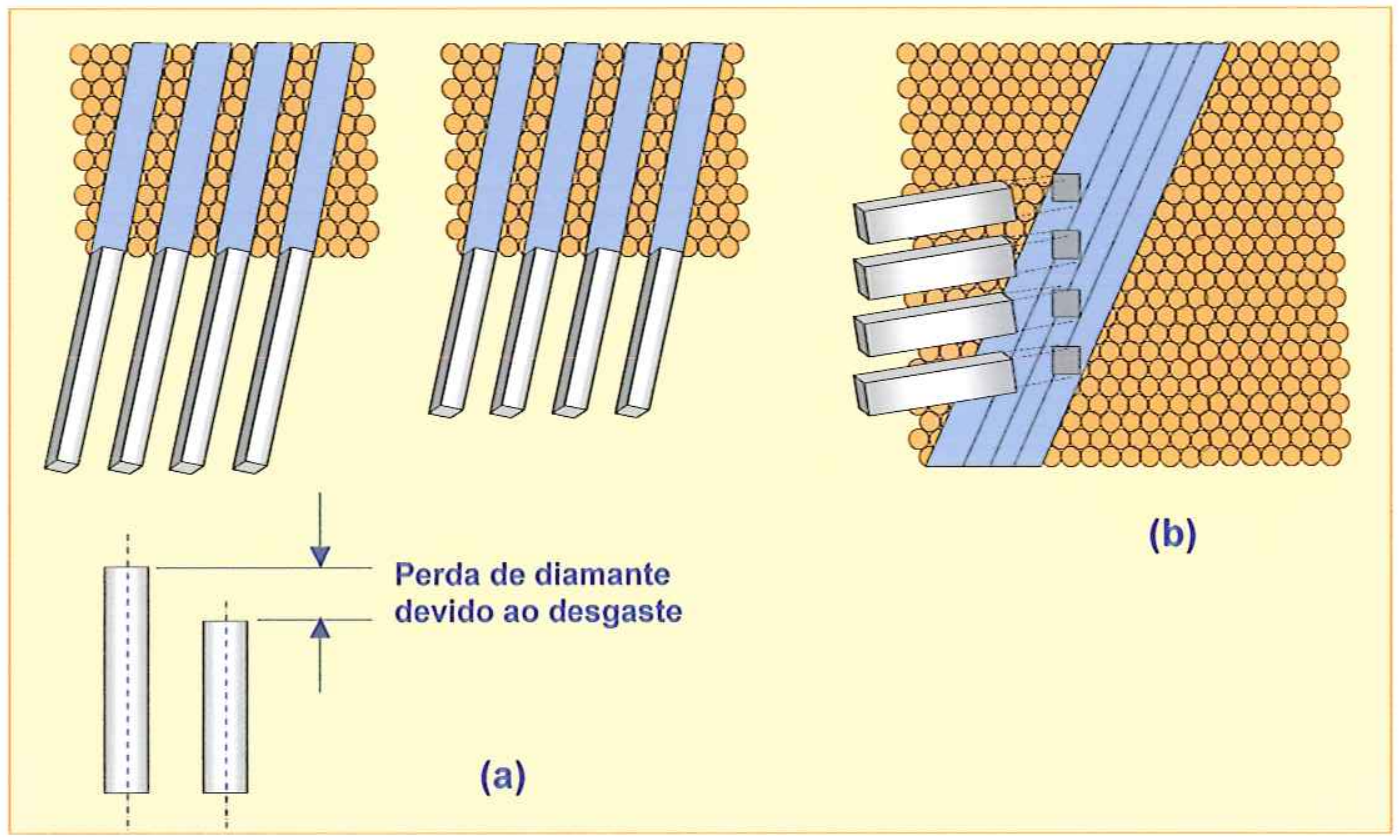

Figura 15: Efeito do uso de diamantes com seç̧ão transversal constante sobre a espiral da face do rebolo: (a) A espiral sobre a face do rebolo se mantém inalterada com o desgaste do dressador; (b) Espiral fechada em grandes rebolos utilizando um dressador do tipo placa (SEN, 2000). 


\subsubsection{3 - Taxa de Desgaste Invariável}

A importância da taxa de desgaste invariável do diamante do dressador tornou-se maior a partir dos anos 80 , quando os fabricantes de máquinas automatizadas começaram a incorporar um fator de compensação de erro em seus pacotes de programação. Isto significa que, uma vez que a taxa de desgaste de um dressador para um ajuste particular de dressagem é conhecida, valores para a perda do volume de rebolo devido à retificação, para o volume de rebolo perdido devido à dressagem e para o desgaste progressivo do diamante do dressador podem todos ser introduzidos no programa da máquina para fornecer uma compensação para o erro dimensional do componente retificado.

Provavelmente a resistência ao desgaste abrasivo, ou a taxa na qual o diamante irá se desgastar em uma operação particular, varie entre dressadores contendo diamantes naturais, devido às variações de qualidade inerentes ao cristal natural. Esta variabilidade entre os cristais se estende desde a sua forma e tamanho até a pureza, tensões internas e arranjo cristalográfico.

Portanto, uma vez que no contexto do ambiente de produção o ideal é a obtenção de repetibilidade da qualidade na usinagem, passa a existir uma justificativa tanto técnica quanto econômica para o uso do diamante sintético. Sendo produtos planejados e produzidos segundo conceitos de engenharia, tanto as barras de diamante sintético monocristalino quanto as do diamante CVD minimizam as variáveis citadas acima, e sua resistência constante ao desgaste abrasivo, através de toda a vida do dressador, contribui significativamente para a economia do processo de dressagem (BAKON e SZYMANSKI, 1993), (WILKS e WILKS, 1991).

\subsubsection{4 - Efficiente Dissipação de Calor}

A importância da dissipação de calor, especialmente para o diamante, não pode ser menosprezada, à medida que na presença de Oxigênio o diamante grafitiza em temperaturas acima de $700{ }^{\circ} \mathrm{C}$ (BAKON e SZYMANSKI, 1993), (TAEYAERTS, 1968), (TRENT, 1984). 
A temperatura na ponta do diamante de um dressador atuando vai depender da severidade da dressagem. O efeito obviamente é mais crítico em rebolos de grande diâmetro.

$\mathrm{Na}$ dissipação de calor tanto o uso eficiente de um refrigerante quanto a condutividade térmica do material sinterizado exercem um papel relevante, mas o mais importante é desempenhado pelo próprio diamante. Uma vez que a secção transversal da barra de diamante deve ser compatível com a granulometria do rebolo, a única maneira de aumentar o seu volume e a sua área superficial de modo a melhorar a capacidade da barra de dissipar calor é aumentar o comprimento da barra (COELHO, 1999).

A resposta obtida da indústria indica que geralmente a falha prematura da barra de diamante do dressador está relacionada ao fato de que a barra escolhida para uma dressagem severa possuía comprimento insuficiente para conduzir o calor para dentro do corpo do dressador (SEN, 2000).

A tentativa mais recente da indústria para minimizar os efeitos danosos da geração de calor na dressagem sobre os diamantes do dressador é a utilização de um dressador contendo canais internos de refrigeração, por onde o fluido refrigerante chega até a região de corte (KUCHER, 2003). Este dressador emprega diamantes sintéticos monocristalinos, cujo número pode variar de 1 até no máximo 6 . O autor comenta que em todos os testes práticos realizados com a ferramenta obteve-se melhorias na dissipação de calor e no desgaste dos diamantes. Entretanto, a utilização desta ferramenta exige a presença de filtros finos no sistema de filtragem do fluido refrigerante para evitar a interrupção dos canais internos no dressador. A figura 16 apresenta uma representação esquemática deste dressador. Os diamantes são representados em amarelo enquanto que os canais para refrigeração estão em azul. Pode-se ver também duas possíveis disposições dos diamantes na ferramenta: arranjo em paralelo de 4 diamantes (à esquerda) e arranjo diagonal de 3 diamantes (à direita). 


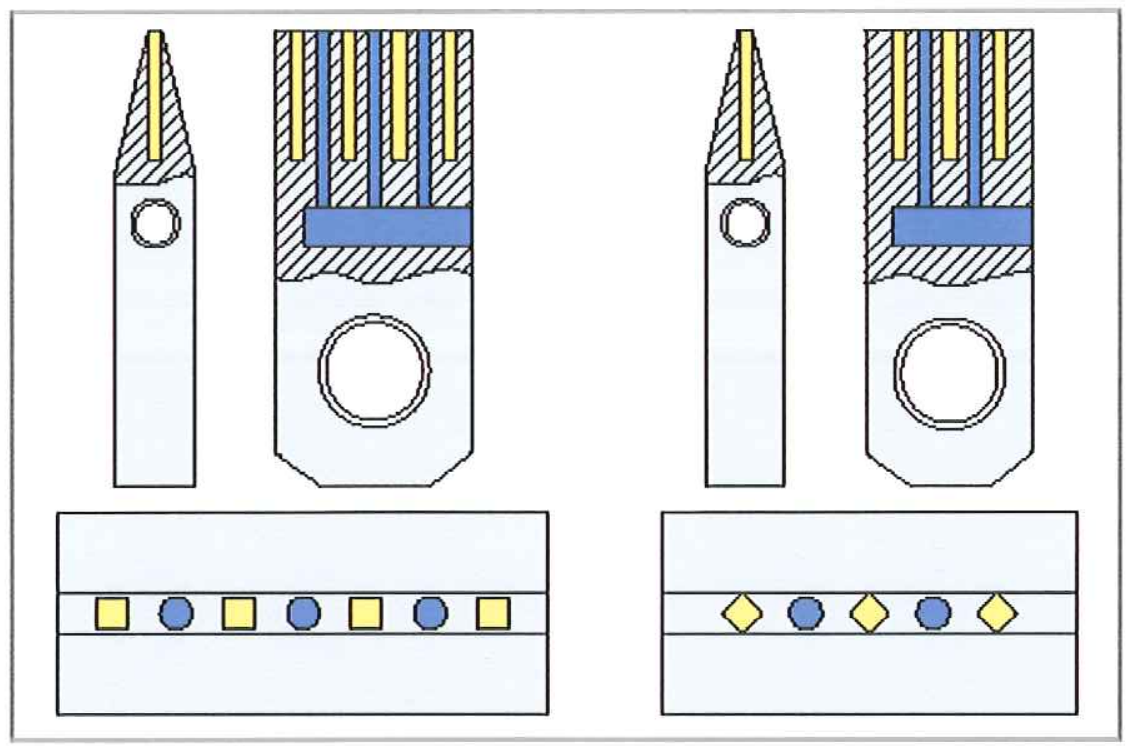

Figura 16: Representação esquemática do dressador contendo canais internos para refrigeração (KUCHER, 2003).

\section{5 - A Forma do Corpo dos Dressadores Estáticos Sinterizados}

Segundo Bakon e Szymanski (1993), em termos termodinâmicos, sob condições normais, o diamante não é uma forma estável de Carbono e sua estrutura cristalina pode ser transformada. Quando o diamante é submetido a temperaturas acima de $700{ }^{\circ} \mathrm{C}$, na presença de Oxigênio, mesmo por curtos períodos de tempo, a sua superfície tende a se converter de volta em grafite, que corresponde à forma alotrópica mais estável nessas condições. Por esta razão, o projeto de uma ferramenta de dressagem necessita minimizar o efeito da temperatura a fim de preservar a estrutura do diamante. Uma das maneiras de se obter isso é considerar a forma geométrica da ferramenta de dressagem.

Esta forma deve ser projetada de modo a favorecer a troca térmica entre a ferramenta e o fluido refrigerante, ajudando na remoção do calor da região dos diamantes (COELHO, 1999). Além disso, deve-se buscar geometrias que evitem o acúmulo de material sobre a ferramenta, como cavacos e resíduos de retificação, que possam vir a prejudicar a troca térmica com o fluido ao longo da vida do dressador.

A forma externa do dressador representa uma dificuldade adicional para os fabricantes, uma vez que ela deve estar adaptada ao tipo de retificadora 
utilizada. Neste sentido, comparativamente, as ferramentas de torneamento, por serem padronizadas, tiveram o seu desenvolvimento facilitado. Para os dressadores esse desenvolvimento certamente seria maior caso as suas formas externas também pudessem ser padronizadas.

CAMPOS (1999) realizou um trabalho no qual comprovou a possibilidade de se otimizar a distribuição de temperaturas em ferramentas de dressagem através da modificação da geometria das mesmas. Este estudo demonstrou, através da simulação com Elementos Finitos, que a adoção de aletas no corpo do dressador melhorou a refrigeração da ferramenta, favorecendo a ação do fluido refrigerante e diminuiu a temperatura máxima resultante na extremidade dos diamantes durante a dressagem. As figuras $17 \mathrm{e}$ 18 apresentam os resultados da simulação, vistos em $1 / 4$ da ferramenta devido às simetrias de forma e de carregamento. $\mathrm{A}$ área hachurada indica a região considerada na simulação.

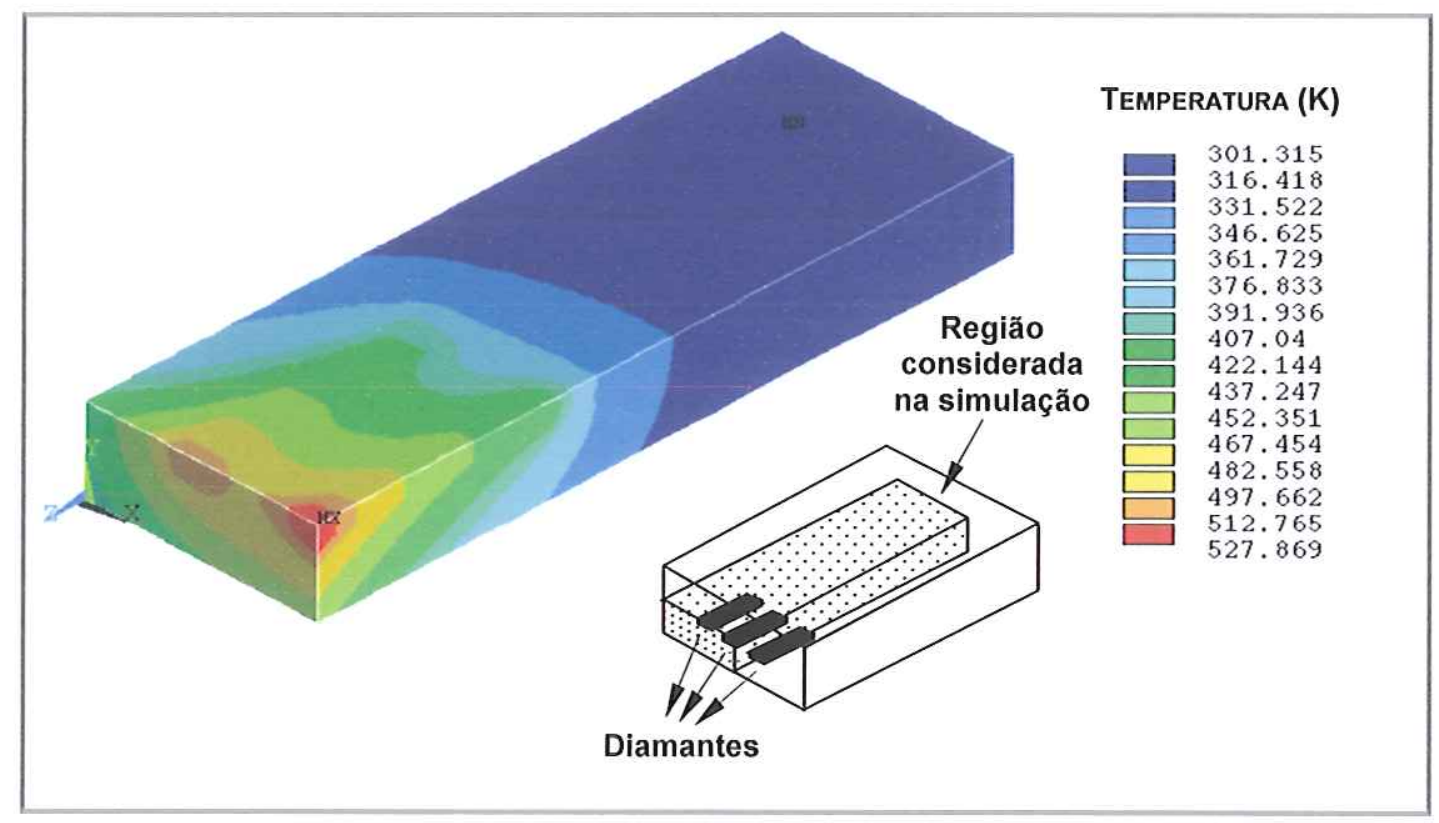

Figura 17: Dressador sem aletas (CAMPOS, 1999). 


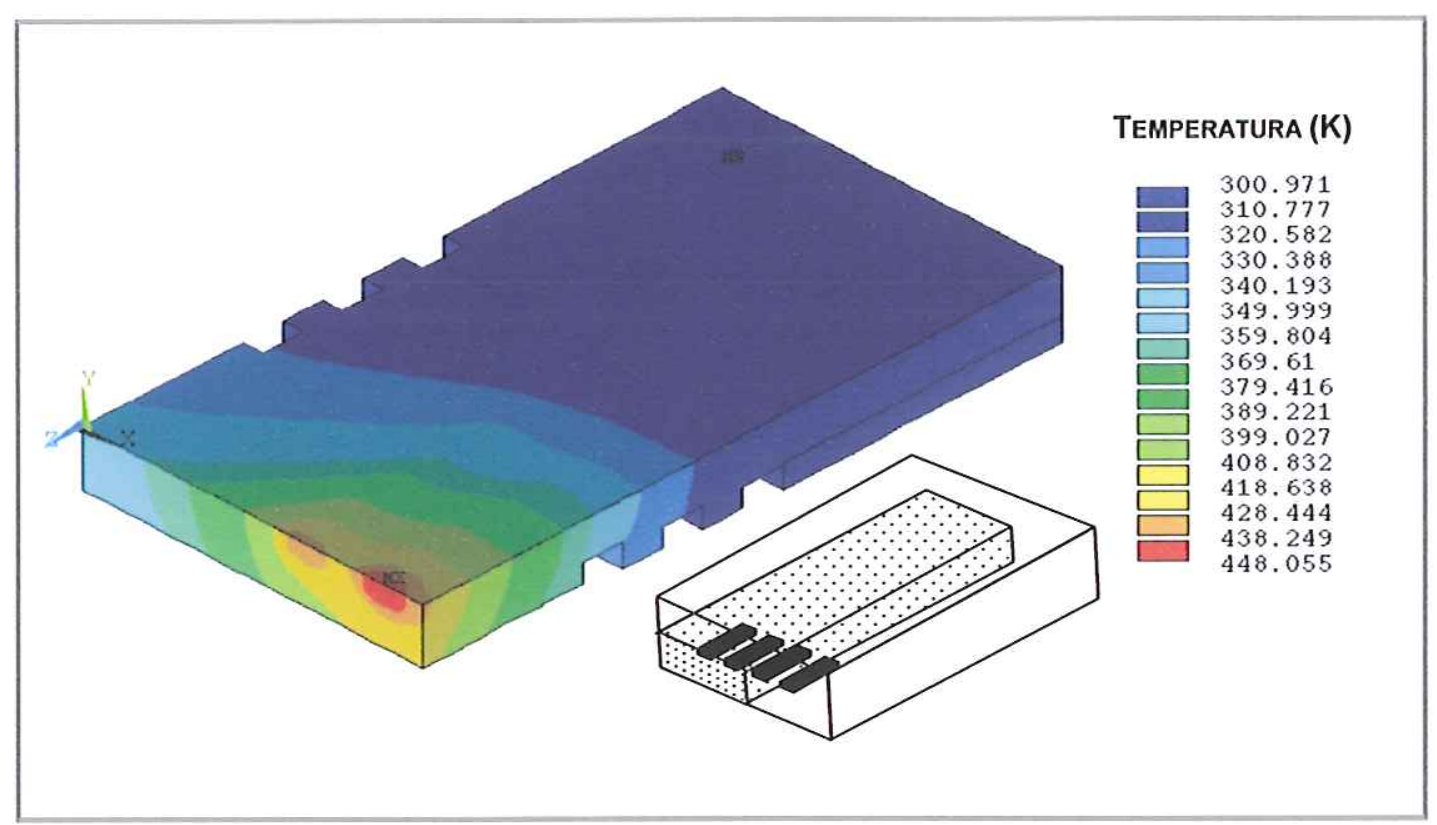

Figura 18: Dressador com aletas (CAMPOS, 1999).

CAMPOS (1999) ainda sugere aumentar o volume do corpo do dressador aletado como forma de melhorar a dissipação do calor, prática adotada no dressador utilizado neste trabalho. Acredita-se que a adoção de aletas no mesmo sentido da passagem do fluido refrigerante seja benéfico para aumentar o fluxo de calor para o fluido de corte.

\section{6 - Simulação da Dissipação de Calor Utilizando o Método dos Elementos Finitos}

\subsection{1 - O MÉtodo dos Elementos Finitos}

O engenheiro de projeto dispõe atualmente de uma série de ferramentas matemáticas que podem ser aplicadas com o objetivo de se prever 0 desempenho de componentes mecânicos. Soluções analíticas podem ser empregadas em certos casos, mas sua aplicação é limitada à situações específicas em que uma solução matemática da estrutura pode ser encontrada. 
Uma maneira mais abrangente de tratar problemas estruturais consiste no uso de métodos numéricos de análise. Apesar de tais métodos fornecerem soluções aproximadas, muitas vezes esta é a única maneira que os engenheiros dispõem para encontrar as respostas que procuram.

O Método dos Elementos Finitos considera a região de solução do problema como sendo formada por pequenos elementos interconectados entre si. A região em estudo é modelada analiticamente ou aproximada por um conjunto de elementos discretos pré-definidos. Uma vez que estes elementos possam ser colocados juntos em um número incontável de diferentes configurações, é possível modelar formas geométricas bastante complexas. Além disto, ele fornece flexibilidade ao projetista na aplicação de cargas e condições de contorno, o que torna este método um dos mais amplamente utilizados em análises estruturais atualmente (CAMPOS, 1999).

O Método dos Elementos Finitos é aplicável a uma grande faixa de problemas de valores de contorno em engenharia. Neste tipo de problema, busca-se uma solução na região do corpo (ou domínio), enquanto que nos contornos desta região os valores das variáveis dependentes (ou suas derivadas) são conhecidos.

Segundo Huebner (1994) o método pode ser resumido basicamente em 3 etapas: pré-processamento, solução (solver) e pós-processamento.

\subsubsection{1 - PRÉ-PROCESSAMENTO}

Corresponde à etapa de preparação do problema para solucioná-lo posteriormente. Nesta fase faz-se a modelagem do fenômeno, assumindo hipóteses, condições iniciais, condições de contorno e carregamentos, bem como a escolha do elemento, das propriedades dos materiais e da geometria que representará a forma do componente a ser analisado. A seguir são descritas duas sub-etapas importantes para o pré-processamento:

- Discretização do contínuo: o contínuo corresponde ao corpo físico, estrutura ou sólido que está sendo analisado. A discretização pode ser descrita como o processo no qual o domínio é subdividido em um sistema equivalente formado por um número finito de pequenas regiões, denominadas elementos 
finitos, as quais podem ser, por exemplo, triângulos ou quadriláteros para problemas considerados em duas dimensões, ou ainda tetraedros e hexaedros para três dimensões. A essa divisão do domínio dá-se o nome de rede de elementos finitos. A malha desse reticulado pode ser aumentada ou diminuída variando o tamanho dos elementos finitos. Os pontos de intersecção das linhas dessa rede são chamados nós. Apesar das tentativas de se automatizar o processo de subdivisão do domínio, esta fase ainda é dependente do julgamento e experiência do engenheiro (ASSAN, 1999).

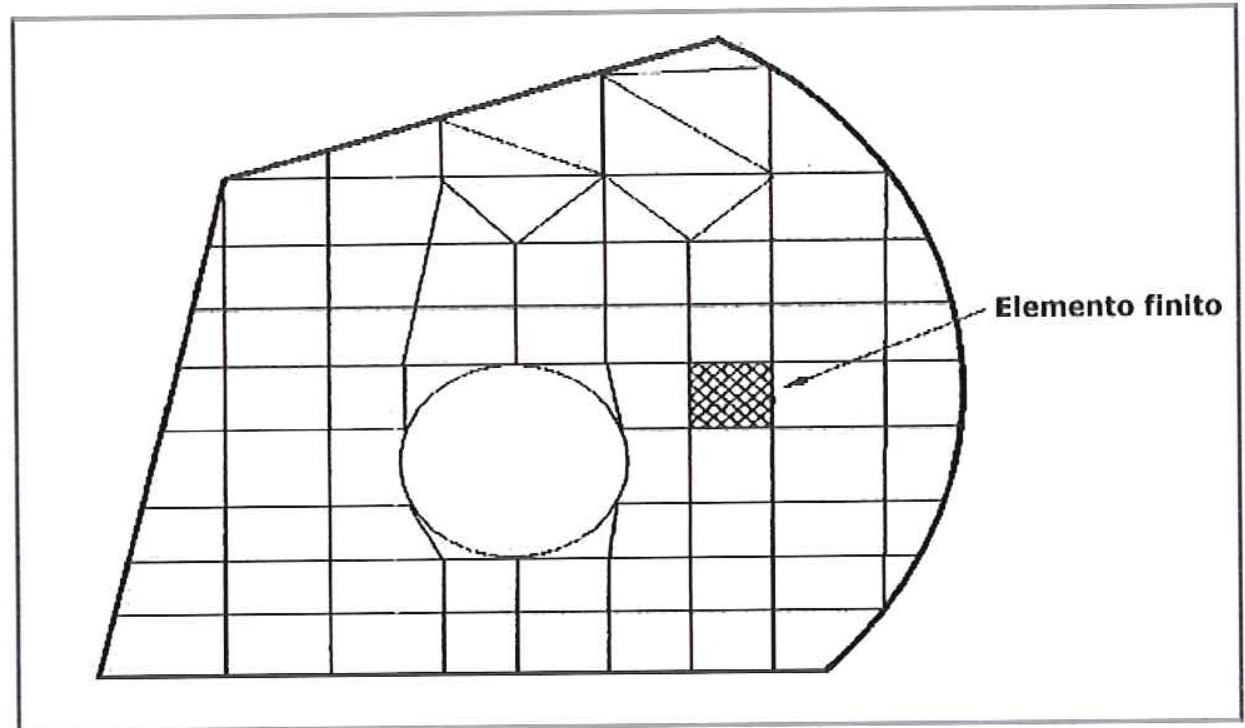

Figura 19: Exemplo de uma rede de elementos finitos (ASSAN, 1999).

- Solução das funções de interpolação: as funções de interpolação ou de deslocamento assumidas representam aproximadamente a distribuição exata ou real dos deslocamentos. A forma adotada para as funções de interpolação geralmente é a polinomial, pela maior simplicidade de tratamento matemático. Existem três fatores inter-relacionados que influenciam a seleção da função de interpolação: escolha do tipo e do grau da função (como o tipo adotado é o polinomial, apenas o grau deve ser escolhido), o tipo das variáveis de campo que descrevem o modelo (normalmente os deslocamentos nos nós ou suas derivadas) e finalmente, o modelo deve satisfazer certos requisitos que garantam que o resultado numérico se aproxime da solução correta. 


\subsubsection{2 - SOLUÇÃO (SOLVER)}

A solução do problema tem como ponto de partida o modelo configurado na etapa anterior. Portanto, a acuracidade das respostas depende basicamente da capacidade do engenheiro em abstrair e representar o fenômeno. A solução é baseada em um algoritmo numérico que visa solucionar da maneira mais rápida e precisa, uma equação diferencial com condições de contorno e/ou condições iniciais impostas pelo modelo.

Um aspecto importante é que esses algoritmos numéricos podem ser implementados computacionalmente para agilizar o cálculo. Esses recursos implementados computacionalmente permitem estimar a solução de um problema complexo em um tempo relativamente pequeno, fazendo com que se otimize o tempo de processo para o desenvolvimento de projetos que empreguem materiais isotrópicos ou anisotrópicos submetidos a carregamentos estáticos, dinâmicos, térmicos, etc. Atualmente encontram-se disponíveis no mercado pacotes computacionais empregados na modelagem de problemas tais como o ANSYS $^{\circledR}$, NASTRAN $^{\circledR}$, ABAQUS $^{\circledR}$ e outros, cada um possuindo facilidades e dificuldades específicas para a sua aplicação (CAMPOS, 1999).

\subsubsection{3 - PÓS-PROCESSAMENTO}

Esta é a última etapa e depende apenas das necessidades do engenheiro que está modelando o problema, ou seja, ela corresponde ao conjunto solução da equação diferencial que descreve o fenômeno em estudo, podendo ser:

- Deslocamentos nodais;

- Deformações da geometria;

- Gradientes de tensão de acordo com o critério de resistência escolhido;

- Gradientes de temperatura;

- Deslocamentos nodais ao longo do tempo;

- Freqüências naturais e formas de vibrar da estrutura. 


\subsection{2 - O SOFTWARE ANSYS ${ }^{\circledR}$}

O ANSYS ${ }^{\circledR}$ é um pacote comercial de Elementos Finitos que permite análises de estruturas através da simulação de um modelo teórico computacional. Ele é capaz de realizar análises estruturais estáticas e dinâmicas, lineares ou não-lineares, assim como análises de transferência de calor, fluídicas e eletromagnéticas. O pré-processador também está incluso no pacote, mas pode ser executado através de outros programas CAD, como por exemplo o PRO-ENGINEER ${ }^{\circledR}$.

Na simulação computacional, em problemas envolvendo dissipação de calor por condução e convecção simultaneamente, a dificuldade normalmente encontrada é estimar os valores dos coeficientes de transferência de calor por convecção ou simplesmente coeficiente de convecção (h) e de fluxo de calor $\left(\boldsymbol{q}_{\mathrm{f}}\right)$, Sem a definição dos valores destes coeficientes, não se pode realizar a simulação. Desta forma, esses valores devem ser medidos experimentalmente em condições semelhantes para que se produzam valores realistas que possam alimentar o programa e produzir resultados satisfatórios. 


\section{3 - PROCEDIMENTO EXPERIMENTAL}

Neste capítulo serão detalhados todos os procedimentos executados para a obtenção do protótipo de dressador e para a realização dos ensaios de aferição das temperaturas obtidas durante a realização das operações de dressagem. Além disso são detalhadas as etapas para a construção do modelo e posterior simulação computacional do uso da ferramenta de dressagem empregando o Método dos Elementos Finitos (Finite Element Method - FEM).

\section{1 - Proposta de um Dressador Otimizado}

\subsection{1 - NOVA GEOMETRIA PARA O DRESSADOR}

No presente trabalho a solução escolhida para a melhoria da dissipação do calor foi a adoção de aletas dispostas no corpo do dressador, no sentido longitudinal, envolvendo a liga sinterizada que sustenta os diamantes. Após a obtenção da liga, e já com os diamantes em seu interior, todo o conjunto foi brasado com solda prata a esta peça aletada, de forma a finalmente constituir o corpo do protótipo de dressador.

Bejan (1996) afirma que o objetivo da adoção de aletas em qualquer equipamento é melhorar o contato térmico entre a superfície de um sólido e o fluido que escoa sobre esta superfície. As aletas constituem uma mudança na 
geometria superficial do sólido que estará em contato com o escoamento do fluido.

O material adotado nesta proposta de geometria é o Latão, de baixo custo, facilidade de usinagem e boa condutividade térmica. Buscou-se criar uma forma que favoreça a passagem do fluido refrigerante pela sua superfície, ou seja, as aletas estão dispostas no mesmo sentido de escoamento do fluido que sai do bocal da retificadora, diferentemente da posição adotada no trabalho de Campos (1999), no qual as aletas estavam dispostas no sentido transversal à passagem do fluido.

Esta disposição adotada evita também o acúmulo de material (detritos de retificação) sobre o dressador que possa vir a dificultar a troca térmica com o fluido. Este é o motivo de ter sido adotada uma forma geométrica inclinada da base ao topo, semelhante a um trapézio, pois assim a tendência de qualquer detrito que caia sobre o dressador é descer e ir embora, acompanhando o fluxo do fluido refrigerante.

Na seqüência, a figura 20 apresenta a proposta de geometria para o dressador que foi adotada neste trabalho, vista sob vários ângulos (a primeira foto mostra a cavidade para a inserção da liga sinterizada com os diamantes). 

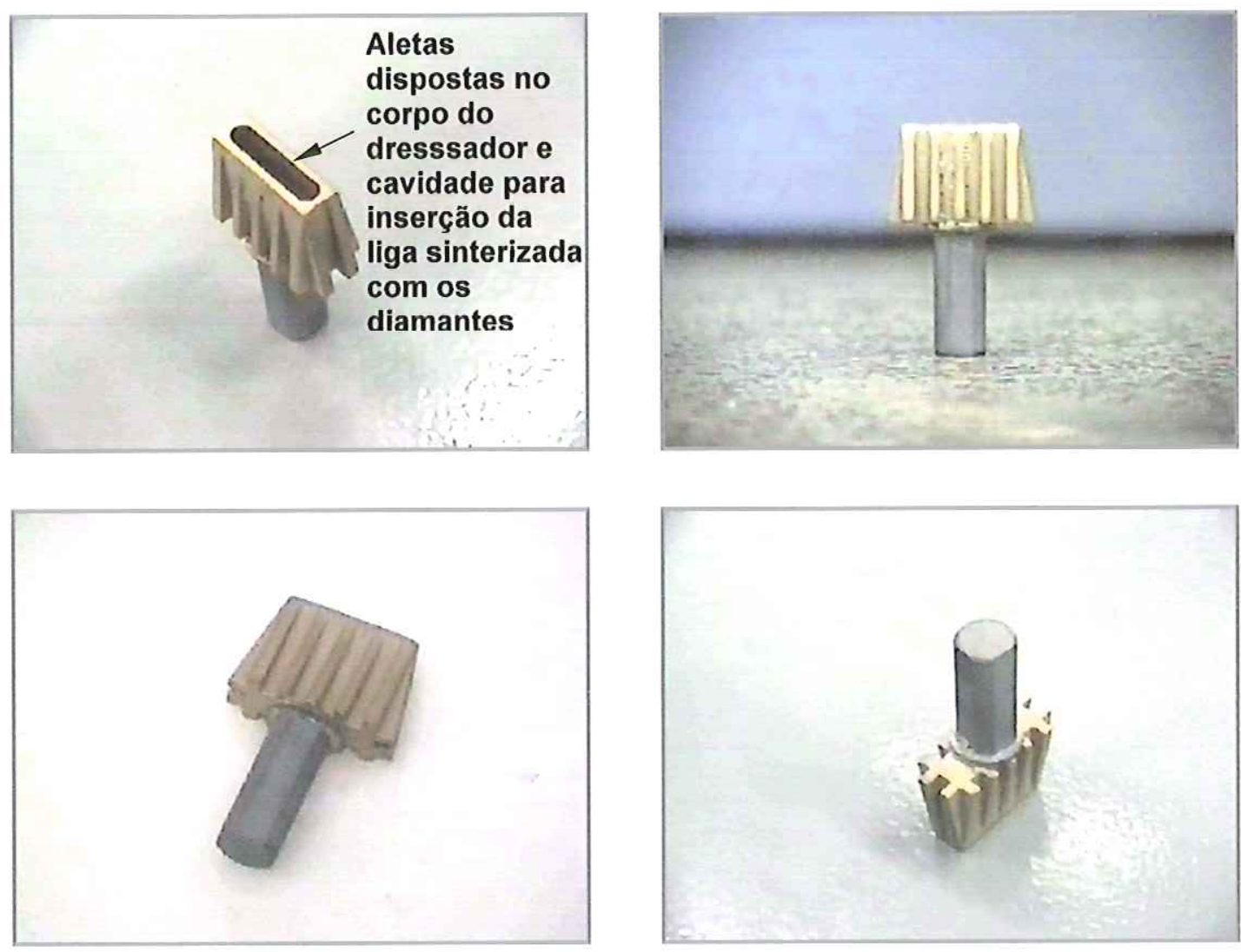

Figura 20: Proposta de geometria para o dressador.

\subsection{2 - Procedimentos PARA Obtenção da Liga Sinterizada}

Os tópicos seguintes dizem respeito aos procedimentos seguidos para a preparação da mistura dos pós metálicos utilizados, assim como sua posterior prensagem, sinterização e avaliação da liga obtida.

Para as tentativas de obtenção da liga, fixou-se o tempo de sinterização em 30 minutos e variou-se as condições de temperatura e de atmosfera protetora, utilizando as composições das misturas de pós apresentadas na tabela 2.

As misturas números 1,3 e 4 foram preparadas a partir dos pós metálicos de Bronze, Cobalto e de Carbeto de Tungstênio. Nestas misturas, as proporções utilizadas mantiveram sempre uma maior quantidade de Bronze, para garantir a boa condutividade térmica da liga em conjunto com uma quantidade menor de Cobalto e Carbeto para assegurar resistência mecânica e 
à abrasão. A mistura número 2 foi preparada a partir das proporções obtidas da análise química da liga de um dressador comercial.

Foram realizadas um total de 25 sinterizações para se chegar às condições adotadas para a liga do protótipo do dressador. Detalhes de todos os procedimentos realizados são dados a seguir.

Tabela 2: Composições das misturas utilizadas nas sinterizações.

\begin{tabular}{|c|c|}
\hline MISTURA & COMPOSIÇÄO (\% EM MASSA DOS PÓS METÁLICOS) \\
\hline 1 & $85 \%$ Bronze; $15 \%$ Cobalto \\
\hline 2 & $\begin{array}{l}53,6 \% \text { Cobre; } 32,4 \% \text { Ferro; } 7,01 \% \text { Estanho; } 3,35 \% \text { Zinco; } 3,0 \% \text { Niquel; } \\
0,64 \% \text { Cromo (pós elementares) }\end{array}$ \\
\hline 3 & 80 \% Bronze; 10 \% Cobalto; 10 \% Carbeto de Tungstênio \\
\hline 4 & 85 \% Bronze; 10 \% Cobalto; 5 \% Carbeto de Tungstênio \\
\hline
\end{tabular}

\subsubsection{1 - PREPARAÇÃo dA MISTURA}

Antes da mistura ser prensada para a obtenção dos compactos verdes, adotou-se como procedimento básico para todas as amostras testadas tomar a mistura inicialmente obtida pela adição proporcional dos pós metálicos e levá-la para ser misturada em um misturador Túrbula existente no Laboratório de Materiais Cerâmicos do DEMa (UFSCar).

Este misturador realiza movimentos giratórios cíclicos e alternados de um recipiente que acondiciona os pós que necessitam ser misturados. Isto foi feito para buscar uma maior homogeneização entre os componentes da mistura para que isto se reflita também na liga sinterizada.

Todas as composições testadas foram submetidas a 30 minutos de mistura prévia neste aparelho antes de serem prensadas.

As fotos das figuras 21 (a) e 21 (b) apresentam o misturador utilizado. 


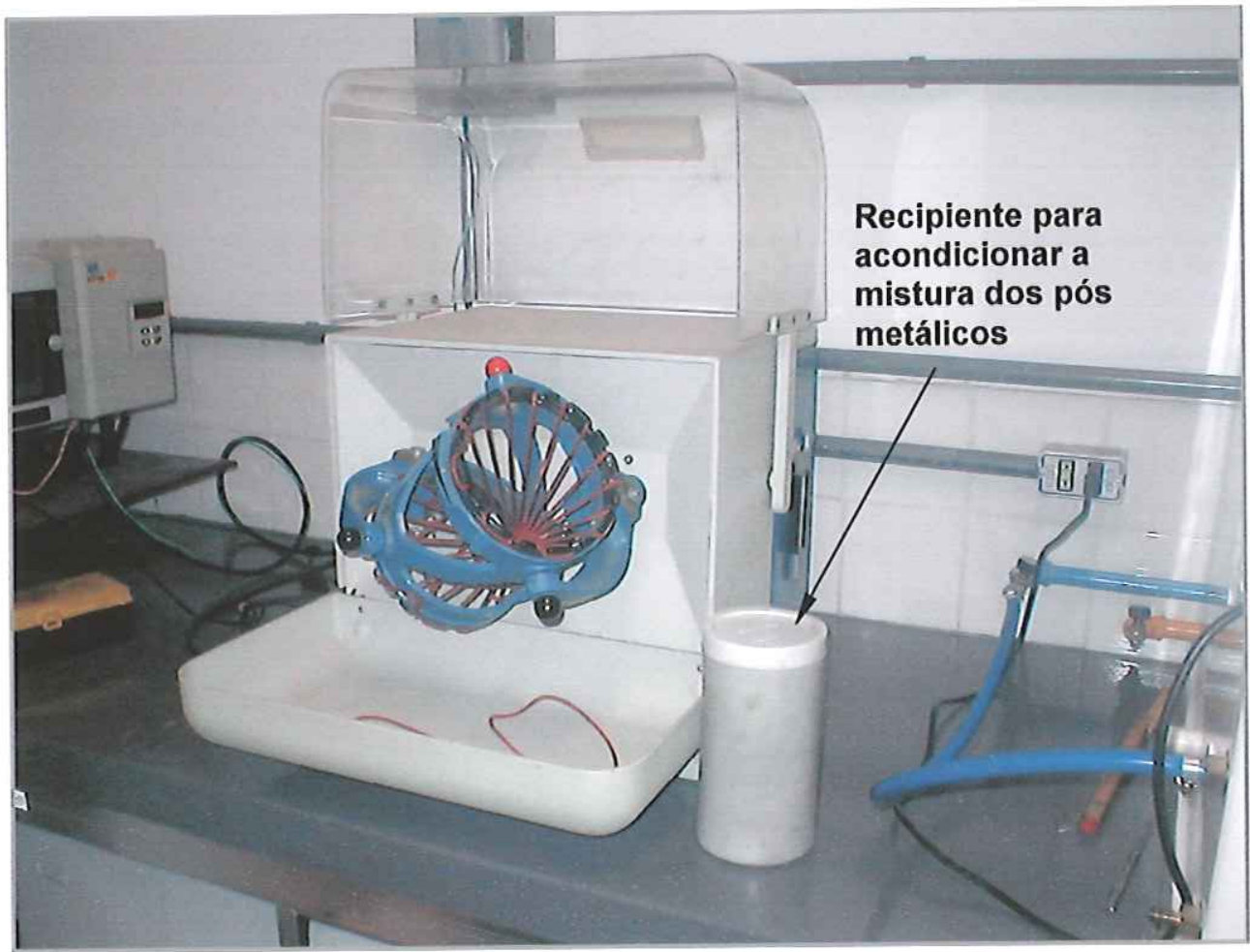

Figura 21 (a): Misturador Túrbula antes do uso.

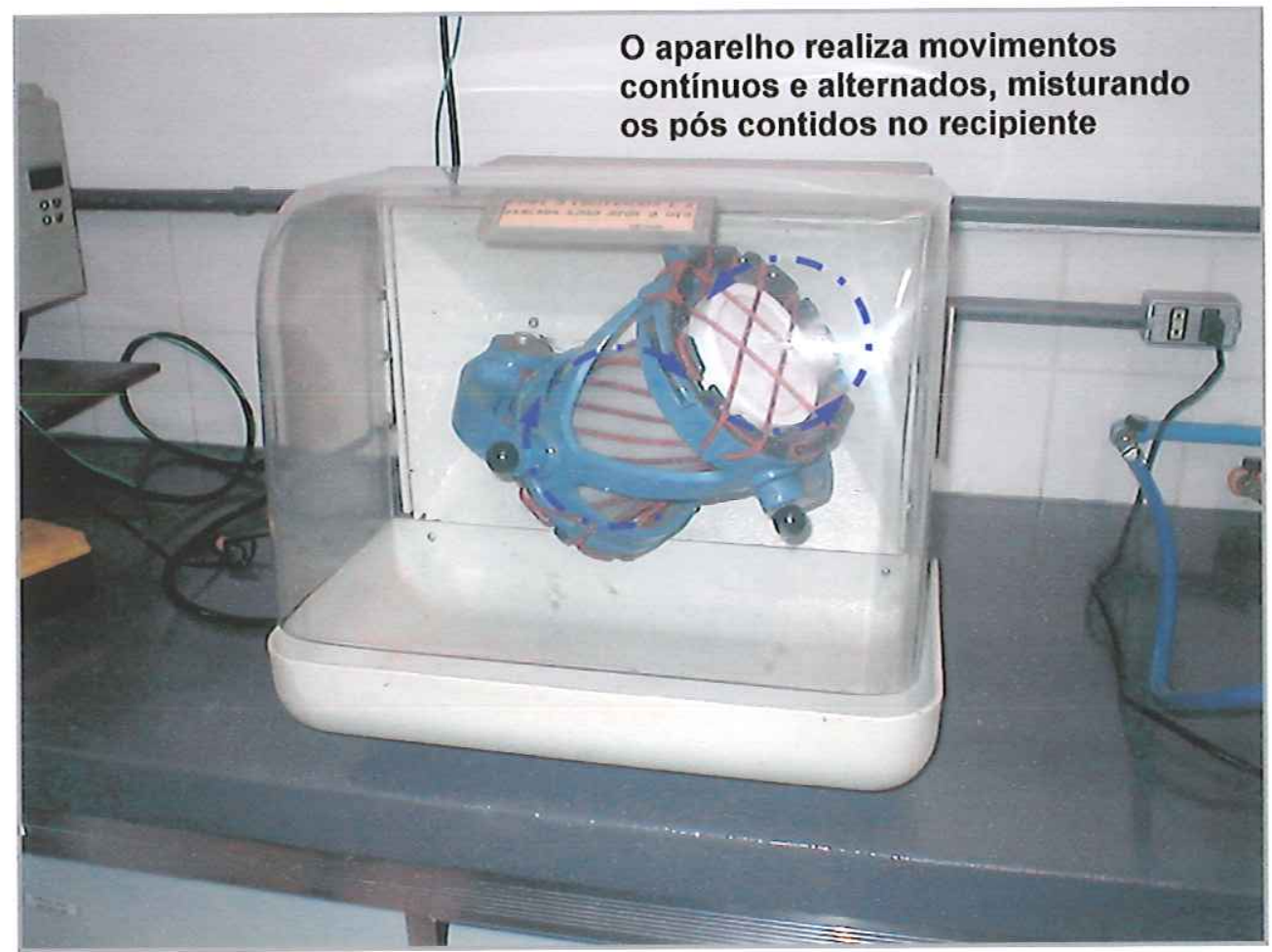

Figura 21 (b): Misturador Túrbula pronto para uso. 


\subsubsection{2 - CÁlCULO dA DENSIDAde TEÓRICA E DA MASSA DA MistuRA}

Para um melhor entendimento, mostra-se aqui um exemplo do procedimento de cálculo seguido para a obtenção da densidade teórica e da massa que foi retirada de uma das misturas de pós metálicos utilizadas nas sinterizações realizadas.

Inicialmente seleciona-se os pós metálicos que farão parte da composição da liga. Tomando como exemplo a mistura de $85 \%$ de Bronze e $15 \%$ de Cobalto, tem-se que:

$$
\begin{aligned}
& \text { Densidade do Cobalto }(\mathrm{Co}) \Rightarrow \rho=8800 \mathrm{~kg} / \mathrm{m}^{3} \\
& \text { Densidade do Bronze } \Rightarrow \rho=8780 \mathrm{~kg} / \mathrm{m}^{3} \\
& \text { Densidade da Mistura } \Rightarrow \rho_{\text {mistura }}=?
\end{aligned}
$$

Separa-se massas proporcionais dos pós relativos à composição adotada, ou seja, toma-se $85 \mathrm{~g}$ de Bronze (proporcional a $85 \%$ de Bronze na mistura) e $15 \mathrm{~g}$ de Cobalto (idem para $15 \%$ de Co), totalizando $100 \mathrm{~g}$ iniciais para a mistura.

Sabe-se que:

$$
\rho_{\text {mistura }}=\frac{\text { massa }_{\text {mistura }}}{\text { volume }_{\text {mistura }}}
$$

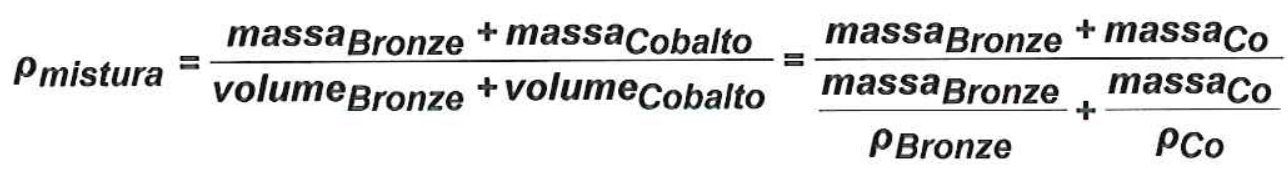

$$
\rho_{\text {mistura }}=\frac{(0,085+0,015)}{10-{ }^{3}\left(\frac{85}{8780}+\frac{15}{8800}\right)} \frac{\mathrm{kg}}{\mathrm{m}^{3}}
$$

$\rho_{\text {mistura }}=8782,99 \frac{\mathrm{kg}}{\mathrm{m}^{3}} \Rightarrow$ Este valor corresponde à densidade teórica para esta mistura, ou seja, este seria o valor obtido caso o material fosse totalmente maciço e isento de poros. Por isso, na Metalurgia do Pó, geralmente se trabalha com o valor da densidade aparente, que considera a existência de 
poros na peça sinterizada e por isso é dada como uma porcentagem da densidade teórica. A densidade aparente é definida como a relação entre a massa e o volume de um determinado material que não seja maciço, ou seja, que contenha poros. Por isso ela representa a densidade que o material "aparenta" possuir, mas não é a densidade real do material porque o volume, neste caso, considera o ar contido nos poros.

De posse do valor da densidade teórica da mistura $\left(\rho_{\text {mistura }}\right)$, é possível obter a massa (massa mistura) que terá de ser retirada da mistura inicialmente preparada (ou seja, dos $100 \mathrm{~g}$ iniciais). Para cada prensagem, a massa mistura será igual ao produto dessa densidade da mistura (no exemplo, $8782,99 \mathrm{~kg} / \mathrm{m}^{3}$ ) pelo volume da pastilha a ser prensada (este volume é definido pela área da cavidade da matriz de prensagem multiplicada pela espessura do compacto). Como a matriz utilizada possui uma cavidade para inserção da mistura de pós com dimensões de $15 \times 21 \mathrm{~mm}$ e estipulou-se uma espessura de $5 \mathrm{~mm}$ para o compacto, tem-se que:

massa $_{\text {mistura }}=\rho_{\text {mistura }} \cdot$ volume $_{\text {compacto }}$

massa $_{\text {mistura }}=(8782,99) \cdot\left[(15 \cdot 21) \cdot 10^{-6} \cdot 5 \cdot 10^{-3}\right]=0,0138 \mathrm{~kg}=13,8 \mathrm{~g}$

Portanto, esta massa de $13,8 \mathrm{~g}$ foi retirada dos $100 \mathrm{~g}$ inicialmente misturados para ser utilizada na produção de cada compacto que foi sinterizado a partir desta mistura específica. Esta massa de $13,8 \mathrm{~g}$ foi posteriormente dividida em duas partes para a prensagem em duas etapas do compacto, devido à necessidade de inserção dos diamantes.

Este mesmo procedimento foi seguido para a produção dos compactos a partir das outras misturas testadas, bastando para isso considerar os valores correspondentes da densidade e da massa de cada elemento presente na mistura dos pós, como indicadas no cálculo. 


\subsubsection{3- CÁlCULO dA DENSIDADE APARENTE}

Para o cálculo da Densidade Aparente, parâmetro comparativo utilizado para avaliar as peças obtidas, empregou-se o chamado "Método de Arquimedes", por ser um procedimento comumente utilizado para este cálculo devido à sua simplicidade de aplicação (GERMAN, 1994). Este método foi utilizado para a avaliação de todas as amostras produzidas.

Para o emprego deste método é necessário a obtenção de três parâmetros da peça sinterizada, a saber: "Peso Seco", "Peso Úmido" e "Peso Imerso". Estes valores foram obtidos com o emprego de uma balança analítica da marca OHAUS (modelo TS4KD), com resolução de $0,001 \mathrm{~g}$ pertencente ao Laboratório de Materiais Cerâmicos do DEMa, da Universidade Federal de São Carlos (UFSCar). O roteiro de procedimentos seguidos foi o seguinte:

a) Para cada série de tentativas, após a prensagem dos compactos, inseriu-se todas as peças em uma estufa de secagem (Modelo 315 SE, fabricada pela FANEM), onde permaneceram por 24 horas a uma temperatura de $90^{\circ} \mathrm{C}$;

b) Após a retirada da estufa, as peças foram levadas até a balança analítica, onde foram realizadas 3 aferições da massa de cada peça. Posteriormente calculou-se a média aritmética destes valores para cada peça. Este valor da média foi considerado como o Peso Seco (PS) da peça;

c) A etapa seguinte consistiu em colocar as peças imersas num recipiente contendo água destilada, no qual permaneceram por mais 24 horas. Decorrido este tempo, utilizou-se novamente a balança analítica para tomar os valores do Peso Úmido e do Peso Imerso.

Para a medida do Peso Úmido as peças são retiradas do recipiente, roladas sobre um papel absorvente para uma secagem rápida e, em seguida, colocadas sobre o prato da balança para a obtenção da medida. Isto também foi repetido 3 vezes para cada peça, retornando-se a mesma para o recipiente após a primeira e segunda medidas. Novamente calculou-se a média aritmética 
para cada peça. Este valor médio resultante foi considerado como o Peso Úmido (PU) da peça.

No caso da medida do Peso Imerso, cada peça foi mantida imersa na água sobre um suporte adaptado para este procedimento, o qual fica preso sob o prato da balança de modo que esta, após o zeramento inicial do seu display para que desconsidere o peso do suporte, afira apenas a massa da peça que foi imersa na água. Esta medida também foi tomada 3 vezes para cada peça, calculando-se a média aritmética ao final. Do mesmo modo, este valor médio resultante para cada peça foi considerado como sendo o Peso Imerso (PI).

Obtidos estes três parâmetros é possível, através do emprego de três fórmulas, chegar-se ao valor da densidade aparente de cada amostra sinterizada. As fórmulas utilizadas são as seguintes:

- $A A=\frac{P U-P S}{P S} \times 100$

- $P A=\frac{P U-P S}{P U-P I} \times 100$

- $\quad D A=\frac{P A}{A A}$

As fotos das figuras 22 e 23 mostram a balança e os elementos utilizados nestas medições. 


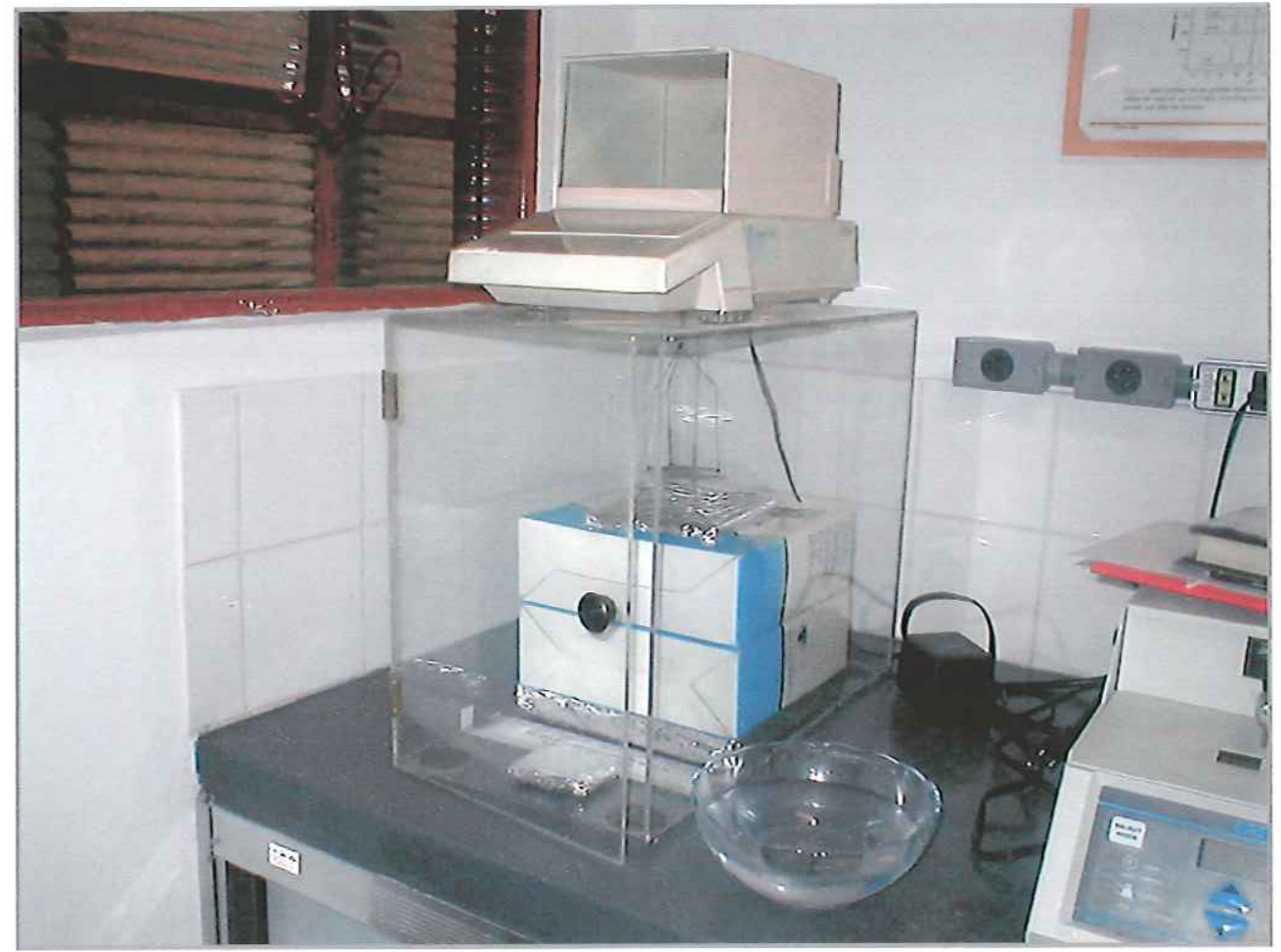

Figura 22: Visão geral da balança utilizada no cálculo da densidade aparente.

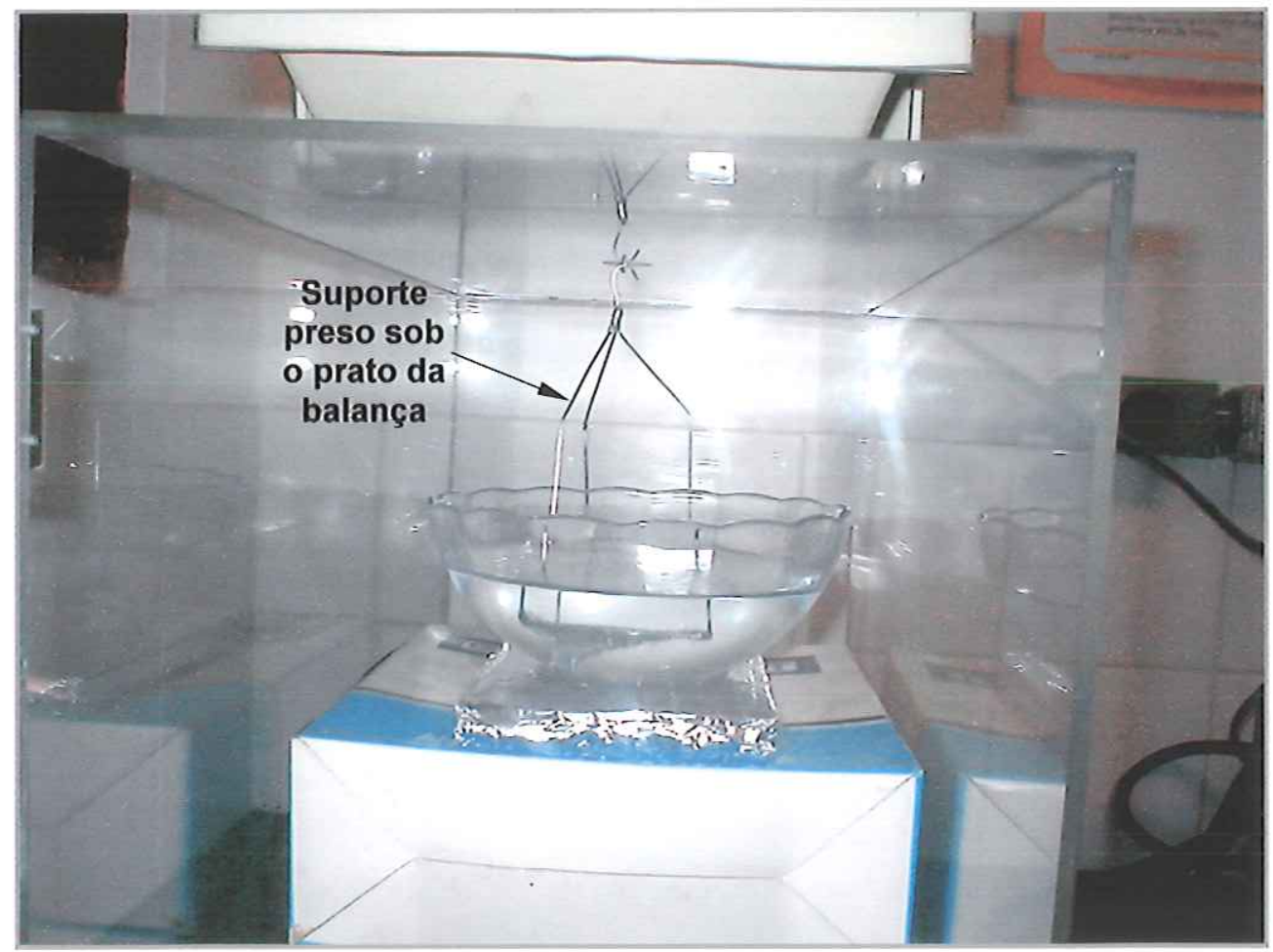

Figura 23: Suporte preso sob a balança e imerso em água destilada. 


\subsection{3 - UTILIZAÇÃO DO FORNO}

As sinterizações para a obtenção da liga que foi utilizada no protótipo de dressador foram realizadas em um forno do tipo tubular horizontal, capaz de operar sob atmosfera de vácuo, do Laboratório de Solidificação do Departamento de Materiais (DEMa) da Universidade Federal de São Carlos (UFSCar). O forno é da marca Lindberg/Blue, modelo STF 54434 C (temperatura máxima de $1700^{\circ} \mathrm{C}, 100 \mathrm{~V}, 50 \mathrm{~A}$, potência de $50 \mathrm{~kW}$ ) com controlador da marca Eurotherm. A bomba à vácuo utilizada é da marca Boc Edwards Brasil Ltda., modelo NCE 213000, com bomba mecânica ligada a uma bomba difusora com capacidade máxima de vácuo de $1.10^{-6}$ Torr $\left(1,3.10^{-6}\right.$ mbar).

O forno contém dois tubos, um tubo maior, feito de cerâmica (Alumina), com $38 \mathrm{~mm}$ de diâmetro, que atravessa todo o forno e dentro do qual é inserido um tubo menor, feito de Sílica Vítrea, com $19 \mathrm{~mm}$ de diâmetro, que acondiciona as peças durante a sinterização. Juntamente com as peças também é inserido neste último tubo um termopar do tipo $\mathrm{K}$ em forma de vareta, cujo comprimento possibilita que a extremidade de aferição da temperatura (ou seja, a ponta do termopar) fique posicionada bem próxima da peça (à cerca de $3 \mathrm{~mm}$ de distância), na região de aquecimento do forno, o que assegura uma maior precisão do valor medido da temperatura no interior do forno. Além disso, a menor dimensão do tubo de Sílica Vítrea proporciona uma maior homogeneidade da temperatura em seu interior durante a sinterização. A figura 24 apresenta uma representação esquemática do forno utilizado. 


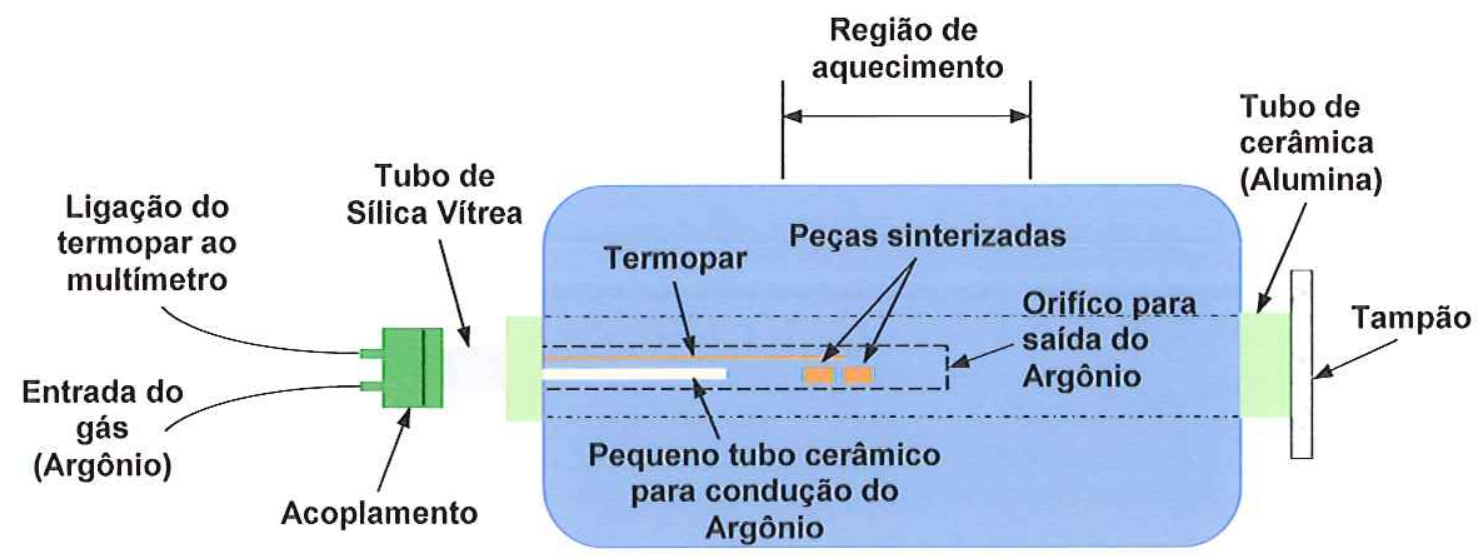

Figura 24: Representação esquemática do forno utilizado.

Nas figuras 25 e 26 a seguir pode-se ver o forno utilizado nas sinterizações, assim como a bomba de vácuo.

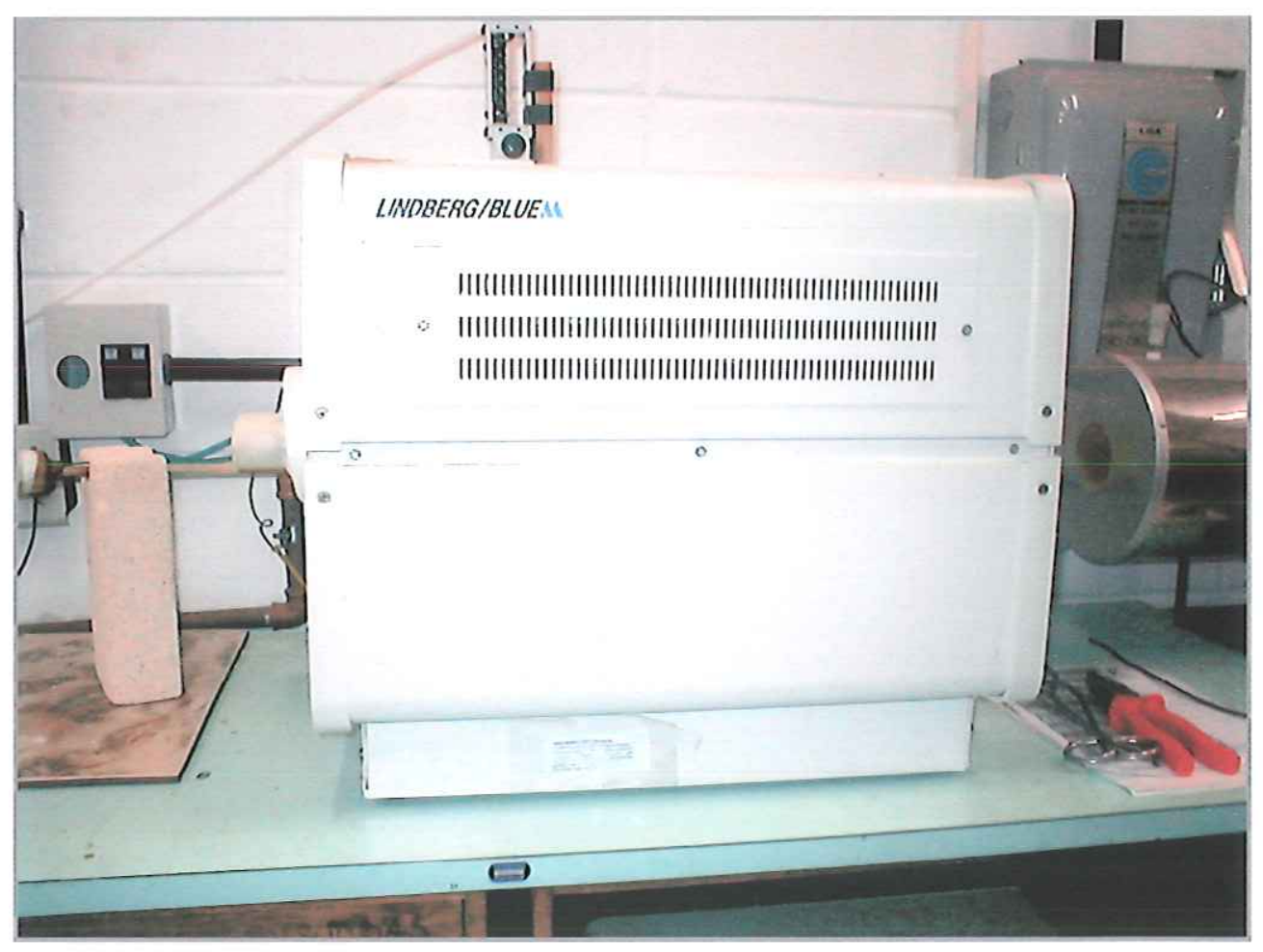

Figura 25: Forno tubular utilizado nas sinterizações. 


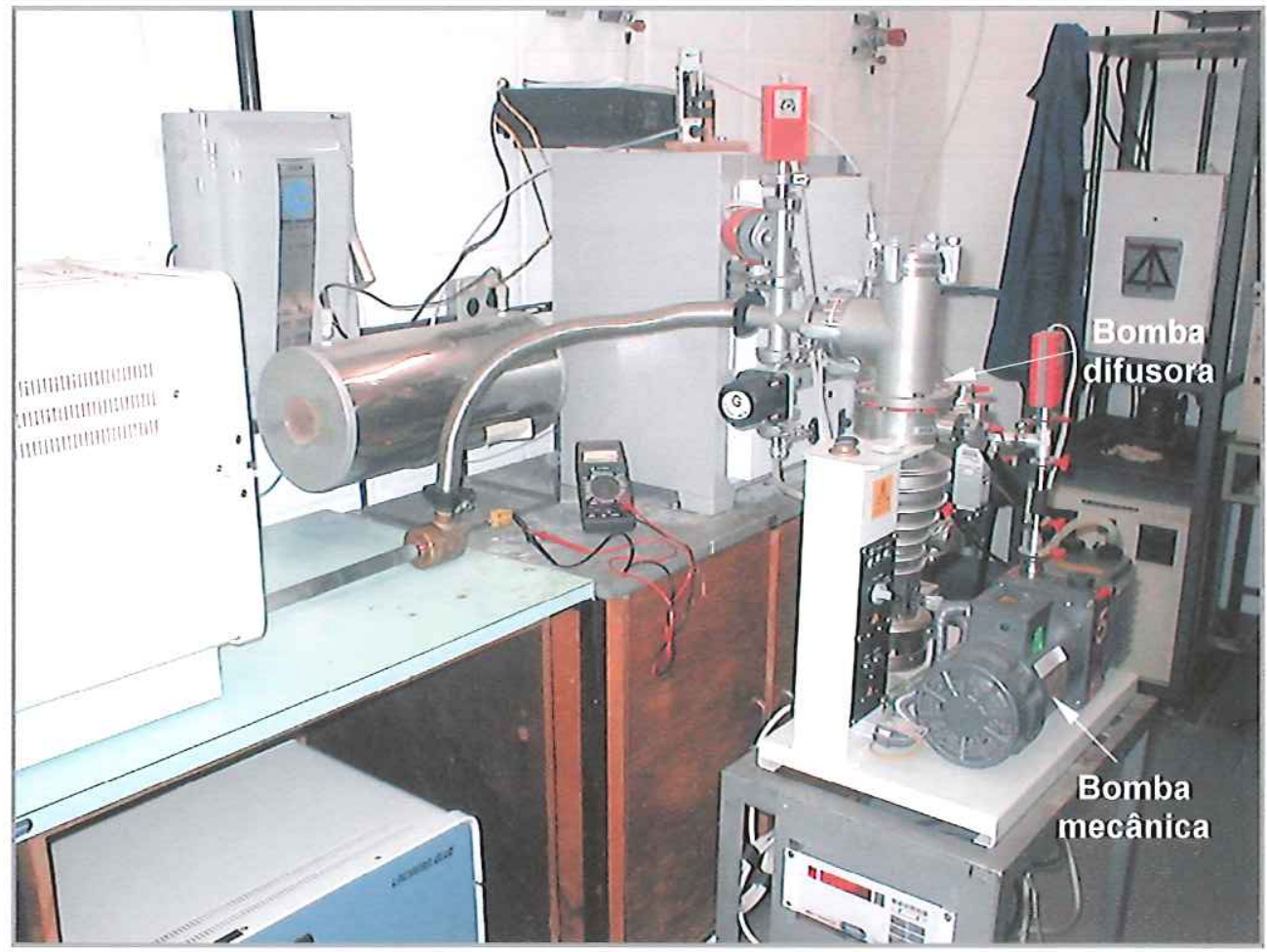

Figura 26: Bomba de vácuo utilizada.

\subsubsection{1 - ATMOSFERAS PROTETORAS UTILIZADAS}

Decidiu-se fazer a sinterização dos compactos utilizando dois tipos de atmosferas protetoras, Argônio e vácuo, para verificar se existe diferença significativa nos resultados obtidos de dureza e porosidade da liga sinterizada resultante. O Argônio empregado foi o de especificação 4.8 da empresa White Martins, cuja composição (valores mínimos) encontra-se na tabela 3.

Tabela 3: Composição do Argônio utilizado nas sinterizações.

\begin{tabular}{|c|c|}
\hline \multicolumn{2}{|c|}{ COMPOSıçĀO DO ARGÔNIO 4.8} \\
\hline Argônio & $99,998 \%$ \\
\hline Umidade* $^{*}$ & $<3 \mathrm{ppm}$ \\
\hline Oxigênio* $^{*}$ & $<3 \mathrm{ppm}$ \\
\hline Nitrogênio* $^{*}$ & $<10 \mathrm{ppm}$ \\
\hline
\end{tabular}

ppm: partes por milhão. 
O controle da temperatura foi realizado através de um multímetro digital. O termopar foi ligado ao multímetro para a aferição da tensão captada pelo termopar. Através de uma tabela de conversão tensão versus temperatura, foi possível saber o nível de temperatura existente no interior do forno. O controle da manutenção da temperatura desejada, após ela ser atingida, é realizado automaticamente pelo forno. O multímetro permite um controle mais preciso desta temperatura pela verificação instantânea da tensão.

Adotou-se como procedimento básico para as sinterizações com os dois tipos de atmosfera, primeiramente ligar o forno e deixá-lo aquecendo até a temperatura desejada, sem inserir o tubo com os compactos verde em seu interior. Atingida a temperatura de sinterização, inseriu-se o tubo de Sílica Vítrea dentro do forno, aguardou-se o tempo de nova estabilização da temperatura (entre 6 e 8 minutos para todos as tentativas) e, a partir daí, marcou-se os 30 minutos adotados como tempo de sinterização.

Ao final do tempo de sinterização, retirou-se o tubo de Sílica Vítrea do interior do forno e fez-se o resfriamento dos compactos ainda dentro deste tubo, mas fora do forno e sob a proteção da atmosfera utilizada, até que a temperatura indicada pelo multímetro atingisse um nível mais baixo (cerca de $200{ }^{\circ} \mathrm{C}$ ), quando então as peças sinterizadas foram retiradas e finalizaram o resfriamento ao ar atmosférico, sem o risco de prejuízo à peça obtida.

\subsubsection{1 - Sinterização com Argônio}

Após a colocação dos compactos verdes no interior do tubo de Sílica Vítrea, a sua extremidade aberta é fechada através de um acoplamento (uma peça semelhante a uma grande rolha) que possibilita a passagem tanto do fio do termopar, quanto da mangueira que conduz o Argônio. O gás ao sair da mangueira é conduzido através de um pequeno tubo cerâmico para dentro do tubo de Sílica Vítrea. Este gás primeiro preenche o espaço onde estão os compactos a serem sinterizados e, depois de circular no interior do tubo, sai por um pequeno orifício (com diâmetro de $2 \mathrm{~mm}$ ) existente na extremidade oposta deste mesmo tubo, de maneira que durante a operação ele permaneça 
fluindo num único sentido, minimizando a possível entrada de Oxigênio do ar ambiente.

O fornecimento do gás para o interior do tubo inicialmente foi feito com um jato mais forte (vazão de 7,5 litros/minuto) para promover a expulsão do Oxigênio existente e posteriormente, com uma vazão constante de 4 litros/minuto, manteve-se o gás circulando num fluxo único e contínuo.

Quando a temperatura de sinterização foi alcançada, inseriu-se o tubo (contendo os compactos em seu interior) até a região de aquecimento do forno (porção média do equipamento) e, após a estabilização da temperatura, aguardou-se o decorrer do tempo de sinterização (30 minutos) para a retirada do tubo. Produziu-se assim uma sinterização com um fluxo contínuo de gás inerte ao redor dos compactos, capaz de evitar a contaminação dos mesmos com o Oxigênio. Adicionalmente, para auxiliar este processo, utilizou-se um tampão com um pequeno orifício para restringir a possível entrada do Oxigênio do ar ambiente na saída do tubo maior de Alumina (ver foto do canto direito da figura 27).
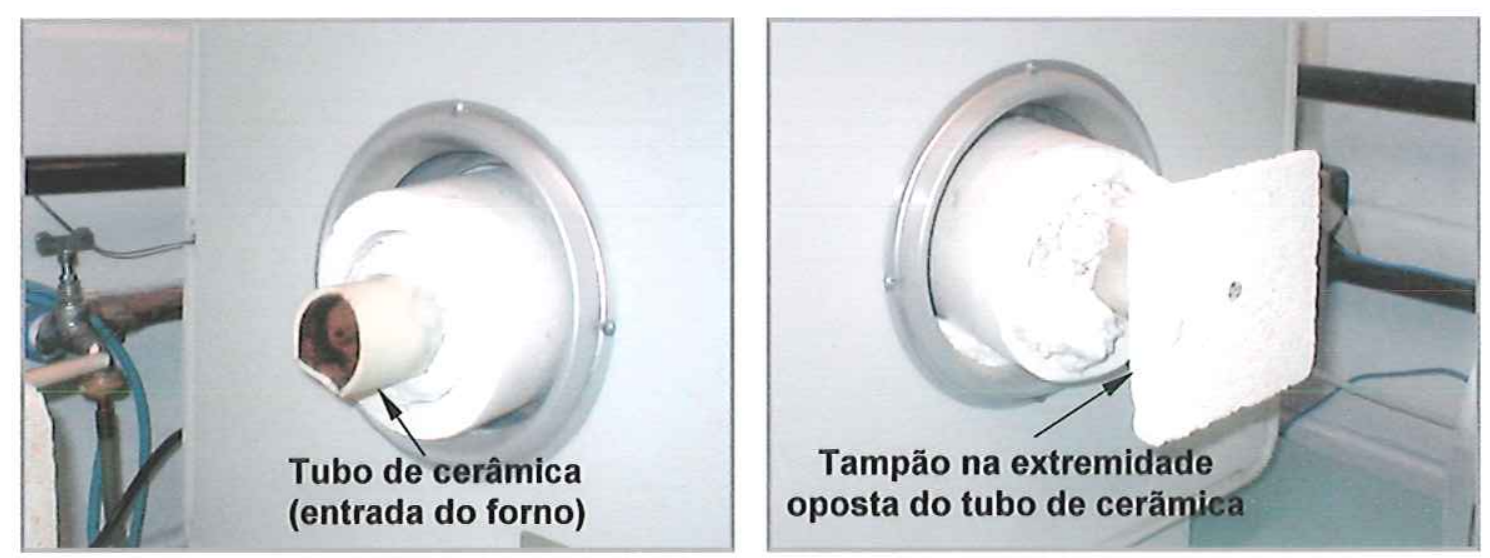

Figura 27: Entrada do forno e extremidade oposta do tubo de cerâmica com o tampão.

As figuras 28 (a) e 28 (b) apresentam uma visualização dos elementos utilizados na sinterização com Argônio. 


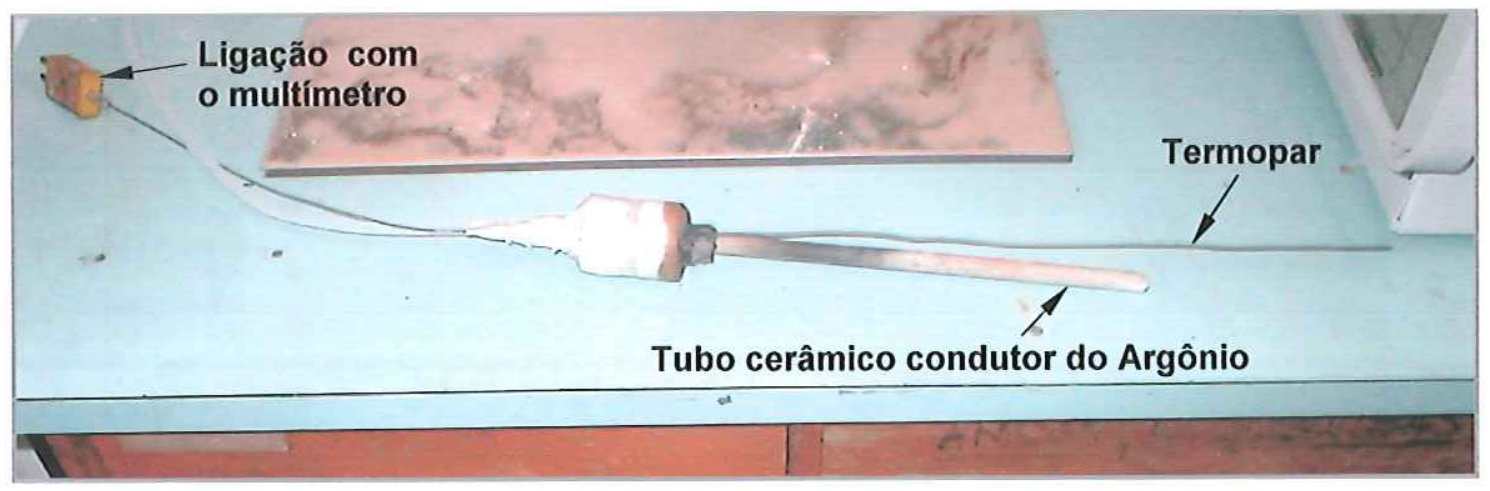

Figura 28 (a): Componentes para a sinterização utilizando Argônio.

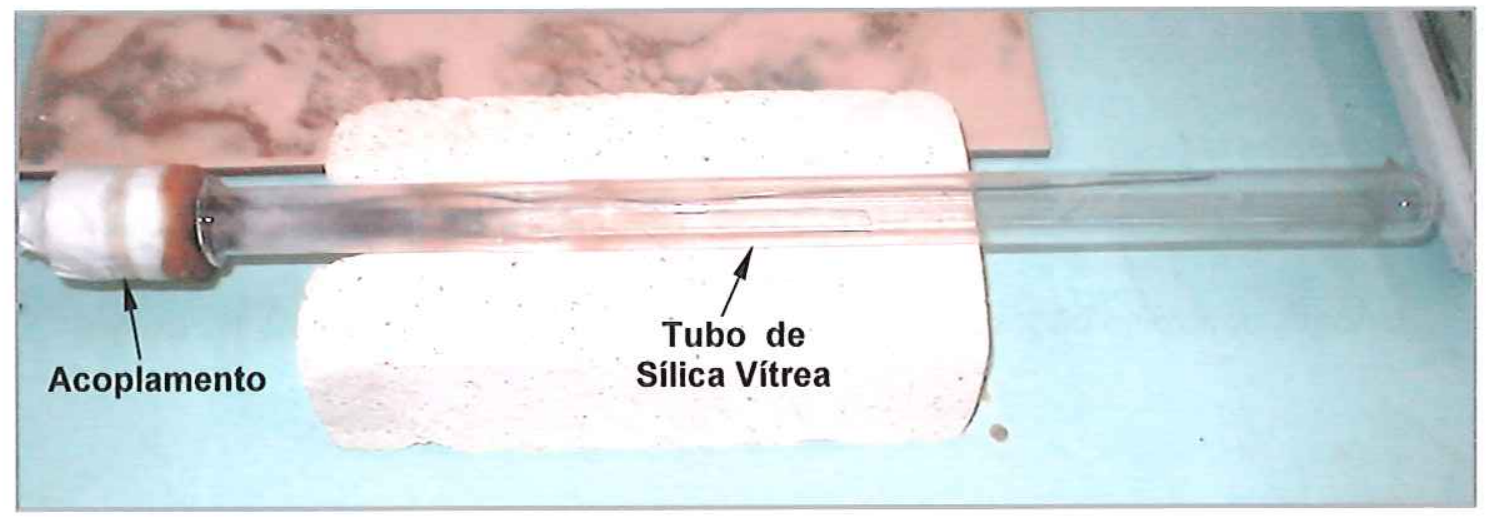

Figura 28 (b): Componentes para a sinterização utilizando Argônio.

A figura 29 mostra o tubo de Sílica Vítrea inserido no forno para o aquecimento e a ligação do termopar com o multímetro. 


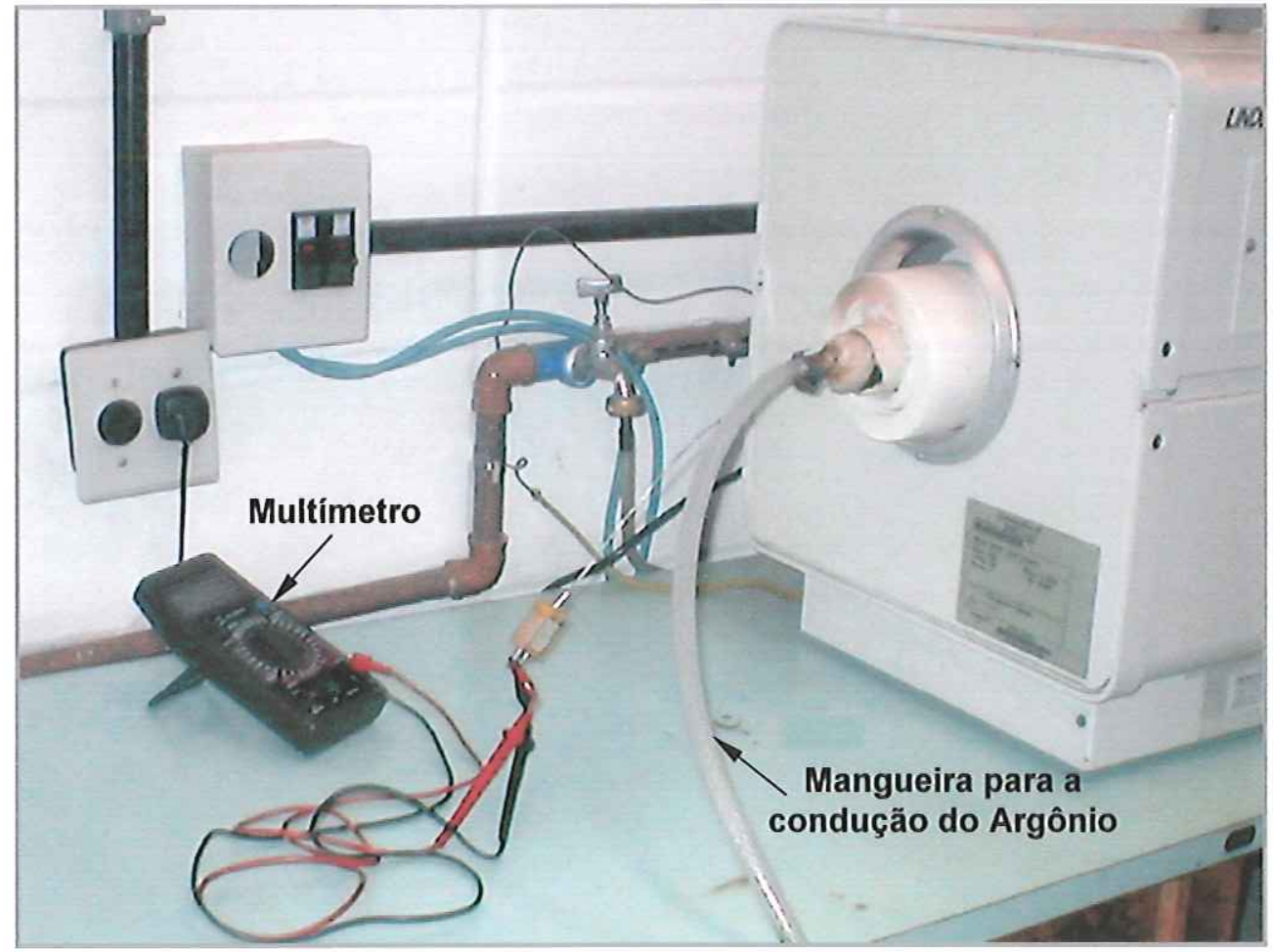

Figura 29: Disposição dos componentes para a sinterização utilizando Argônio.

\subsubsection{2 - Sinterização com Vácuo}

Para a sinterização utilizando atmosfera protetora de vácuo foi necessário o emprego de um outro tipo de acoplamento, uma peça metálica que contém apenas uma única passagem para o termopar e uma derivação lateral para a conexão com a bomba de vácuo, através de um tubo flexível. Também utilizou-se um outro tubo de Sílica Vítrea, sem orifício na extremidade oposta, ou seja, com apenas uma extremidade aberta, por onde são inseridas as peças e que se liga à bomba de vácuo pelo acoplamento. As figuras $30 \mathrm{e}$ 31 permitem uma melhor visualização dos elementos empregados. A primeira apresenta a disposição dos elementos antes da inserção do tubo de Sílica Vítrea com as peças no forno e a seguinte mostra este tubo inserido no forno durante a sinterização. 


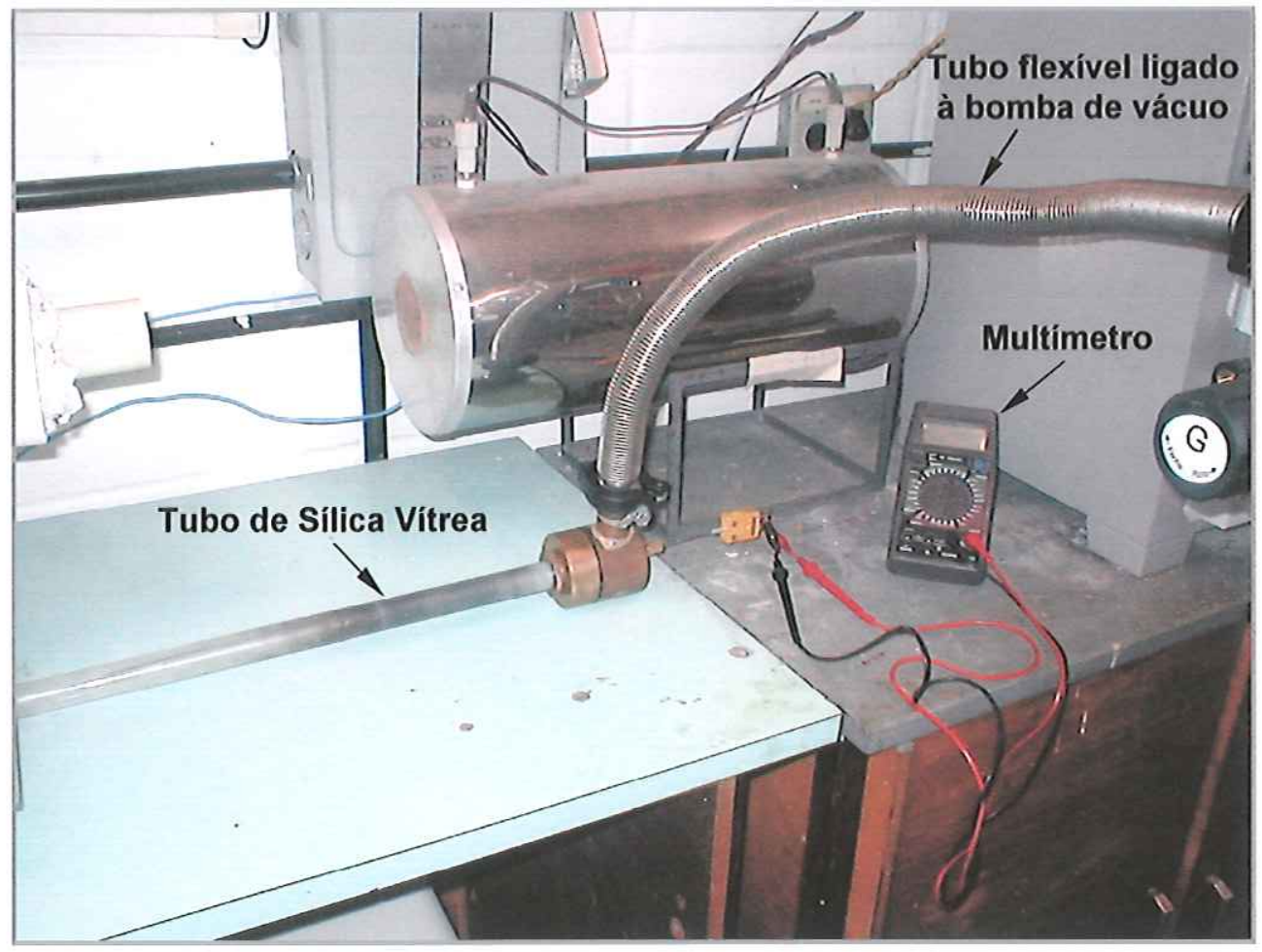

Figura 30: Componentes para a sinterização à vácuo.

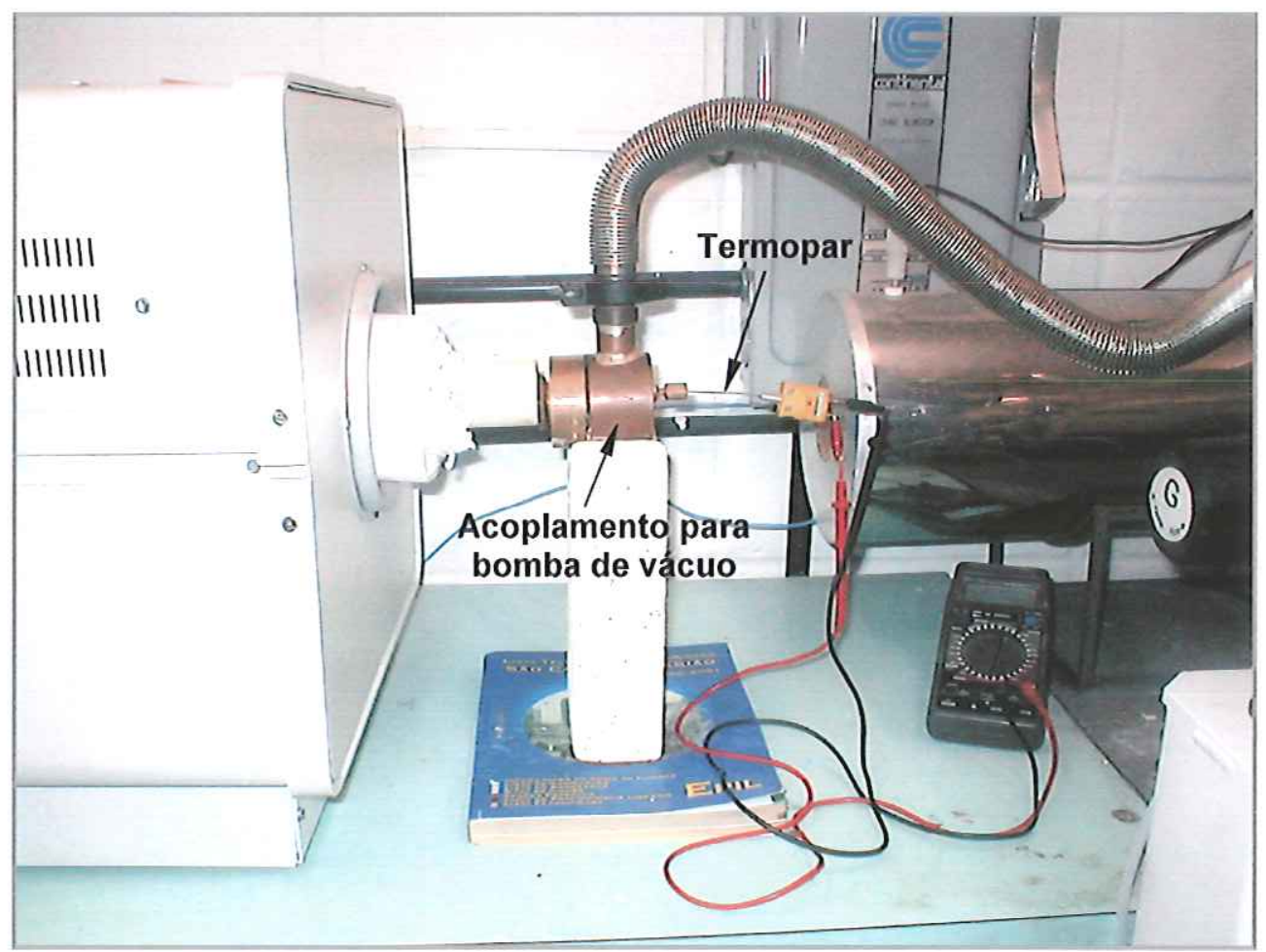

Figura 31: Disposição dos componentes na sinterização à vácuo. 
Enquanto o forno atingia a temperatura desejada, ligou-se a bomba e esperou-se até que a pressão se estabilizasse dentro do tubo. Somente após a estabilização do nível de vácuo obtido no interior do tubo de Sílica Vítrea (contendo os compactos) e do forno ter alcançado a temperatura desejada é que se inseriu o tubo no forno. Aqui o principal problema enfrentado foi o de manter a pressão estável, pois ao se manusear o tubo para inseri-lo no forno, sempre ocorreu uma variação da pressão, que novamente se estabilizou algum tempo após a inserção do tubo no forno. A pressão dentro do tubo nestas tentativas de sinterização variou entre os níveis de $1.10^{-3}$ mbar e $7.10^{-4} \mathrm{mbar}$. Tomou-se o cuidado de nunca trabalhar com um nível de vácuo no interior do tubo inferior a $1.10^{-2}$ Torr (cerca de $1,3.10^{-2} \mathrm{mbar}$ ), nível sugerido pelo Prof. Ferrante como limite mínimo aceitável de trabalho (o Prof. Titular Maurizzio Ferrante, do Departamento de Materiais da UFSCar prestou valoroso auxílio nesta etapa do trabalho).

\subsection{4 - Resultados de Dureza e Densidade Aparente da Liga} SINTERIZADA

Inicialmente utilizou-se 4 compactos produzidos a partir da mistura de $85 \%$ de Bronze e $15 \%$ de Cobalto (mistura 1 na tabela 2 ), prensadas em dois estágios. A tabela 4 apresenta um resumo das condições utilizadas. As sinterizações referentes às peças 1,2 e 3 tiveram que ser repetidas devido à dificuldade inicial de utilização da bomba de vácuo para se conseguir a estabilização da pressão dentro do tubo durante o tempo da sinterização.

Tabela 4: Condições de sinterização para as peças 1, 2, 3 e 4.

\begin{tabular}{|c|c|c|c|c|c|c|}
\hline PEÇA & MISTURA & TEMPO & TEMPERATURA & $\begin{array}{l}\text { PRESSÃO } \\
\text { INICIAL }\end{array}$ & $\begin{array}{c}\text { PRESSÄO } \\
\text { FINAL }\end{array}$ & $\begin{array}{l}\text { ATMOSFERA } \\
\text { PROTETORA }\end{array}$ \\
\hline 1 & 1 & $30 \mathrm{~min}$ & $850^{\circ} \mathrm{C}$ & $10 \mathrm{tf}$ & $10 \mathrm{tf}$ & Vácuo \\
\hline 2 & 1 & $30 \mathrm{~min}$ & $850^{\circ} \mathrm{C}$ & $10 \mathrm{tf}$ & $10 \mathrm{tf}$ & Vácuo \\
\hline 3 & 1 & $30 \mathrm{~min}$ & $850^{\circ} \mathrm{C}$ & $10 \mathrm{tf}$ & $10 \mathrm{tf}$ & Vácuo \\
\hline 4 & 1 & $30 \mathrm{~min}$ & $850^{\circ} \mathrm{C}$ & $10 \mathrm{tf}$ & $10 \mathrm{tf}$ & Argônio \\
\hline
\end{tabular}


Em termos de dureza e densidade os resultados obtidos para estas 4 amostras encontram-se na tabela 5 a seguir.

As medições de dureza para todas as amostras sinterizadas foram realizadas em um Durômetro existente no Departamento de Engenharia de Materiais, Aeronáutica e Automobilística da EESC, utilizando a escala Brinell de medida e uma condição padrão de carga de 62,5 kgf e penetrador esférico com ponta de aço de $2,5 \mathrm{~mm}$ de diâmetro.

Tabela 5: Resultados de dureza e densidade para as peças 1, 2, 3 e 4.

\begin{tabular}{|c|c|c|c|c|c|c|}
\hline PEÇA & \multicolumn{3}{|c|}{ DUREZA BRINELL } & DA $\left(\mathrm{g} / \mathrm{cm}^{3}\right)$ & \% DENS. TEÓRICA & \% POROS \\
\hline 1 & 83,0 & 83,0 & 81,3 & 7,914 & 94,5 & 5,5 \\
\hline 2 & 83,0 & 79,6 & 84,9 & 7,932 & 94,7 & 5,3 \\
\hline 3 & 88,7 & 88,7 & 83,0 & 7,972 & 95,1 & 4,9 \\
\hline 4 & 83,0 & 81,3 & 84,9 & 7,926 & 94,6 & 5,4 \\
\hline Liga comercial & 131,0 & 150,0 & 131,0 & 7,968 & 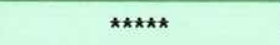 & 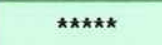 \\
\hline
\end{tabular}

Como pode-se ver na tabela 5 , a dureza obtida dos compactos após a sinterização ainda ficou longe do valor da liga comercial, apesar dos valores de densidade aparente (DA) estarem bem próximos (ou até superior, caso da peça número 3) do valor da liga do dressador comercial.

A fim de se obter melhores valores de dureza e de densidade foram sinterizadas mais 4 amostras, agora tanto da mistura número 1 quanto da mistura número 2, utilizando-se temperaturas mais elevadas. A atmosfera protetora empregada foi o Argônio. As condições utilizadas e os resultados obtidos encontram-se nas tabelas 6 e 7 a seguir. 
Tabela 6: Condições de sinterização para as peças número 5, 6, 7 e 8.

\begin{tabular}{|c|c|c|c|c|c|c|}
\hline PEÇA & MISTURA & TEMPO & TEMPERATURA & $\begin{array}{l}\text { PRESSÃo } \\
\text { INICIAL }\end{array}$ & $\begin{array}{l}\text { PRESSÃo } \\
\text { FINAL }\end{array}$ & $\begin{array}{l}\text { ATMOSFERA } \\
\text { PROTETORA }\end{array}$ \\
\hline 5 & 1 & $30 \mathrm{~min}$ & $900^{\circ} \mathrm{C}$ & $10 \mathrm{tf}$ & $10 \mathrm{tf}$ & Argônio \\
\hline 6 & 2 & $30 \mathrm{~min}$ & $900^{\circ} \mathrm{C}$ & $10 \mathrm{tf}$ & $10 \mathrm{tf}$ & Argônio \\
\hline 7 & 1 & $30 \mathrm{~min}$ & $880^{\circ} \mathrm{C}$ & $10 \mathrm{tf}$ & $10 \mathrm{tf}$ & Argônio \\
\hline 8 & 2 & $30 \mathrm{~min}$ & $880^{\circ} \mathrm{C}$ & $10 \mathrm{tf}$ & $10 \mathrm{tf}$ & Argônio \\
\hline
\end{tabular}

Tabela 7: Resultados de dureza e densidade para as peças número 5, 6, 7 e 8.

\begin{tabular}{|c|c|c|c|c|c|c|}
\hline PEÇA & \multicolumn{3}{|c|}{ DUREZA BRINELL } & $D A\left(g / \mathrm{cm}^{3}\right)$ & \% DENS. TEÓRICA & $\%$ POROS \\
\hline 5 & 64,9 & 55,8 & 54,6 & 7,446 & 88,9 & 11,1 \\
\hline 6 & 86,8 & 83,0 & 73,2 & 6,800 & 77,4 & 22,6 \\
\hline 7 & 83,0 & 84,9 & 74,7 & 7,941 & 94,8 & 5,2 \\
\hline 8 & 73,2 & 70,2 & 70,2 & 6,602 & 75,2 & 24,8 \\
\hline Liga comercial & 131,0 & 150,0 & 131,0 & 7,968 & $\star \star \star \star \star *$ & $\star \star \star \star \star *$ \\
\hline
\end{tabular}

Comparados às primeiras 4 peças, os resultados obtidos para as peças de número 5 a 8 foram inferiores tanto em nível de dureza quanto em nível de densidade. Provavelmente a temperatura utilizada foi muito alta, pois nas peças sinterizadas a partir da mistura Bronze/Cobalto notou-se a presença de algumas pequenas protuberâncias na superfície, como calombos. Este fato não foi observado nas peças sinterizadas anteriormente a $850{ }^{\circ} \mathrm{C}$. Assim, decidiuse voltar aos níveis iniciais de temperatura e verificar se a combinação de uma pequena pressão inicial com uma alta pressão final durante a prensagem em dois estágios surtiria algum efeito sobre a dureza e a densidade finais das amostras. Foram sinterizadas mais 3 amostras, cujas condições e resultados obtidos estão nas tabelas 8 e 9 . 
Tabela 8: Condições de sinterização para as peças número 9, 10 e 11.

\begin{tabular}{|c|c|c|c|c|c|c|}
\hline PEÇA & MISTURA & TEMPO & TEMPERATURA & $\begin{array}{l}\text { PRESSÃO } \\
\text { INICIAL }\end{array}$ & $\begin{array}{c}\text { PRESSÃo } \\
\text { FINAL }\end{array}$ & $\begin{array}{l}\text { ATMOSFERA } \\
\text { PROTETORA }\end{array}$ \\
\hline 9 & 1 & $30 \mathrm{~min}$ & $850^{\circ} \mathrm{C}$ & $2 \mathrm{tf}$ & $12 \mathrm{tf}$ & Argônio \\
\hline 10 & 1 & $30 \mathrm{~min}$ & $850^{\circ} \mathrm{C}$ & $2 \mathrm{tf}$ & $14 \mathrm{tf}$ & Argônio \\
\hline 11 & 1 & $30 \mathrm{~min}$ & $850^{\circ} \mathrm{C}$ & $2 \mathrm{tf}$ & $16 \mathrm{tf}$ & Argônio \\
\hline
\end{tabular}

Tabela 9: Resultados de dureza e densidade para as peças número 9, 10 e 11.

\begin{tabular}{|c|c|c|c|c|c|c|}
\hline PEÇA & \multicolumn{3}{|c|}{ DUREZA BRINELL } & $\mathrm{DA}\left(\mathrm{g} / \mathrm{cm}^{3}\right)$ & \% DENS. TEÓRICA & $\%$ POROS \\
\hline 9 & 88,7 & 94,9 & 88,7 & 8,095 & 96,6 & 3,4 \\
\hline 10 & 90,7 & 88,7 & 88,7 & 8,084 & 96,5 & 3,5 \\
\hline 11 & 88,7 & 86,8 & 84,9 & 8,163 & 97,4 & 2,6 \\
\hline Liga comercial & 131,0 & 150,0 & 131,0 & 7,968 & 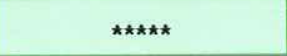 & $\star \star \star \star \star ~$ \\
\hline
\end{tabular}

Para estes resultados pode-se observar que, embora os valores obtidos de dureza ainda estejam abaixo dos correspondentes à liga comercial, houve uma melhoria geral. Os dados relativos à densidade aparente por sua vez mostraram uma pequena melhoria, superando o valor da liga comercial.

$\mathrm{Na}$ tentativa de melhorar os níveis de dureza, decidiu-se aumentar os valores das pressões utilizadas na obtenção dos compactos verdes. Assim, foram sinterizadas mais 6 amostras, combinando-se valores iguais para as pressões. As tabelas 10 e 11 apresentam as condições utilizadas e os resultados obtidos. 
Tabela 10: Condições de sinterização para as peças de número 12 a 17.

\begin{tabular}{|c|c|c|c|c|c|c|}
\hline PEÇA & MISTURA & TEMPO & TEMPERATURA & $\begin{array}{l}\text { PRESSÃO } \\
\text { INICIAL }\end{array}$ & $\begin{array}{c}\text { PRESSÃO } \\
\text { FINAL }\end{array}$ & $\begin{array}{l}\text { ATMOSFERA } \\
\text { PROTETORA }\end{array}$ \\
\hline 12 & 1 & $30 \mathrm{~min}$ & $850^{\circ} \mathrm{C}$ & $12 \mathrm{tf}$ & $12 \mathrm{tf}$ & Argônio \\
\hline 13 & 1 & $30 \mathrm{~min}$ & $850^{\circ} \mathrm{C}$ & $14 \mathrm{tf}$ & $14 \mathrm{tf}$ & Argônio \\
\hline 14 & 2 & $30 \mathrm{~min}$ & $850^{\circ} \mathrm{C}$ & $16 \mathrm{tf}$ & $16 \mathrm{tf}$ & Vácuo \\
\hline 15 & 1 & $30 \mathrm{~min}$ & $850^{\circ} \mathrm{C}$ & $16 \mathrm{tf}$ & $16 \mathrm{tf}$ & Vácuo \\
\hline 16 & 2 & $30 \mathrm{~min}$ & $850^{\circ} \mathrm{C}$ & $16 \mathrm{tf}$ & $16 \mathrm{tf}$ & Argônio \\
\hline 17 & 1 & $30 \mathrm{~min}$ & $850^{\circ} \mathrm{C}$ & $16 \mathrm{tf}$ & $16 \mathrm{tf}$ & Argônio \\
\hline
\end{tabular}

Tabela 11: Resultados de dureza e densidade para as peças de número 12 a 17.

\begin{tabular}{|c|c|c|c|c|c|c|}
\hline Peça & \multicolumn{3}{|c|}{ DUREZA BRINELL } & DA $\left(\mathrm{g} / \mathrm{cm}^{3}\right)$ & \% DENS. TEÓRICA & $\%$ POROS \\
\hline 12 & 92,8 & 90,7 & 92,8 & 8,081 & 96,4 & 3,6 \\
\hline 13 & 94,9 & 97,2 & 97,2 & 8,196 & 97,8 & 2,2 \\
\hline 14 & 54,6 & 48,4 & 49,2 & 6,196 & 70,5 & 29,5 \\
\hline 15 & 83,0 & 83,0 & 83,0 & 8,000 & 95,5 & 4,5 \\
\hline 16 & 57,9 & 55,8 & 55,8 & 6,558 & 74,7 & 25,3 \\
\hline 17 & 97,2 & 99,5 & 104,0 & 8,271 & 98,7 & 1,3 \\
\hline Liga comercial & 131,0 & 150,0 & 131,0 & 7,968 & 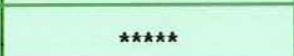 & 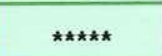 \\
\hline
\end{tabular}

Pode-se ver pelos valores que, de maneira geral, os melhores resultados foram obtidos para os compactos produzidos a partir da mistura $\mathrm{n}^{\circ} 1$ ( $85 \%$ de Bronze $+15 \%$ de Cobalto). A mistura a partir de pós elementares (mistura $\mathrm{n}^{\circ} 2$ na tabela 2) não produziu bons resultados nem mesmo após 0 aumento da pressão durante a prensagem.

Nota-se também que os maiores valores de pressão utilizados na prensagem foram progressivamente melhorando os resultados tanto de dureza quanto de densidade finais das amostras sinterizadas a partir da mistura Bronze/Cobalto, chegando-se até mesmo a níveis de densidade superiores aos da liga comercial. Em termos de dureza não foi possível igualar os valores obtidos aos do dressador comercial, provavelmente devido à diferença dos métodos de produção empregados. Neste aspecto é difícil estabelecer alguma 
comparação entre as ligas sinterizadas obtidas e a liga comercial, pois este assunto é tratado como segredo pela indústria.

Através da comparação da aparência das peças após o resfriamento pode-se dizer que, de uma maneira geral, a atmosfera à vácuo proporciona realmente uma maior proteção contra a contaminação por Oxigênio, pois enquanto as peças permaneciam dentro do tubo pressurizado, a aparência das superfícies das mesmas era praticamente igual à do compacto verde.

Por outro lado, a atmosfera de Argônio permitiu uma proteção aceitável das amostras, cujas superfícies aparentavam um leve escurecimento, indicando uma oxidação apenas superficial dos compactos. Assim, decidiu-se passar a utilizar apenas Argônio nas sinterizações, por ser de aplicação bem mais simples do que o emprego da bomba de vácuo, cuja aplicação sempre demandou um tempo relativamente longo (cerca de 2 horas) para a estabilização da pressão dentro do tubo de Sílica Vítrea.

Seguindo uma sugestão do Eng ${ }^{\circ}$. Luís Carlos Caetano (representante da empresa De Beers do Brasil, que doou os diamantes para o dressador), que recomendou a adição de Carbeto de Tungstênio (WC) à mistura de Bronze e Cobalto, realizou-se ainda mais algumas sinterizações com uma nova composição para a mistura dos pós metálicos. Preparou-se duas misturas básicas de pós metálicos (misturas 3 e 4, segundo a tabela 2) a partir das quais sinterizou-se mais 8 amostras de peças para avaliação da dureza e da densidade obtida. As tabelas 12 e 13 apresentam as condições empregadas e os resultados obtidos. 
Tabela 12: Condições de sinterização para as peças de número 18 a 25.

\begin{tabular}{|c|c|c|c|c|c|c|}
\hline PEÇA & MISTURA & TEMPO & TEMPERATURA & $\begin{array}{l}\text { PRESSÃo } \\
\text { INICIAL }\end{array}$ & $\begin{array}{c}\text { PRESSÃo } \\
\text { FINAL }\end{array}$ & $\begin{array}{l}\text { ATMOSFERA } \\
\text { PROTETORA }\end{array}$ \\
\hline 18 & 3 & $30 \mathrm{~min}$ & $850^{\circ} \mathrm{C}$ & $12 \mathrm{tf}$ & $12 \mathrm{tf}$ & Argônio \\
\hline 19 & 3 & $30 \mathrm{~min}$ & $850^{\circ} \mathrm{C}$ & $14 \mathrm{tf}$ & 14 if & Argônio \\
\hline 20 & 3 & $30 \mathrm{~min}$ & $850^{\circ} \mathrm{C}$ & $16 \mathrm{tf}$ & $16 \mathrm{tf}$ & Argônio \\
\hline 21 & 3 & $30 \mathrm{~min}$ & $850^{\circ} \mathrm{C}$ & $16 \mathrm{tf}$ & $16 \mathrm{tf}$ & Argônio \\
\hline 22 & 4 & $30 \mathrm{~min}$ & $850^{\circ} \mathrm{C}$ & $16 \mathrm{tf}$ & 16 tf & Argônio \\
\hline 23 & 4 & $30 \mathrm{~min}$ & $850^{\circ} \mathrm{C}$ & $16 \mathrm{tf}$ & $16 \mathrm{tf}$ & Argônio \\
\hline 24 & 4 & $30 \mathrm{~min}$ & $850^{\circ} \mathrm{C}$ & $16 \mathrm{tf}$ & $16 \mathrm{tf}$ & Argônio \\
\hline 25 & 4 & $30 \mathrm{~min}$ & $850^{\circ} \mathrm{C}$ & $16 \mathrm{tf}$ & $16 \mathrm{tf}$ & Argônio \\
\hline
\end{tabular}

Tabela 13: Resultados de dureza e densidade para as peças de número 18 a 25.

\begin{tabular}{|c|c|c|c|c|c|c|}
\hline PEÇA & \multicolumn{3}{|c|}{ DUREZA BRINELL } & $\mathrm{DA}\left(\mathrm{g} / \mathrm{cm}^{3}\right)$ & \% DENS. TEÓRICA & $\%$ POROS \\
\hline 18 & 66.2 & 67.5 & 67.5 & 7.733 & 84.4 & 15,6 \\
\hline 19 & 67.5 & 67.5 & 70.2 & 7.763 & 84.7 & 15,3 \\
\hline 20 & 67.5 & 68.8 & 63.6 & 7.709 & 84.1 & 15,9 \\
\hline 21 & 55.8 & 51.0 & 54.6 & 7.454 & 81.3 & 19,7 \\
\hline 22 & 66.2 & 67.5 & 67.5 & 7.719 & 86.1 & 13,9 \\
\hline 23 & 68.8 & 63.6 & 67.5 & 7.737 & 86.3 & 13,7 \\
\hline 24 & 57.9 & 62.4 & 58.9 & 7.509 & 83.7 & 16,3 \\
\hline 25 & 62.4 & 66.2 & 66.2 & 7.619 & 84.9 & 15,1 \\
\hline Liga comercial & 131,0 & 150,0 & 131,0 & 7,968 & 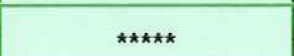 & $\star \star \star \star \star * *$ \\
\hline
\end{tabular}

Pode-se perceber por estes últimos resultados que tanto o nível de dureza da liga sinterizada quanto o de densidade foram insatisfatórios, ficando todos abaixo dos níveis obtidos para as peças resultantes das misturas números 1 e 2 . Sendo assim, após uma comparação de todos os resultados obtidos para estas 25 novas tentativas de sinterização, concluiu-se que a melhor combinação de resultados foi a obtida para a peça número 17 (conforme tabelas 11 e 12), obtida a partir da mistura número 2 (85\% de Bronze $+15 \%$ de Cobalto), empregando atmosfera protetora de Argônio, 
temperatura do forno de $850^{\circ} \mathrm{C}$ para um tempo de sinterização de 30 minutos. Portanto, decidiu-se adotar estas condições de sinterização para a produção da liga do protótipo de dressador que foi empregado nos ensaios experimentais.

As tabelas 14 e 15 apresentam respectivamente um resumo geral das condições de sinterização e dos resultados de dureza e densidade aparente para todas as tentativas de obtenção da liga sinterizada, destacando a liga escolhida (a de número 17).

Tabela 14: Resumo das condições de sinterização empregadas para todas as peças.

\begin{tabular}{|c|c|c|c|c|c|c|}
\hline PEÇA & MISTURA & TEMPO & TEMPERATURA & $\begin{array}{l}\text { PRESSĀO } \\
\text { INICIAL }\end{array}$ & $\begin{array}{l}\text { PRESSÃO } \\
\text { FINAL }\end{array}$ & $\begin{array}{l}\text { ATMOSFERA } \\
\text { PROTETORA }\end{array}$ \\
\hline 1 & 1 & $30 \mathrm{~min}$ & $850^{\circ} \mathrm{C}$ & $10 \mathrm{tf}$ & $10 \mathrm{tf}$ & Vácuo \\
\hline 2 & 1 & $30 \mathrm{~min}$ & $850^{\circ} \mathrm{C}$ & $10 \mathrm{tf}$ & $10 \mathrm{tf}$ & Vácuo \\
\hline 3 & 1 & $30 \mathrm{~min}$ & $850^{\circ} \mathrm{C}$ & $10 \mathrm{tf}$ & $10 \mathrm{tf}$ & Vácuo \\
\hline 4 & 1 & $30 \mathrm{~min}$ & $850^{\circ} \mathrm{C}$ & $10 \mathrm{tf}$ & $10 \mathrm{tf}$ & Argônio \\
\hline 5 & 1 & $30 \mathrm{~min}$ & $900^{\circ} \mathrm{C}$ & $10 \mathrm{tf}$ & $10 \mathrm{tf}$ & Argônio \\
\hline 6 & 2 & $30 \mathrm{~min}$ & $900^{\circ} \mathrm{C}$ & $10 \mathrm{tf}$ & $10 \mathrm{tf}$ & Argônio \\
\hline 7 & 1 & $30 \mathrm{~min}$ & $880^{\circ} \mathrm{C}$ & $10 \mathrm{tf}$ & $10 \mathrm{tf}$ & Argônio \\
\hline 8 & 2 & $30 \mathrm{~min}$ & $880^{\circ} \mathrm{C}$ & $10 \mathrm{tf}$ & $10 \mathrm{tf}$ & Argônio \\
\hline 9 & 1 & $30 \mathrm{~min}$ & $850^{\circ} \mathrm{C}$ & $2 \mathrm{tf}$ & $12 \mathrm{tf}$ & Argônio \\
\hline 10 & 1 & $30 \mathrm{~min}$ & $850^{\circ} \mathrm{C}$ & $2 \mathrm{tf}$ & $14 \mathrm{tf}$ & Argônio \\
\hline 11 & 1 & $30 \mathrm{~min}$ & $850^{\circ} \mathrm{C}$ & $2 \mathrm{tf}$ & $16 \mathrm{tf}$ & Argônio \\
\hline 12 & 1 & $30 \mathrm{~min}$ & $850^{\circ} \mathrm{C}$ & $12 \mathrm{tf}$ & $12 \mathrm{tf}$ & Argônio \\
\hline 13 & 1 & $30 \mathrm{~min}$ & $850^{\circ} \mathrm{C}$ & $14 \mathrm{tf}$ & $14 \mathrm{tf}$ & Argônio \\
\hline 14 & 2 & $30 \mathrm{~min}$ & $850^{\circ} \mathrm{C}$ & $16 \mathrm{tf}$ & $16 \mathrm{tf}$ & Vácuo \\
\hline 15 & 1 & $30 \mathrm{~min}$ & $850^{\circ} \mathrm{C}$ & $16 \mathrm{tf}$ & $16 \mathrm{tf}$ & Vácuo \\
\hline 16 & 2 & $30 \mathrm{~min}$ & $850^{\circ} \mathrm{C}$ & $16 \mathrm{tf}$ & $16 \mathrm{tf}$ & Argônio \\
\hline 17 & 1 & $30 \mathrm{~min}$ & $850^{\circ} \mathrm{C}$ & $16 \mathrm{tf}$ & $16 \mathrm{tf}$ & Argônio \\
\hline 18 & 3 & $30 \mathrm{~min}$ & $850^{\circ} \mathrm{C}$ & $12 \mathrm{tf}$ & $12 \mathrm{tf}$ & Argônio \\
\hline 19 & 3 & $30 \mathrm{~min}$ & $850^{\circ} \mathrm{C}$ & $14 \mathrm{tf}$ & $14 \mathrm{tf}$ & Argônio \\
\hline 20 & 3 & $30 \mathrm{~min}$ & $850^{\circ} \mathrm{C}$ & $16 \mathrm{tf}$ & $16 \mathrm{tf}$ & Argônio \\
\hline 21 & 3 & $30 \mathrm{~min}$ & $850^{\circ} \mathrm{C}$ & $16 \mathrm{tf}$ & $16 \mathrm{tf}$ & Argônio \\
\hline 22 & 4 & $30 \mathrm{~min}$ & $850^{\circ} \mathrm{C}$ & $16 \mathrm{tf}$ & $16 \mathrm{tf}$ & Argônio \\
\hline 23 & 4 & $30 \mathrm{~min}$ & $850^{\circ} \mathrm{C}$ & $16 \mathrm{tf}$ & $16 \mathrm{tf}$ & Argônio \\
\hline 24 & 4 & $30 \mathrm{~min}$ & $850^{\circ} \mathrm{C}$ & $16 \mathrm{tf}$ & $16 \mathrm{tf}$ & Argônio \\
\hline 25 & 4 & $30 \mathrm{~min}$ & $850^{\circ} \mathrm{C}$ & $16 \mathrm{tf}$ & $16 \mathrm{tf}$ & Argônio \\
\hline
\end{tabular}


Tabela 15: Resumo dos resultados de dureza e densidade para todas as peças.

\begin{tabular}{|c|c|c|c|c|c|c|}
\hline \multirow{2}{*}{$\begin{array}{c}\text { PEÇA } \\
1 \\
\end{array}$} & \multicolumn{3}{|c|}{ DUREZA BRINELL } & \multirow{2}{*}{$\begin{array}{c}\mathrm{DA}\left(\mathrm{g} / \mathrm{cm}^{3}\right) \\
7,914\end{array}$} & \multirow{2}{*}{\begin{tabular}{|c|} 
\% DENS. TEÓRICA \\
94,5 \\
\end{tabular}} & \multirow{2}{*}{$\begin{array}{c}\% \text { POROS } \\
5,5\end{array}$} \\
\hline & 83,0 & 83,0 & 81,3 & & & \\
\hline 2 & 83,0 & 79,6 & 84,9 & 7,932 & 94,7 & 5,3 \\
\hline 3 & 88,7 & 88,7 & 83,0 & 7,972 & 95,1 & 4,9 \\
\hline 4 & 83,0 & 81,3 & 84,9 & 7,926 & 94,6 & 5,4 \\
\hline 5 & 64,9 & 55,8 & 54,6 & 7,446 & 88,9 & 11,1 \\
\hline 6 & 86,8 & 83,0 & 73,2 & 6,800 & 77,4 & 22,6 \\
\hline 7 & 83,0 & 84,9 & 74,7 & 7,941 & 94,8 & 5,2 \\
\hline 8 & 73,2 & 70,2 & 70,2 & 6,602 & 75,2 & 24,8 \\
\hline 9 & 88,7 & 94,9 & 88,7 & 8,095 & 96,6 & 3,4 \\
\hline 10 & 90,7 & 88,7 & 88,7 & 8,084 & 96,5 & 3,5 \\
\hline 11 & 88,7 & 86,8 & 84,9 & 8,163 & 97,4 & 2,6 \\
\hline 12 & 92,8 & 90,7 & 92,8 & 8,081 & 96,4 & 3,6 \\
\hline 13 & 94,9 & 97,2 & 97,2 & 8,196 & 97,8 & 2,2 \\
\hline 14 & 54,6 & 48,4 & 49,2 & 6,196 & 70,5 & 29,5 \\
\hline 15 & 83,0 & 83,0 & 83,0 & 8,000 & 95,5 & 4,5 \\
\hline 16 & 57,9 & 55,8 & 55,8 & 6,558 & 74,7 & 25,3 \\
\hline 17 & 97,2 & 99,5 & 104,0 & 8,271 & 98,7 & 1,3 \\
\hline 18 & 66.2 & 67.5 & 67.5 & 7.733 & 84.4 & 15,6 \\
\hline 19 & 67.5 & 67.5 & 70.2 & 7.763 & 84.7 & 15,3 \\
\hline 20 & 67.5 & 68.8 & 63.6 & 7.709 & 84.1 & 15,9 \\
\hline 21 & 55.8 & 51.0 & 54.6 & 7.454 & 81.3 & 19,7 \\
\hline 22 & 66.2 & 67.5 & 67.5 & 7.719 & 86.1 & 13,9 \\
\hline 23 & 68.8 & 63.6 & 67.5 & 7.737 & 86.3 & 13,7 \\
\hline 24 & 57.9 & 62.4 & 58.9 & 7.509 & 83.7 & 16,3 \\
\hline 25 & 62.4 & 66.2 & 66.2 & 7.619 & 84.9 & 15,1 \\
\hline Liga comercial & 131,0 & 150,0 & 131,0 & 7,968 & 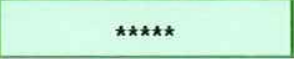 & $\star \star \star \star \star$ \\
\hline
\end{tabular}

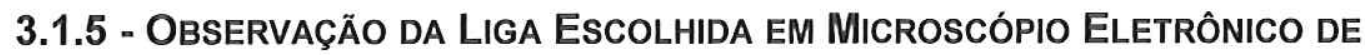
VARREDURA

Após a definição da mistura e das condições de sinterização da liga a ser empregada no protótipo de dressador, foram realizadas algumas observações em Microscópio Eletrônico de Varredura (M.E.V.), utilizando-se 
um microscópio de alta resolução da marca PHILIPS, modelo FEG XL 30, do Departamento de Materiais (DEMa) da UFSCar.

Todas as imagens foram geradas utilizando-se feixe de elétrons retroespalhados, para visualizar o contraste das fases na liga. Entretanto, essa visualização não resultou muito boa porque os pesos atômicos dos elementos predominantes na mistura (casos do Cobre e do Cobalto) possuem valores próximos (58,9 para o Cobre e 63,5 para o Cobalto segundo a Tabela Periódica). As figuras 32,33 e 34 apresentam as imagens obtidas em três condições de ampliação. A matriz de Bronze constitui a fase contínua da liga sinterizada. Na figura 34 os componentes da liga são identificados para facilitar a visualização. Nesta figura, a região com coloração mais clara corresponde ao Bronze. O Cobalto está representado por regiões levemente mais escuras do que o Bronze, enquanto que os poros são identificados por regiões totalmente escurecidas.

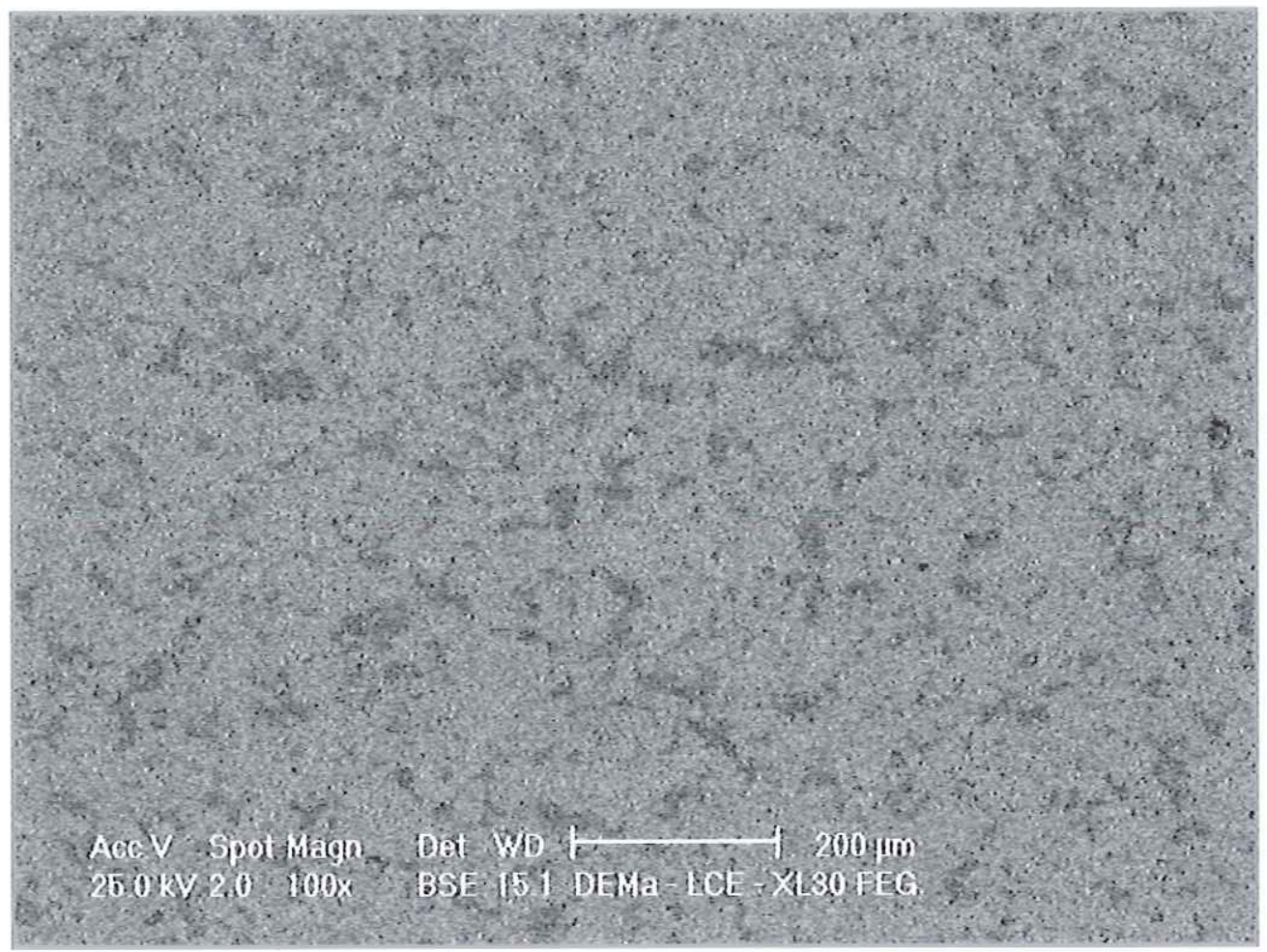

Figura 32: Superfície da amostra observada (100x). 


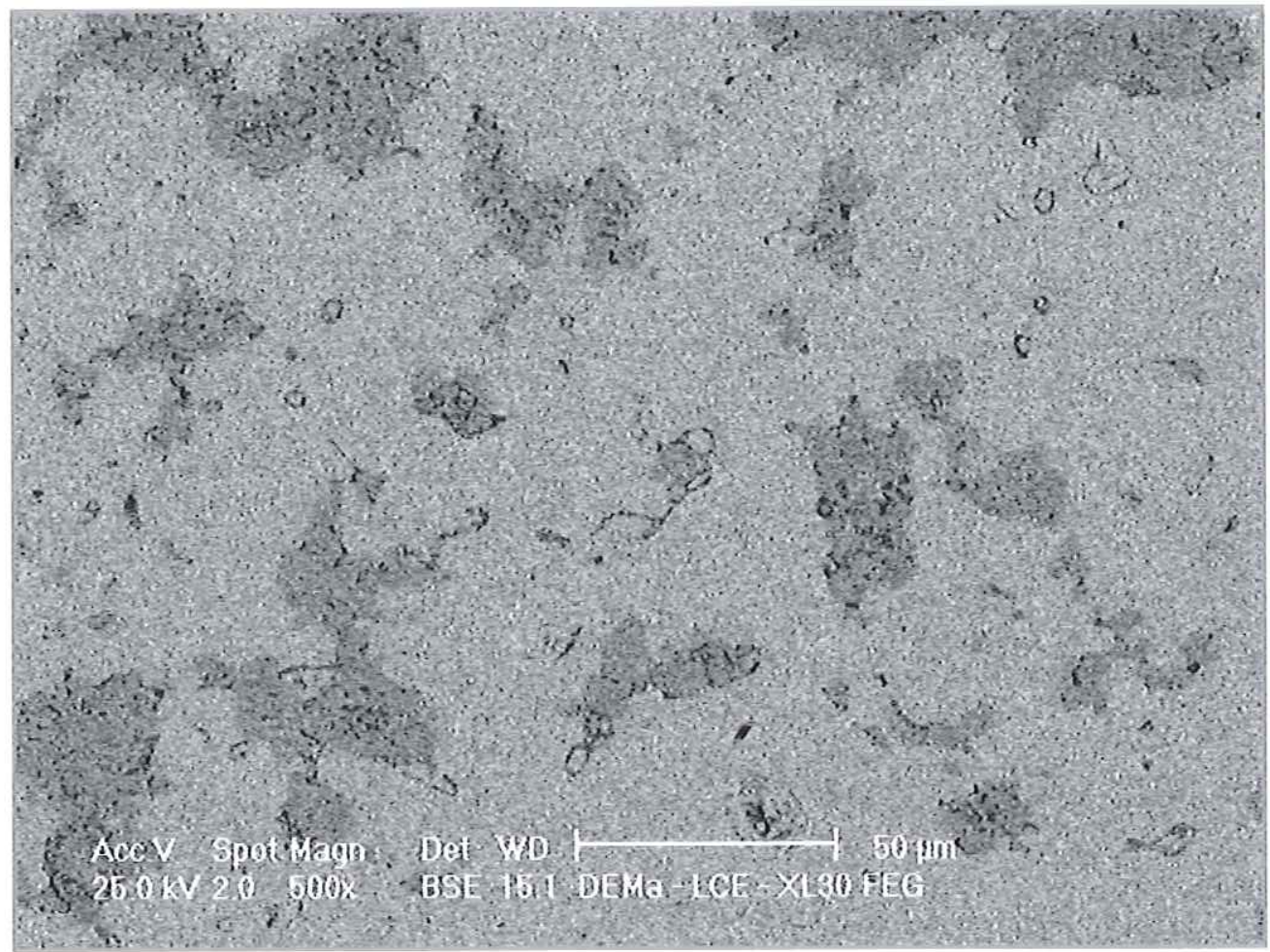

Figura 33: Superfície da amostra observada (500x).

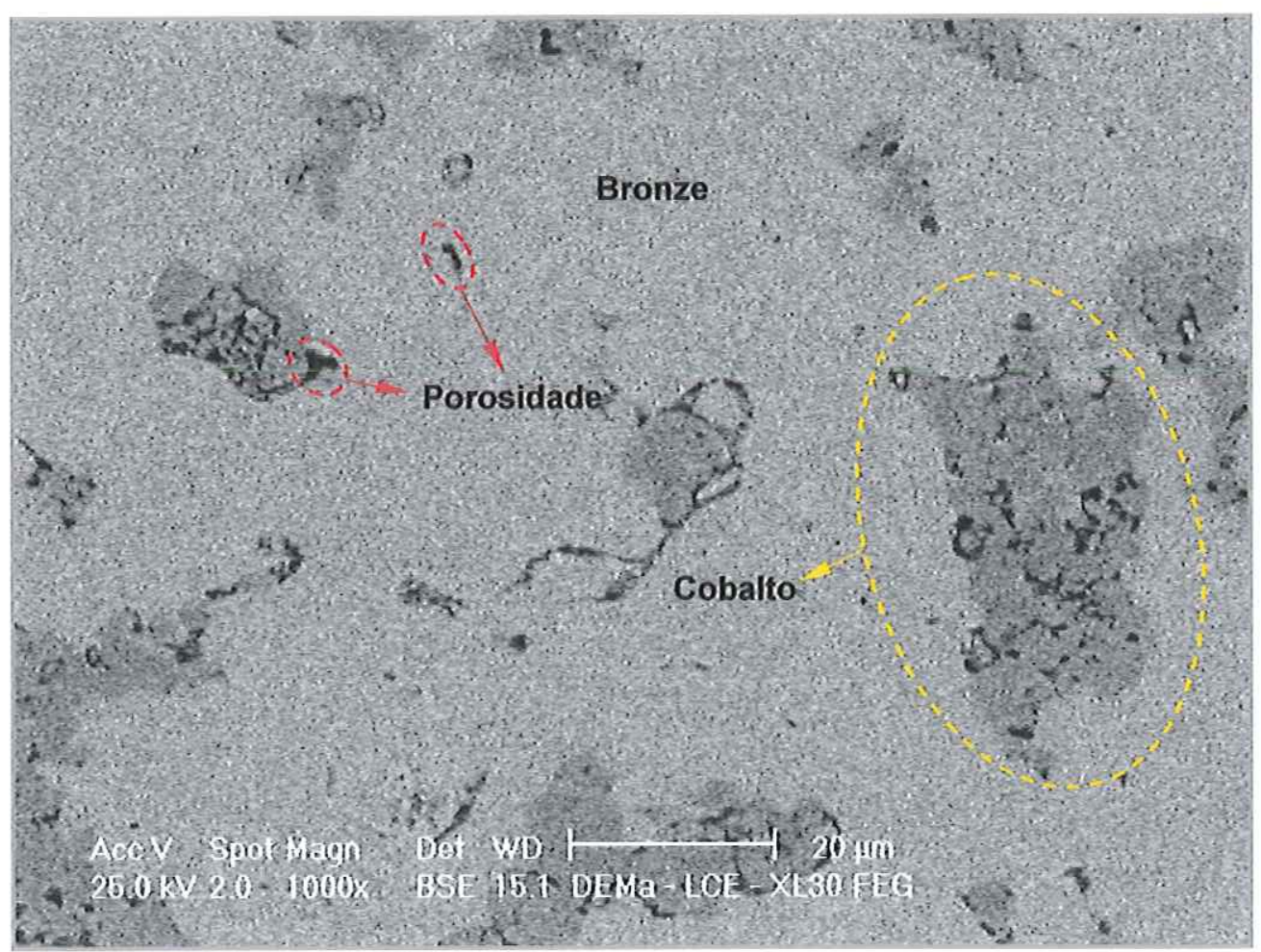

Figura 34: Superfície da amostra observada (1000x). 
As imagens mostraram que a liga obtida apresentou uma distribuição de fases bem homogênea, com boa distribuição e praticamente sem porosidades, o que certamente contribuirá para uma melhor dissipação do calor gerado na operação de dressagem.

\section{2 - O Dressador Obtido}

A partir das condições definidas para a obtenção da liga sinterizada do dressador, produziu-se o compacto final contendo em seu interior 4 barras de diamante sintético do tipo CVD (denominado CVDress ${ }^{\circledR}$ ), doados pela empresa De Beers (Debid do Brasil), por intermédio do Sr. Caetano. Segundo as considerações dele, o diamante sintético começa a grafitizar quando em presença de Oxigênio, ao redor de $750{ }^{\circ} \mathrm{C}$ a $800{ }^{\circ} \mathrm{C}$. Essa grafitização é primeiramente superficial e em casos extremos, interna ao cristal.

O diamante sintético é um cristal que contém impurezas internas (restos de catalisadores) que acabam por reduzir a resistência térmica do cristal. Quanto menor for o nível de impurezas, maior será a sua estabilidade térmica. No caso do diamante CVD, o produto está livre dessas impurezas e é formado unicamente por cristais de diamante. Portanto a sua estabilidade térmica é maior. Por isso, o diamante CVD começa a se danificar a $800{ }^{\circ} \mathrm{C}$, mas muito pouco dano ocorre até $950-1000^{\circ} \mathrm{C}$ em atmosfera oxidante.

A figura 35 apresenta a matriz posicionada sob a prensa hidráulica utilizada para a prensagem da mistura de pós metálicos e a figura 36 mostra uma representação esquemática da colagem das barras de diamante na primeira metade prensada da mistura dos pós. As dimensões das barras de diamante são: 5 × 1,2 x 1,2 mm, ou seja, possuem secção quadrada (ou perfil constante). 

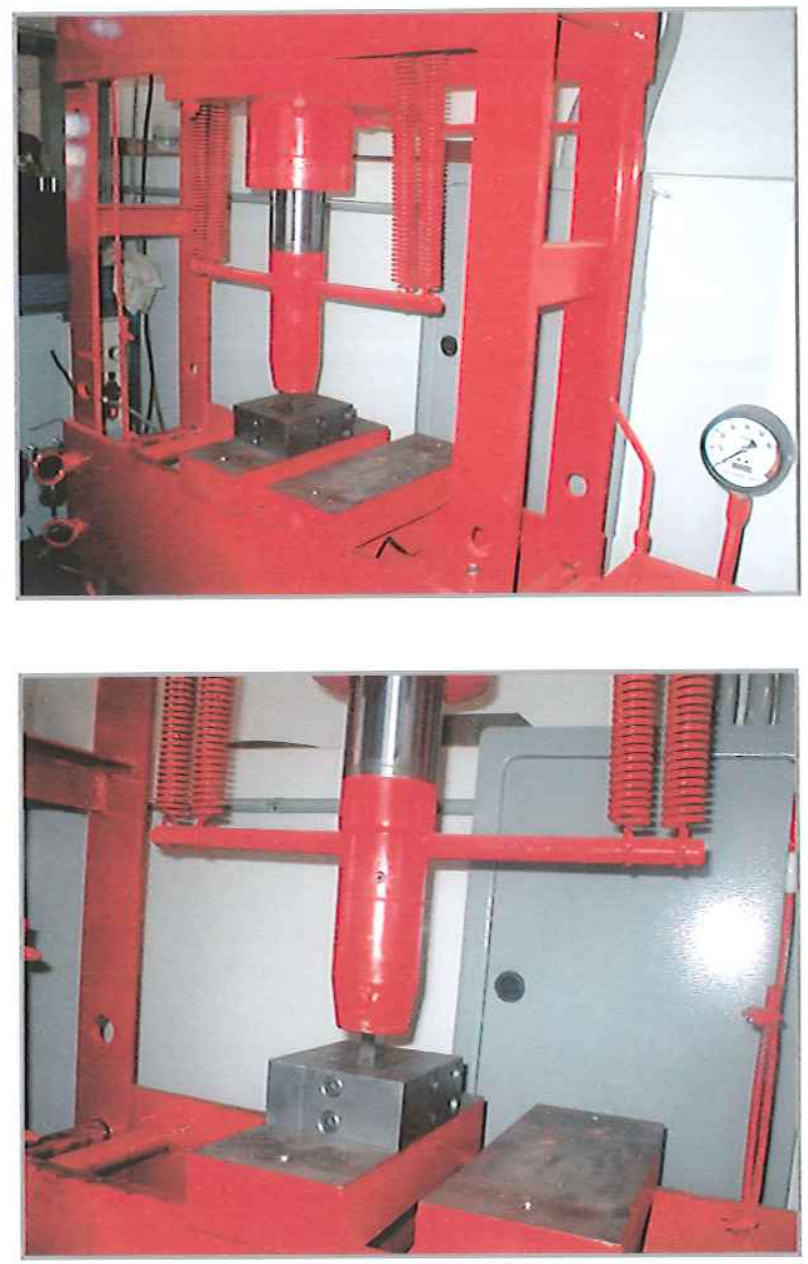

Figura 35: Posicionamento da matriz para a prensagem manual.

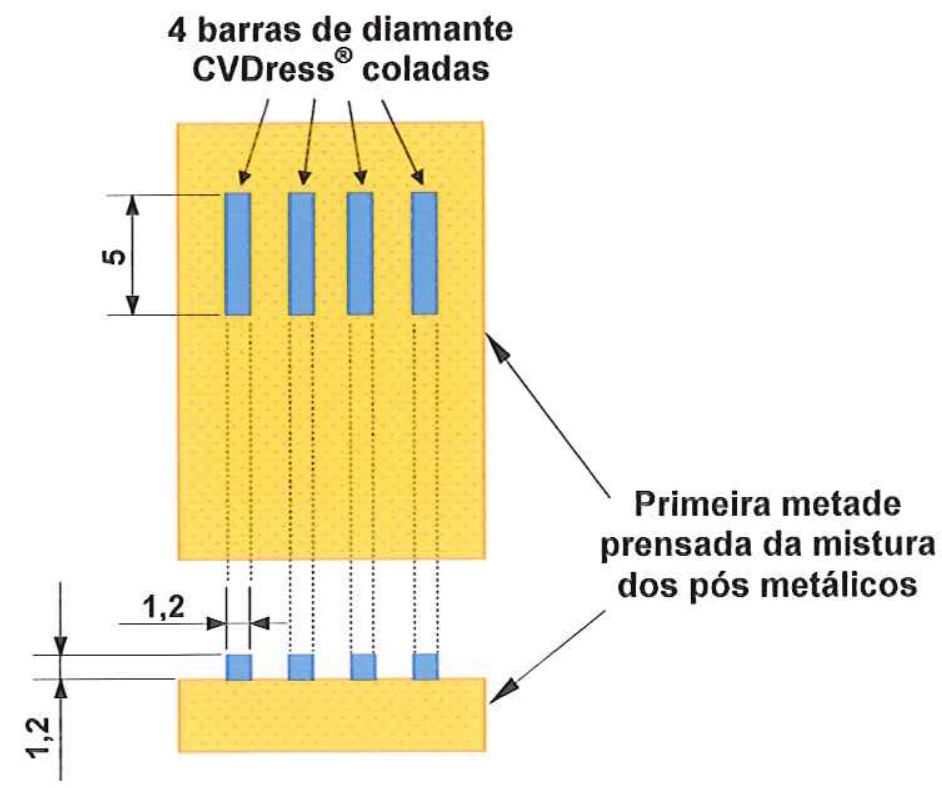

Figura 36: Primeira metade da mistura prensada com as 4 barras de diamante CVDress ${ }^{\circledR}$ coladas (antes da sinterização). 
Após a obtenção da peça sinterizada contendo as barras de diamante, a mesma foi brasada com solda Prata à peça aletada de Latão, que previamente havia sido soldada a um suporte para ser fixado na retificadora.

Durante esta brasagem tomou-se a precaução de realizar um aquecimento lento e gradual apenas da porção inferior do corpo da ferramenta, ou seja, direcionou-se a chama ao lado oposto ao dos diamantes, de maneira a preservá-los de um nível excessivo de aquecimento que poderia ser prejudicial às suas propriedades.

Na figura 37 vê-se, em duas vistas, o protótipo de dressador produzido, denominado a partir deste ponto simplesmente de dressador aletado.
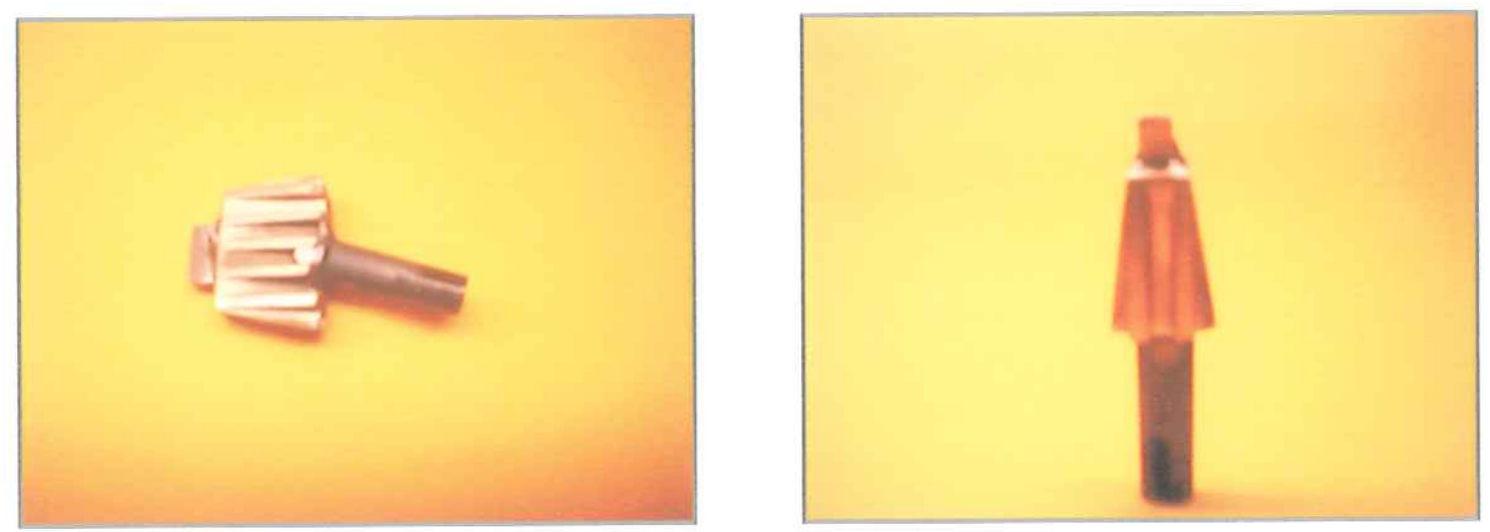

Figura 37: O protótipo de dressador obtido (dressador aletado).

As figuras 38 e 39 a seguir mostram a posição do dressador aletado após a sua fixação na retificadora. 


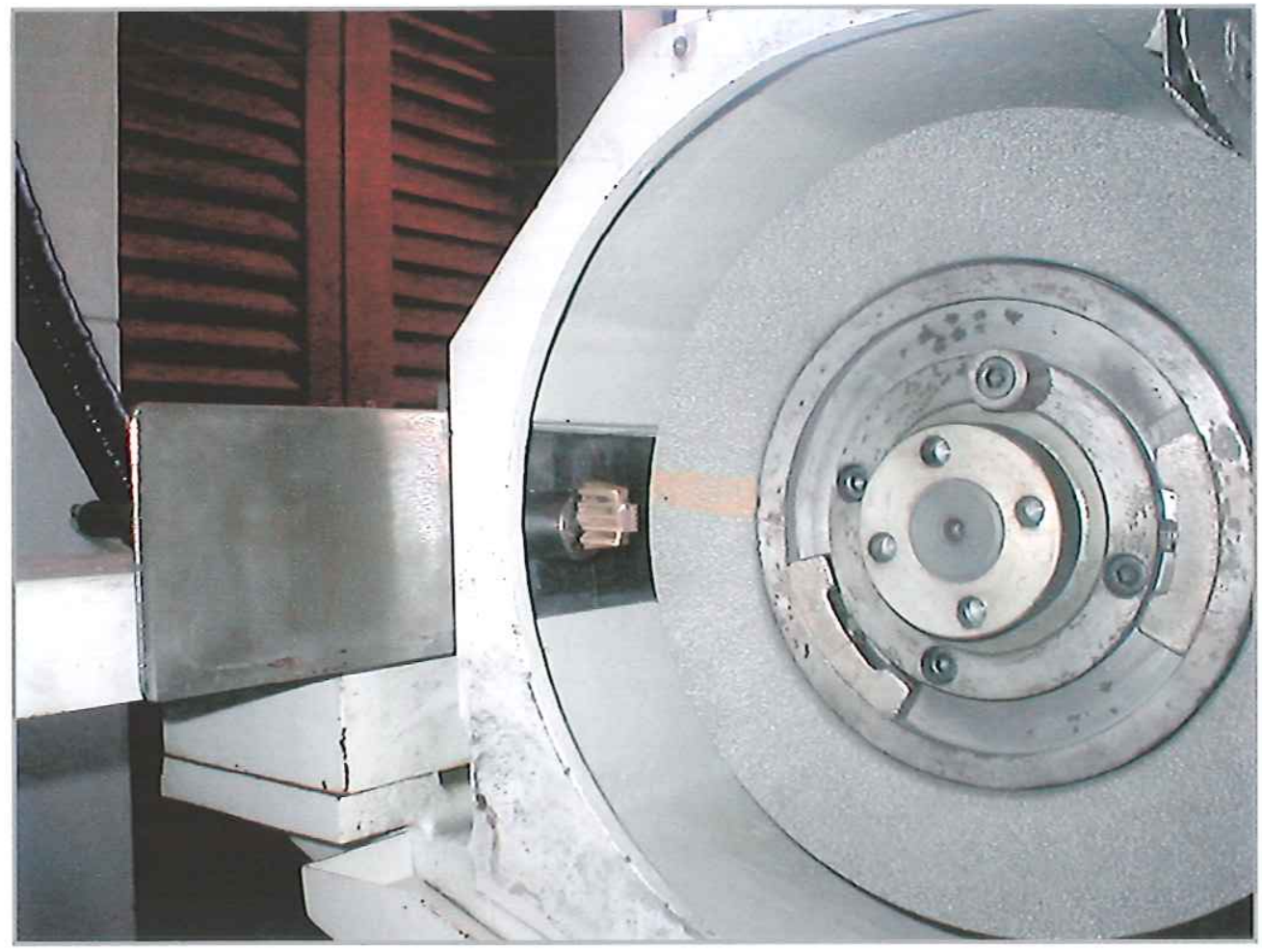

Figura 38: Posição do dressador aletado na retificadora.

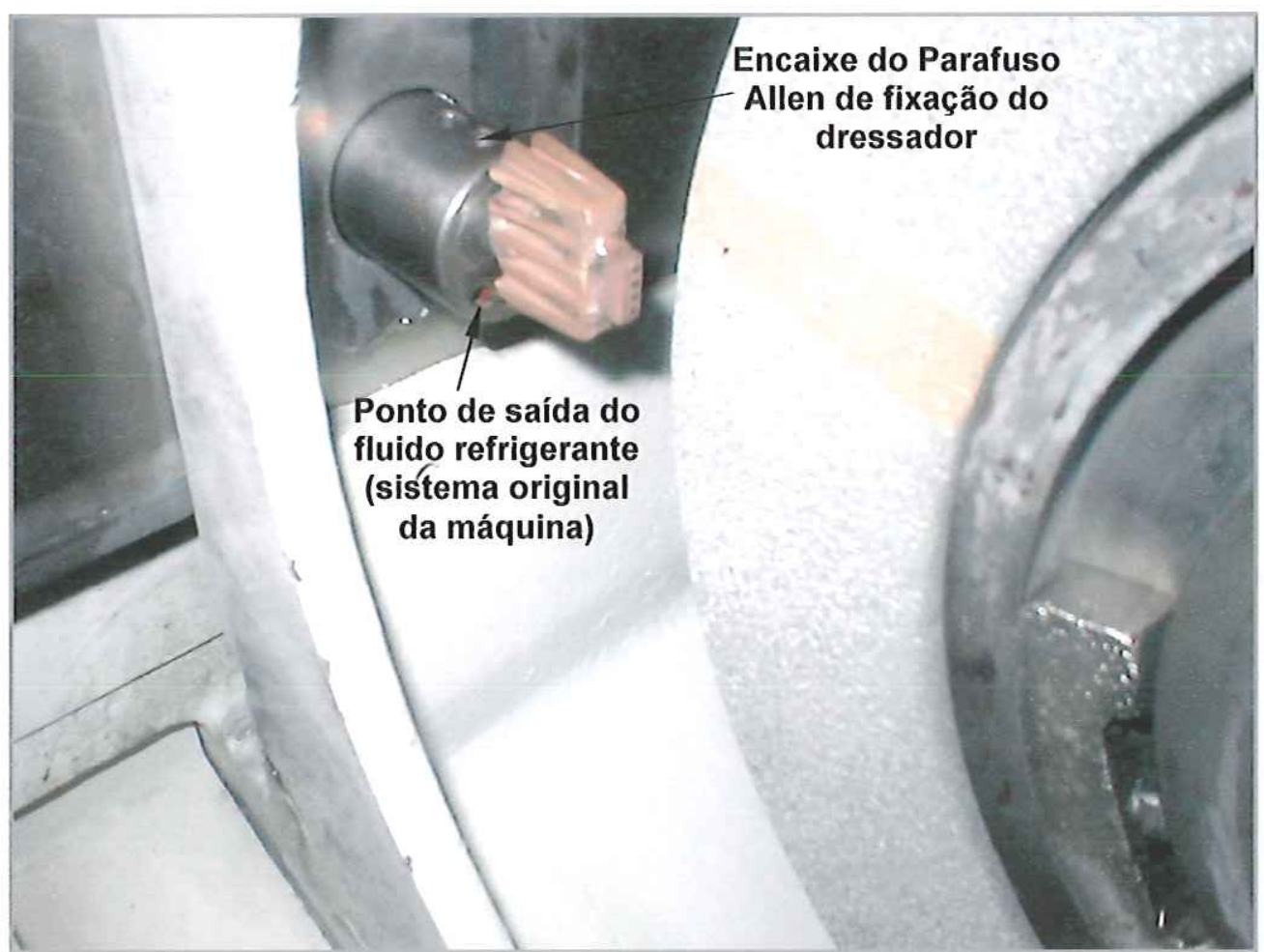

Figura 39: Detalhe da fixação do dressador aletado na retificadora. 


\section{3 - Simulações em Elementos Finitos com o Dressador Proposto}

\subsection{1 - MOdELAgem do DRESSADOR UTILIZANDo o SOFTWARE ANSYS ${ }^{\circledR}$}

Paralelamente ao trabalho prático de confecção do dressador, foi desenvolvida a modelagem do mesmo através do software ANSYS $^{\circledR}$, versão 6.0 .

$\mathrm{Na}$ construção do modelo considerou-se apenas uma parte do dressador, aproveitando a existência de simetrias de geometria na sua forma e de carregamento na sua utilização. Desta maneira, tomou-se apenas as dimensões correspondentes a $1 / 4$ do corpo da ferramenta. Este procedimento possibilita economizar tempo de processamento e memória do computador, devido ao menor número de elementos presentes na malha obtida, ao contrário do que ocorreria caso fosse necessário modelar a ferramenta inteira. A figura 40 mostra a modelagem para $1 / 4$ do dressador.

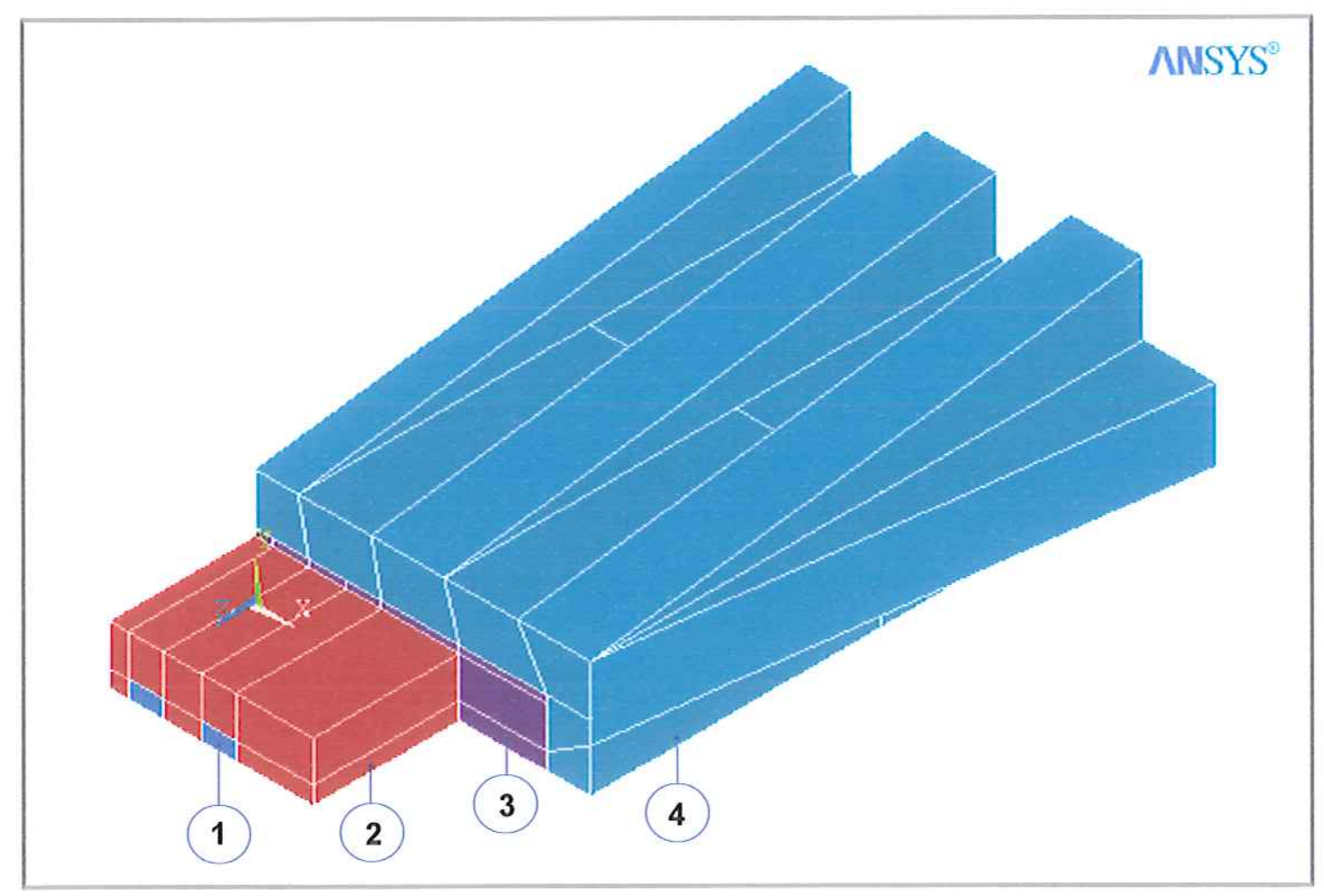

Figura 40: Modelagem de 1/4 do dressador com o software ANSYS ${ }^{\circledR}$. 
Nesta figura pode-se ver que cada elemento componente do dressador está representado com uma cor diferente para melhor visualização. A tabela 16 apresenta a correspondência dos números presentes na figura $39 \mathrm{com}$ os respectivos materiais adotados na confecção do dressador aletado.

Tabela 16: Materiais utilizados na modelagem do dressador.

\begin{tabular}{|c|c|c|}
\hline PEÇA & ELEMENTO & MATERIAL \\
\hline 1 & Diamante & CVDress $^{\circ}$ \\
\hline 2 & Liga sinterizada & $85 \%$ Bronze $+15 \%$ Co \\
\hline 3 & Solda & Liga à base de Prata (45\%) \\
\hline 4 & Corpo do dressador & Latão \\
\hline
\end{tabular}

Para cada um dos elementos considerados foi necessário fornecer ao software $\mathrm{ANSYS}^{\circledR}$ algumas propriedades físicas dos respectivos materiais utilizados. A tabela 17 apresenta essas propriedades.

Tabela 17: Propriedades físicas dos materiais utilizados na confecção do dressador.

\begin{tabular}{|l|c|c|c|}
\hline \multirow{2}{*}{\multicolumn{1}{|c|}{ MATERIAL }} & \multicolumn{3}{|c|}{ PROPRIEDADES $^{1}$} \\
\cline { 2 - 4 } & $\begin{array}{c}\text { DENSIDADE } \\
\left(\mathrm{kg} / \mathrm{m}^{3}\right)\end{array}$ & $\begin{array}{c}\text { CALOR } \\
\text { ESPECIFICO (J/kg.K) }\end{array}$ & $\begin{array}{c}\text { CONDUTIVIDADE } \\
\text { TÉRMICA (W/m.K) }\end{array}$ \\
\hline CVDress $^{\circ}$ & $3.500,0$ & 509,0 & $2.300,0$ \\
\hline $85 \%$ Bronze + 15\% Co & $8.780,0$ & 355,0 & 54,0 \\
\hline Liga à base de Prata (45\%) & $10.500,0$ & 235,0 & 429,0 \\
\hline Latão & $8.530,0$ & 380,0 & 110,0 \\
\hline
\end{tabular}

Fonte: 1 - Valores da literatura, não experimentais (Tabela A1 de Incropera e DeWitt, 1998).

Neste ponto vale observar que para o material "Liga à base de Prata" constante na tabela 17 foram adotadas as propriedades físicas da Prata, devido à impossibilidade de se obter os reais valores das propriedades consideradas para a vareta de solda prata utilizada para fixar a liga sinterizada 
no corpo aletado de Latão. Além disso, para a liga sinterizada foram adotadas as propriedades do Bronze, visto que é muito difícil saber o valor da condutividade térmica da liga sinterizada. Nesta liga o Bronze constitui a fase contínua da microestrutura obtida.

Atualmente existem algumas técnicas para a medição da condutividade térmica dos materiais. Para as ligas metálicas o método mais utilizado é a chamada Técnica do Pulso de Energia introduzida na década de 60 (PARKER et al., 1961). Entretanto, o acesso a este exame é restrito.

A figura 41 apresenta o modelo correspondente ao dressador inteiro, permitindo visualizar a ferramenta como um todo.

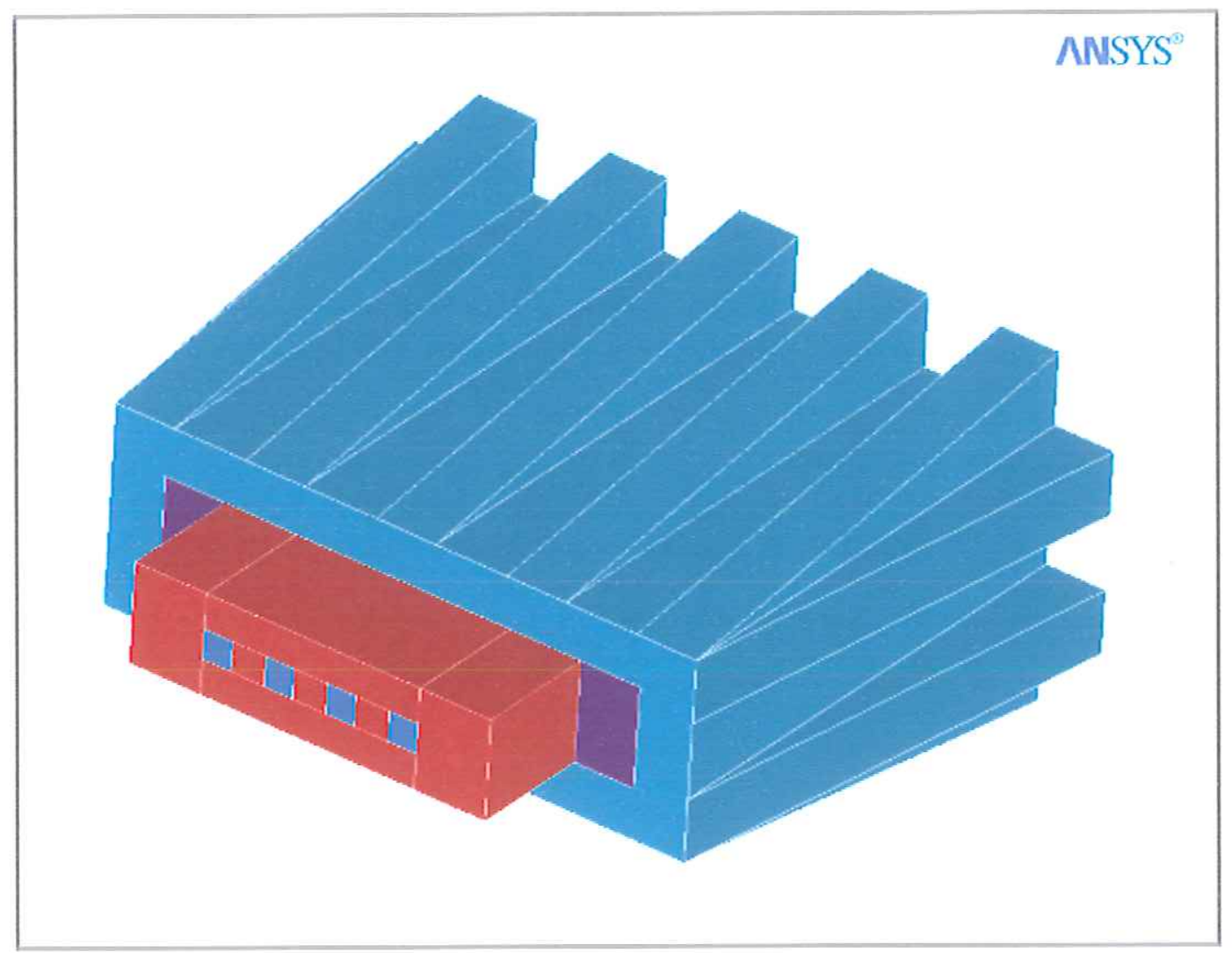

Figura 41: Modelagem do dressador com o software ANSYS ${ }^{\circledR}$. 


\subsubsection{1 - ESCOLHA DOS ELEMENTOS NO ANSYS ${ }^{\circledR}$}

O ANSYS ${ }^{\circledR}$ possui 3 elementos específicos para a modelagem de um sólido com capacidade de condução térmica tridimensional, sendo que a análise térmica pode ser em regime permanente ("steady state") ou transiente. Assim, para qualquer análise térmica que se deseja realizar, deve-se empregar um desses elementos indicados pelo software para a modelagem do sólido.

O primeiro elemento é denominado SOLID 70. Trata-se de um elemento com 8 nós, sendo que cada nó possui 1 grau de liberdade associado (neste caso, com a temperatura). O segundo elemento é denominado SOLID 87 . Ele possui 10 nós e cada um desses possui 1 grau de liberdade associado (temperatura), sendo utilizado em modelos com meshas irregulares, como as produzidas por sistemas CAD/CAM. O terceiro é denominado SOLID 90. Este é um elemento de ordem maior (possui 20 nós), com cada nó tendo igualmente 1 grau de liberdade associado (temperatura). Indicado para modelos com fronteiras curvas.

A figura 42 a seguir mostra a geometria, a localização dos nós e o sistema de coordenadas para o elemento SOLID 70, escolhido para a modelagem do dressador aletado (ANSYS ${ }^{\circledR}$ ELEMENTS REFERENCE, 1998).

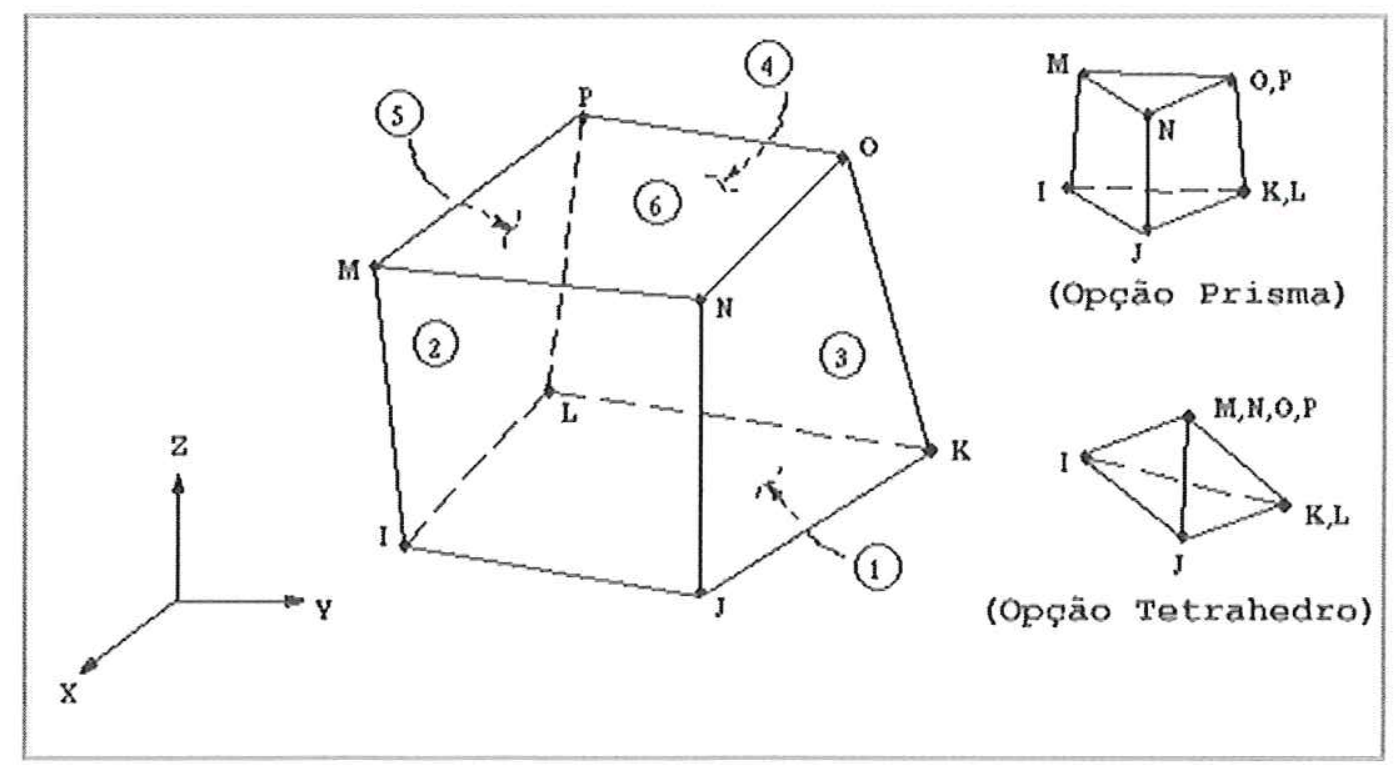

Figura 42: Elemento SOLID 70 (ANSYS ${ }^{\circledR}$ ELEMENTS REFERENCE, 1998). 
A figura 43 apresenta $1 / 4$ do modelo discretizado. O corpo todo do dressador foi modelado utilizando-se elementos hexaédricos, e apenas as regiões correspondentes às aletas foram modeladas com elementos tetraédricos, em virtude da dificuldade de se obter uma malha mapeada nessa região. Isso foi feito respeitando-se as interconexões nodais entre o corpo e as aletas para garantir a continuidade do modelo. Ao final da modelagem obtevese um modelo com um total de 8316 elementos. No apêndice $A$ encontra-se a listagem do programa em linguagem APDL (Ansys Parametric Design Language) desenvolvido para gerar o modelo utilizado nas simulações em elementos finitos.

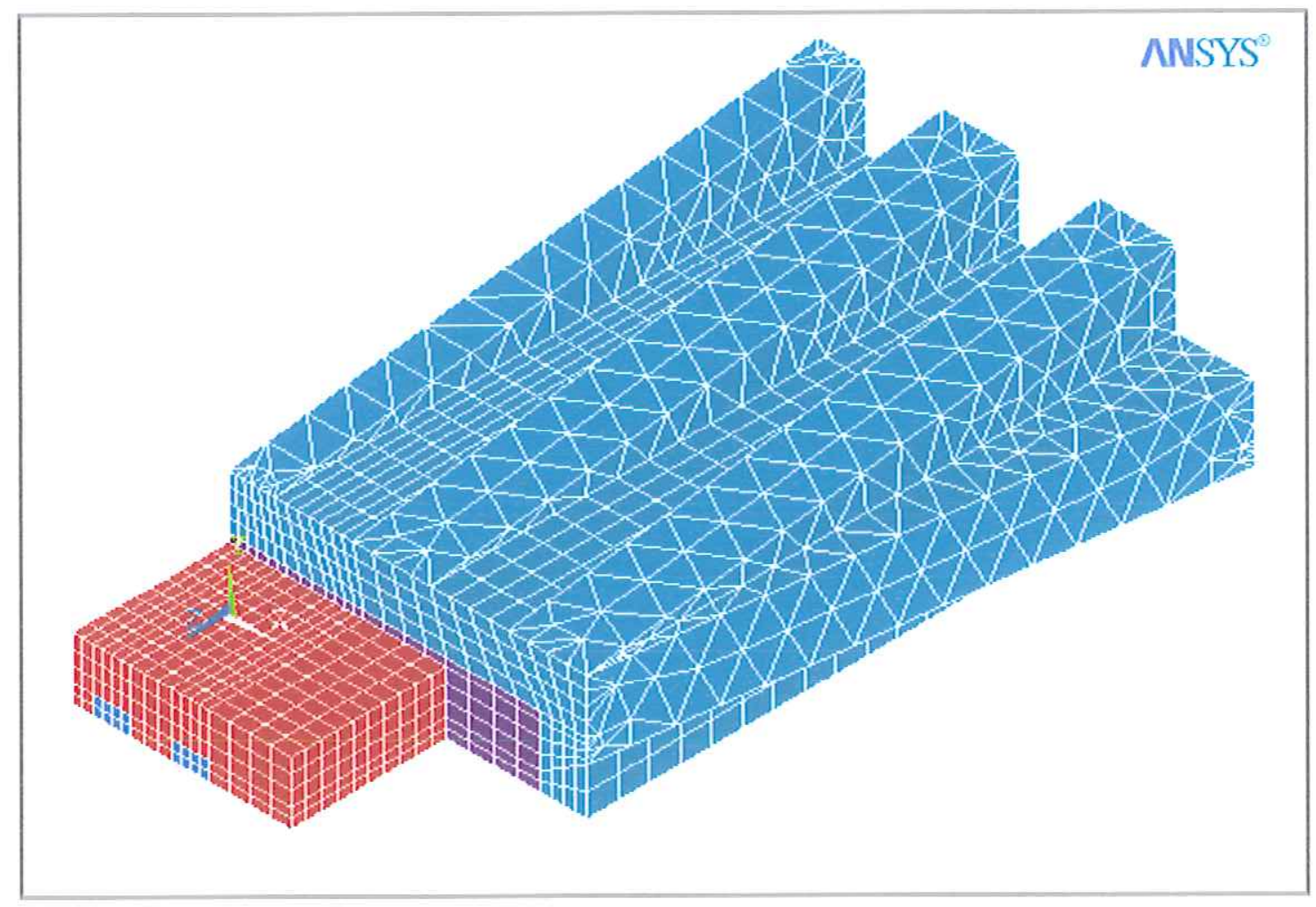

Figura 43: Modelo discretizado para $1 / 4$ do dressador.

\subsubsection{2 - CARREgAmentos E Condições de CONTORNo}

A simulação da distribuição de temperaturas no dressador foi obtida a partir da modelagem da região correspondente a $1 / 4$ da ferramenta de dressagem. Para isso foi necessário o estabelecimento dos carregamentos e 
das condições de contorno. Neste trabalho a condição de contorno foi considerar as 2 superfícies da região que se unem aos outros $3 / 4$ da ferramenta como sendo superfícies adiabáticas, ou seja, que não trocam calor entre si.

Quanto ao carregamento, as condições adotadas foram as seguintes:

- Carregamento 1: Considerou-se as faces dos diamantes em contato com o rebolo durante a dressagem como submetidas à condução de calor. O calor resultante da dressagem será conduzido através das áreas das faces dos diamantes e teremos, portanto, um fluxo de calor por área. $\mathrm{O}$ valor do fluxo de calor nos diamantes foi estimado através de ensaios com um dressador de ponta única (procedimento descrito adiante no item 3.4.1) e o valor obtido, para cada ensaio, foi fornecido ao software ANSYS $^{\circledR}$ como um dos requisitos para a simulação;

- Carregamento 2: Considerou-se a face da liga sinterizada (somente a região correspondente à liga que sustenta os diamantes) em contato com o rebolo como também submetida à condução de calor. Assim, através desta face também será conduzido um fluxo de calor, que também foi estimado através dos ensaios com o dressador de ponta única;

- Carregamento 3: Considerou-se todas as superfícies da ferramenta em contato com o fluido refrigerante durante a dressagem como submetidas a uma convecção forçada. A temperatura do fluido nestas superfícies foi considerada como sendo igual à temperatura ambiente $\left(27^{\circ} \mathrm{C}\right)$;

- Carregamento 4: Considerou-se toda a superfície posterior da ferramenta como estando à mesma temperatura da retificadora, considerada como constante e igual à temperatura ambiente $\left(27^{\circ} \mathrm{C}\right)$.

A primeira tentativa de simulação computacional foi feita utilizando os dados obtidos no trabalho de Campos (1999), que obteve os seguintes valores para os coeficientes $\mathbf{h}$ e $\boldsymbol{q}_{\mathbf{f}}$ (conforme a tabela 18$)$. 
Tabela 18: Valores dos coeficientes utilizados na simulação (CAMPOS, 1999).

\begin{tabular}{|l|c|}
\hline \multicolumn{1}{|c|}{ COEFICIENTE } & VALOR \\
\hline Coeficiente médio de transferência de calor por convecção $\left(\mathrm{h}_{\text {médio }}\right)$ & $15.845,93 \mathrm{~W} / \mathrm{m}^{2} \mathrm{~K}$ \\
\hline Fluxo de calor para o diamante $\left(q \mathrm{f}_{\mathrm{D}}\right)$ & $90.105 .543,79 \mathrm{~W} / \mathrm{m}^{2}$ \\
\hline Fluxo de calor para a liga sinterizada $\left(q \mathrm{f}_{\mathrm{L}}\right)$ & $1.533 .622,87 \mathrm{~W} / \mathrm{m}^{2}$ \\
\hline
\end{tabular}

A figura 44 apresenta o resultado da simulação da distribuição de temperaturas, em graus Celsius, para o dressador aletado utilizando os dados de Campos (1999). A imagem refere-se à secção longitudinal interna média do dressador. As posições de medição de temperatura pelos dois termopares no interior da ferramenta estão indicadas pelos símbolos T1 e T2, com as suas respectivas temperaturas nestes pontos. Através da simulação computacional é possivel obter as temperaturas locais nestes pontos para efeito de comparação com as temperaturas medidas nos ensaios com o dressador aletado.

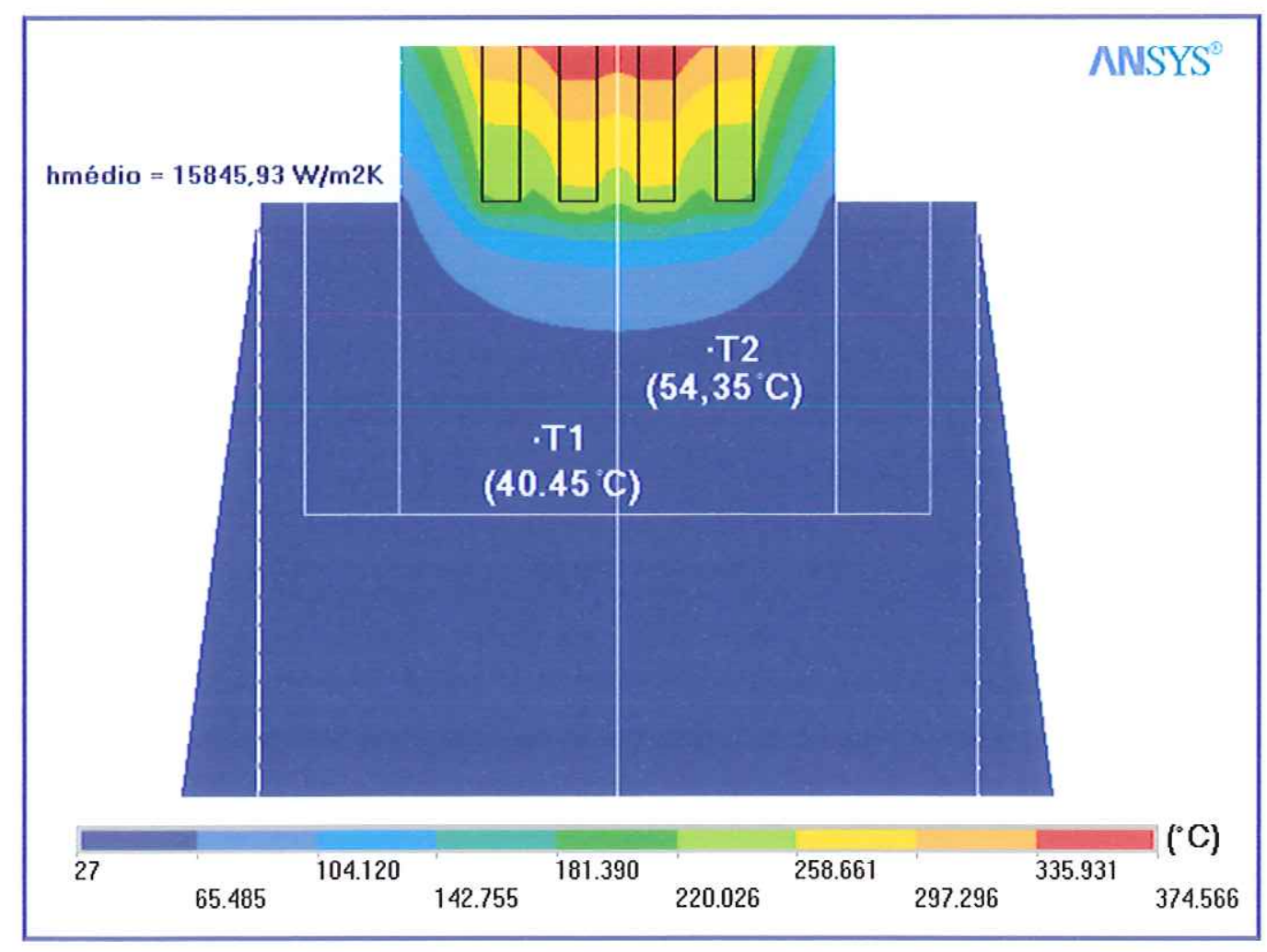

Figura 44: Simulação da distribuição de temperatura para o dressador aletado utilizando os dados de Campos (1999). 
Esta simulação inicial indica uma temperatura máxima na extremidade dos diamantes de cerca de $375^{\circ} \mathrm{C}$ e temperaturas de $40,45^{\circ} \mathrm{C}$ para o termopar número 1 (T1) e de $54,35^{\circ} \mathrm{C}$ para o termopar número 2 (T2).

Provavelmente estes dados não se aplicam ao dressador aletado deste trabalho, uma vez que foram obtidos com uma outra ferramenta, de dimensão menor, empregando diamantes menores (possuíam secção quadrada de $0,8 \mathrm{x}$ $0,8 \mathrm{~mm}$ contra $1,2 \times 1,2 \mathrm{~mm}$ dos diamantes empregados neste trabalho) durante ensaios experimentais de dressagem em um rebolo de largura menor $(50 \mathrm{~mm})$ do que o utilizado neste trabalho $(120 \mathrm{~mm})$.

\section{4 - Sistema de Avaliação do Fluxo de Calor Através do Dressador}

\subsection{1 - Ensaios para a Estimativa do fluxo de Calor através do} DIAMANTE ( $\left.q f_{D}\right)$

A equação de transferência de calor na sua forma geral considera as 3 dimensões do espaço ( $x, y$ e $z$ ) para a estimativa desse parâmetro. Isso impossibilita que se estime o fluxo de calor na região da superfície aletada do dressador, pois considerando-se este tipo de geometria, certamente iria-se obter uma equação diferencial de difícil solução. Para contornar este problema, adotou-se o procedimento de estimar o fluxo de calor através de um único diamante com a utilização de um dressador de ponta única.

Segundo Incropera e DeWitt (1998), é possível estimar o fluxo de calor (ou fluxo térmico) através de um sólido submetido à condução em regime estacionário. Para isso basta que o material seja conhecido, que o trecho considerado tenha a sua superfície lateral isolada termicamente e que as temperaturas nos extremos deste trecho sejam diferentes e conhecidas, conforme esquema da figura 45. 


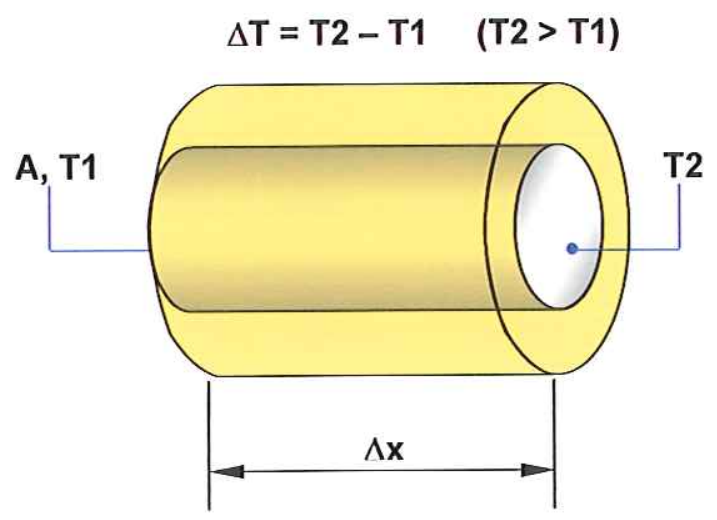

Figura 45: Experimento de condução de calor em regime estacionário (Incropera e DeWitt, 1998).

Uma vez que as condições sejam satisfeitas, a taxa de transferência de calor por unidade de comprimento $(\mathrm{W} / \mathrm{m})$ pode ser estimada através da fórmula:

$$
q_{x}=k \cdot A \cdot \Delta T / \Delta x
$$

onde:

- $\quad k=$ condutividade térmica do material (W/m.K);

- $\quad \Delta \mathbf{T}=$ diferença de temperatura no trecho considerado $(\mathrm{K})$;

- $\Delta \mathbf{x}=$ comprimento do trecho isolado considerado $(\mathrm{m})$;

- $\mathbf{A}=$ área da secção reta do sólido $\left(\mathrm{m}^{2}\right)$.

Para obter o fluxo de calor, basta dividir qx pela área da secção considerada, ou seja:

$$
q f=q_{x} / A=k \cdot \Delta T / \Delta x
$$

Assim, para a obtenção do fluxo de calor para cada diamante do dressador (qfí) realizou-se uma nova série de experimentos com o dressador de ponta única, com as mesmas condições de dressagem utilizadas nos ensaios de aferição de temperatura no dressador aletado. Construiu-se um 
dressador de ponta única, com corpo feito de aço ABNT 1020 e contendo um único diamante do tipo CVDress ${ }^{\circledR}$, mas com as mesmas características dos diamantes empregados no dressador aletado.

Foram feitos dois orifícios no dressador de ponta única para a colocação de 2 termopares, para que fosse possível saber a diferença de temperaturas dentro de uma distância conhecida (neste caso, o espaço de 0,015 m entre os dois orifícios). As pontas dos termopares foram posicionadas na porção média do corpo do dressador de ponta única, para que o fluxo de calor fosse estimado a partir da temperatura existente nesta posição, correspondente à mesma direção da posição do diamante. Novamente utilizou-se silicone para fixar os termopares em suas posições, da mesma maneira que foi feita com o dressador aletado.

O dressador de ponta única foi isolado termicamente na direção radial com uma peça circular de Celeron (um tipo de material isolante obtido a partir de tecido de algodão impregnado com resinas fenólicas) para assegurar que o calor fluísse apenas em uma única direção, no trecho de aferiçäo das temperaturas. Para aumentar o isolamento térmico, recobriu-se a peça de Celeron com o silicone e, após a secagem deste, aplicou-se várias camadas de fita de Teflon $^{\circledR}$ (popularmente conhecida como "fita veda rosca") sobre o conjunto (Celeron + dressador), deixando apenas a porção metálica da ponta do dressador livre de cobertura.

A ponta do dressador de ponta única foi feita com uma pequena inclinação (ângulo de $25^{\circ}$ ) para garantir que o calor fosse gerado apenas pelo diamante em contato com o rebolo durante os ensaios. A partir do momento em que a área metálica na ponta da ferramenta se tornava maior, devido ao desgaste do diamante, o ensaio foi encerrado e a ferramenta foi trocada por uma nova, com as mesmas dimensões da anterior.

A figura 46 mostra uma representação esquemática da disposição dos elementos no dressador de ponta única utilizado. 


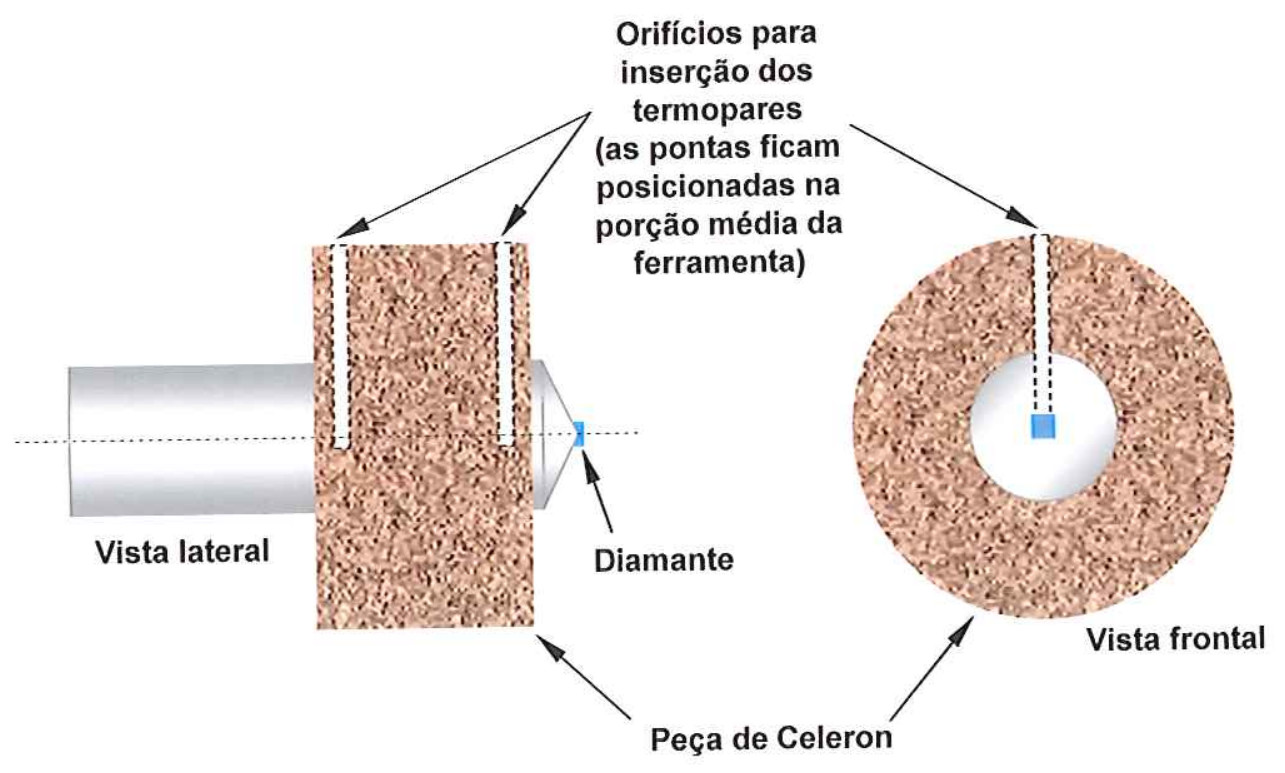

Figura 46: Representação do dressador de ponta única utilizado.

Inicialmente o corpo do dressador foi construído a partir de uma barra de Cobre de $3 / 8$ " $(0,009525 \mathrm{~m})$ de diâmetro. Porém, como nos testes preliminares não foi possível captar uma diferença de temperatura entre os 2 termopares, decidiu-se trocar o material do corpo para o aço ABNT 1020, que possui menor coeficiente de condutividade térmica do que o Cobre, o que possibilitou a captação de uma diferença de temperatura entre os 2 termopares nos ensaios.

A figura 47 apresenta fotos da montagem final do dressador de ponta única (mostrando ainda o corpo de Cobre inicialmente adotado), nas quais pode-se notar os fios dos termopares inseridos na ferramenta e a fita de Teflon $^{\circledR}$ envolvendo o conjunto. Vê-se também que tanto a frente como a parte de trás do dressador foi revestida com silicone para evitar o contato do fluido refrigerante com a peça de Celeron, o que poderia encharcá-la.

Nos ensaios realizados com este dressador, repetiu-se as mesmas condições utilizadas nos ensaios com o dressador aletado, inclusive utilizandose o mesmo dispositivo de refrigeração. Os termopares utilizados também foram os mesmos. 

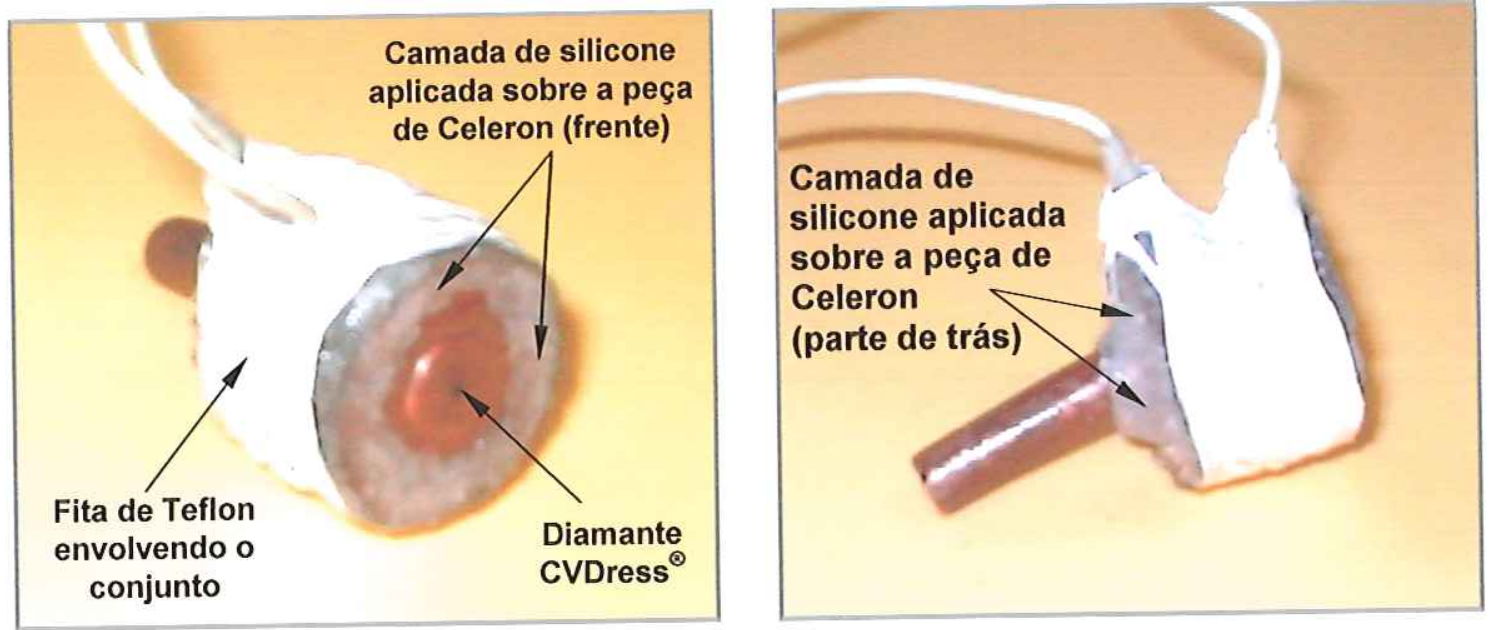

Figura 47: O dressador de ponta única após a preparação para $o$ ensaio de estimativa do fluxo de calor no diamante (qf $\left.f_{D}\right)$.

A partir da diferença das temperaturas obtidas nestes ensaios com o dressador de ponta única de aço, aplicou-se a equação número 2 para se obter o fluxo de calor por área para o dressador (qffço), ou seja:

$$
q f_{A C ̧ O}=k_{A C ̧ O} \cdot \Delta T_{A C ̧ O} / \Delta x_{A C ̧ O}
$$

onde:

- $\mathbf{k}_{\mathrm{Aço}}=51,9 \mathrm{~W} / \mathrm{m} . \mathrm{k}$ (valor extraído de http://www.matweb.com);

- $\Delta \mathbf{x}_{\mathrm{AÇO}}=15 \mathrm{~mm}(0,015 \mathrm{~m})$;

- $\Delta \mathrm{T}_{\mathrm{Aço}}=>$ valor obtido nos ensaios.

Devido à ponta cônica do dressador de ponta única, assume-se que todo fluxo de calor nestes ensaios esteja entrando na ferramenta apenas pelo diamante. Assim, para obter o fluxo de calor por área do diamante (qfiD) basta aplicar novamente a mesma equação e dividí-la pela área do diamante, tomando a precaução de considerar também a área circular do dressador que estava implícita na fórmula inicial, ou seja:

$$
q f_{D}=k_{A C ̧ O} \cdot \Delta T_{A C ̧ O} \cdot A_{A C ̧ o} / \Delta x_{A C ̧ O} \cdot A_{D}
$$


onde:

- $A_{A c ̧ O}=$ área circular do dressador (corresponde à área circular de uma barra de aço com 3/8" de diâmetro);

- $A_{D}=$ área do diamante (área de uma secção quadrada de 1,2 mm).

Os valores obtidos de $q f_{A c ̧ o}$ e qfi para cada ensaio foram inseridos no software ANSYS ${ }^{\circledR}$ para realizar a simulação.

\section{5 - Ensaios de Avaliação do Dressador Proposto}

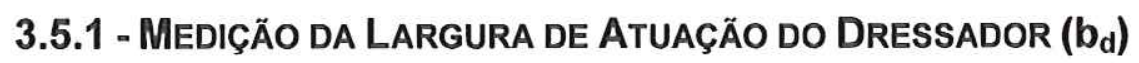

A medição da largura de atuação do dressador construído foi executada através do método de impressão do perfil da ferramenta de dressagem na superfície de corte de um rebolo e transferência desse perfil para uma chapa metálica, para a posterior medição dessa largura.

Utilizando-se uma morsa, fixou-se o dressador perpendicularmente sob a superfície de corte do rebolo de uma retificadora cilíndrica plana. Acionou-se o rebolo e após o toque inicial deste com a superfície do dressador, mergulhouse o rebolo com uma profundidade de retificação de $100 \mu \mathrm{m}$ sobre o dressador. Decorridos um tempo de 10 segundos de retificação, recuou-se o rebolo e retirou-se o dressador da morsa, substituindo-o por uma chapa de aço (ABNT 1020).

A seguir, repetiu-se o mesmo procedimento, mergulhando o rebolo sobre a chapa para a impressão do seu perfil sobre a mesma. Terminado o procedimento, retirou-se a chapa para a medição da largura de atuação do dressador que ficou registrada na superfície retificada. A medição foi realizada através de um equipamento Form Talysurf, modelo 120L, fabricado pela HANK TAYLOR HOBSON, pertencente ao Laboratório de Engenharia de Precisão da EESC - USP. 
A figura 48 apresenta uma representação esquemática do procedimento de impressão da largura de atuação do dressador $\left(\mathbf{b}_{\mathbf{d}}\right)$ na superfície da chapa de aço.

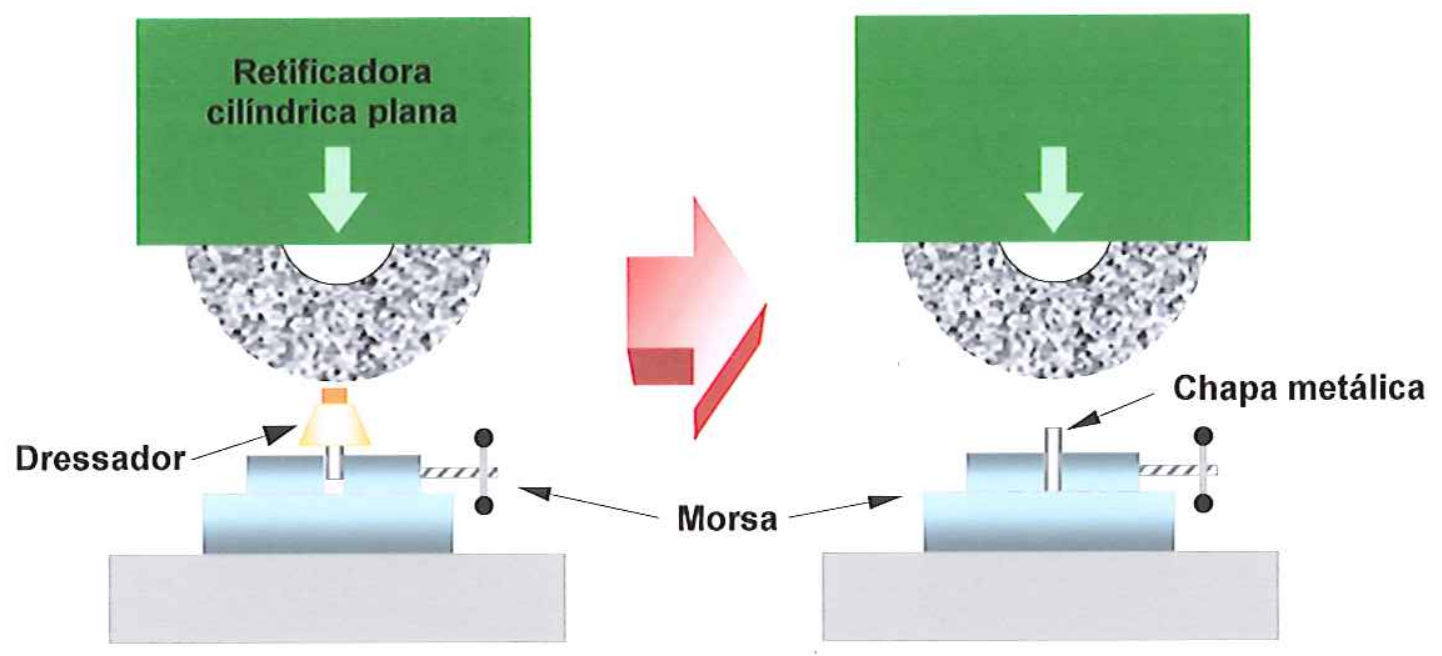

Figura 48: Procedimento para a impressão na superfície da chapa metálica da largura de atuação do dressador $\left(\boldsymbol{b}_{d}\right)$.

\subsection{2 - NOVO DISPOSITIVO DE REFRIGERAÇÃO DO DRESSADOR}

A figura 49 permite a visualização do sistema original de refrigeração da retificadora utilizada. Ele consiste basicamente de dois canais que conduzem o fluido refrigerante enviado pela bomba desde o reservatório até o dressador. 


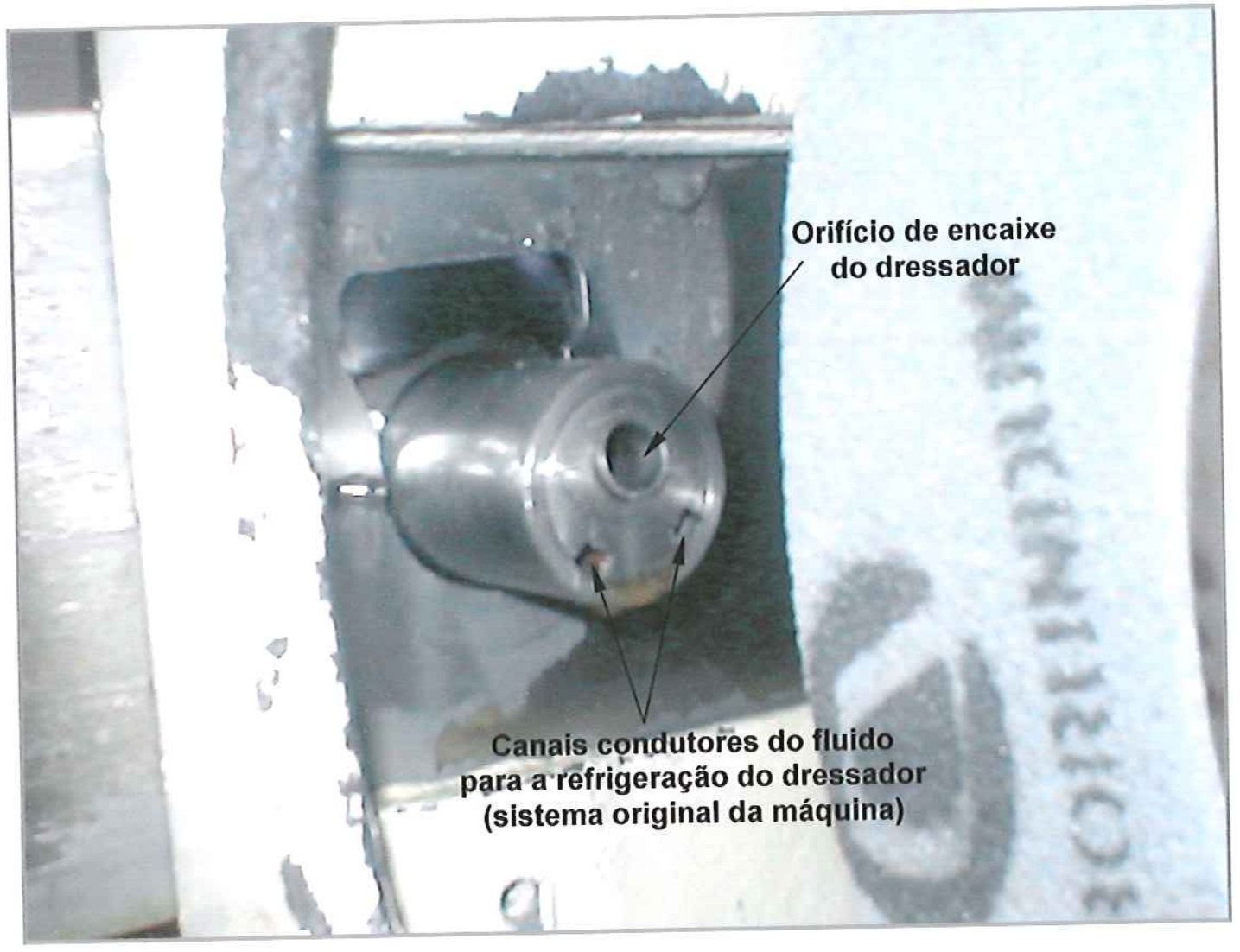

Figura 49: Sistema original de refrigeração do dressador na retificadora.

Devido a esta configuração da máquina, foi necessário desenvolver um novo dispositivo para a refrigeração das operações de dressagem, pois apenas estes 2 pontos seriam insuficientes para refrigerar todos os 4 diamantes presentes na ferramenta. Sendo assim, foi construído um dispositivo capaz de proporcionar a distribuição do fluido refrigerante em toda a volta do dressador.

Este dispositivo consiste de uma peça circular feita de Latão (material de fácil usinabilidade), que se encaixa sob pressão no eixo de fixação do dressador antes da colocação deste na máquina. Esta peça circular, ao ser encaixada no eixo, forma uma câmara onde o fluido refrigerante será armazenado e distribuído por 6 orifícios. Na saída destes orifícios foram soldados 6 tubos flexíveis de Cobre de 3/16" $(\approx 0,0048 \mathrm{~m})$ de diâmetro. A vedação da câmara junto ao eixo para evitar o vazamento do fluido é assegurada por 2 anéis elásticos do tipo O'ring posicionados no interior da peça circular. Através do manuseio dos tubos flexíveis é possível direcionar o fluido sobre os diamantes do dressador de maneira a melhorar a refrigeração 
durante a dressagem. As figuras 50 e 51 mostram os detalhes deste dispositivo.

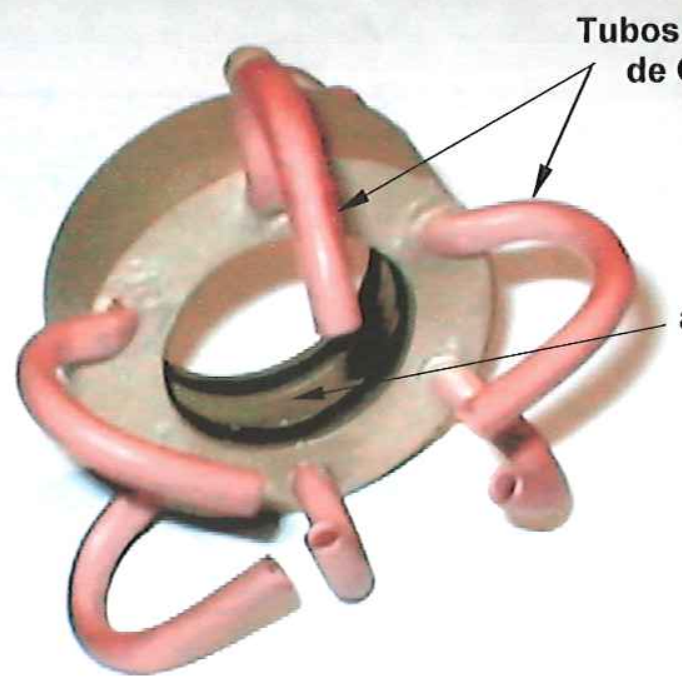

Câmara de armazenamento do fluido refrigerante

Figura 50: Vista frontal do dispositivo de refrigeração do dressador.

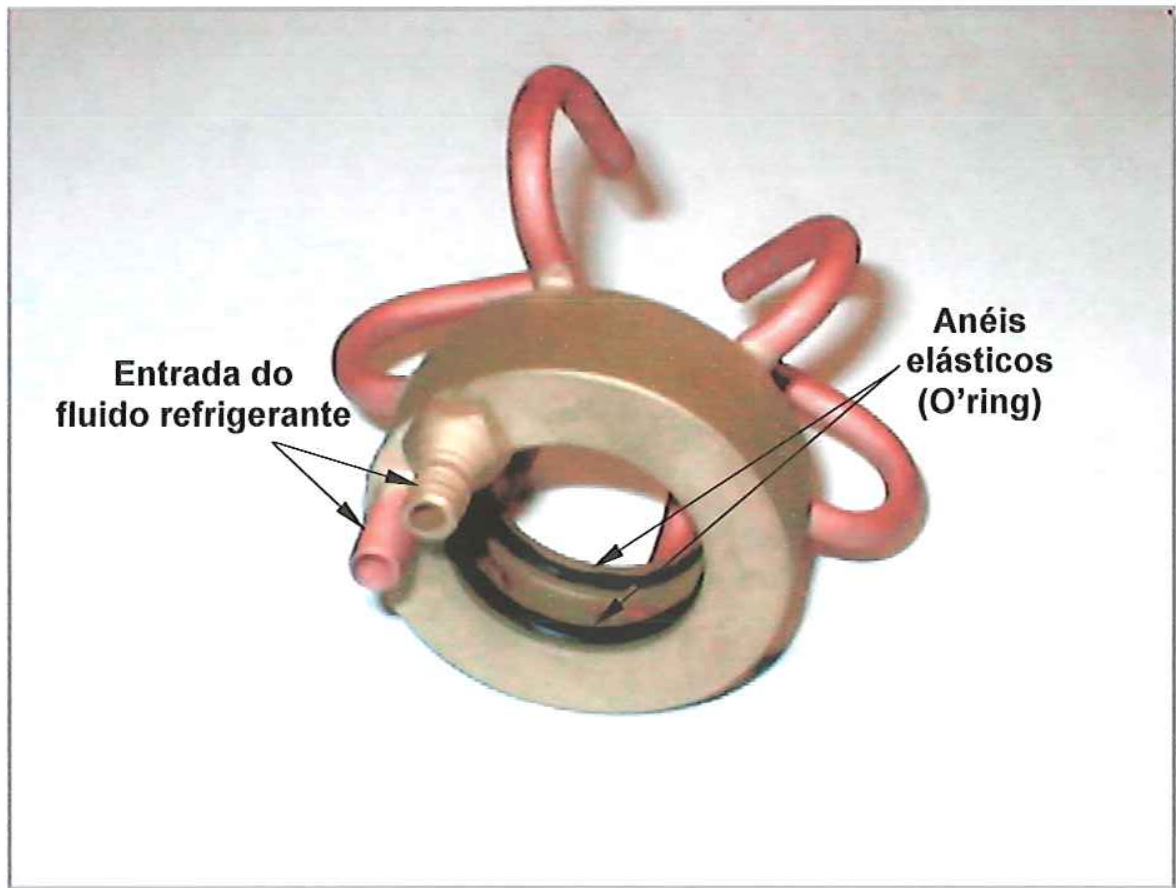

Figura 51: Vista posterior do dispositivo de refrigeração do dressador. 
3.5.2.1 - TRoca da AlimentaçÃo do Dispositivo de REFRIGERAÇÃo do DRESSADOR

Outra adaptação feita foi a troca da posição de acoplamento da mangueira que conduz o fluido refrigerante do reservatório da retificadora até o dressador. A posição de acoplamento deixou de ser a entrada padrão da máquina, na porção traseira do carro do dressador e passou a ser diretamente para o novo dispositivo de refrigeração do dressador que foi construído.

Para realizar o controle da vazão do fluido enviado pela bomba adaptouse à mangueira, antes de chegar à máquina, um registro tipo "Esfera" e um bocal redutor de maneira que o fluido pudesse chegar a duas pequenas mangueiras de $3 / 8$ " de diâmetro $(\approx 0,0095 \mathrm{~m})$, que finalmente se acoplavam ao dispositivo de refrigeração do dressador. Inicialmente foram feitos três orifícios de saída do bocal redutor, mas após alguns testes iniciais concluiu-se que apenas duas saídas seriam suficientes para assegurar a vazão do fluido para o dispositivo. Por isso uma das saídas do bocal foi isolada.

As figuras 52 e 53 a seguir possibilitam visualizar melhor estas adaptações.

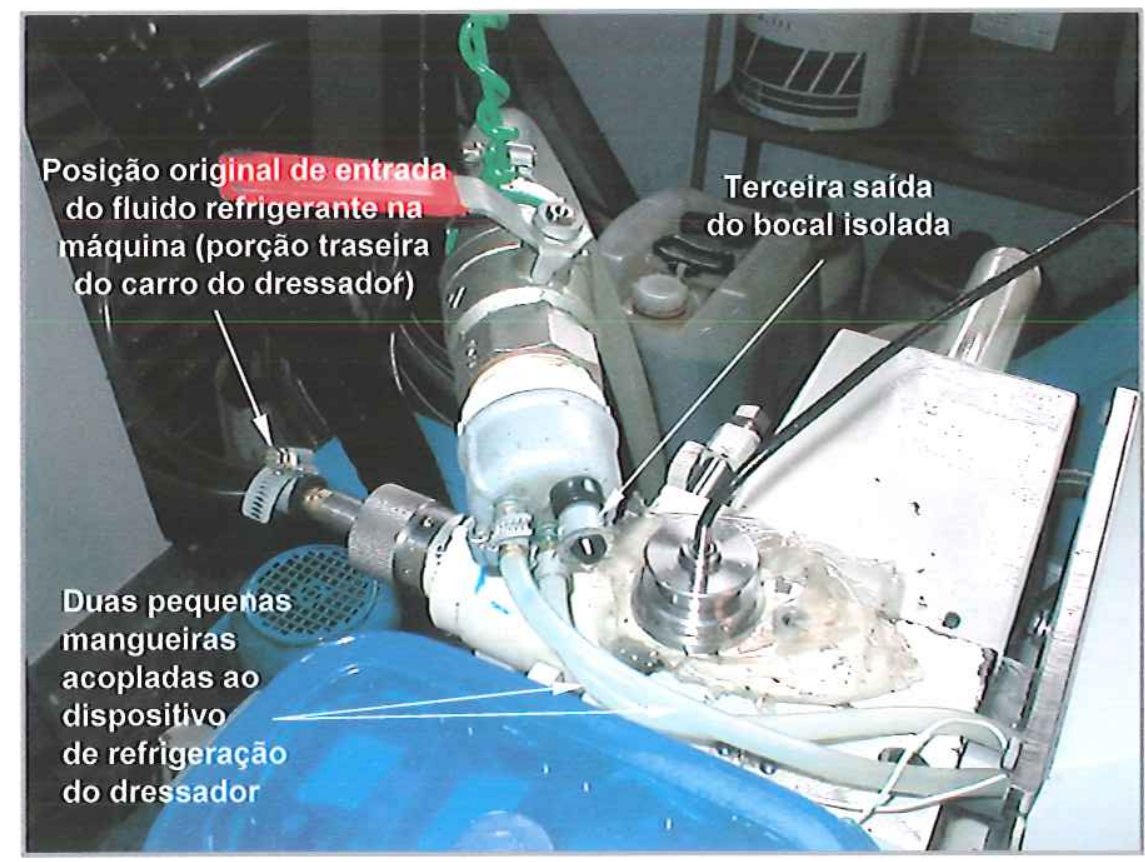

Figura 52: Registro para o controle de vazão do fluido refrigerante e mangueiras de alimentação do dispositivo de refrigeração do dressador. 


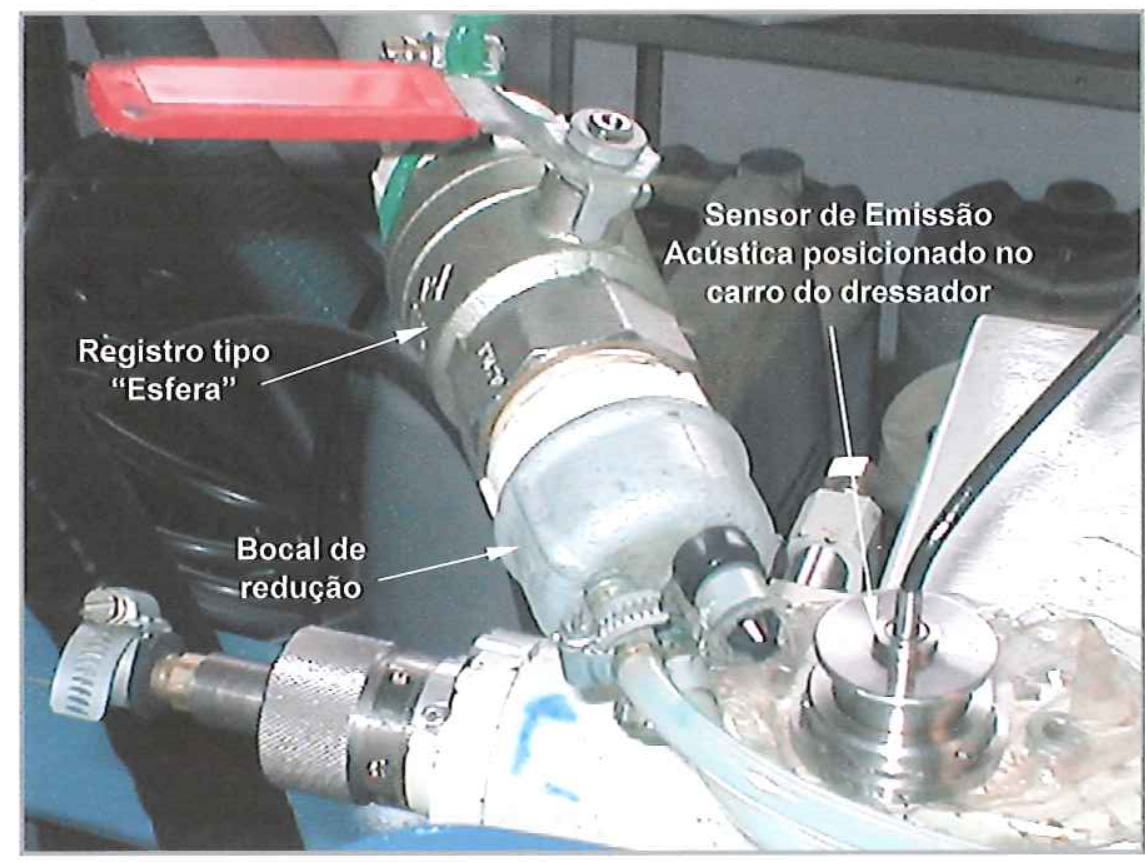

Figura 53: Detalhe do registro e do posicionamento do sensor de Emissão Acústica.

\subsection{3 - ColocaÇÃo dos TERMOPARES NO DRESSADOR}

A figura 54 apresenta esquematicamente os orifícios feitos no corpo do dressador para a inserção dos termopares responsáveis pela aferição das temperaturas nos ensaios realizados. Os orifícios foram executados através de furação com uma broca de aço rápido de $2 \mathrm{~mm}$ de diâmetro, utilizando uma morsa graduada para a fixação da peça na mesa da furadeira. Esta morsa possibilitou o giro da peça para o posicionamento preciso nos ângulos de $45^{\circ} \mathrm{e}$ $52^{\circ}$ nos quais os orifícios foram feitos. Os pontos de medição de temperatura no dressador (correspondentes à localização da ponta dos termopares no interior da peça) estão defasados de $3 \mathrm{~mm}$ um do outro na direção vertical (eixo y) e de cerca de $5,6 \mathrm{~mm}$ na direção horizontal (eixo $\mathrm{x}$ ). 


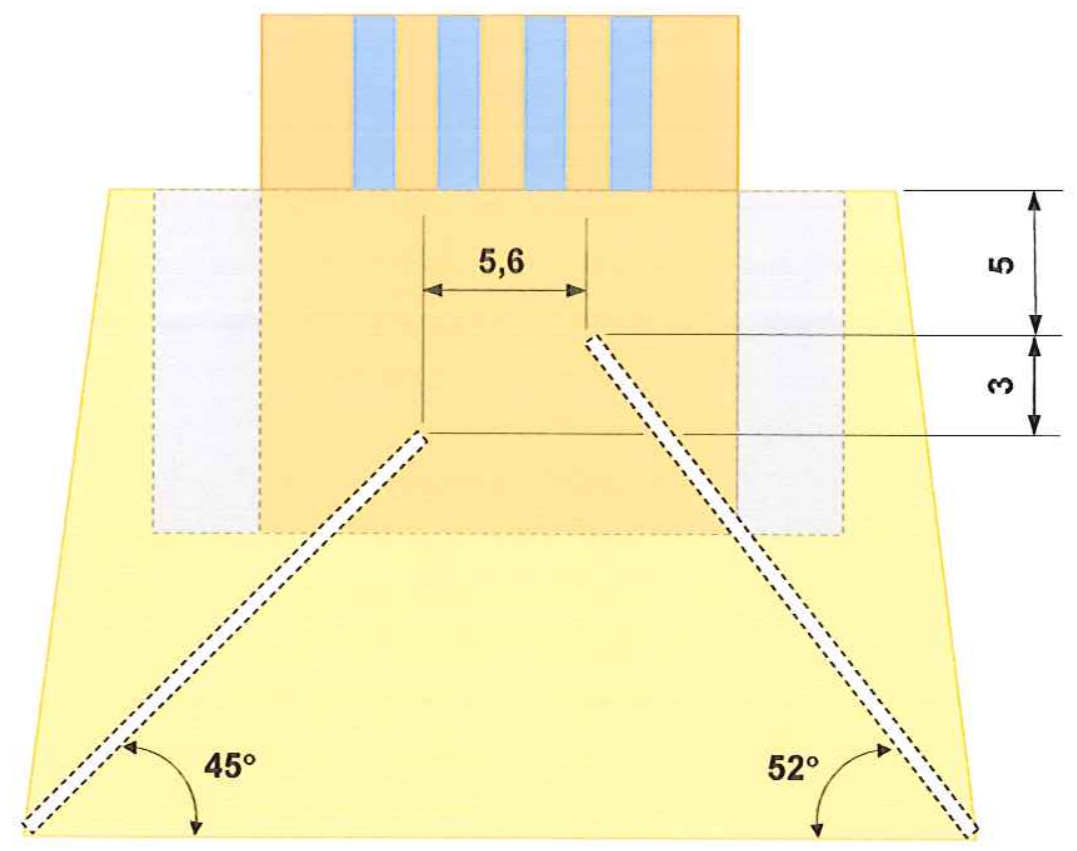

Figura 54: Desenho esquemático do posicionamento dos orifícios no corpo do dressador para a inserção dos termopares.

Para assegurar a manutenção do posicionamento dos termopares no dressador e evitar a entrada de fluido refrigerante nos orifícios, aplicou-se silicone na região do orifício após a inserção dos termopares. Após cada aplicação do silicone foi necessário um tempo de 24 horas de espera para a sua completa secagem antes de se fixar o dressador com os termopares na máquina para iniciar o ensaio. Os termopares utilizados para a aferição da temperatura durante os ensaios são do tipo K (Chromel-Alumel).

Na figura 55 pode-se ver o silicone aplicado para a fixação de um dos termopares, assim como a braçadeira plástica utilizada para prender os fios dos termopares, para evitar que eles balancem durante os ensaios quando o carro do dressador se deslocar. 


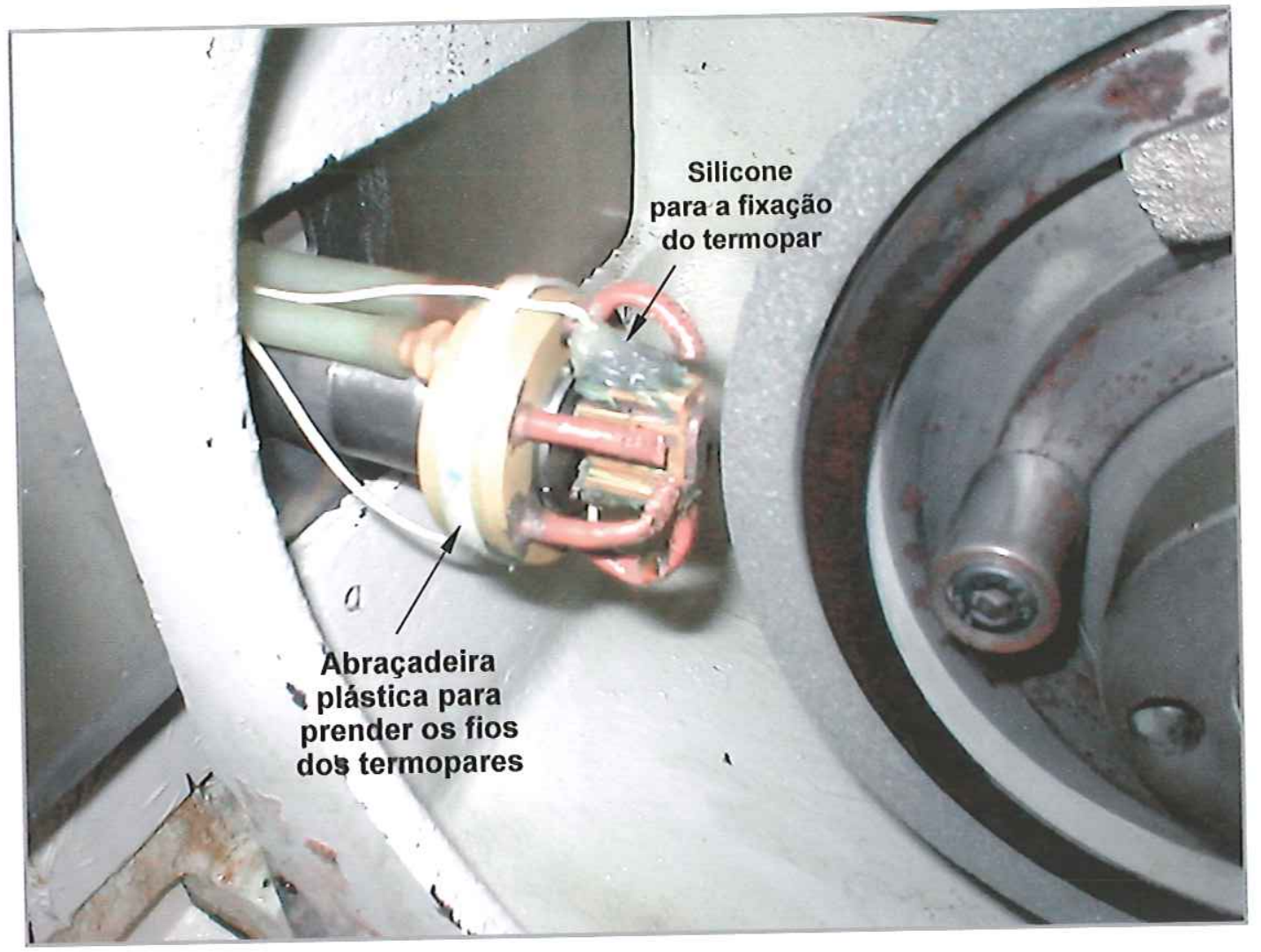

Figura 55: Detalhe da fixação dos termopares no dressador.

\subsubsection{1 - PROTEÇÃo dos TERMOPARES}

Os fios dos termopares utilizados são revestidos com uma camada fina de verniz eletro-isolante para evitar qualquer contato adicional entre eles, além daquele da ponta (ou cabeça do termopar), que é o ponto de medição da temperatura. Antes da inserção dos termopares no dressador aletado, aplicouse na ponta dos mesmos uma camada de resina acrílica autopolimerizante (de secagem rápida), da marca Clássico ${ }^{\circledR}$, com dois objetivos simultâneos. Primeiramente, impedir o contato direto dos termopares com a estrutura da máquina, evitando ruídos elétricos provenientes da mesma que pudessem prejudicar a leitura e, ao mesmo tempo, impedir que a temperatura gerada nas dressagens avariasse o verniz protetor e danificasse os termopares. A figura 56 apresenta uma representação esquemática deste procedimento. Após a secagem da resina, a mesma foi lixada manualmente até ficar com uma espessura mínima para o isolamento. 


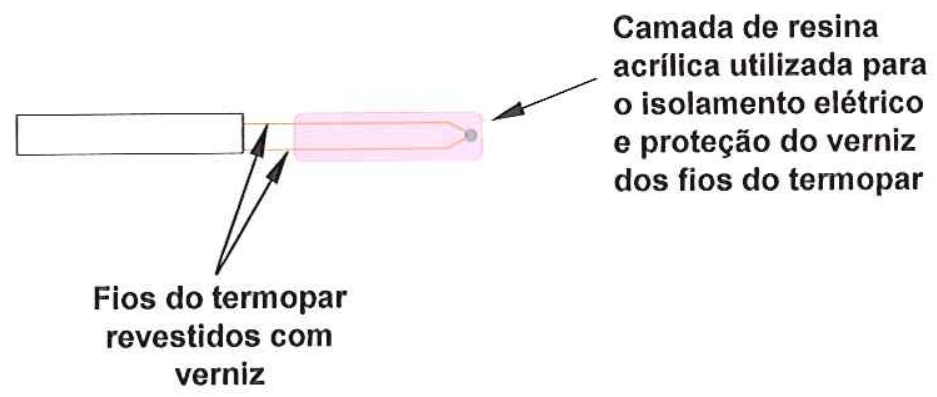

Figura 56: Representação esquemática da proteção dos fios do termopar.

\subsection{4 - Dispositivo PARA Miedição do DESGASte RADIAL dOS DiamANTES}

Após o final de cada ensaio, realizou-se a medição do desgaste radial de cada um dos 4 diamantes do dressador. Para que isto fosse possível, foi construído um dispositivo específico para esta finalidade.

Este dispositivo consistiu basicamente de uma chapa de aço de 3/16" de espessura, usinada na forma de semi-círculo, que foi fixada na parte frontal da retificadora, na mesma posição da tampa de proteção que é utilizada para confinar o rebolo de corte na máquina durante a sua operação.

$\mathrm{Na}$ chapa de aço foram fixadas duas peças retangulares, de mesmo tamanho, feitas de Alumínio sobre as quais foi presa a mesa graduada de um microscópio óptico. Esta mesa é capaz de realizar deslocamentos centesimais nas direções ortogonais $x$ e $y$, conforme o avanço manual que se forneça aos respectivos tambores de acionamento. No orifício central desta mesa, foi encaixada sob ajuste uma peça de Latão na qual foi fixado um relógio apalpador da marca Mitutoyo, modelo $\mathrm{n}^{0} 513$ - 404, com resolução de 0,01 mm, utilizado para aferir o desgaste dos diamantes. Uma vez que o relógio foi fixado à mesa, através do acionamento dos tambores foi possível aproximar ou recuar o apalpador da superfície dos diamantes do dressador.

As figuras 57, 58 e 59 permitem visualizar a posição de fixação do dispositivo na retificadora e alguns detalhes construtivos. 


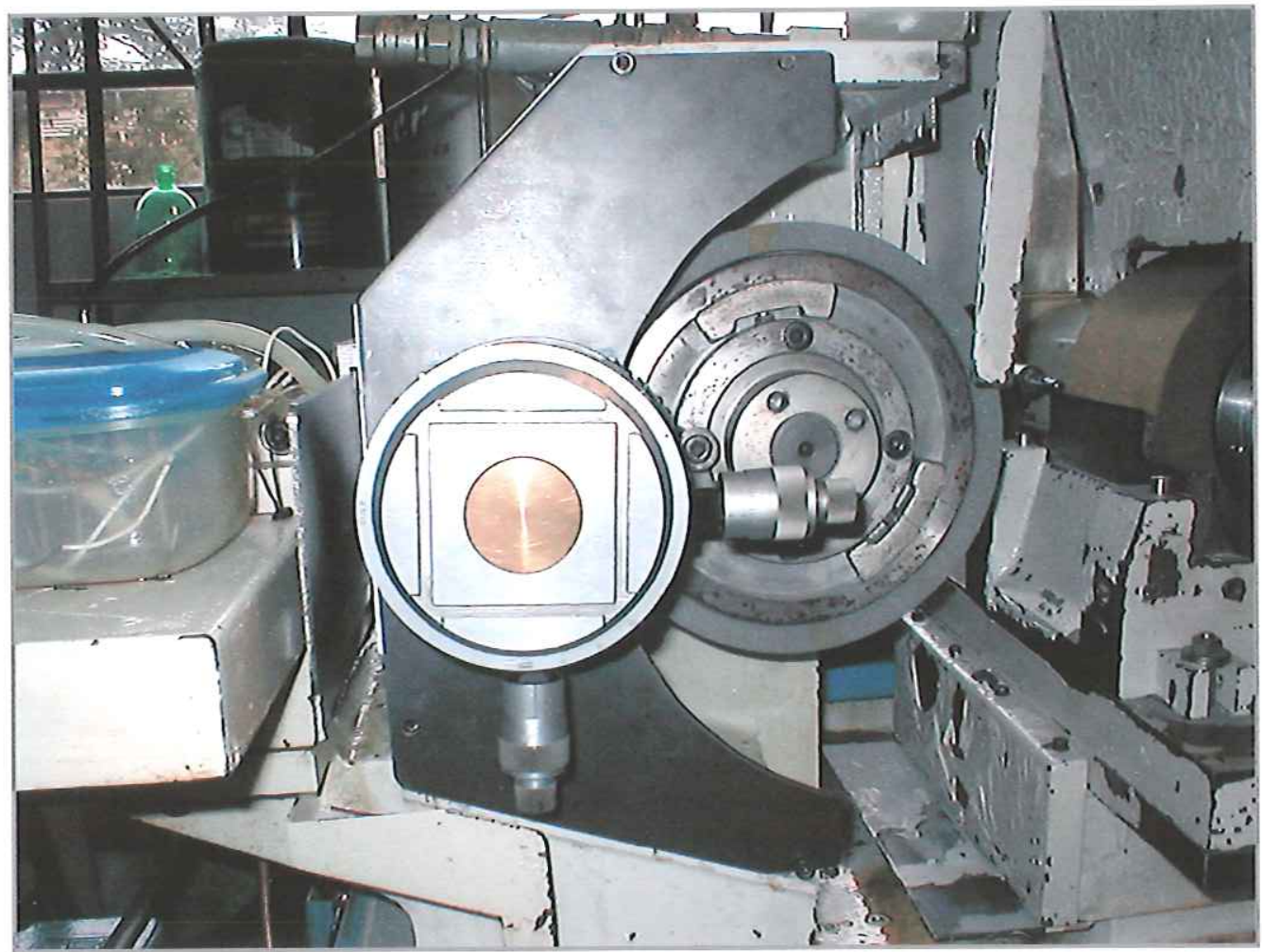

Figura 57: Posição na máquina do dispositivo de medição do desgaste dos diamantes.

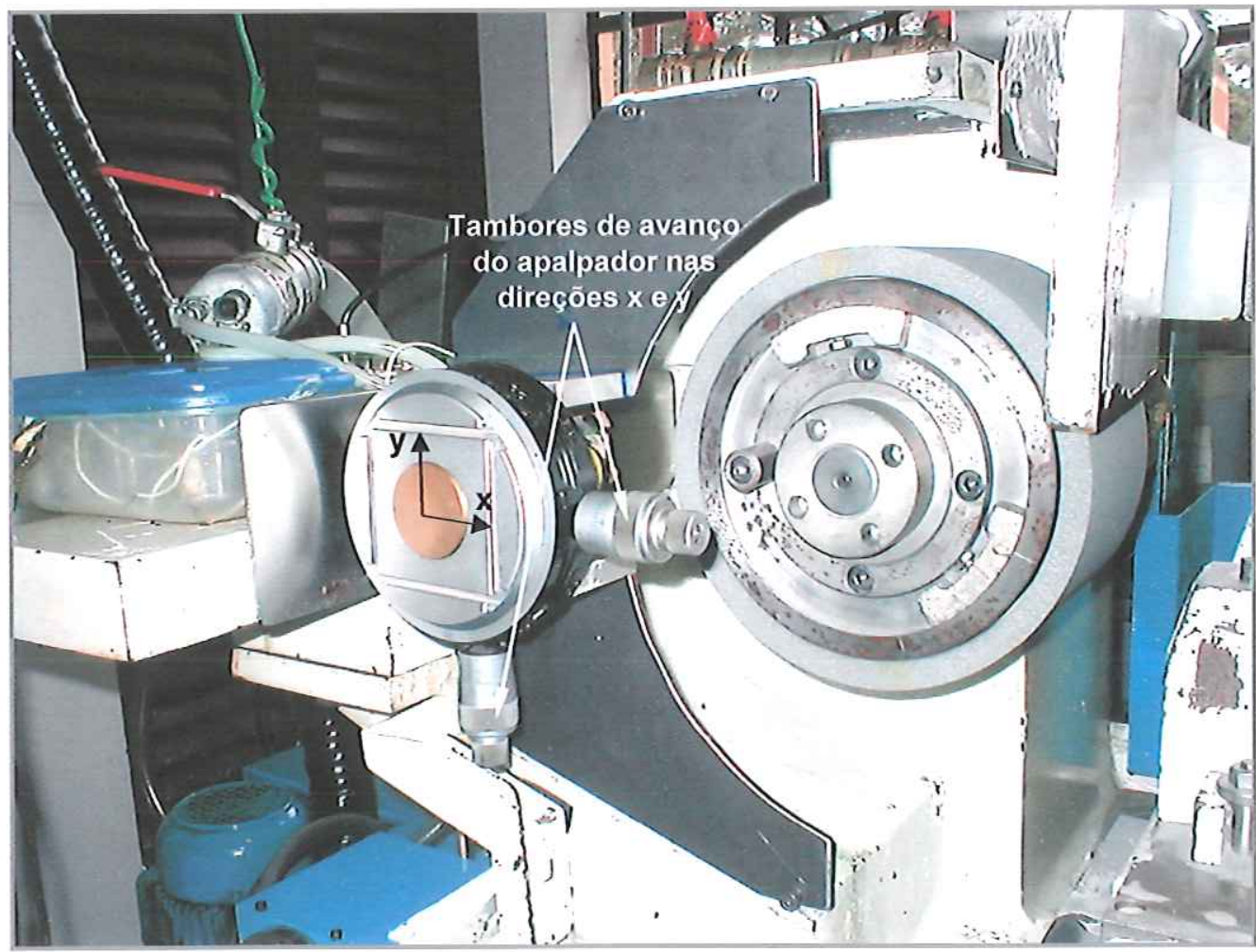

Figura 58: Detalhe do dispositivo de medição do desgaste dos diamantes. 


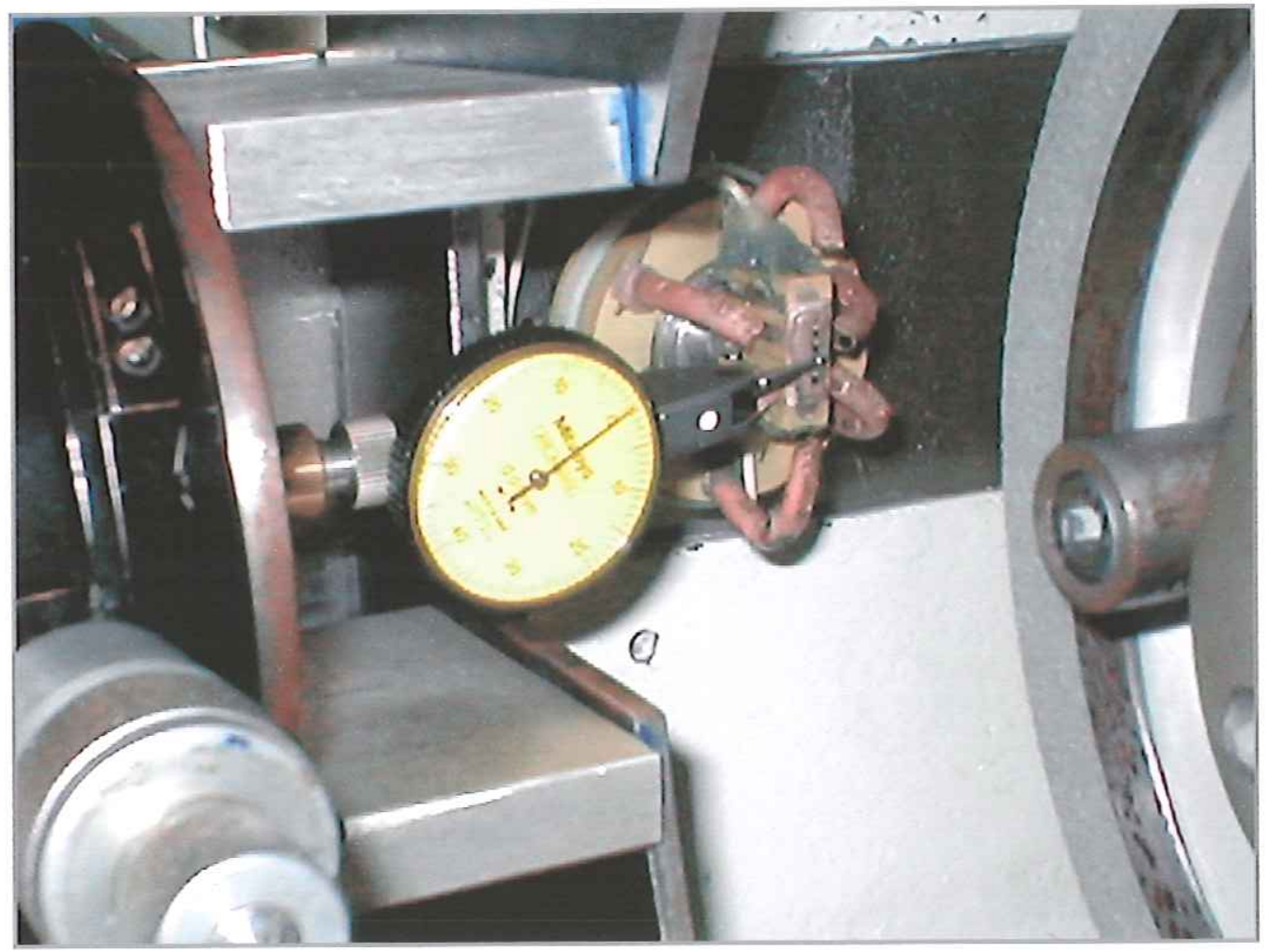

Figura 59: Detalhe da aproximação do apalpador à superfície dos diamantes.

\subsection{5 - MEdiçÄo do Desgaste Radial dos Diamantes}

O desgaste radial dos diamantes foi aferido através de um método de medição indireta. Para isso, foi retificada uma superfície na extremidade superior do corpo do dressador, adotada como posição de referência para as medições. Na figura 60 é possível visualizar a superfície de referência utilizada (destacada pelo retângulo vermelho). 


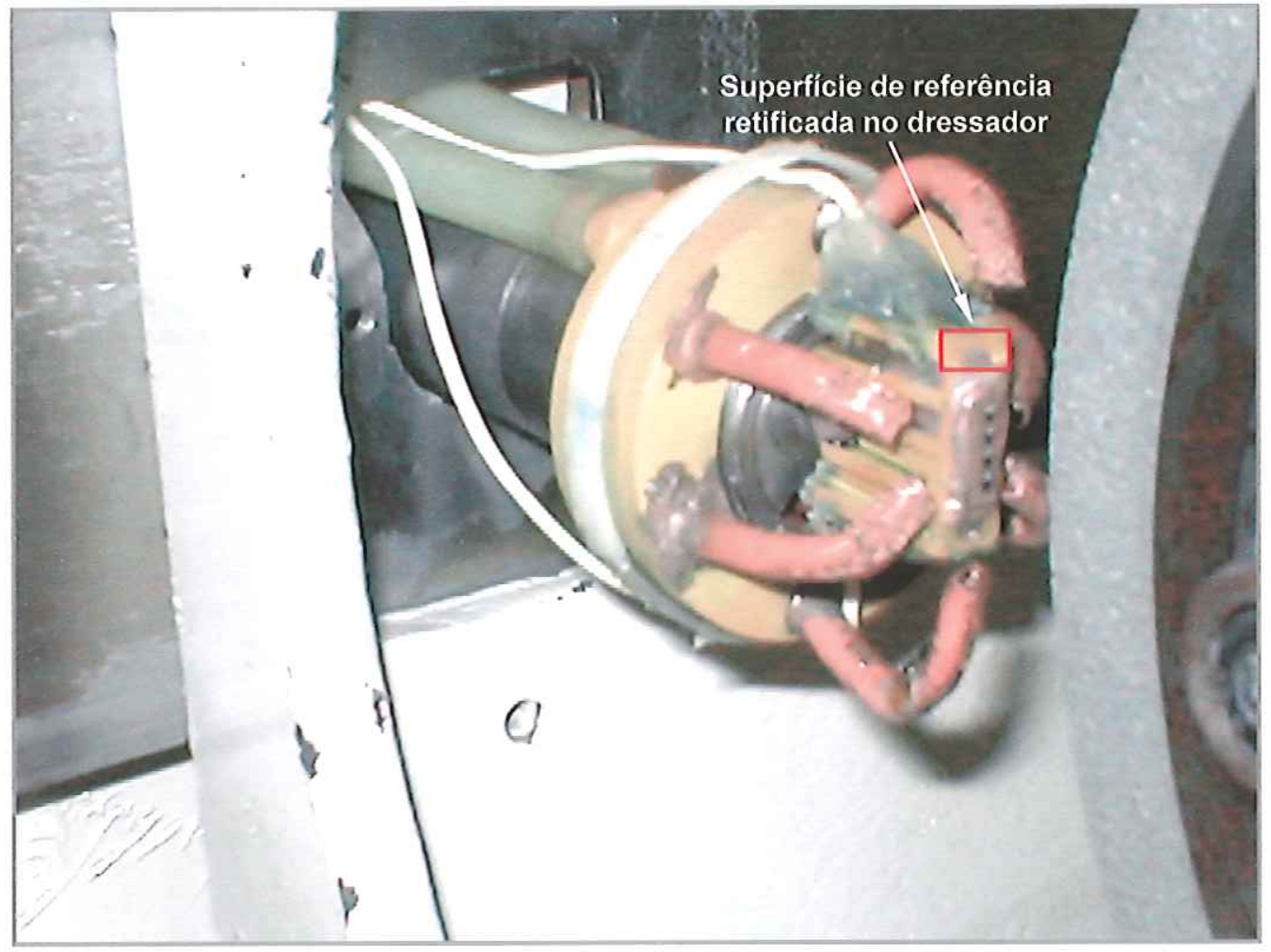

Figura 60: Superfície retificada de referência utilizada na medição do desgaste radial dos diamantes.

A seqüência de procedimentos para a medição do desgaste foi esta:

1) Terminado o ensaio, desliga-se a máquina, retira-se a tampa de proteção e coloca-se no mesmo lugar o dispositivo de medição do desgaste dos diamantes;

2) Aciona-se o tambor de deslocamento horizontal e aproxima-se a ponta do apalpador até que ela toque a superfície de referência do dressador. Após o toque, continua avançando-se o tambor até que o ponteiro dê uma volta completa no mostrador do relógio. Ao completar uma volta, interrompe-se o avanço no tambor. Anota-se o valor correspondente dessa posição no anel graduado do tambor;

3) Manuseando os dois tambores, recua-se a ponta do relógio, posicionando-a sobre o primeiro diamante do dressador (considerando o sentido descendente, a partir da superfície retificada de referência). Novamente aproxima-se a ponta do relógio até que ela toque a superfície do diamante, 
prosseguindo o avanço até que o ponteiro dê uma volta completa no mostrador. Após completar uma volta, interrompe-se o movimento. Feito isso, anota-se a posição correspondente no anel graduado do tambor. Este procedimento foi sucessivamente repetido para cada diamante do dressador;

4) Calcula-se a diferença entre os valores indicados no anel graduado do tambor de deslocamento horizontal, correspondentes às posições da superfície de cada diamante em relação à posição da superfície de referência no dressador. A comparação dessas diferenças entre ensaios consecutivos fornece o desgaste radial de cada diamante.

O toque da ponta do apalpador na superfície de referência do dressador, na direção vertical, foi sempre feito na mesma posição, para minimizar a ocorrência de erros entre um ensaio e outro. Além disso, em todo procedimento de aproximação da ponta do apalpador aos diamantes, utilizou-se uma lupa para visualizar melhor o toque, buscando sempre posicionar a ponta do apalpador na porção central da superfície de cada diamante.

\subsection{6 - ÍNDice de Desgaste do Dressador (ID)}

Para comparar o desgaste dos dressadores, utilizou-se um parâmetro, denominado Índice de Dressagem, ID [ $\mathrm{cm}^{3} / \mathrm{mm}$ ] proposto no trabalho de SILVA JUNIOR (1998). Este índice é calculado pelo quociente entre o volume de rebolo removido $\left[\mathrm{cm}^{3}\right]$ e o desgaste radial do dressador $[\mathrm{mm}]$ em uma operação de dressagem específica. Assim, quanto maior for o valor deste índice, maior será a durabilidade do dressador, em termos de volume de rebolo que pode ser dressado pelo mesmo. Desta forma, este índice foi utilizado como parâmetro de comparação para a durabilidade do dressador aletado nos ensaios realizados.

\subsection{7 - Cálculo do Volume de Rebolo Gasto}

O cálculo do volume de rebolo gasto para a obtenção do índice ID foi feito utilizando-se a seguinte fórmula: 


$$
\mathrm{V}_{\mathrm{REBOLO}}=\pi \cdot\left(\mathrm{R}^{2}-\mathrm{r}^{2}\right) \cdot(\text { LARGURA DRESSADA })
$$

na qual:

$$
\begin{aligned}
\mathbf{R}= & \text { raio inicial do rebolo, ou seja, o raio do rebolo antes } \\
& \text { do início dos passes de dressagem para cada } \\
& \text { ensaio; }
\end{aligned}
$$
$\mathbf{r}=$ raio final do rebolo, ou seja, o raio do rebolo após a finalização de todos os passes de dressagem para cada ensaio;

LARGURA DRESSADA = largura dressada na superfície de trabalho do rebolo, que no caso foi a largura total de corte do rebolo.

\section{6 - Banco de Ensaios}

O banco de ensaios utilizado consistiu de uma retificadora cilíndrica do tipo sem centros (ou centerless), fabricada pela empresa Microma de São Carlos (modelo E1, com potência de 12,5 CV disponível no motor principal), de um microcomputador do tipo Laptop, da marca COMPAQ, modelo Presario 12XL325, com processador Pentium 3 de 450 MHz, 192 Mb de memória RAM, no qual estava instalado o programa LABVIEW $^{\circledR}$, versão 6.1 , utilizado para obter os gráficos de temperatura obtidos durante as dressagens.

Utilizou-se também uma fonte DC ajustável, da marca MINIPA, modelo MPS-3003D, que alimentou com uma tensão de $12 \mathrm{~V}$ o circuito eletrônico utilizado e uma unidade de tratamento do sinal de emissão acústica, modelo DM42, fabricado pela empresa Sensis São Carlos, que foi conectada a um sensor piezoelétrico de captação do sinal de emissão acústica posicionado sobre o carro do dressador. O sinal de emissão acústica foi utilizado apenas para indicar o início e o final do contato dressador/rebolo. 
Os cabos condutores dos sinais de tensão captados pelos termopares e do sinal RMS de emissão acústica, oriundo da unidade DM42, foram ligados a um bloco de conectores da marca National Instruments (modelo SCB 68) que contém terminais de parafuso onde os cabos foram acoplados. Na seqüência, todos estes sinais foram enviados para o LABVIEW através de um cartão de aquisição DAQCARD ${ }^{\circledR}$ também da National Instruments, modelo 6062E, com capacidade de aquisição de $500 \mathrm{kS} / \mathrm{s}$. Este cartão realizou a leitura e conversão A/D (conversão do sinal analógico para digital) de todos os sinais captados para o LABVIEW, que apresentou na tela do laptop os correspondentes gráficos de temperatura.

A figura 61 apresenta uma foto do banco de ensaios descrito.

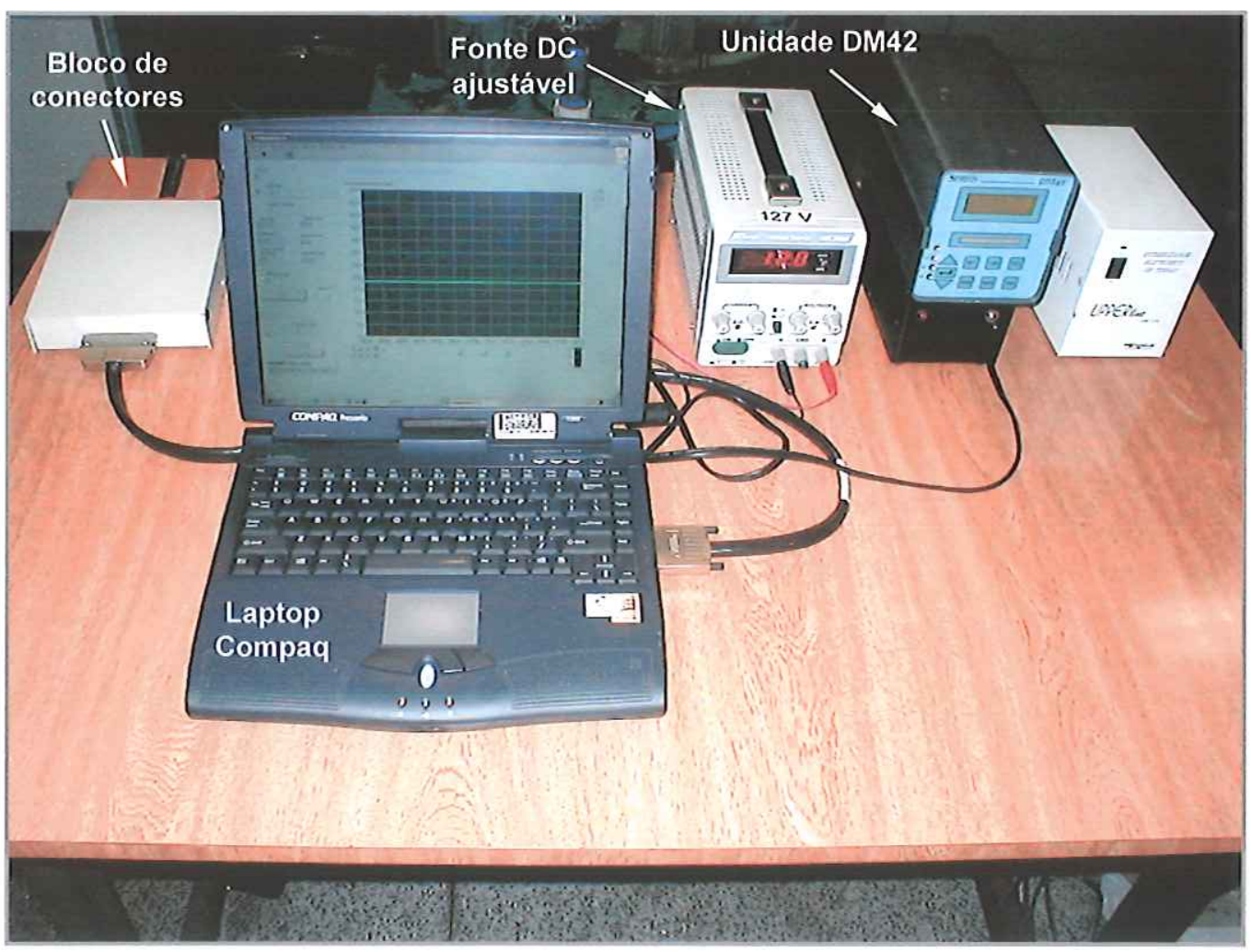

Figura 61: O banco de ensaios utilizado nos ensaios. 


\subsection{1 - Sistema de AqUisiçÃo dA TEMPERATURA}

No presente trabalho os termopares e o circuito eletrônico utilizados foram os mesmos que foram construídos e empregados no trabalho de BRAGHINI JUNIOR (2002). O circuito eletrônico realiza a conversão da tensão de entrada (captada pelos termopares), da ordem de microVolts e por isso muito sensível a ruídos elétricos, em uma tensão de saída em Volts (menos sensível a interferências elétricas). Os termopares conectados ao circuito possuem comprimento reduzido (aproximadamente $0,25 \mathrm{~m}$ ) uma vez que termopares muito longos podem estar sujeitos a ruídos que alteram sua leitura.

Resumidamente o circuito eletrônico transforma a tensão captada pelos termopares, que está originalmente em microVolts em uma tensão de saída em Volts. Este sinal segue através de cabos blindados até o bloco de conectores.

A figura 62 mostra uma placa de circuito eletrônico montada. A placa tem a função de receber a tensão de entrada do termopar (microVolts) e transformá-la em uma corrente elétrica que varia de 4 a 20 miliAmpéres.

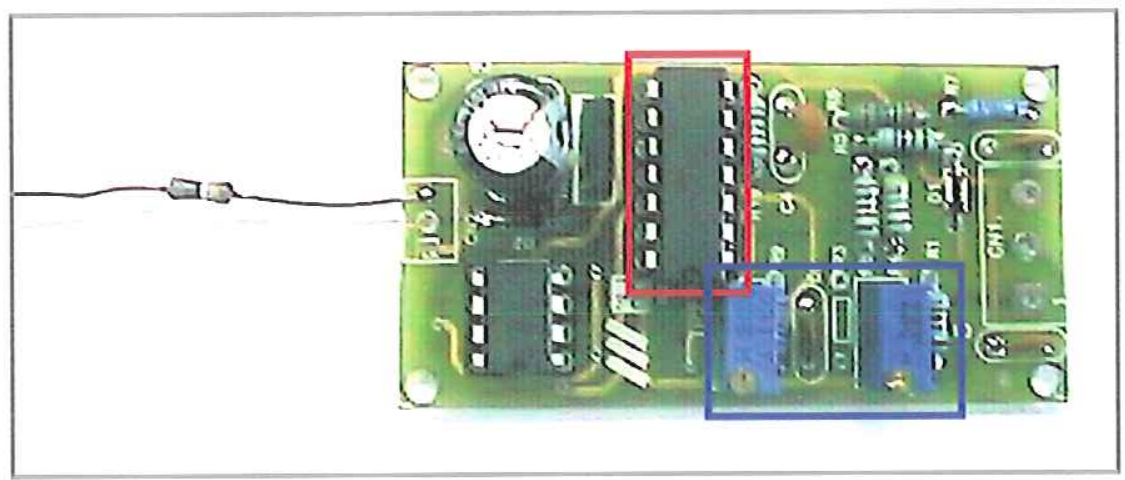

Figura 62: Circuito eletrônico utilizado para a conversão do sinal captado pelos termopares (BRAGHINI JUNIOR, 2002).

O circuito integrado (xtr 106), visto dentro do retângulo vermelho na figura 62, transforma a tensão oriunda do termopar em corrente. Os dois potenciômetros, dentro do retângulo azul, têm a função de ajustar a corrente mínima $(4 \mathrm{~mA})$ e a corrente máxima $(20 \mathrm{~mA})$. A tensão de saída pode variar 
entre 1 a 5 Volts e a sua leitura é feita pelo resistor que aparece à esquerda da placa na figura 62 (BRAGHINI JUNIOR, 2002).

\subsection{2 - CALibraçÃo dos Termopares}

Buscando verificar a possível existência de algum dano nos termopares após a utilização destes no trabalho de BRAGHINI JUNIOR (2002), realizou-se, previamente aos ensaios deste trabalho, uma nova aferição das respostas dos 2 termopares em um banho termostático. Utilizou-se para isto o equipamento da marca HAAKE, modelo C35 com controlador modelo F6, pertencente ao Laboratório de Refrigeração - SEM da EESC - USP.

$\mathrm{O}$ resultado mostrou que não havia diferenças significativas entre os níveis de temperatura aferidos pelos termopares e aqueles indicados no equipamento do banho, no máximo uma diferença de $1^{\circ} \mathrm{C}$ ou $2{ }^{\circ} \mathrm{C}$ entre as leituras, o que mostrou que as curvas de calibração continuavam válidas. Por isso, no LABVIEW $^{\circledR}$ foram utilizadas as mesmas equações das retas de calibração dos termopares obtidas no trabalho de BRAGHINI JUNIOR (2002) para a obtenção dos gráficos de temperatura.

\subsection{3 - TEMPO DE RESPOSTA DOS TERMOPARES}

A utilização da resina acrílica autopolimerizante para proteger os fios do termopar trouxe como inconveniente um retardo no tempo de leitura da temperatura aferida, uma vez que a resina atuou como uma barreira a mais para a passagem do fluxo de calor. As figuras 63 e 64 apresentam respectivamente os gráficos nos quais se verificam, respectivamente, a resposta dos 2 termopares utilizados neste trabalho e os tempos de resposta dos termopares com e sem resina, aferidos no mesmo equipamento utilizado para a verificação da calibração. 


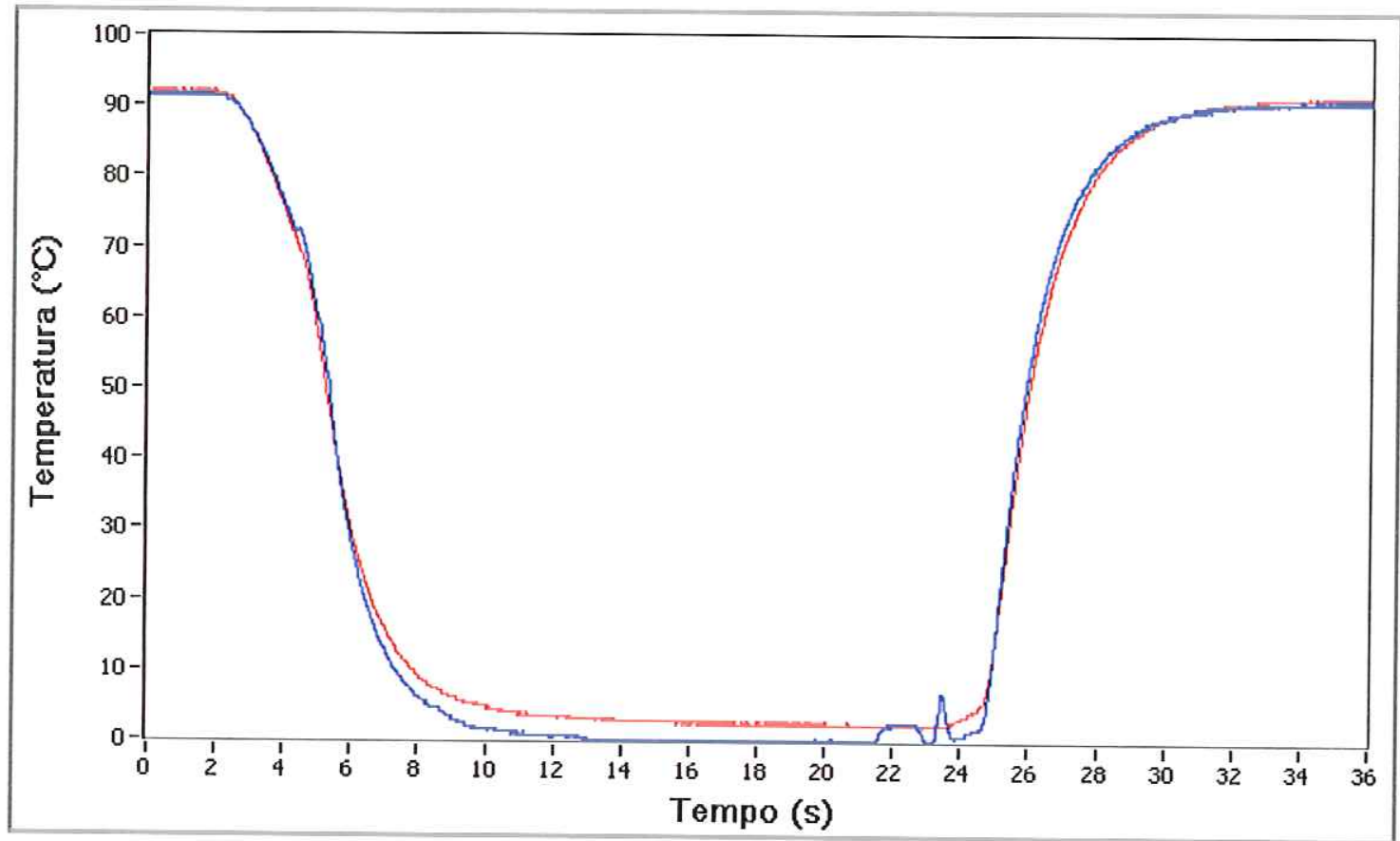

Figura 63: Resposta dos 2 termopares utilizados nos ensaios.

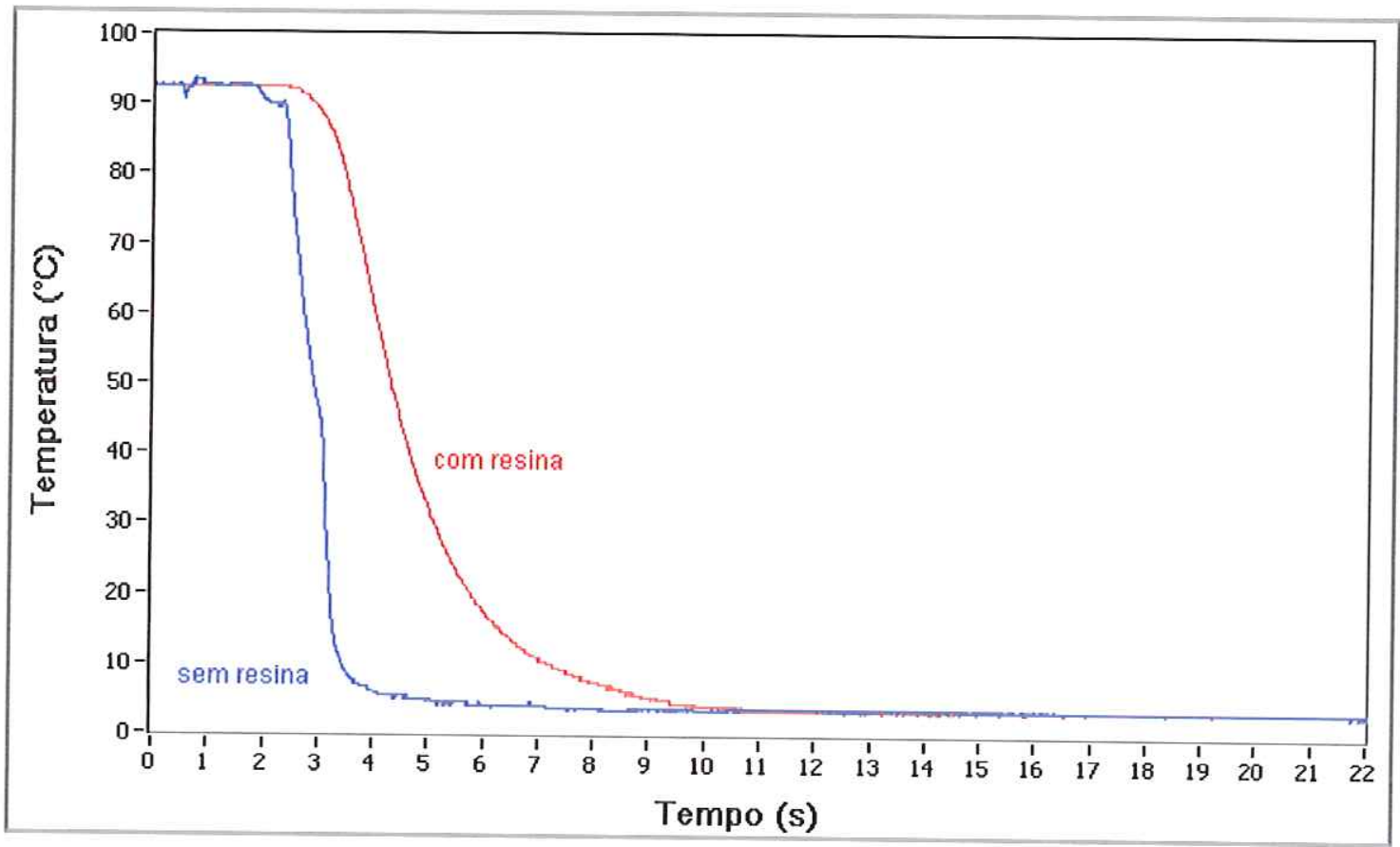

Figura 64: Tempos de resposta dos termopares com e sem resina.

Pode-se ver inicialmente na figura 63 que os dois termopares utilizados nos ensaios apresentam praticamente a mesma resposta para um mesmo sinal 
de tensão. $\mathrm{Na}$ figura 64 nota-se que a presença da resina provocou um atraso de aproximadamente $8 \mathrm{~s}$ na leitura da temperatura (considerando até a estabilizaçäo da resposta no gráfico da figura 64). Entretanto, este fato não chegou a impedir a realização dos ensaios, uma vez que os tempos de dressagem utilizados foram de $22 \mathrm{~s}, 31 \mathrm{~s}$ e $41 \mathrm{~s}$, suficientes para o sistema entrar em regime estacionário (quando ocorre a formação de um patamar de temperaturas), permitindo a aferição da temperatura obtida.

\subsection{4 - ENSAIOS REALIZADOS}

Os ensaios consistiram basicamente na realização de diversas operações de dressagem, sob várias condições, em uma retificadora cilíndrica do tipo sem centros, utilizando os dressadores aletado e de ponta única construídos. Durante cada passe de dressagem, as temperaturas no corpo das duas ferramentas foram aferidas através dos termopares.

Nos ensaios com o dressador aletado também foram feitas medições do desgaste radial de cada diamante do dressador, após o final de todos os passes de dressagem realizados em cada condição de ensaio. Estas mesmas condiçöes de ensaio empregadas com o dressador aletado foram repetidas nos ensaios com o dressador de ponta única, com a finalidade de estimar o fluxo de calor através de um único diamante (qfí), a ser utilizado posteriormente na simulação computacional.

Para a realização dos ensaios decidiu-se utilizar três níveis de variação para três parâmetros básicos da operação, buscando verificar o seu efeito sobre a temperatura gerada na ferramenta durante a dressagem. Os três parâmetros considerados foram a profundidade de dressagem $\left(\mathbf{a}_{\mathbf{d}}\right)$, o grau de recobrimento de dressagem $\left(\mathbf{U}_{\mathbf{d}}\right)$ e a vazão do fluido refrigerante $(\mathbf{Q})$. Neste caso, o total de combinaçöes possíveis para a realização de ensaios seria $3 \times 3$ x 3 , totalizando 27 ensaios diferentes. Mas isto ficou praticamente impossível, pois caso fossem realizadas todas essas combinações de ensaios, ocorreria um consumo muito elevado de rebolo (a realização de todas as 27 possíveis condiçőes certamente acarretaria o consumo de vários rebolos). 
Considerando estas limitações, decidiu-se selecionar os ensaios que pudessem fornecer os resultados mais diretos, escolhendo-se as condições teoricamente mais favoráveis para verificar a influência de cada parâmetro sobre a temperatura gerada na dressagem. Durante os ensaios, manteve-se constante a rotação do rebolo de corte, o qual possui a seguinte especificação:

- Rebolo de corte: DA120/150P7V17 da marca SIVAT.

onde:

DA: indica uma mistura de grãos abrasivos de Óxido de Alumínio branco e marrom;

120/150: indica que o rebolo utiliza grãos com duas granulometrias, a saber, 120 mesh e 150mesh;

P: $\quad$ indica que a dureza é P (rebolo duro);

7: $\quad$ indica que a estrutura do rebolo é 7 (estrutura aberta);

V17: indica que o ligante utilizado é do tipo vitrificado (o número 17 é um código do fabricante).

A tabela 19 apresenta as várias condições empregadas nos ensaios.

Tabela 19: Matriz de experimentos realizados.

\begin{tabular}{|c|c|c|c|c|c|c|}
\hline ENSAIO & $\mathrm{U}_{\mathrm{d}}$ & $a_{d}(\mu m)$ & $\begin{array}{c}\mathrm{S}_{\mathrm{d}} \\
\text { (mm/volta) }\end{array}$ & $\begin{array}{c}b_{d} \\
(\mathrm{~mm})\end{array}$ & Q (litros/minuto) & $\begin{array}{c}\mathrm{VS}_{\text {média }} \\
(\mathrm{m} / \mathrm{s})\end{array}$ \\
\hline 1 & 12,6 & 60 & 0,11 & 1,39 & 3,2 & 35,2 \\
\hline 2 & 12,6 & 40 & 0,11 & 1,39 & 3,2 & 43,4 \\
\hline 3 & 12,6 & 20 & 0,11 & 1,39 & 3,2 & 43,1 \\
\hline 4 & 19,9 & 60 & 0,07 & 1,39 & 3,2 & 42,8 \\
\hline 5 & 23,2 & 60 & 0,06 & 1,39 & 3,2 & 41,8 \\
\hline 6 & 19,9 & 60 & 0,07 & 1,39 & 4,1 & 36,8 \\
\hline 7 & 19,9 & 60 & 0,07 & 1,39 & 13,3 & 40,0 \\
\hline
\end{tabular}


Em todos os ensaios foi utilizado como fluido refrigerante o fluido semisintético Bio- $\mathrm{G}^{\circledR}$, fabricado pela empresa Microquímica, misturado com água na concentração de $3 \%$, nível recomendado por este fabricante para operações de retificação. O controle desta concentração foi realizado através de inspeções periódicas com um refratômetro de mão da marca QUIMIS ${ }^{\circledR}$, modelo Q -107-1 visualizado na figura 65.

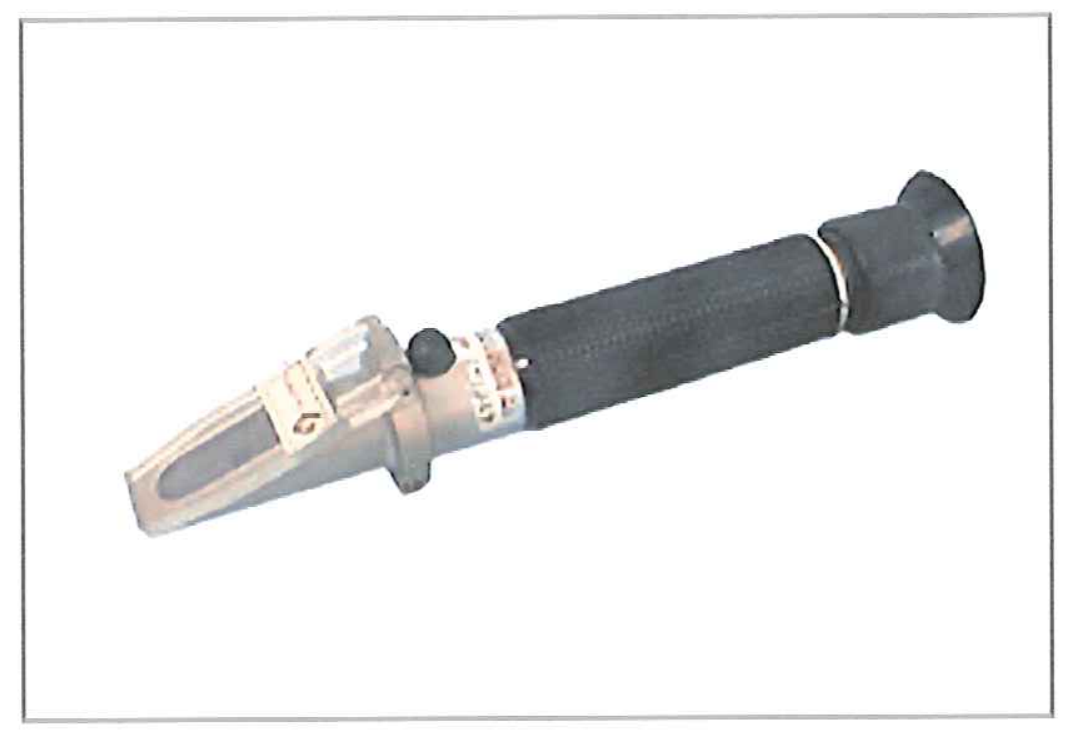

Figura 65: Refratômetro QUIMIS ${ }^{\circledast}$ utilizado para medir a concentração do fluido refrigerante durante os ensaios (www.quimis.com.br).

As fotos da superfície do dressador constantes no final do próximo capítulo (especificamente nas figuras 88 a 93) foram obtidas através de um microscópio óptico da marca ZEISS ${ }^{\circledR}$, modelo STEMI 2000-C existente no laboratório OPF. 


\section{4 - RESULTADOS E DISCUSSÕES}

\section{1 - Estimativa do Fluxo de Calor}

As figuras 66 e 67 apresentam gráficos típicos obtidos para as temperaturas nos termopares 1 (TP1) e 2 (TP2) nos ensaios com o dressador de ponta única para a estimativa do fluxo de calor. Os demais gráficos estão no Apêndice B.

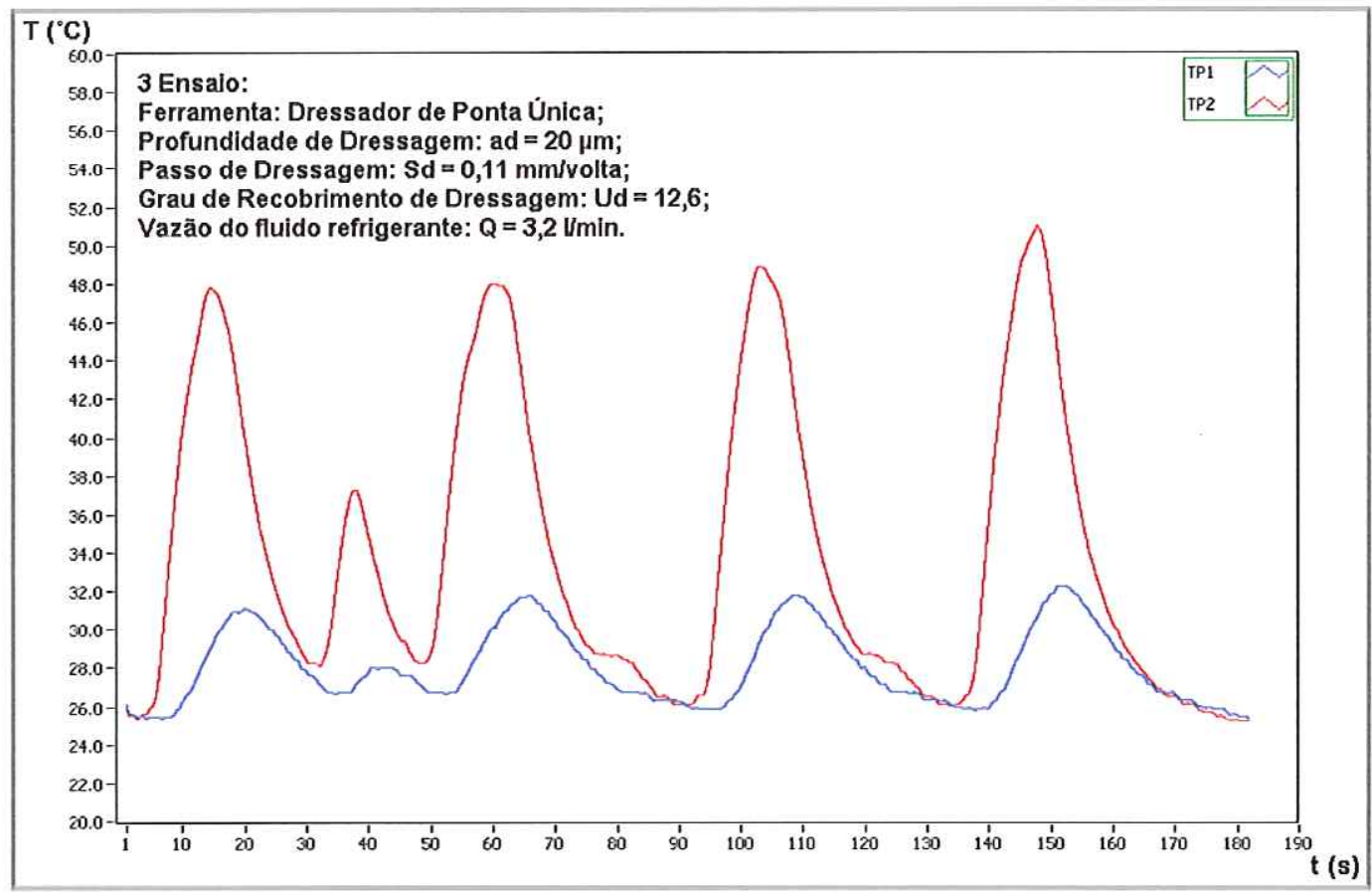

Figura 66: Temperaturas obtidas no $3^{\circ}$ ensaio com o dressador de ponta única com $Q=3,2 \mathrm{l} / \mathrm{min}, U_{d}=12,6$ e $a_{d}=20 \mu \mathrm{m}$. 


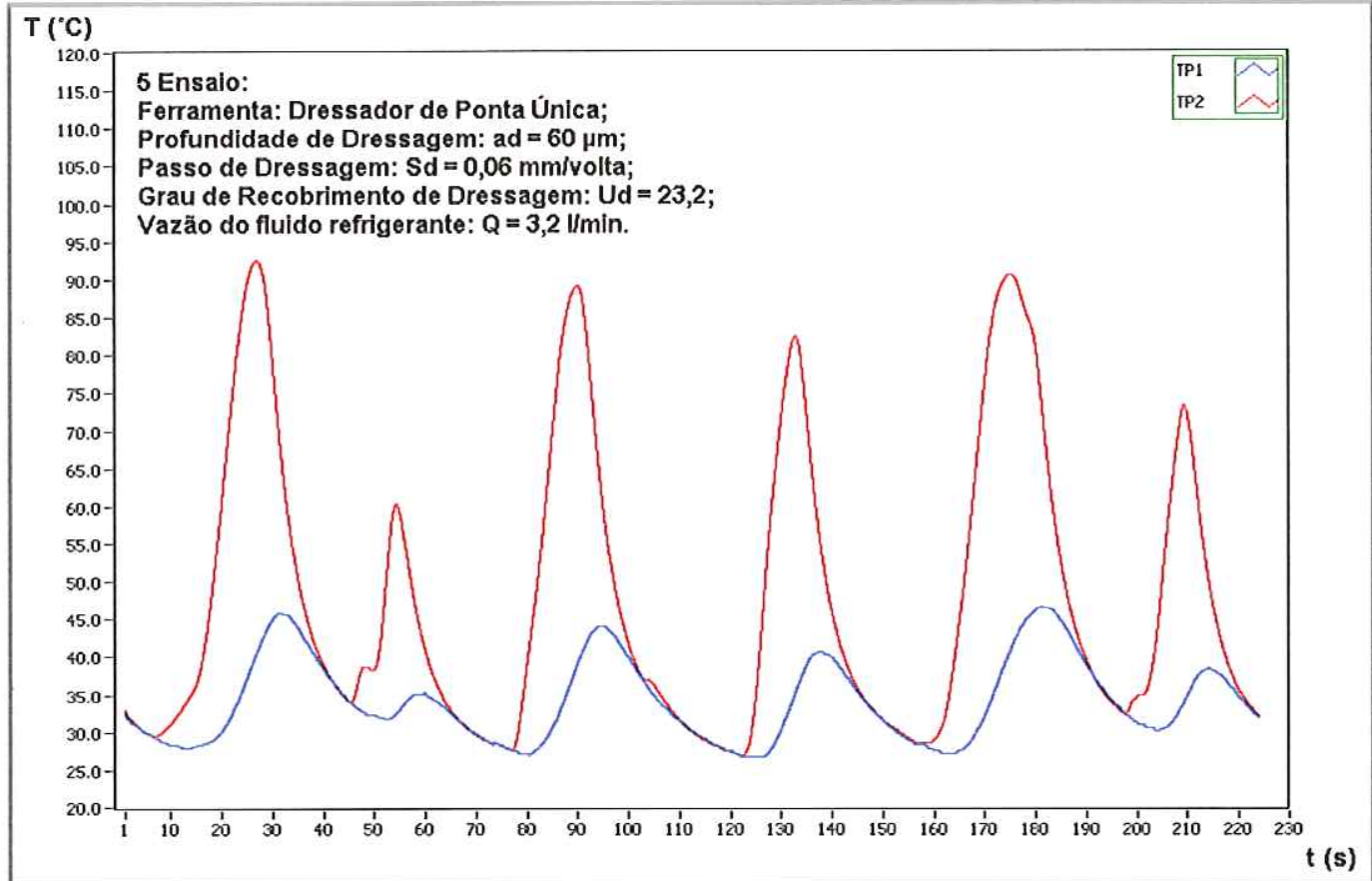

Figura 67: Temperaturas obtidas no $5^{\circ}$ ensaio com o dressador de ponta única com $Q=3,2 \mathrm{l} / \mathrm{min}, U_{d}=23,2$ e $a_{d}=60 \mu \mathrm{m}$.

A estimativa do fluxo de calor através do diamante (qfí) para cada ensaio foi feita através das Equações (3) e (4), mostradas no item 3.4.1 e repetidas abaixo:

$$
q f_{A C ̧ O}=k_{A C ̧ O} \cdot \Delta T_{A C ̧ O} / \Delta x_{A C ̧ O}
$$

e

$$
q f_{D}=k_{A C ̧ O} \cdot \Delta T_{A C ̧ O} \cdot A_{A C ̧ o} / \Delta x_{A C ̧ O} \cdot A_{D}
$$

onde:

- $\mathbf{k}_{\mathrm{Aço}}=51,9 \mathrm{~W} / \mathrm{m} \cdot \mathrm{K}$ (valor extraído de http://www.matweb.com);

- $\Delta \mathbf{x}_{\text {AÇo }}=15 \mathrm{~mm}$;

- $\Delta \mathrm{T}_{\mathrm{Aço}}=$ diferença de temperatura entre os dois termopares inseridos no dressador de ponta única (valor obtido nos ensaios);

- $\mathrm{A}_{\mathrm{Aço}}=$ área circular do dressador (corresponde à área circular de uma barra de aço com 3/8" de diâmetro);

- $A_{D}$ = área do diamante (área da secção quadrada de 1,2 mm). 
A diferença de temperatura entre os termopares 1 e $2\left(\Delta \mathrm{T}_{\mathrm{Aço}}\right)$ nos gráficos referentes ao dressador de ponta única foi utilizada para a estimativa do fluxo de calor que atravessa o diamante (conforme item 3.4.1).

Para a execução de todos os ensaios foram utilizados 3 dressadores de ponta única. Nestas ferramentas, o termopar 2 foi sempre posicionado mais próximo aos diamantes, captando assim níveis mais elevados de temperatura. Para todas as 7 condições de ensaios empregadas os gráficos obtidos foram semelhantes aos representados nas figuras 66 e 67.

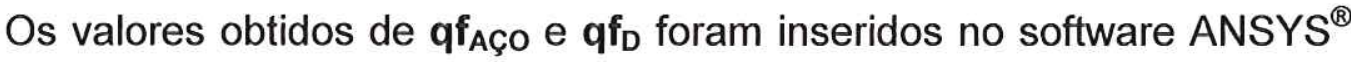
para realizar a simulação.

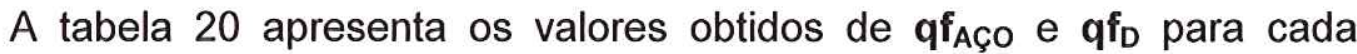
ensaio realizado.

Tabela 20: Valores obtidos de $q f_{A c ̧ o}$ e $q f_{D}$ para cada ensaio.

\begin{tabular}{|c|c|c|}
\hline ENSAIO & $q f_{A C ̧ O}\left(W / m^{2}\right)$ & $q f_{D}\left(W / m^{2}\right)$ \\
\hline 1 & $174.626,2$ & $8.595 .753,99$ \\
\hline 2 & $100.686,0$ & $4.956 .141,09$ \\
\hline 3 & $57.782,0$ & $2.844 .245,92$ \\
\hline 4 & $136.670,0$ & $6.727 .408,01$ \\
\hline 5 & $156.841,8$ & $7.720 .339,37$ \\
\hline 6 & $192.479,8$ & $9.474 .574,88$ \\
\hline 7 & $103.903,8$ & $5.114 .533,23$ \\
\hline
\end{tabular}

\section{2 - Medição de Temperatura no Dressador Aletado}

As figuras 68 e 69 apresentam gráficos típicos obtidos na medição das temperaturas pelos termopares 1 (TP1) e 2 (TP2) nos ensaios com o dressador aletado. Os demais gráficos estão no Apêndice $\mathrm{C}$. 


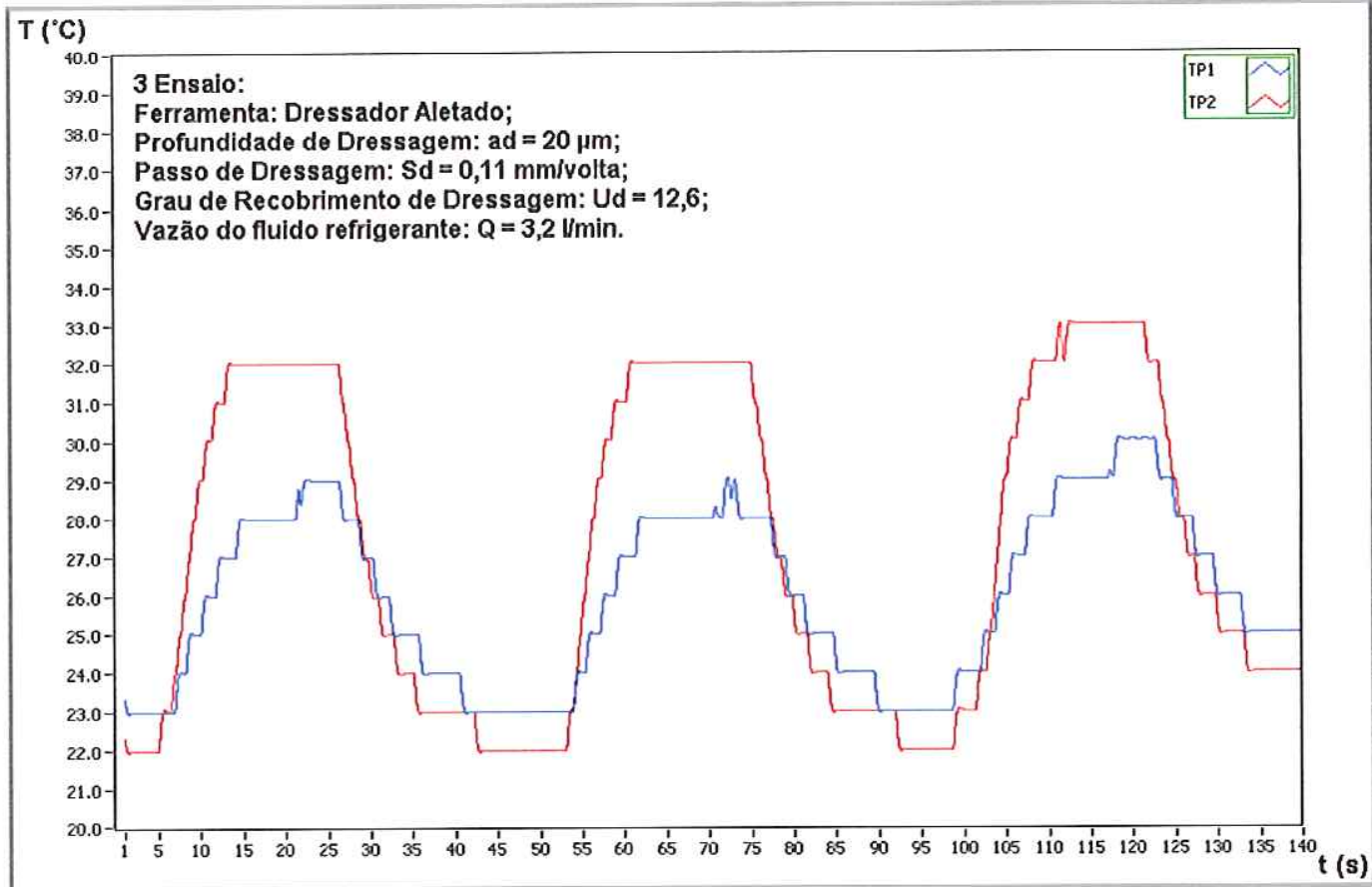

Figura 68: Temperaturas obtidas no $3^{\circ}$ ensaio com o dressador aletado com $Q=3,2 \mathrm{l} / \mathrm{min}, U_{d}=12,6$ e $\mathrm{a}_{d}=20 \mu \mathrm{m}$.

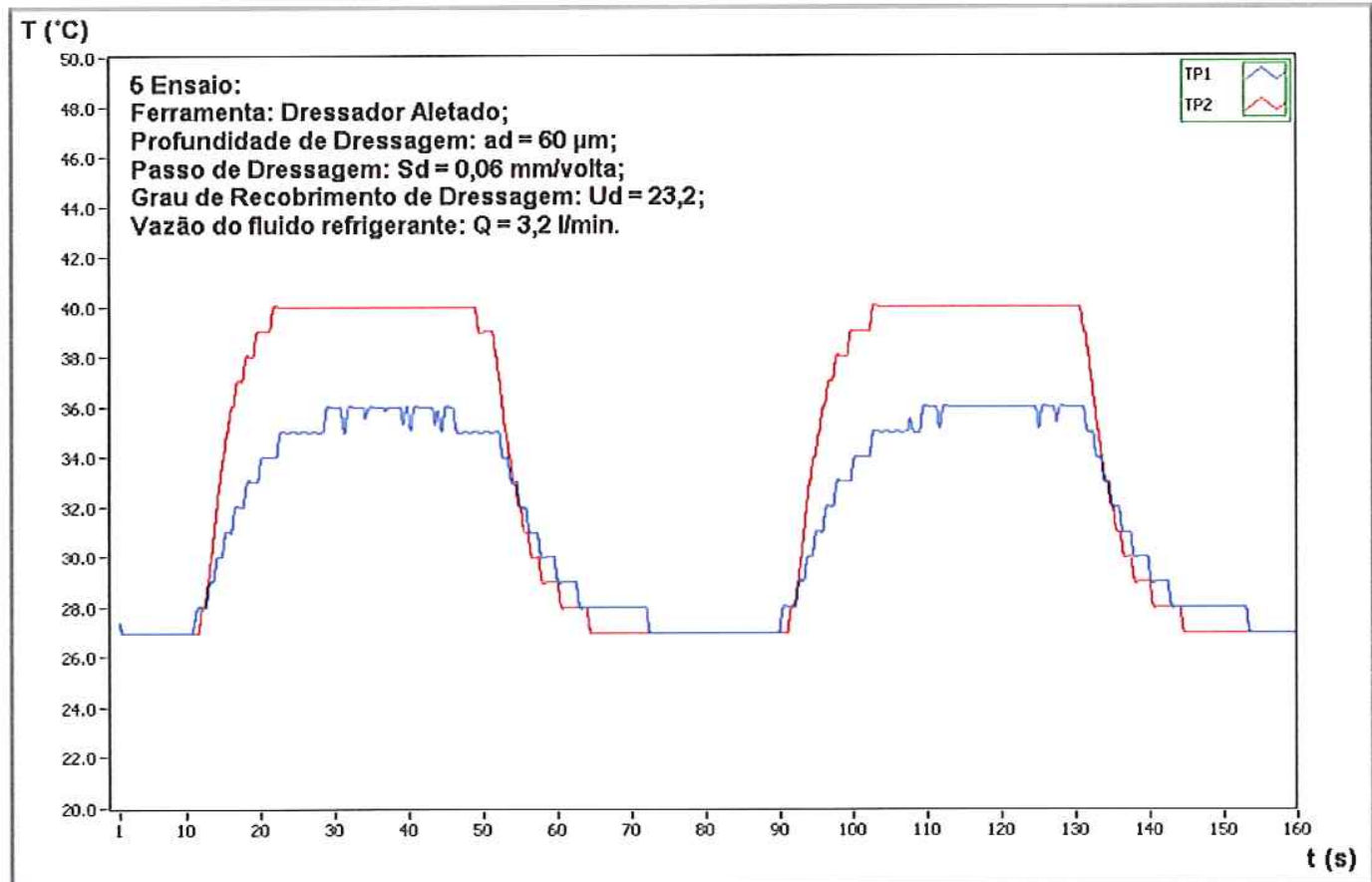

Figura 69: Temperaturas obtidas no $5^{\circ}$ ensaio com o dressador aletado com $Q=3,2 \mathrm{l} / \mathrm{min}, U_{d}=23,2$ e $\mathrm{a}_{d}=60 \mu \mathrm{m}$. 
Para cada ensaio as temperaturas médias das regiões planas desses gráficos (patamares) foram utilizadas para a análise dos resultados, correlacionando-as com os parâmetros considerados alternadamente nos ensaios (ou seja, $\mathbf{Q}, \mathbf{U}_{\mathbf{d}}$ e $\mathbf{a}_{\mathbf{d}}$ ). Todos os ensaios foram realizados utilizando-se um único dressador aletado para a medição das temperaturas no seu interior.

\subsection{1 - Resultados de temperatura Variando-se a Profundidade de} DRESSAGEM $a_{d}$ (ENSAIOS 1, 2 e 3)

Inicialmente, nos três primeiros ensaios, fixou-se o valor da vazão $\left(\mathbf{Q}_{1}=\right.$ $3,2 \mathrm{I} / \mathrm{minuto})$ e do grau de recobrimento de dressagem $\left(\mathbf{U}_{\mathbf{d} \mathbf{1}}=12,6\right)$, variando-se apenas a profundidade de dressagem em três níveis $\left(\mathbf{a}_{\mathbf{d} 1}=60 \mu \mathrm{m}\right.$ para $\circ 1^{\circ}$ ensaio; $\mathbf{a}_{\mathrm{d} 2}=40 \mu \mathrm{m}$ para o $2^{\circ}-$ ensaio e $\mathbf{a}_{\mathrm{d} 3}=20 \mu \mathrm{m}$ no $3^{\circ}$ - ensaio).

A figura 70 mostra os resultados do acréscimo de temperatura atingido pelos termopares, ou seja, descontando-se a temperatura ambiente. Os valores adotados também foram a média dos patamares atingidos durante a dressagem.

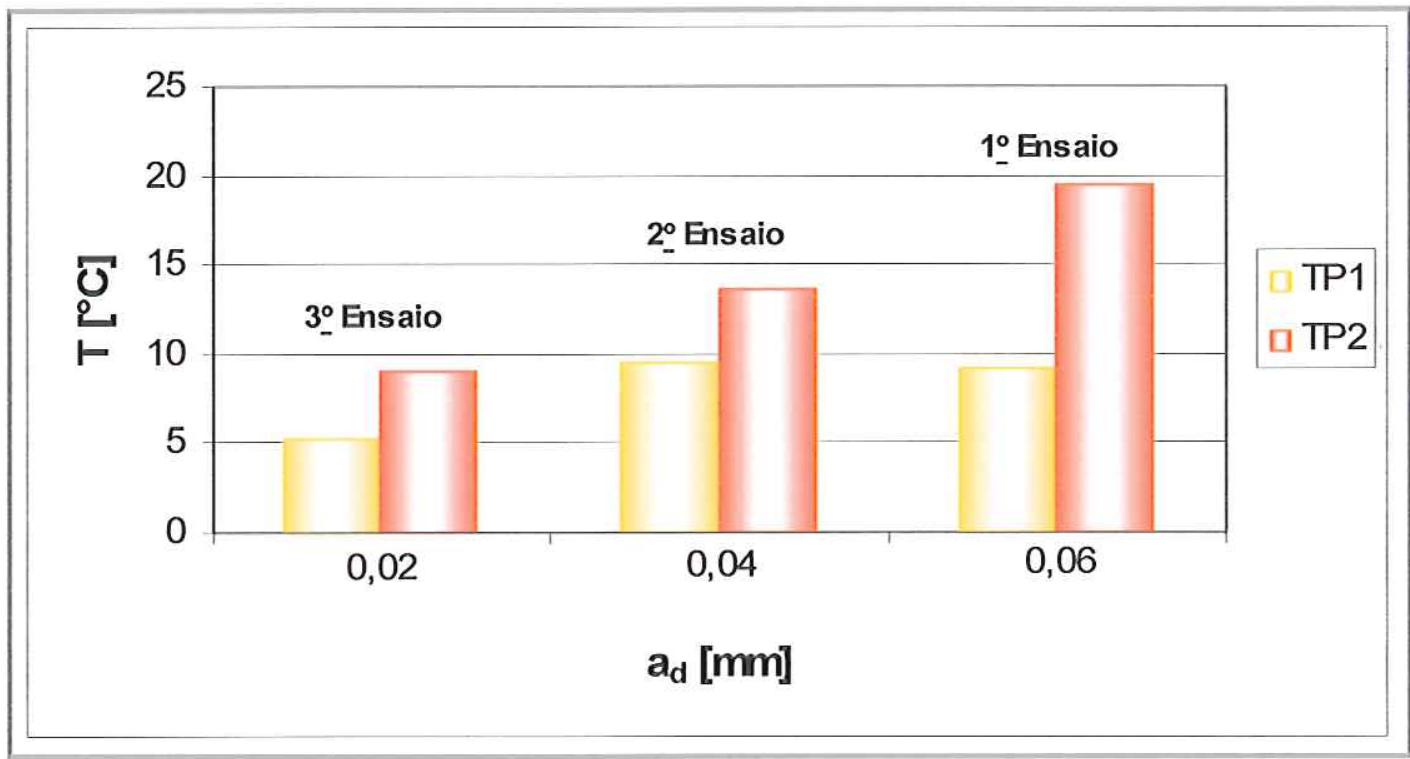

Figura 70: Temperatura média versus $\mathbf{a}_{d} \operatorname{com} U_{d}=12,6$ e $Q=3,2 \mathrm{l} / \mathrm{min}$ (ensaios 1, 2 e 3). 
Observando-se a figura 70 , pode-se ver que os níveis de temperatura foram aumentando à medida que a profundidade de dressagem foi sendo aumentada. Isto devido ao fato dos diamantes estarem cada vez com uma maior área atritando com os abrasivos do rebolo. Conseqüentemente, uma maior área de corte resultará em maior geração de calor. Assim, os resultados mostram uma relação direta entre os níveis de temperatura no dressador com a profundidade de dressagem utilizada.

\subsection{2 - Resultados de temperatura VARIANDo-se O Grau dE} RECOBRIMENTO $U_{d}$ (ENSAIOS 1,4 e 5 )

Após os resultados iniciais de temperatura obtidos nos 3 primeiros ensaios, decidiu-se fixar os valores para os parâmetros $\mathbf{a}_{\mathbf{d}}$ e $\mathbf{Q}$ para $\mathbf{a}$ realização dos ensaios seguintes. Para $\mathbf{a}_{\mathbf{d}}$ fixou-se o valor $\mathbf{a}_{\mathbf{d} 1}=60 \mu \mathrm{m}$, e manteve-se o mesmo valor de $\mathbf{Q}=3,2 \mathrm{l} / \mathrm{min}$, variando-se $\mathbf{U}_{\mathbf{d}}$ em três níveis $\left(\mathbf{U}_{\mathbf{d} 1}\right.$ $=12,6, \mathbf{U}_{\mathrm{d} 2}=19,9$ e $\left.\mathbf{U}_{\mathrm{d} 3}=23,2\right)$.

A figura 71 mostra o aumento de temperatura, em relação à ambiente, obtido para estas novas condições de dressagem.

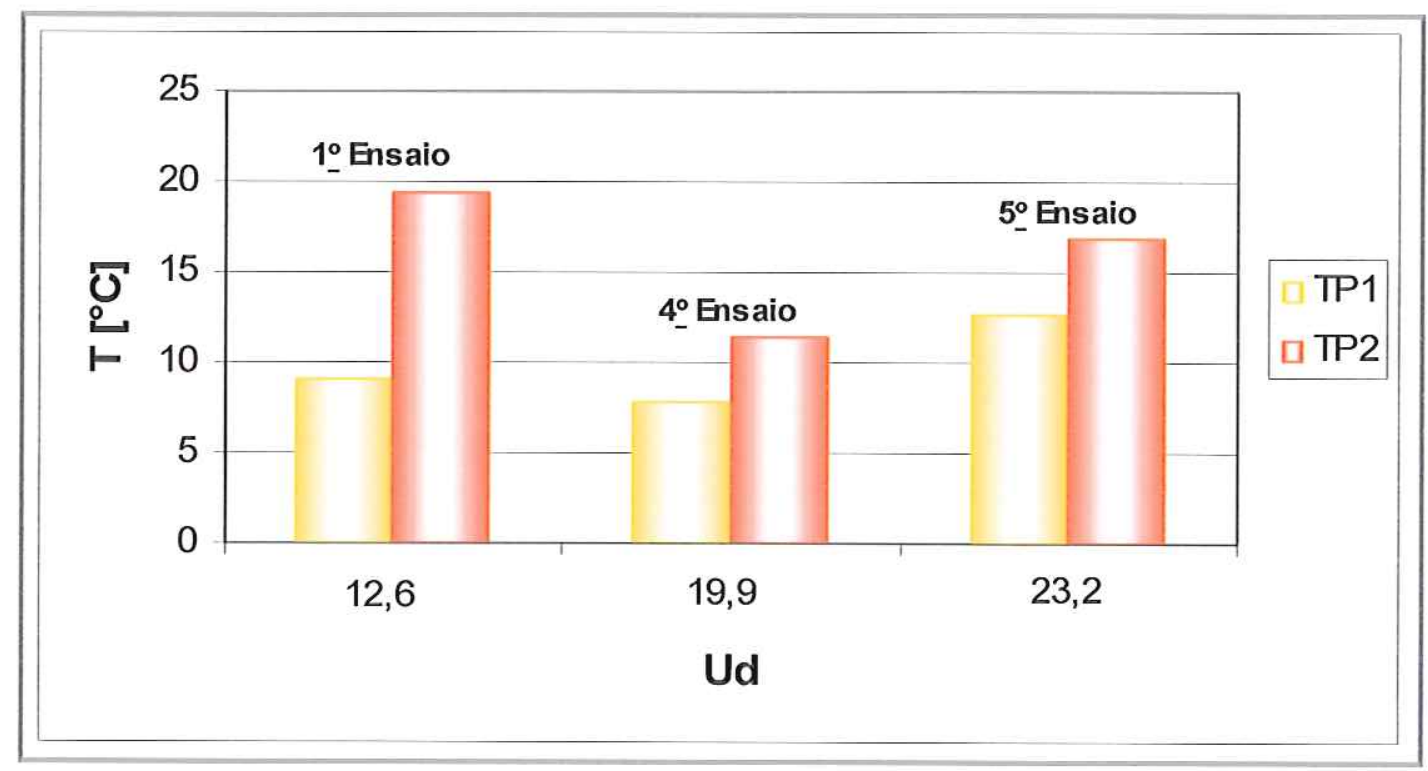

Figura 71: Temperatura média versus $\boldsymbol{U}_{d} \operatorname{com} \mathrm{a}_{d}=60 \mu \mathrm{m}$ e $Q=3,2 \mathrm{l} / \mathrm{min}$ (ensaios 1, 4 e 5). 
Observando-se a figura 71 pode-se ver que os níveis de temperatura obtidos apresentaram um comportamento relativamente indefinido. $\mathrm{O}$ aumento do valor do grau de recobrimento $\left(\mathbf{U}_{\mathrm{d}}\right)$ entre os ensaios foi feito diminuindo-se o valor do passo de dressagem $\left(\mathbf{S}_{\mathrm{d}}\right)$, considerando que os diamantes do dressador mantiveram a sua largura de atuação inalterada. Isto provoca um aumento do tempo de contato entre o dressador e o rebolo, mas uma diminuição da área da secção de corte. Nestas condições, empregando o mesmo valor de profundidade de dressagem $\left(\mathbf{a}_{\mathbf{d}}\right)$ e de vazão do fluido refrigerante $(\mathbf{Q})$, o aumento do tempo de contato dressador-rebolo conduziria a um aumento de temperatura, devido ao atrito, enquanto que a diminuição na área de corte produziria um efeito contrário. Conforme essas duas variáveis se combinam o resultado em termos de temperatura pode variar. Isso pode ser observado quando se aumenta $U_{d}$ de 12,6 para 19,9 , um aumento de $57 \%$, que provoca uma diminuição de temperatura. Neste caso o efeito de diminuição do passo foi mais significativo em diminuir a temperatura, do que o maior tempo de atrito o foi em aumentá-la. No caso de um novo aumento de $\mathbf{U}_{\mathbf{d}}$ de 19,9 para 23,2 , o longo tempo de contato praticamente re-estabeleceu as temperaturas iniciais.

\subsection{3 - Resultados de temperatura VARIANDO-SE A VAZÃo do Fluido} REFRIGERANTE Q (ENSAIOS 4, 6 e 7)

Nesta última série de ensaios variou-se a vazão do fluido refrigerante também entre três níveis $\left(\mathbf{Q}_{1}=3,2 \mathrm{l} / \mathrm{min}, \mathbf{Q}_{2}=4,1 \mathrm{l} / \mathrm{min}\right.$ e $\left.\mathbf{Q}_{3}=13,3 \mathrm{l} / \mathrm{min}\right)$, enquanto se manteve constantes o grau de recobrimento $\mathbf{U}_{\mathbf{d}}=19,9$ e a profundidade de dressagem $\mathbf{a}_{\mathbf{d}}=60 \mu \mathrm{m}$.

A figura 72 apresenta os resultados de temperatura obtidos com a variação da vazão do fluido refrigerante $(\mathbf{Q})$. 


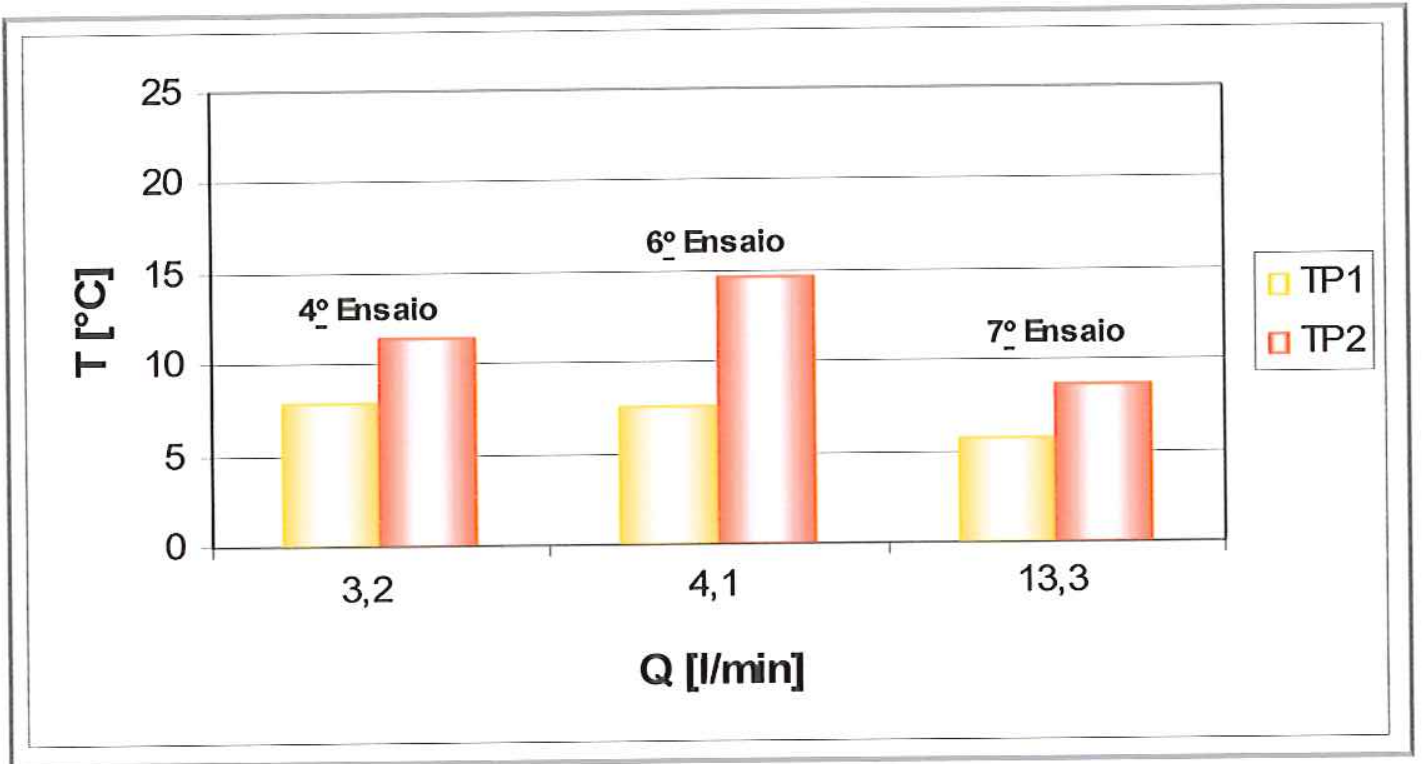

Figura 72: Temperatura média versus $Q$ com $a_{d}=60 \mu m$ e $U_{d}=19,9$ (ensaios 4, 6 e 7).

Observando-se a figura 72 vê-se que o aumento da vazão do fluido refrigerante somente produziu algum efeito sobre os níveis de temperatura quando se utilizou a vazão máxima (condição do $7^{-}$ensaio). Mudanças pequenas de vazão de fluido refrigerante não produziram efeito significativo na temperatura do dressador. Somente um aumento de 4 vezes na vazão inicial foi capaz de produzir alguma diminuição consistente da temperatura no dressador. $O$ aumento da pressão de fluido também poderia ser significativo em diminuir a temperatura, porém esse efeito não pôde ser facilmente testado neste trabalho.

\section{3 - Medição do Desgaste do Dressador}

A tabela 21 apresenta os valores referentes ao total de passes de dressagem para cada ensaio realizado. 
Tabela 21: Quantidade total de passes de dressagem em cada ensaio.

\begin{tabular}{|c|c|}
\hline ENSAIO & TOTAL DE PASSES DE DRESSAGEM \\
\hline 1 & 62 \\
\hline 2 & 20 \\
\hline 3 & 34 \\
\hline 4 & 36 \\
\hline 5 & 21 \\
\hline 6 & 114 \\
\hline 7 & 44 \\
\hline
\end{tabular}

O desgaste individual de cada diamante do dressador aletado foi medido, considerando-se o desgaste total após a realização de todos os ensaios. A tabela 22 apresenta estes valores. A ordem de referência aos diamantes nesta tabela considera a ordem de início de contato dos grãos abrasivos com cada diamante do dressador segundo a direção da velocidade periférica. Assim, na tabela 22 o termo "1ํ diamante" refere-se ao diamante do dressador aletado que primeiramente estabelece contato com os grãos abrasivos do rebolo e assim por diante.

Tabela 22: Desgaste radial total dos diamantes do dressador aletado.

\begin{tabular}{|c|c|}
\hline DIAMANTE & DESGASTE RADIAL $(\mathrm{mm})$ \\
\hline $1^{\circ}$ & 2,08 \\
\hline $2_{-}^{\circ}$ & 2,08 \\
\hline $3_{-}^{\circ}$ & 2,05 \\
\hline $4^{\circ}$ & 2,02 \\
\hline
\end{tabular}


De acordo com a tabela 22 observa-se que o primeiro e segundo diamantes tiveram um desgaste ligeiramente maior que os outros dois. Embora os valores de desgaste não sejam muito diferentes, este comportamento concorda com os resultados de MARINELLI FILHO et al. (1998), o qual concluiu que, para um dressador do tipo placa, contendo 4 diamantes de perfil constante alinhados, o primeiro diamante que toca o rebolo durante a dressagem é aquele que suporta os maiores esforços da operação, apresentando por isso um maior nível de desgaste comparado aos demais (MARINELLI FILHO et al. (1999).

\subsection{1 - Resultados do Índice ID Variando-se a Profundidade de} DREsSAgem $a_{d}$ (ENSAIOS 1, 2 e 3)

A figura 73 mostra os resultados obtidos para o índice ID $\left[\mathrm{cm}^{3} / \mathrm{mm}\right]$, definido como volume de rebolo consumido em relação ao desgaste radial médio dos diamantes do dressador, para os 3 primeiros ensaios.

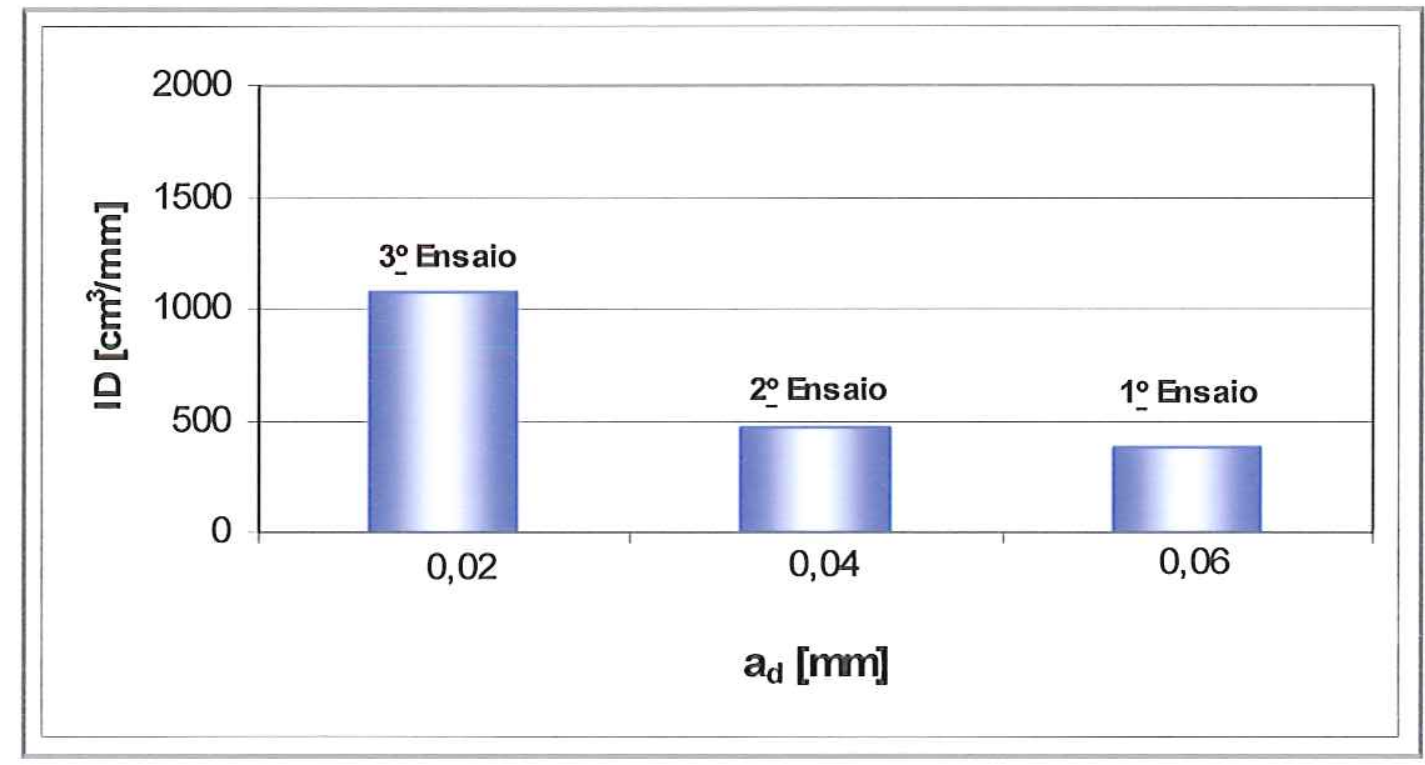

Figura 73: Resultados do índice ID com $Q=3,2 \mathrm{I} / \mathrm{min}$ e $U_{d}=12,6$ (ensaios 1, 2 e 3).

Observando-se a figura 73 nota-se que o índice ID apresentou uma diminuição contínua entre os ensaios, mostrando que para um menor valor de 
$\mathbf{a}_{\mathbf{d}}$ (condição do $3^{\circ}$ - ensaio) o dressador apresenta uma maior durabilidade, ou seja, é capaz de remover uma maior quantidade de rebolo para uma mesma quantia de desgaste radial do dressador. Por outro lado, um maior valor de $\mathbf{a}_{\mathbf{d}}$ provoca um maior desgaste do dressador, resultando num menor valor de ID, conforme se pode ver no resultado referente ao $1^{\circ}$ - ensaio.

\subsection{2 - RESUltados do ÍNDICE ID VARIANDO-SE O GRAU DE RECOBRIMENTO $\mathrm{U}_{\mathrm{d}}$ (ENSAIOS 1, 4 e 5)}

A figura 74 mostra os resultados obtidos para o índice ID $\left[\mathrm{cm}^{3} / \mathrm{mm}\right]$ para os ensaios 1,4 e 5 .

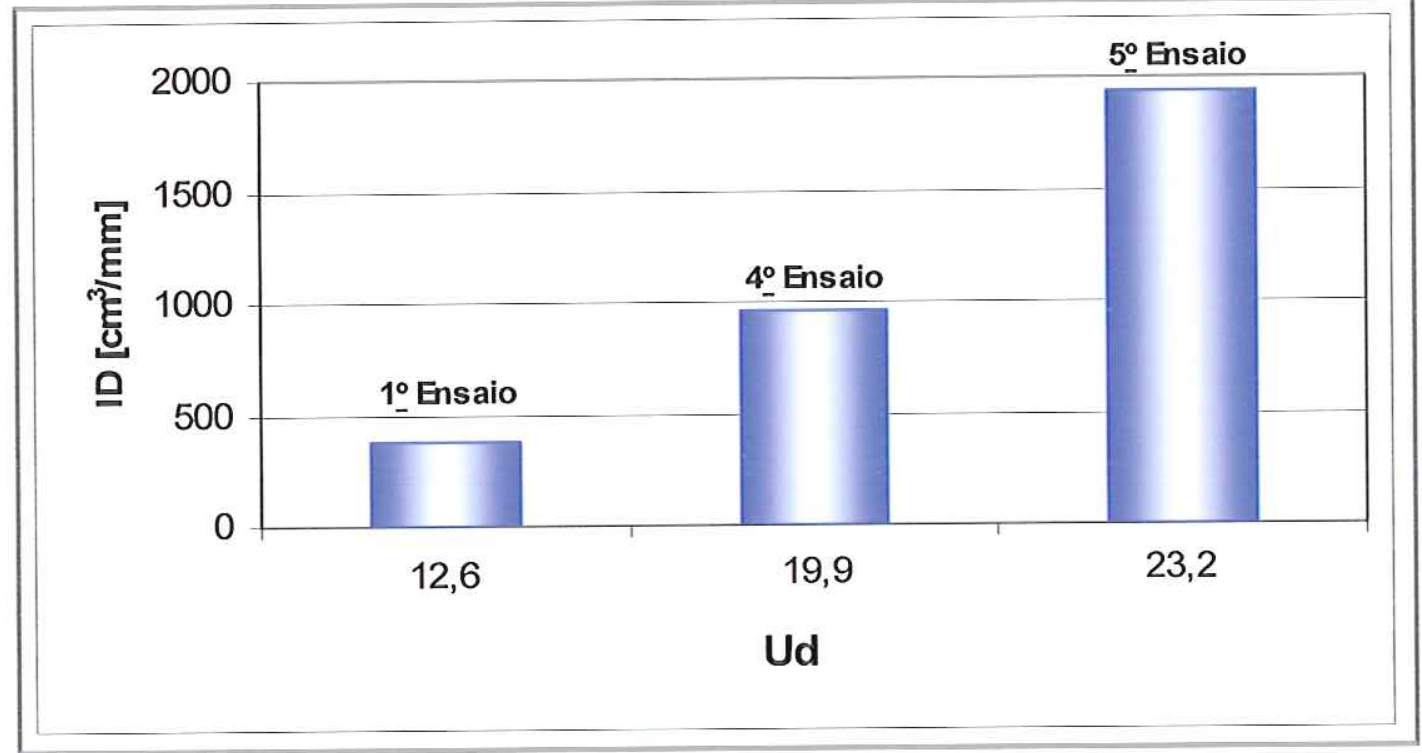

Figura 74: Resultados do índice ID com $\mathrm{a}_{d}=60 \mu \mathrm{m}$ e $Q=3,2 \mathrm{I} / \mathrm{min}$ (ensaios 1, 4 e 5).

Observando-se a figura 74 nota-se que o índice ID apresentou um crescimento contínuo entre os ensaios, mesmo para valores constantes de $\mathbf{a}_{\mathbf{d}}$. Este comportamento provavelmente se deve ao fato de que valores crescentes de $\mathbf{U}_{\mathrm{d}}$ tornam o rebolo comparativamente menos agressivo (deixam a superfície de corte do rebolo mais "lisa"), o que contribui para diminuir o desgaste do dressador, indicando que, para as mesmas condições de ensaio, um rebolo com uma superfície de corte menos agressiva provoca um desgaste 
comparativamente menor do dressador do que um rebolo mais agressivo. Comparando-se a figura 71, a qual mostra que não há um aumento significativo de temperatura e a figura 74 , mostrando uma diminuição de desgaste, pode-se ver que o desgaste do dressador, neste caso, está mais ligado à ruptura dos diamantes do que propriamente à grafitização por temperatura. Isso pode ser atribuído aos efeitos de refrigeração produzidos pelo processo de aplicação de fluido e pelas aletas de dissipação de calor no corpo do dressador.

4.3.3 - Resultados do Índice ID Variando-se a Vazão do Fluido REFRIGERANTE Q (ENSAIOS 4, 6 e 7)

A figura 75 mostra os resultados obtidos para o índice ID $\left[\mathrm{cm}^{3} / \mathrm{mm}\right]$ para os ensaios 4, 6 e 7 .

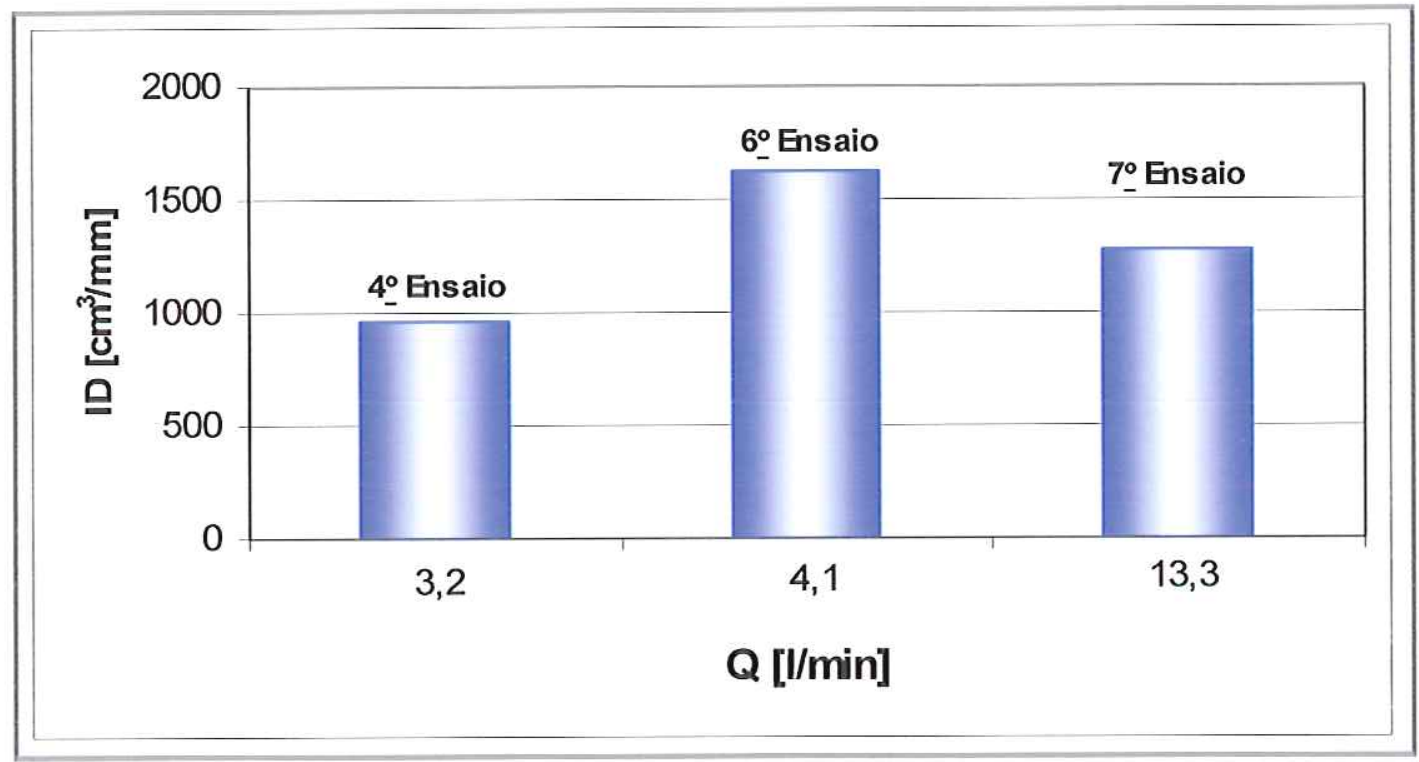

Figura 75: Resultados do índice ID com $a_{d}=60 \mu m$ e $U_{d}=19,9$ (ensaios 4, 6 e 7).

No gráfico da figura 75 os valores obtidos para o índice ID apresentaram um comportamento indefinido, indicando que nestes ensaios (onde foram consideradas as variações de vazão do fluido refrigerante) e para as condições empregadas, o desgaste do dressador foi mais fortemente influenciado pelos parâmetros de dressagem, ou seja, pelo grau de recobrimento de dressagem 
$\left(\mathbf{U}_{\mathrm{d}}\right)$ e pela profundidade de dressagem $\left(\mathbf{a}_{\mathrm{d}}\right)$. Os valores de vazão do fluido refrigerante utilizados näo foram capazes de produzir grandes efeitos no desgaste do dressador, ou mesmo na temperatura, indicando que somente altos valores de vazão e dirigidos exclusivamente para a região de contato dressador-rebolo poderiam produzir efeitos significativos.

\section{4 - Resultados Obtidos com a Simulação por Elementos Finitos}

Os gráficos das figuras $76 a$ a $82 b$ apresentam os níveis de temperatura obtidos nas simulações em computador realizadas com o software ANSYS ${ }^{\circledR}$ utilizando o Método dos Elementos Finitos (Finite Element Method - FEM).

As figuras referentes ao ítem " $a$ " correspondem à distribuição de temperaturas, em graus Celsius, resultante na secção longitudinal interna média do dressador aletado. Nestas figuras, as posições dos dois termopares na ferramenta estão indicadas pelos símbolos T1 e T2, bem como as respectivas temperaturas obtidas pela simulação nestes pontos.

Nas figuras do item "a" o valor do coeficiente médio de transferência de calor por convecção $\left(\boldsymbol{h}_{\text {médio }}\right)$ que, pela simulação forneceu a menor diferença simultânea entre as temperaturas da simulação (assinaladas no centro da figura) e as temperaturas médias obtidas nos ensaios com o dressador aletado (constantes na legenda à esquerda na mesma figura) corresponde ao valor

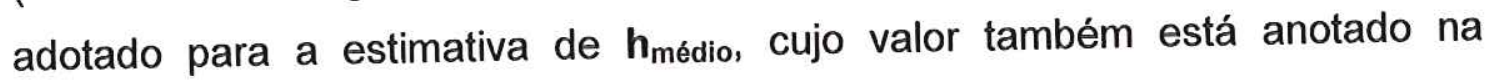
legenda à esquerda de cada figura.

As figuras referentes ao ítem " $b$ " correspondem à distribuiçäo de temperaturas na ferramenta inteira, obtida a partir da mesma simulação para cada ensaio considerado. 


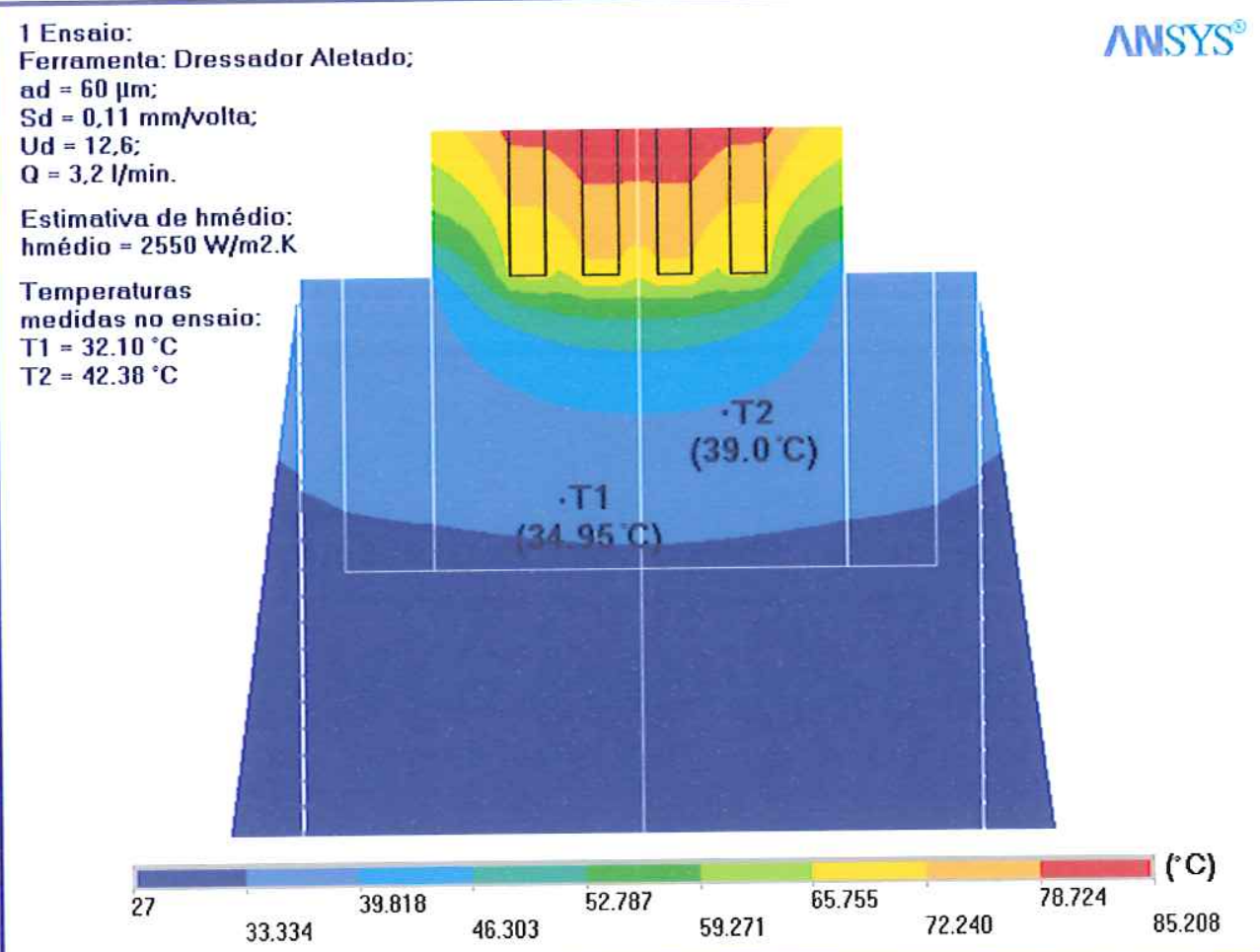

Figura 76a: Distribuição de temperaturas obtidas na simulação computacional para as condições do $1^{\circ}$ ensaio $\left(Q=3,2 \mathrm{l} / \mathrm{min}, U_{d}=12,6\right.$ e $\left.a_{d}=60 \mu \mathrm{m}\right)$ - seç̧ão longitudinal.

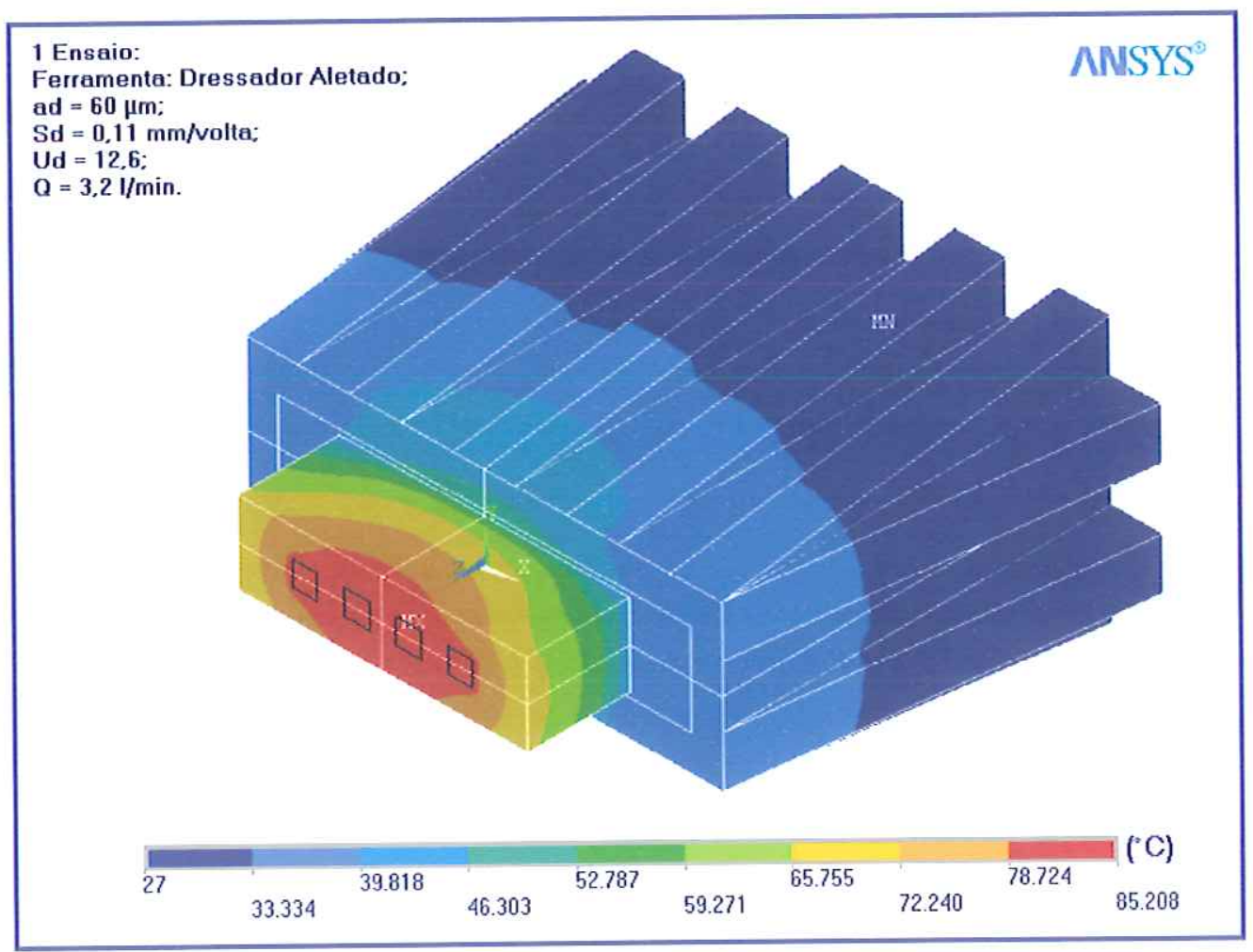

Figura 76b: Distribuição de temperaturas obtidas na simulação computacional para as condições do $1^{\circ}$ ensaio $\left(Q=3,2 \mathrm{l} / \mathrm{min}, U_{d}=12,6\right.$ e $\left.a_{d}=60 \mu \mathrm{m}\right)$ - ferramenta inteira. 


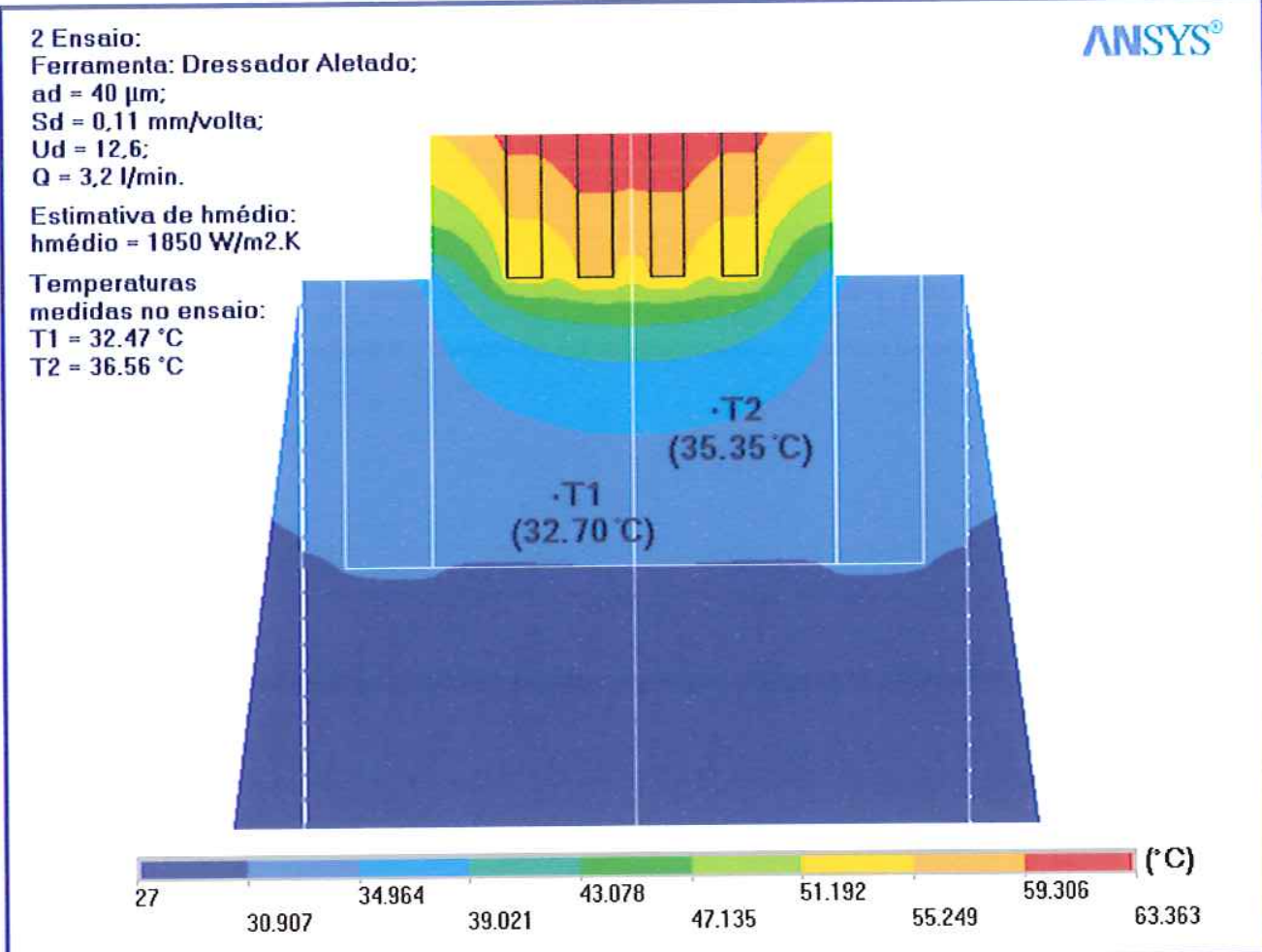

Figura 77a: Distribuição de temperaturas obtidas na simulação computacional para as condições do $2^{\circ}$ ensaio $\left(Q=3,2 \mathrm{l} / \mathrm{min}, U_{d}=12,6\right.$ e $\left.a_{d}=40 \mu \mathrm{m}\right)$ - secção longitudinal.

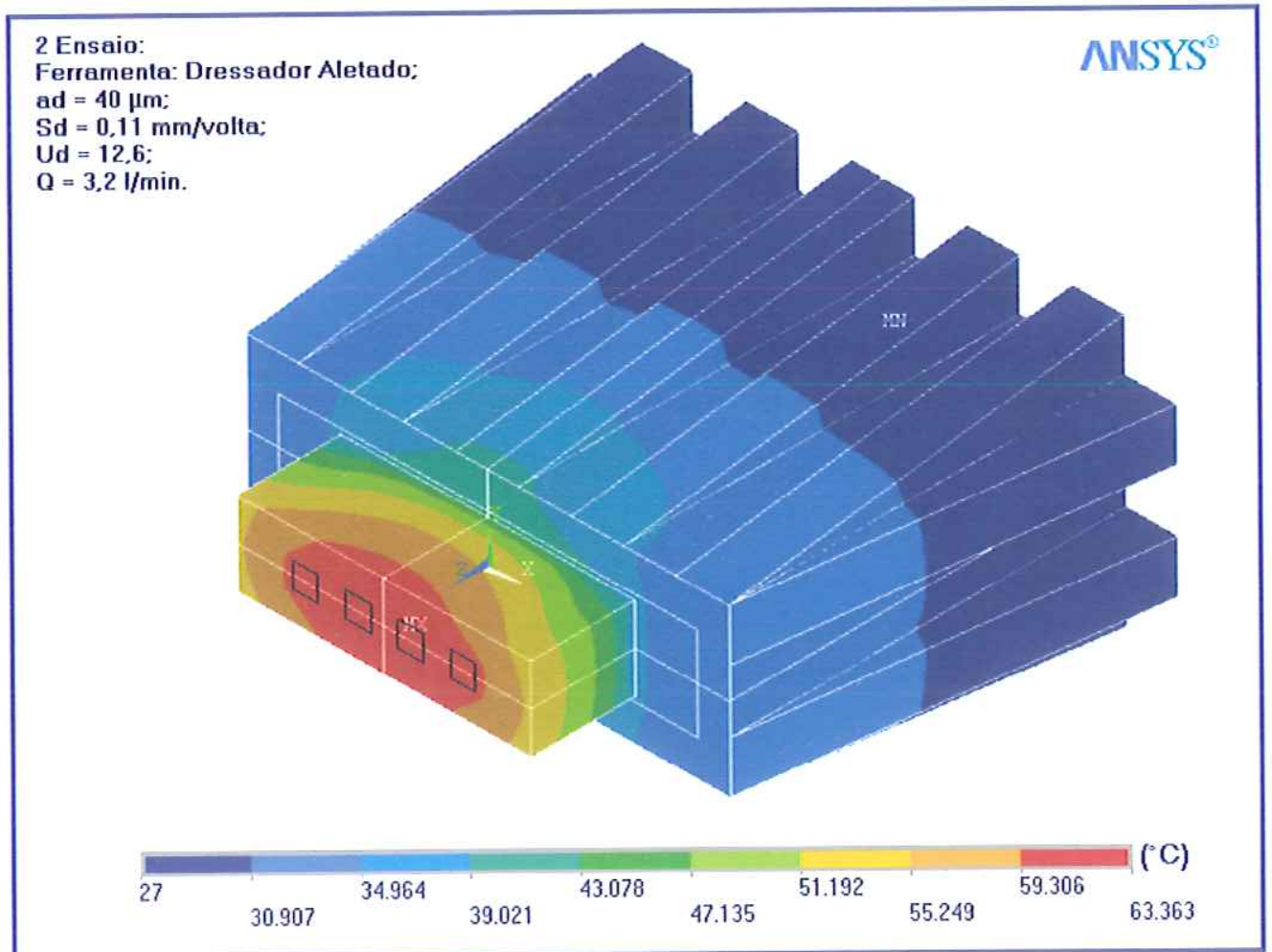

Figura 77b: Distribuição de temperaturas obtidas na simulação computacional para as condições do $2^{\circ}$ ensaio $\left(Q=3,2 \mathrm{l} / \mathrm{min}, U_{d}=12,6\right.$ e $\left.a_{d}=40 \mu \mathrm{m}\right)$ - ferramenta inteira. 


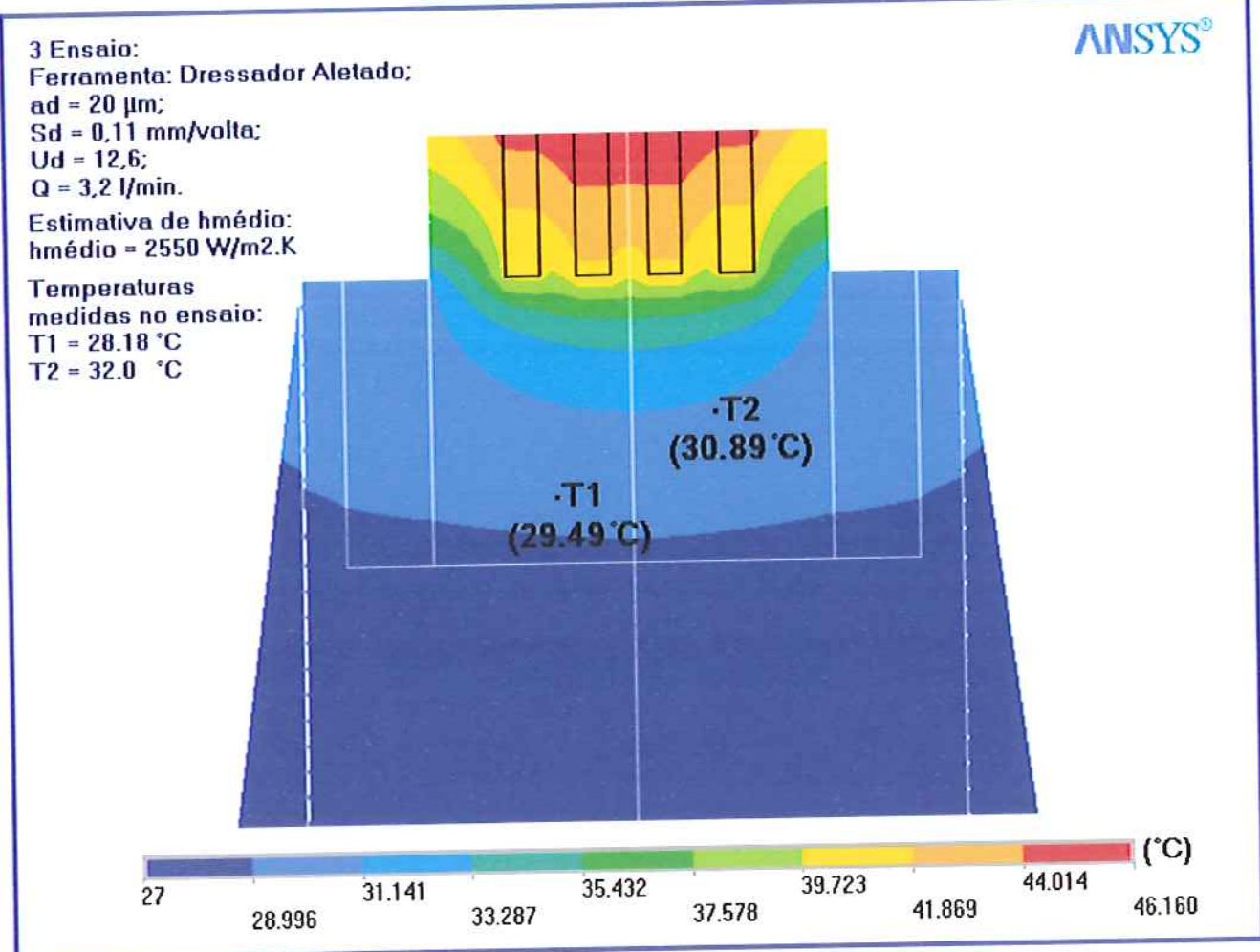

Figura 78a: Distribuição de temperaturas obtidas na simulação computacional para as condições do $3^{\circ}$ ensaio $\left(Q=3,2 \mathrm{l} / \mathrm{min}, U_{d}=12,6\right.$ e $\left.a_{d}=20 \mu \mathrm{m}\right)$ - secção longitudinal.

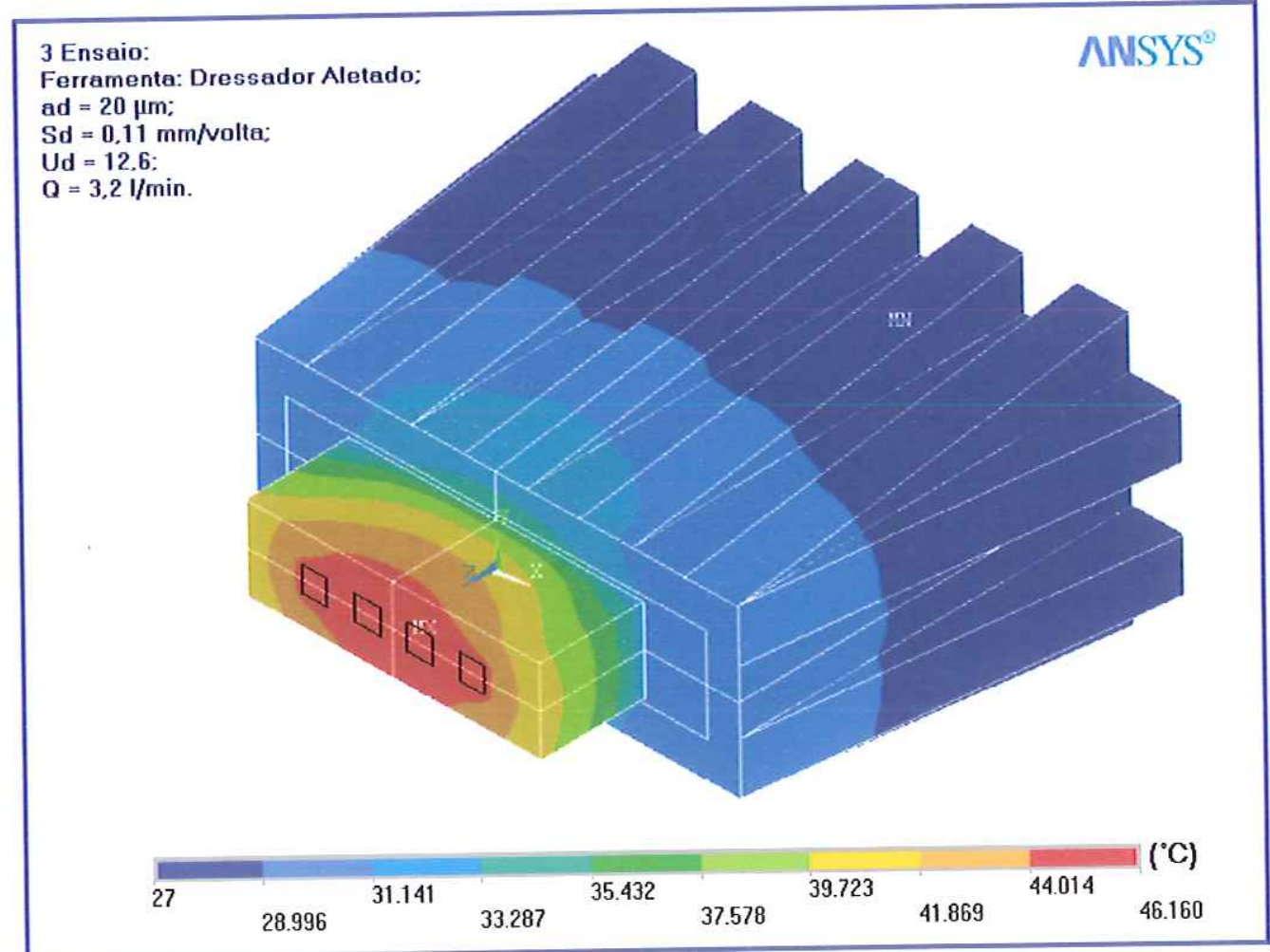

Figura 78b: Distribuição de temperaturas obtidas na simulação computacional para as condições do $3^{\circ}$ ensaio $\left(Q=3,2 \mathrm{l} / \mathrm{min}, U_{d}=12,6\right.$ e $\left.a_{d}=20 \mu \mathrm{m}\right)$ - ferramenta inteira. 


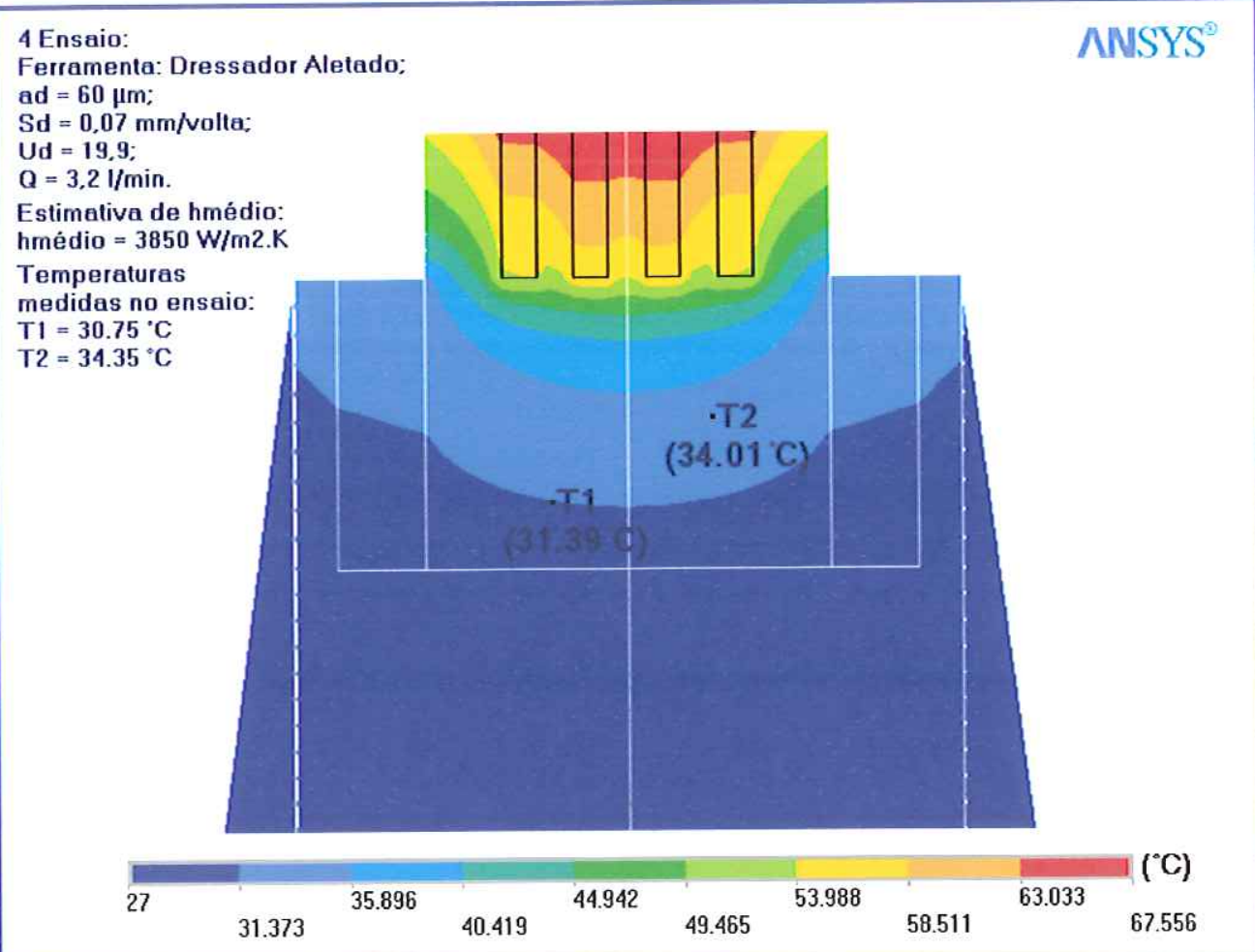

Figura 79a: Distribuição de temperaturas obtidas na simulação computacional para as condições do 4- ensaio $\left(Q=3,2 \mathrm{l} / \mathrm{min}, U_{d}=19,9\right.$ e $\left.a_{d}=60 \mu \mathrm{m}\right)$ - secção longitudinal.

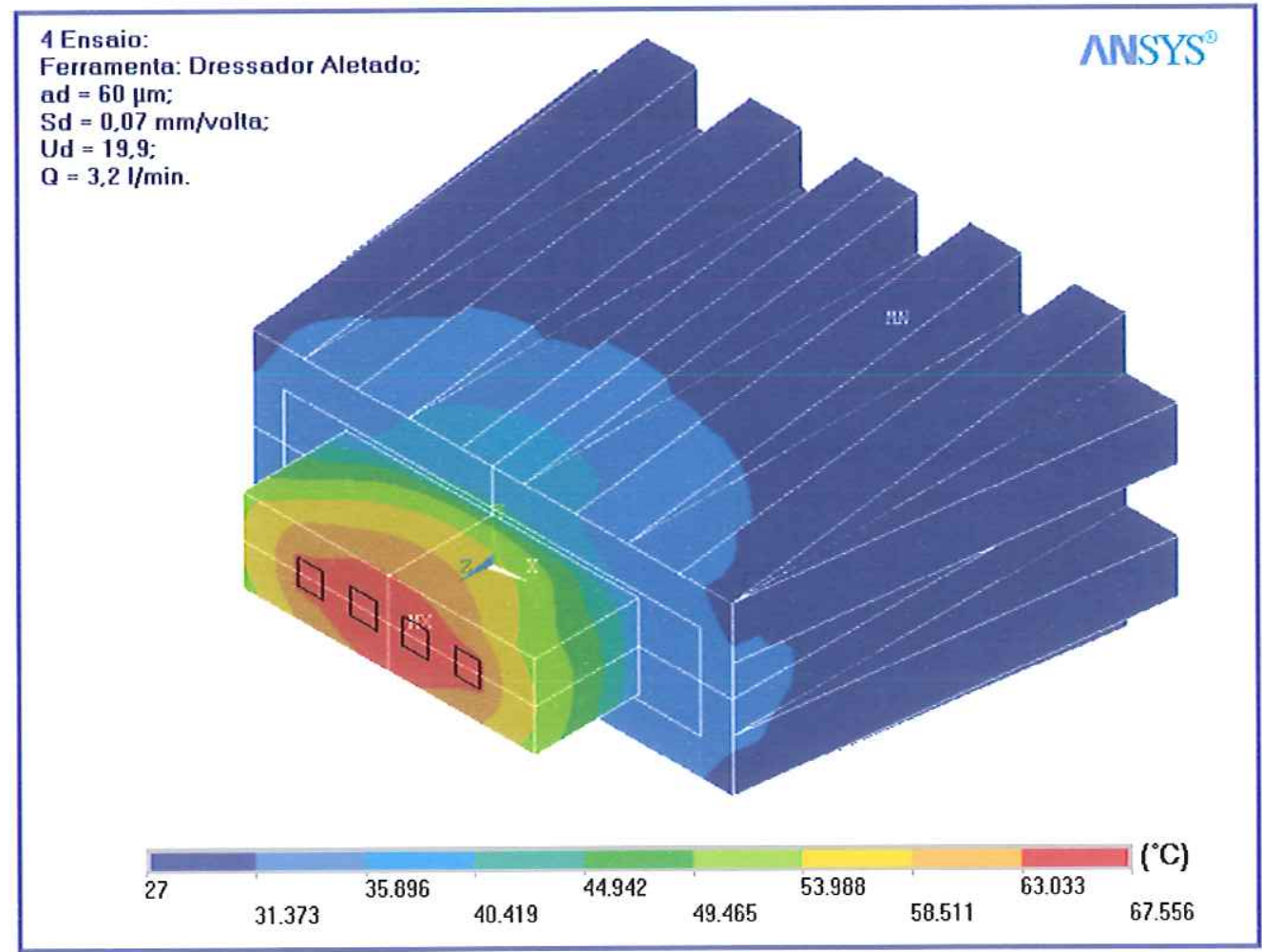

Figura 79b: Distribuição de temperaturas obtidas na simulação computacional para as condições do $4^{\circ}$ ensaio $\left(Q=3,2 \mathrm{l} / \mathrm{min}, U_{d}=19,9\right.$ e $\left.a_{d}=60 \mu \mathrm{m}\right)$ - ferramenta inteira. 


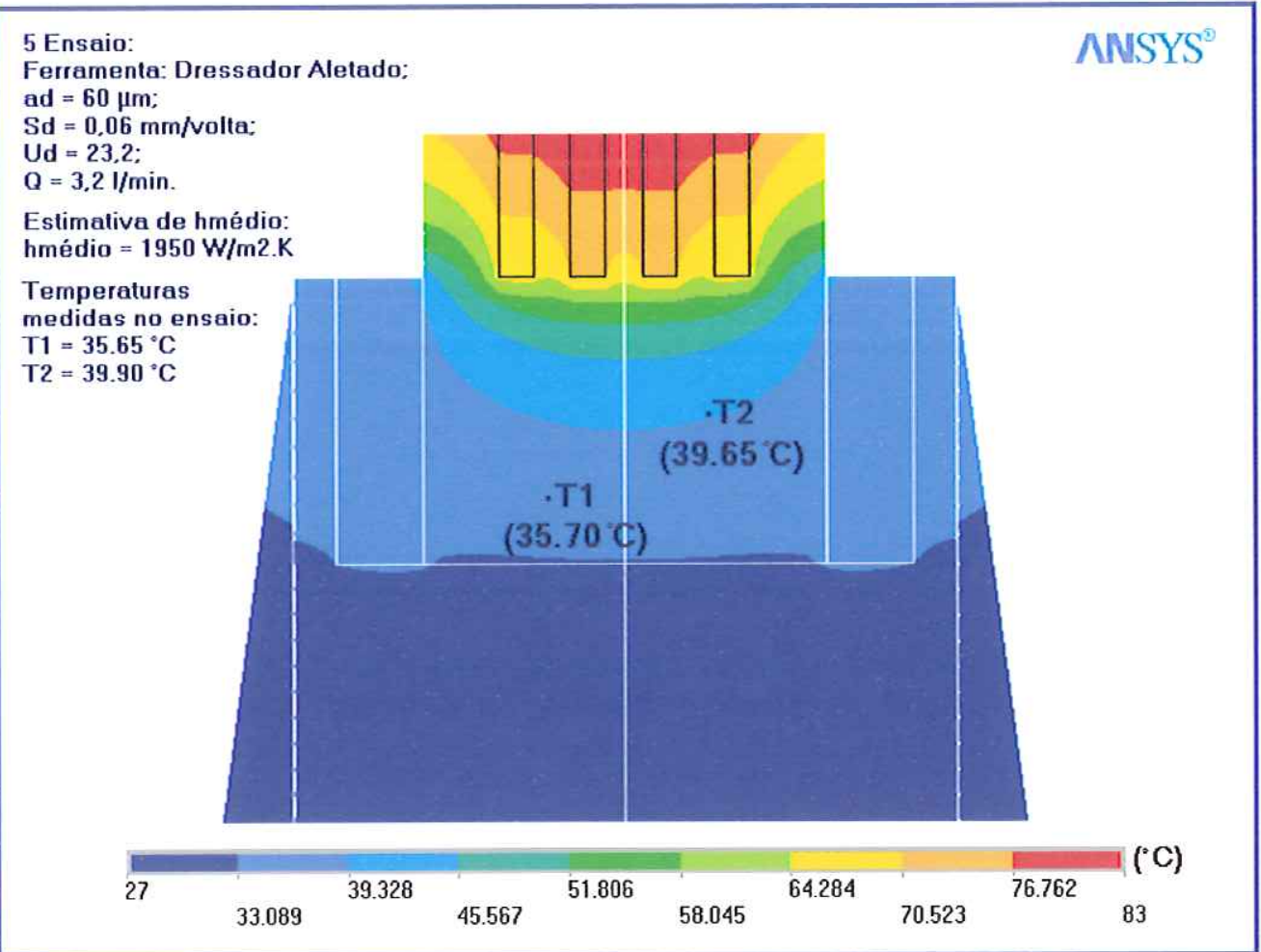

Figura 80a: Distribuição de temperaturas obtidas na simulação computacional para as condições do $5^{\circ}$ ensaio $\left(Q=3,2 \mathrm{l} / \mathrm{min}, U_{d}=23,2\right.$ e $\left.a_{d}=60 \mu \mathrm{m}\right)$ - secção longitudinal.

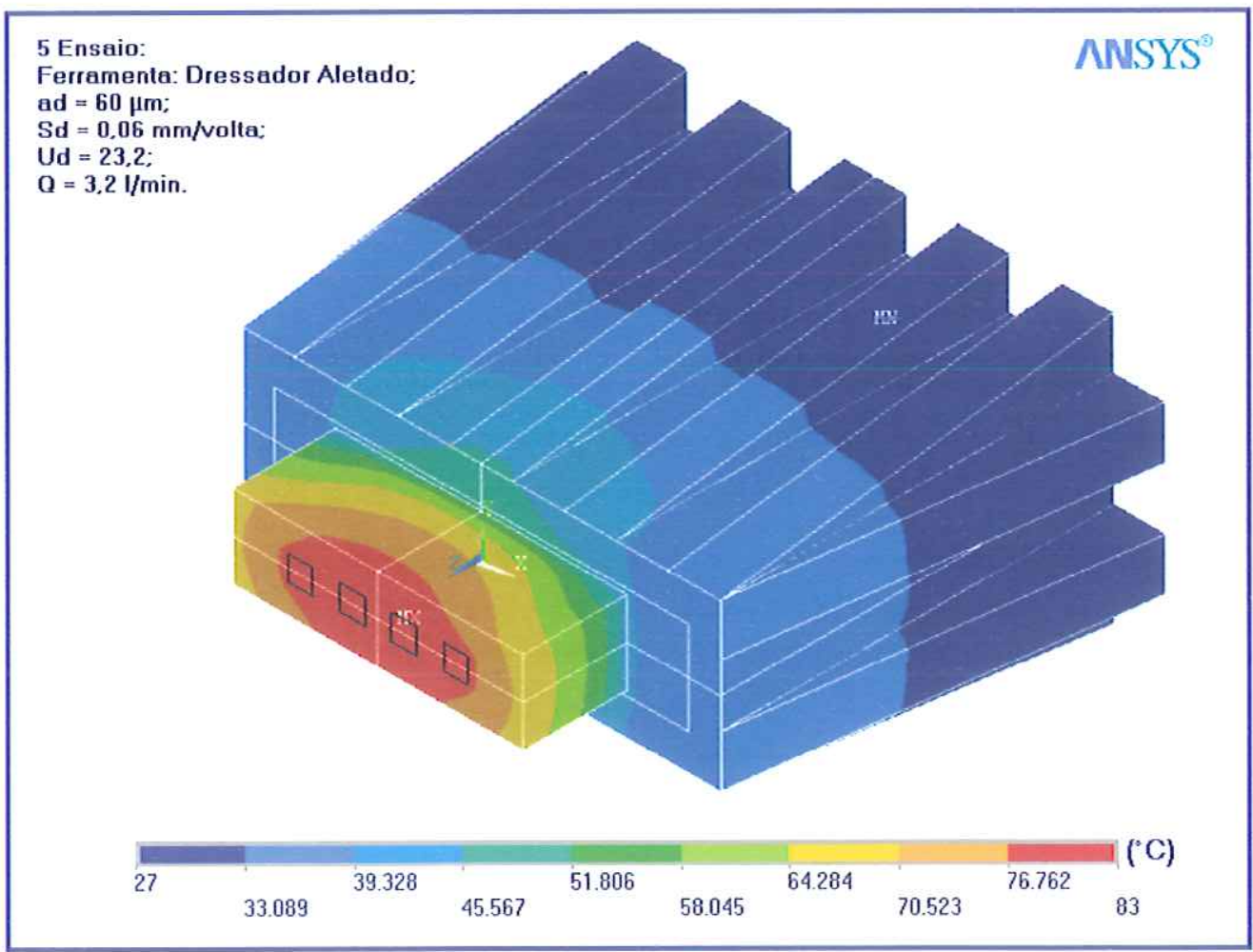

Figura 80b: Distribuição de temperaturas obtidas na simulação computacional para as condições do $5^{\circ}$ ensaio $\left(Q=3,2 \mathrm{l} / \mathrm{min}, U_{d}=23,2\right.$ e $\left.a_{d}=60 \mu \mathrm{m}\right)$ - ferramenta inteira. 


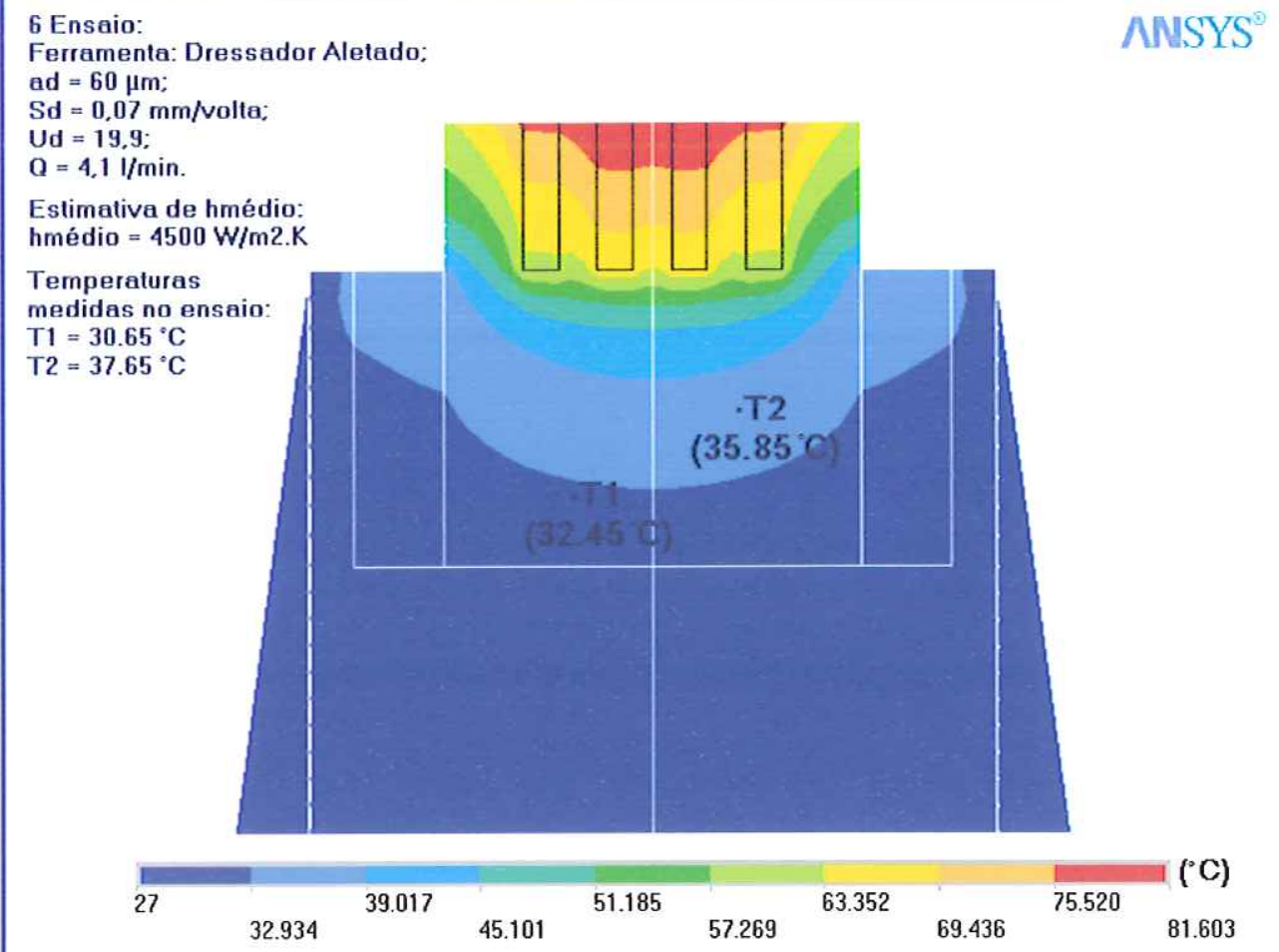

Figura 81a: Distribuição de temperaturas obtidas na simulação computacional para as condições do 6- ensaio $\left(Q=4,1 \mathrm{l} / \mathrm{min}, U_{d}=19,9\right.$ e $\left.a_{d}=60 \mu \mathrm{m}\right)$ - secção longitudinal.

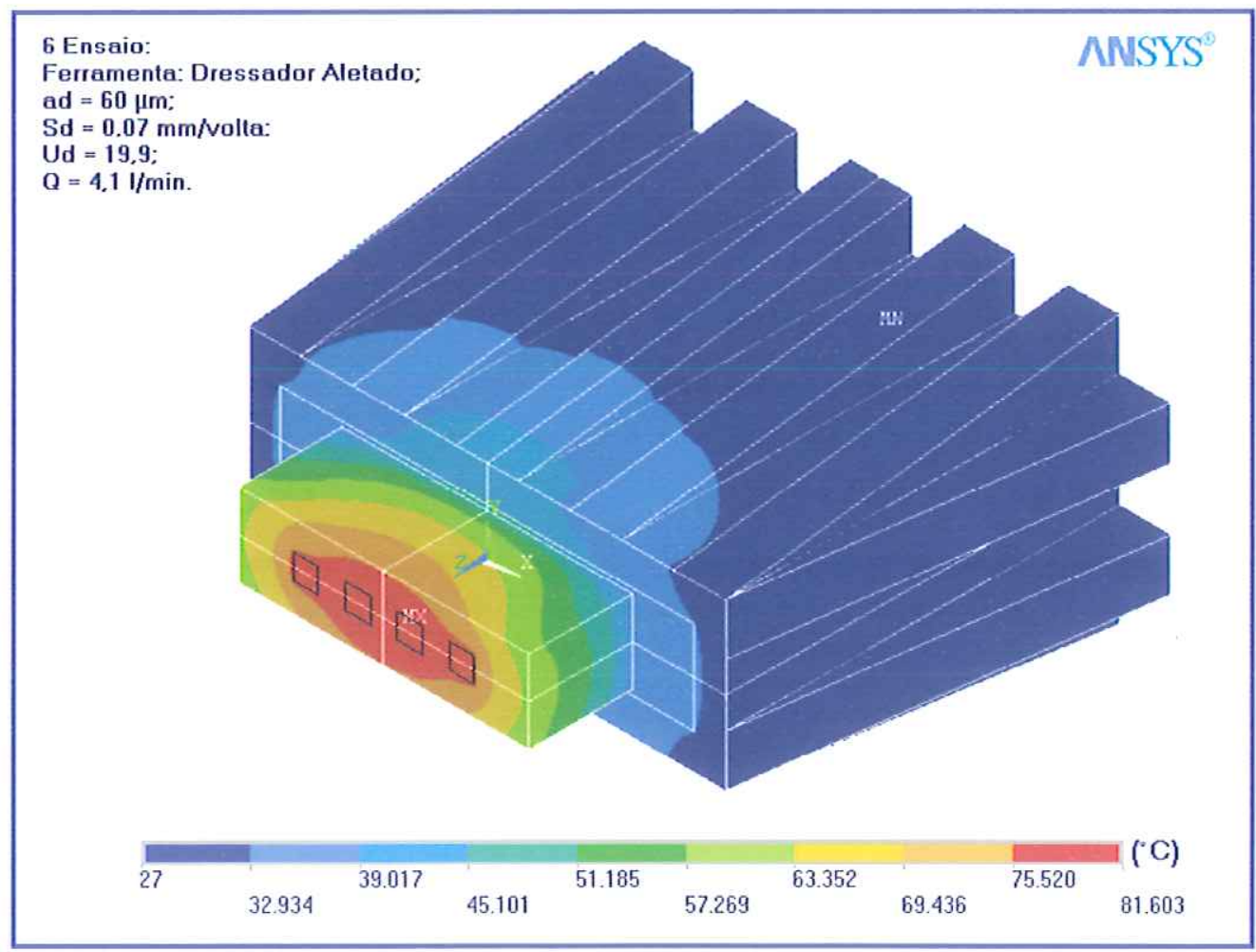

Figura 81b: Distribuição de temperaturas obtidas na simulação computacional para as condições do $6^{\circ}$ ensaio $\left(Q=4,1 \mathrm{l} / \mathrm{min}, U_{d}=19,9\right.$ e $\left.a_{d}=60 \mu \mathrm{m}\right)$ - ferramenta inteira. 


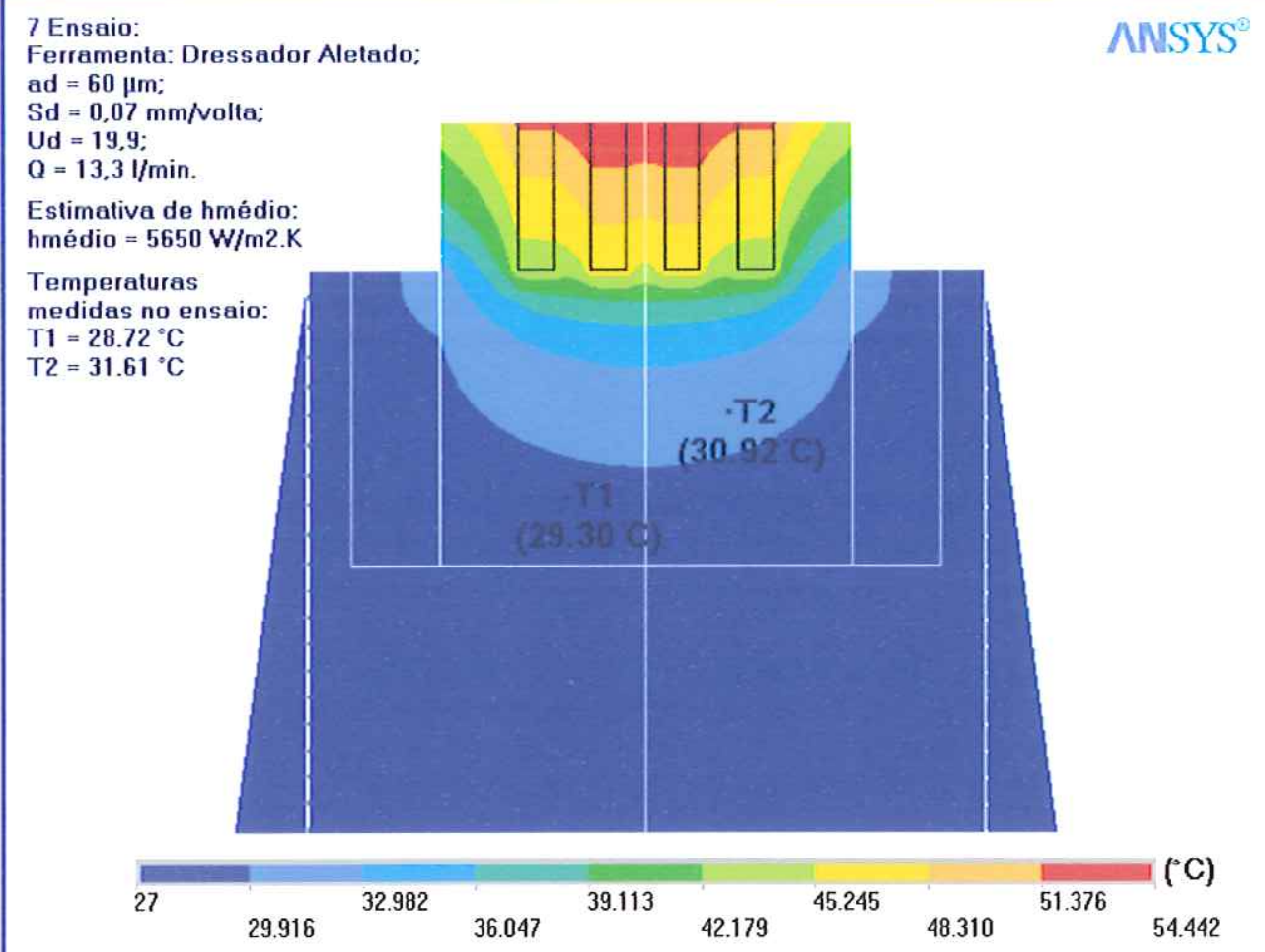

Figura 82a: Distribuição de temperaturas obtidas na simulação computacional para as condições do $7^{\circ}$ ensaio $\left(Q=13,3 \mathrm{l} / \mathrm{min}, U_{d}=19,9\right.$ e $\left.a_{d}=60 \mu \mathrm{m}\right)$ - seç̧ão longitudinal.

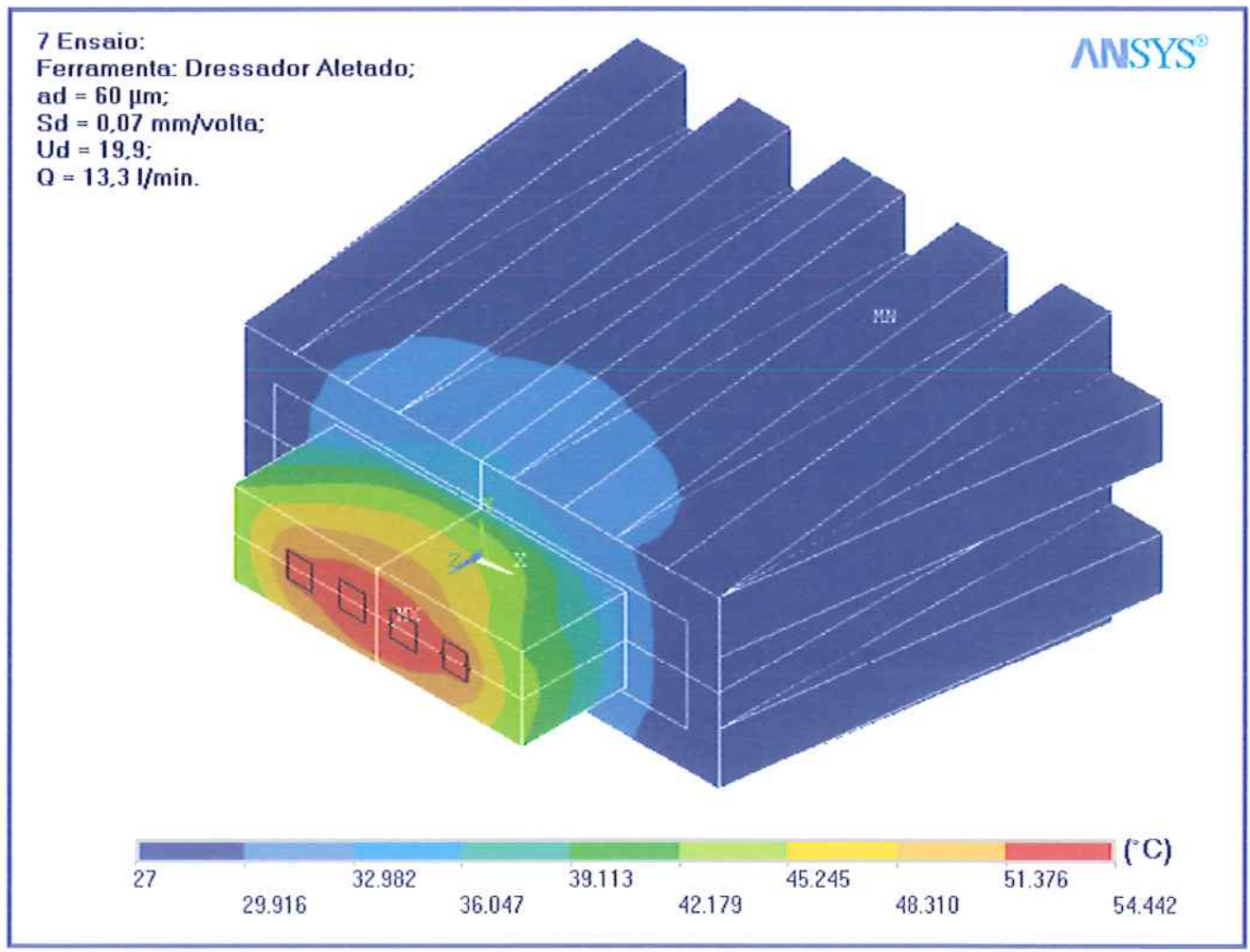

Figura 82b: Distribuição de temperaturas obtidas na simulação computacional para as condições do $7^{\circ}$ ensaio $\left(Q=13,3 \mathrm{l} / \mathrm{min}, U_{d}=19,9\right.$ e $\left.a_{d}=60 \mu \mathrm{m}\right)$ - ferramenta inteira. 
Observando-se as figuras $76 a$ a $82 b$, verifica-se que os níveis de temperatura máxima no contato dressador-rebolo obtidos pela simulação resultaram da ordem de $46^{\circ} \mathrm{C}$ a $85^{\circ} \mathrm{C}$. Na realidade pode-se inferir que o gradiente de temperatura no corpo do dressador é muito acentuado, uma vez que, em certos casos pode-se observar centelhas saindo da região de contato. Desta forma, as medições de temperatura com termopares não sendo realizadas muito próximas ao contato, estimam apenas parte deste gradiente e a extrapolação da temperatura na região de contato sofre com essa limitação. Portanto, acredita-se que a simulação não tenha sido capaz de representar os níveis reais de temperatura no contato dressador-rebolo, sendo adequada para efeitos de comparação, especialmente na região dos diamantes. As outras possíveis causas para a limitação encontrada na simulação podem ser:

- Durante os ensaios com o dressador de ponta única, a não obtenção de um patamar de temperaturas nos gráficos indica que, durante o tempo de contato com o rebolo, provavelmente a ferramenta permanece acumulando calor. Isto ocorre porque a quantidade de calor entrando na ferramenta é maior do que a quantidade que sai, sendo a diferença continuamente absorvida pela peça isolante de Celeron. Assim, durante o ensaio o sistema é aquecido, mas não atinge uma condição de regime estacionário. Sendo assim, a avaliação do fluxo de calor através dos diamantes na dressagem contém imprecisões;

- Nos ensaios com o dressador de ponta única os valores de temperatura lidos pelos termopares podem ter sido subestimados. Isto se deve ao fato de se utilizar uma resina para a isolação elétrica dos termopares. Esta resina pode ter atuado como uma "resistência térmica" entre o valor real de temperatura e a ponta de medida do termopar;

- O dressador de ponta única, utilizado para a estimativa do fluxo de calor, possui uma parte cônica para assegurar que haja apenas o contato rebolo-diamante. Neste cone houve uma perda de calor por convecção, que pode ter levado a um valor menor do fluxo de calor. 


\subsection{1 - Resultados para o Coeficiente de Convecção ( $\left.h_{\text {médio }}\right)$}

O coeficiente médio de transferência de calor por convecção $\left(h_{\text {médio }}\right)$ é um parâmetro influenciado pelas condições de escoamento do fluido sobre a superfície à qual ele se refere. Assim, para valores maiores de vazão (Q) do fluido esperam-se valores maiores de $\mathbf{h}_{\text {médio, significando uma maior }}$ transferência de calor da ferramenta para o fluido.

A tabela 23 apresenta os valores obtidos nas simulações para o coeficiente médio de transferência de calor por convecção ( $\mathbf{h}_{\text {médio }}$ para cada ensaio realizado, juntamente com a respectiva vazão $\mathbf{Q}$ (litros/minuto) empregada.

Tabela 23: Valores do coeficiente de convecção ( $\boldsymbol{h}_{\text {médio }}$ ) obtidos nas simulações.

\begin{tabular}{|c|c|c|}
\hline ENSAIO & VAZÄO Q (litros/minuto) & $\mathbf{h}_{\text {médlo }}\left(\mathbf{W} / \mathbf{m}^{2} \cdot \mathbf{K}\right)$ \\
\hline 1 & 3,2 & 2550 \\
\hline 2 & 3,2 & 1850 \\
\hline 3 & 3,2 & 2550 \\
\hline 4 & 3,2 & 3850 \\
\hline 5 & 3,2 & 1950 \\
\hline 6 & 4,1 & 4500 \\
\hline 7 & 13,3 & 5650 \\
\hline
\end{tabular}

Após uma observação da tabela 23 , nota-se que os valores estimados para $\mathbf{h}_{\text {médio }}$ nos ensaios de 1 a 5 em geral se mantiveram em valores próximos, exceto o $4^{\circ}$, uma vez que em todos estes ensaios utilizou-se um mesmo valor para a vazão do fluido refrigerante (a mesma vazão mínima $Q_{1}=3,21 / \mathrm{min}$ ). $O$ $4^{\circ}$ ensaio, cujo valor estimado para $\mathbf{h}_{\text {médio }}$ resultou um pouco alto, destoando dos demais ensaios $(1,2,3$ e 5) pode ter sido devido a algum erro na execução deste ensaio. 
Quando se consideram os ensaios nos quais foram alterados os valores da vazão do fluido refrigerante (a vazão foi crescente para os ensaios 6 e 7), os

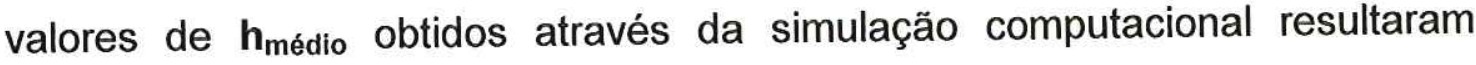
progressivamente maiores, estando de acordo com a teoria. Deve-se salientar ainda que esses são valores indicativos, obtidos através da simulação em elementos finitos, utilizando-se como dados de entrada os valores medidos de fluxo de calor e as temperaturas.

\subsection{2 - Estudo da Sensibilidade do Modelo de Elementos Finitos}

\section{ADOTADO}

Considerando que os dados de entrada no programa de elementos finitos são o fluxo de calor (qf), medido através dos experimentos com o dressador de ponta única e os valores de temperatura medidos no dressador aletado (temperaturas T1 e T2), mostra-se a seguir os efeitos provocados por variações nesses parâmetros sobre a temperatura máxima na região de contato dressador-rebolo. Toma-se as condições do 1- ensaio como exemplo para este estudo, ou seja, $\mathbf{a}_{\mathbf{d}}=60 \mu \mathrm{m}, \mathbf{U}_{\mathbf{d}}=12,6$ e $\mathbf{Q}=3,2 \mathrm{I} / \mathrm{min}$ (a simulação referente a este ensaio tomado como exemplo encontra-se nas figuras $74 \mathrm{a} e$ 74b).

Partindo-se do princípio de que a temperatura máxima na região de contato dressador-rebolo é maior do que a encontrada na simulação, inicia-se testando um aumento de $100 \%$ no valor estimado para o fluxo de calor. A simulação resultante está na figura 83. 


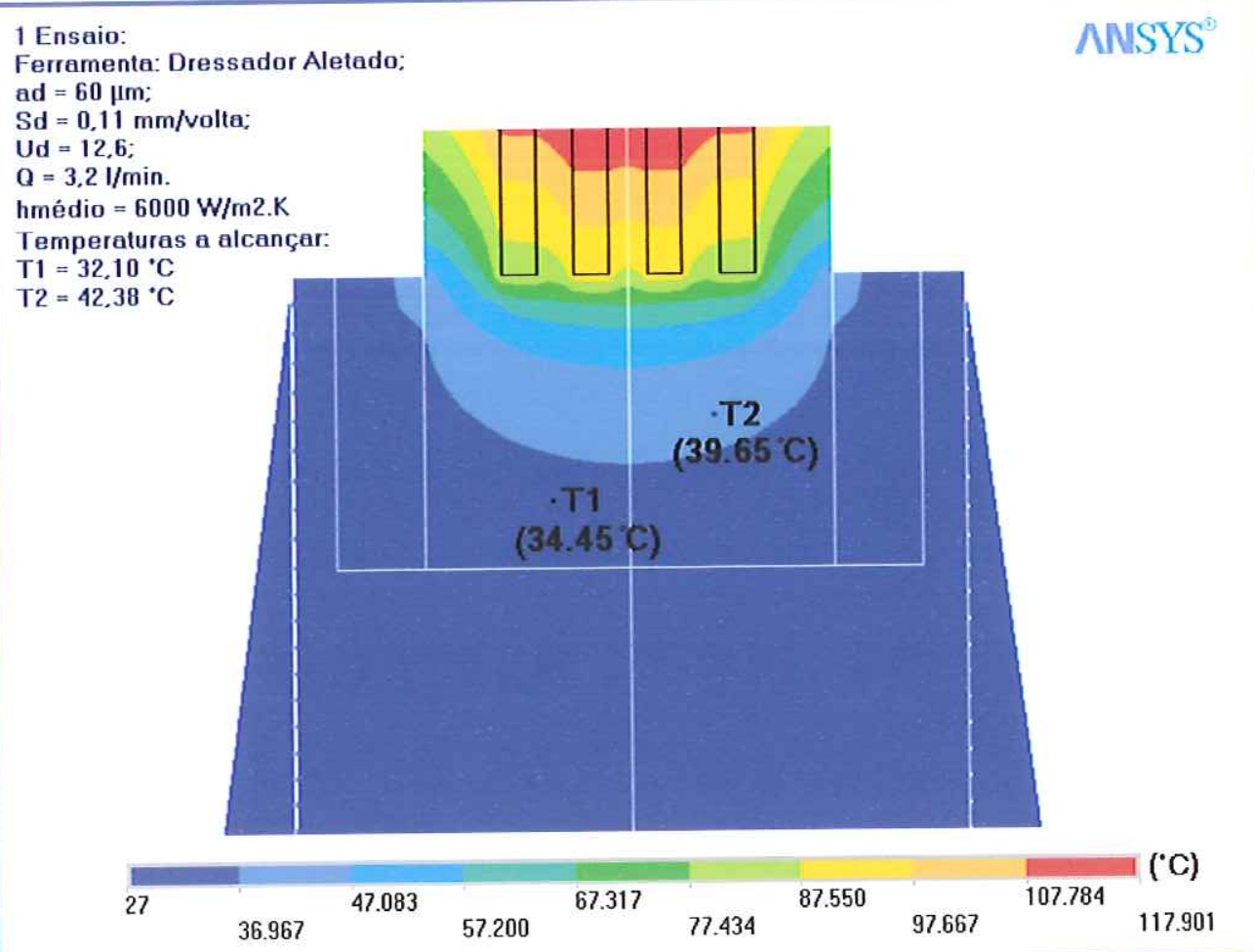

Figura 83: Distribuição de temperaturas obtidas na simulação computacional para uma condição de $100 \%$ de aumento no fluxo de calor (secção longitudinal).

Comparando-se as figuras 76 a e 83 verifica-se que a temperatura máxima na interface dressador-rebolo experimentou um aumento de $38 \%$, passando de $85,208{ }^{\circ} \mathrm{C}$ para $117,901{ }^{\circ} \mathrm{C}$, mostrando uma pequena influência do fluxo de calor, pois mesmo dobrando-se este fluxo, o aumento resultante na temperatura máxima não foi tão significativo.

Em um segundo estudo aumenta-se também em 100\% apenas os valores das temperaturas médias T1 e T2 aferidas no dressador aletado durante o $1^{\circ}$ - ensaio. Com este aumento, a temperatura T1 mudou de $32.1^{\circ} \mathrm{C}$ (valor original) para $64,2{ }^{\circ} \mathrm{C}$ e a temperatura T2 passou de $42,38^{\circ} \mathrm{C}$ (valor original) para $84,76^{\circ} \mathrm{C}$. O resultado da simulação está na figura 84 . 


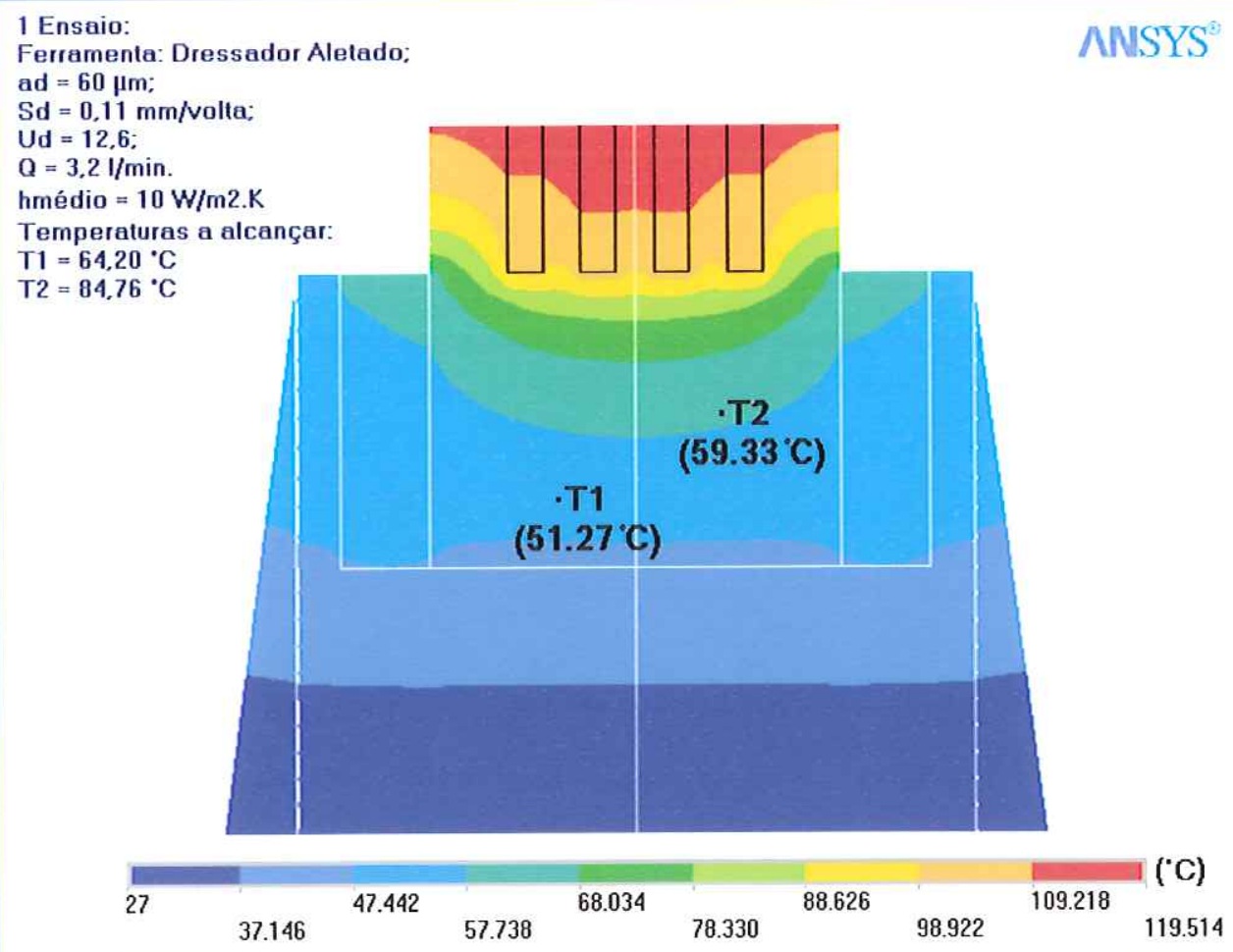

68.034

78.330

88.626

98.922

109.218

Figura 84: Distribuição de temperaturas obtidas na simulação computacional para uma condição de 100\% de aumento nas temperaturas T1 e T2 (secção longitudinal).

Verifica-se pela figura 84 que, nesta condição, mesmo para uma situação de praticamente nenhuma perda convectiva (como a representada nesta figura, onde foi utilizado um valor mínimo de $\mathbf{h}_{\text {médio }}=10 \mathrm{~W} / \mathrm{m}^{2} . \mathrm{K}$ para o ajuste das faixas de temperaturas) não foi possível alcançar pela simulação os niveis das temperaturas $\mathrm{T} 1$ e $\mathrm{T} 2$, que, neste caso, chegaram no máximo a $51,27{ }^{\circ} \mathrm{C}$ e a $59,33{ }^{\circ} \mathrm{C}$ respectivamente. A temperatura máxima passou dos $85,208^{\circ} \mathrm{C}$ originais para $119,514{ }^{\circ} \mathrm{C}$, um aumento de aproximadamente $40 \%$.

Em um terceiro caso, usam-se os dois aumentos combinados, ou seja, simulou-se a distribuição de temperaturas na ferramenta aumentando-se simultaneamente em $100 \%$ os valores originalmente estimados do fluxo de calor e das temperaturas medidas no dressador aletado. Os resultados obtidos para esta simulação estão na figura 85 . 


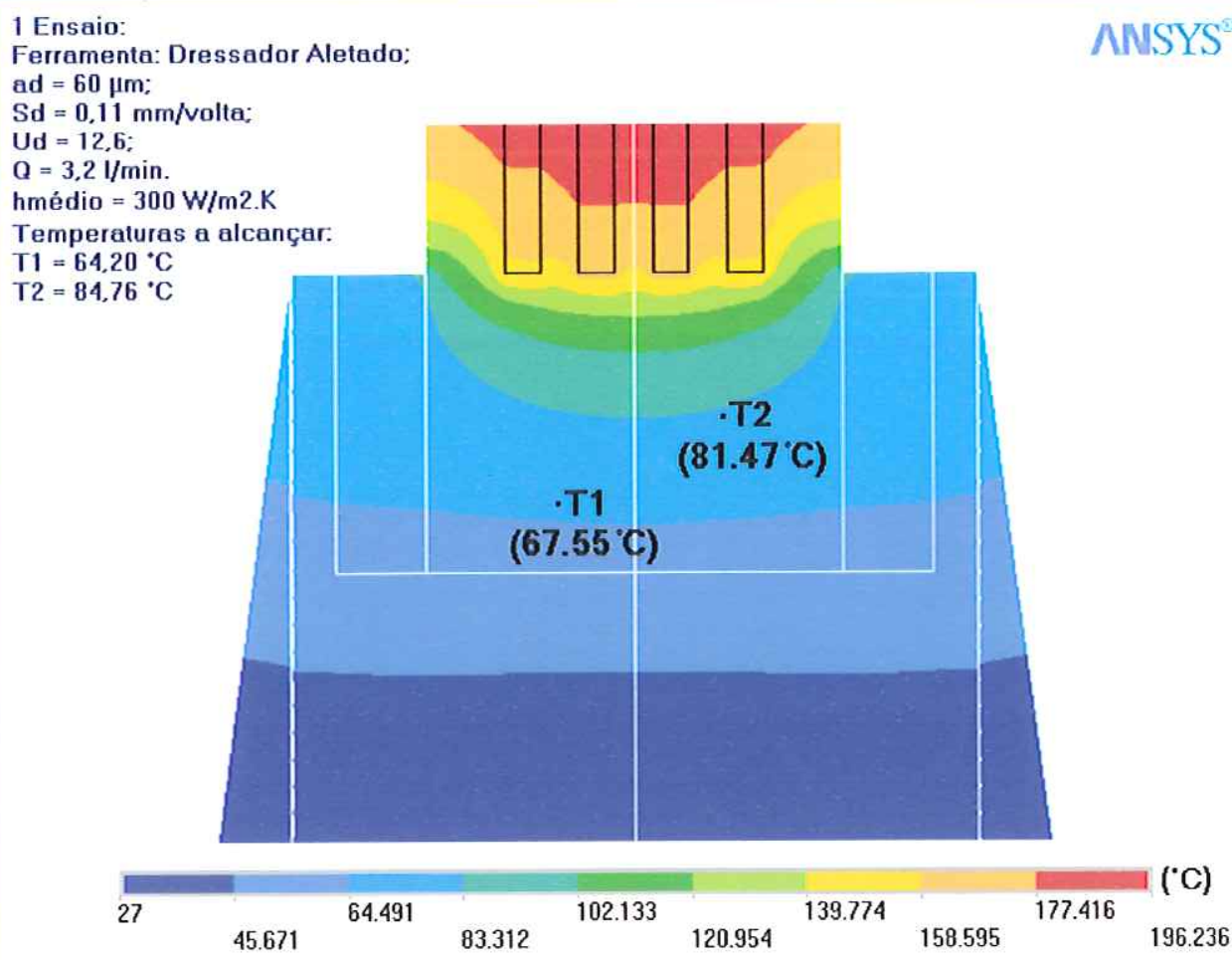

Temperaturas a alcançar.

$\mathrm{T} 1=64,20^{\circ} \mathrm{C}$

$\mathrm{T} 2=84,76{ }^{\circ} \mathrm{C}$

$\cdot .11$

T2

$\left(81.47^{\circ} \mathrm{C}\right)$

$\left(67.55^{\circ}\right.$ C)

27

139.774

Figura 85: Distribuição de temperaturas obtidas na simulação computacional para uma condição de $100 \%$ de aumento simultâneo para as temperaturas medidas e para o fluxo de calor (secção longitudinal).

Como pode-se ver na figura 85 , a combinação do aumento simultâneo dos dois parâmetros resultou num aumento bem mais significativo da temperatura máxima, que subiu de $85,208{ }^{\circ} \mathrm{C}$ para $196,236^{\circ} \mathrm{C}$, uma elevação de $130 \%$.

Num quarto caso testa-se um aumento de $100 \%$ apenas na diferença entre as temperaturas T1 e T2 originalmente medidas, ou seja, um aumento no gradiente térmico, mantendo-se o fluxo de calor originalmente estimado. Os resultados estão na figura 86 . 


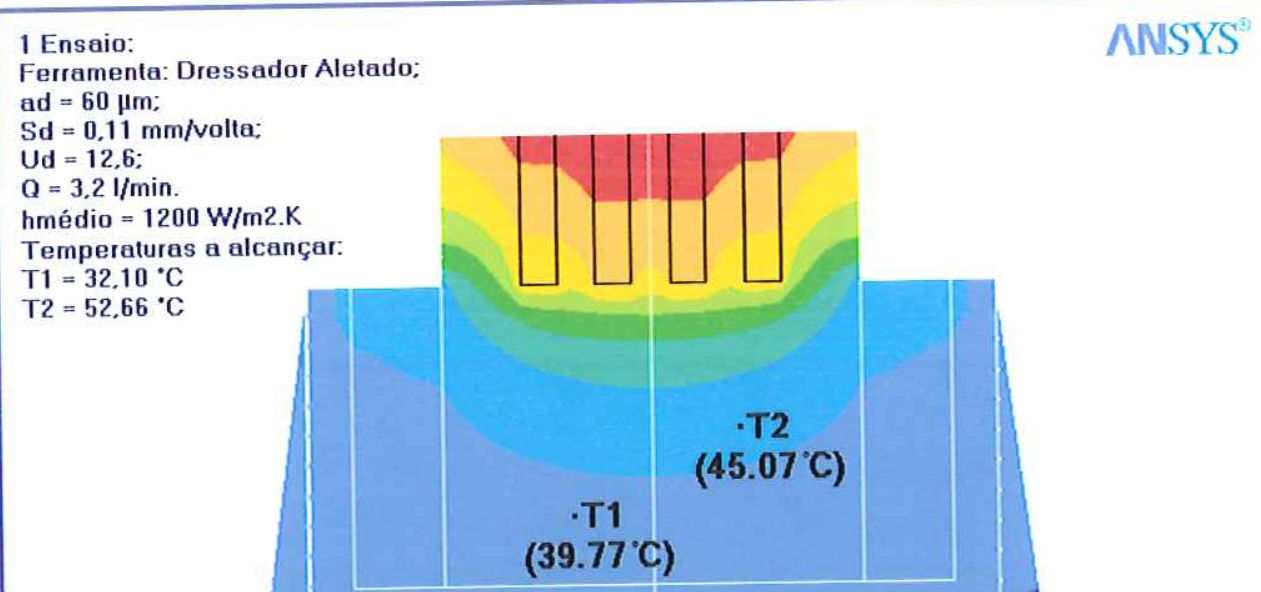

Figura 86: Distribuição de temperaturas obtidas na simulação computacional para uma condição de $100 \%$ de aumento nas temperaturas medidas (secção longitudinal).

O aumento isolado do gradiente térmico não resultou em grande alteração no nível da temperatura máxima, que passou dos originais $85,208{ }^{\circ} \mathrm{C}$ para $96,597^{\circ} \mathrm{C}$, um aumento de apenas $13 \%$.

No último caso testam-se os valores máximos de todos os casos anteriores, ou seja, simula-se uma condição de aumento no fluxo de calor combinado com aumento nas temperaturas medidas (T1 e T2) e aumento na diferença entre essas temperaturas. Os resultados da simulação para este caso estão na figura 87.

Iniciou-se com um aumento de $100 \%$ tanto para o fluxo de calor, quanto para as temperaturas medidas e para a diferença entre essas temperaturas. $O$ resultado da simulação foi que inicialmente não foi possível obter um ajuste da faixa de temperaturas através da variação do coeficiente médio de transferência convectiva de calor ( $\boldsymbol{h}_{\text {médio }}$ ) porque as faixas de temperaturas não convergiam para níveis próximos das novas temperaturas T1 e T2 (obtidas após o aumento de 100\%). A solução foi aumentar o fluxo de calor para níveis 
bem maiores. Na simulação final representada na figura 87 o fluxo de calor utilizado é $500 \%$ maior do que o original, mas com níveis de $100 \%$ de aumento nas temperaturas T1 e T2 e 100\% de aumento na diferença entre essas temperaturas.

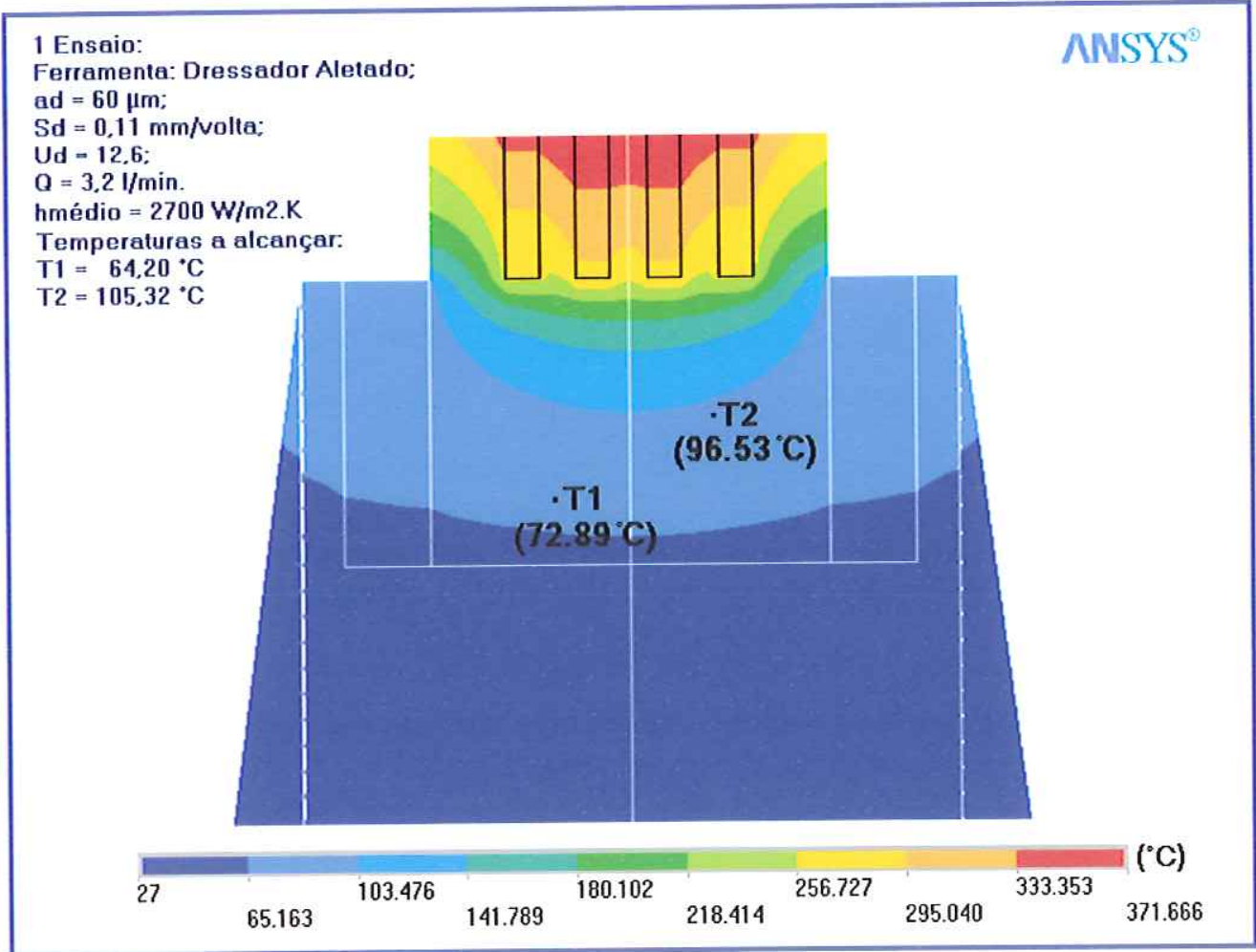

Figura 87: Distribuição de temperaturas obtidas na simulação computacional para uma condição de aumento simultâneo de $500 \%$ no fluxo de calor e de $100 \%$ nas temperaturas medidas e no gradiente entre essas temperaturas (secção longitudinal).

Como era de se esperar, esta combinação dos valores máximos resultou num aumento máximo da temperatura na interface dressador-rebolo, que passou de $85,208^{\circ} \mathrm{C}$ (valor original) para $371,666^{\circ} \mathrm{C}$, uma diferença de $336 \%$.

Após uma observação dos 5 casos simulados neste teste de sensibilidade do modelo, verifica-se que o parâmetro de maior influência isolada em termos de aumento da temperatura máxima na interface dressadorrebolo obtida pela simulação foi o aumento das temperaturas T1 e T2, vista no $2^{\circ}$ caso, quando aumentou-se em $100 \%$ apenas as temperaturas T1 e T2. Entretanto, o aumento resultante de $40 \%$ na temperatura máxima obtido na 
simulação do $2^{\circ}$ caso foi apenas levemente maior do que o aumento de $38 \%$ obtido para o $1^{\circ}$ caso, quando aumentou-se apenas o fluxo de calor. Além disso, pode-se dizer que o aumento isolado do gradiente entre as temperaturas T1 e T2 não proporciona aumentos significativos da temperatura máxima, tendo, portanto pouca influência.

\section{5 - Aspecto Visual do Dressador após os Ensaios}

As figuras a seguir apresentam o aspecto visual do dressador após o término dos ensaios. A seta vermelha indica a direção da velocidade de corte do rebolo $\left(\mathbf{V}_{\mathbf{s}}\right)$ e a seta azul indica a direção de avanço do dressador para início da dressagem. As figuras 88 e 89 mostram um aspecto geral da superfície do dressador, enquanto as figuras 90, 91, 92 e 93 permitem visualizar cada um dos 4 diamantes da ferramenta, segundo a ordem de início de contato com o rebolo durante os ensaios, considerando a direção da velocidade de corte $\left(\mathbf{V}_{\mathbf{s}}\right)$.

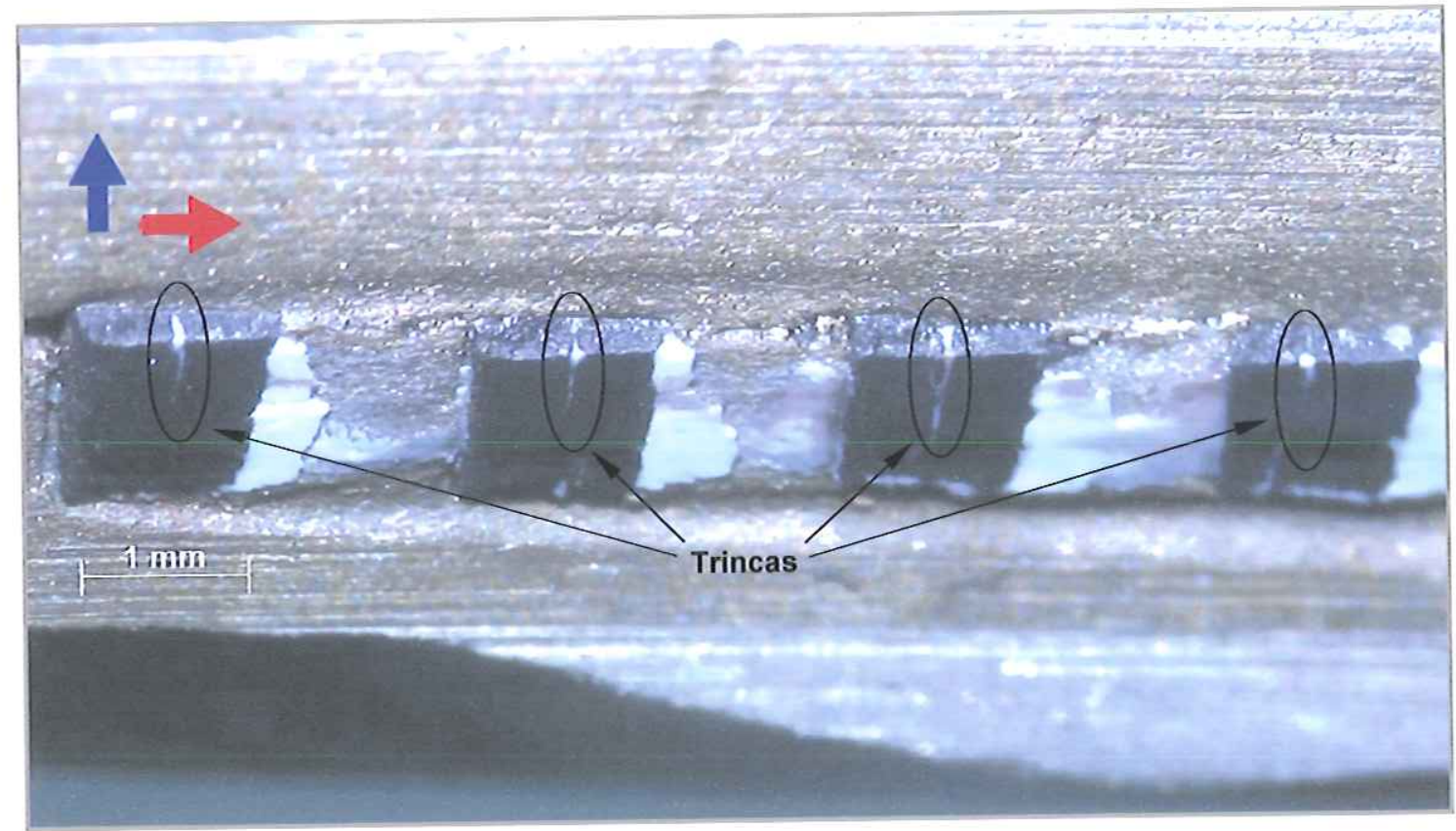

Figura 88: Superfície do dressador após os ensaios (vista com o dressador inclinado). 


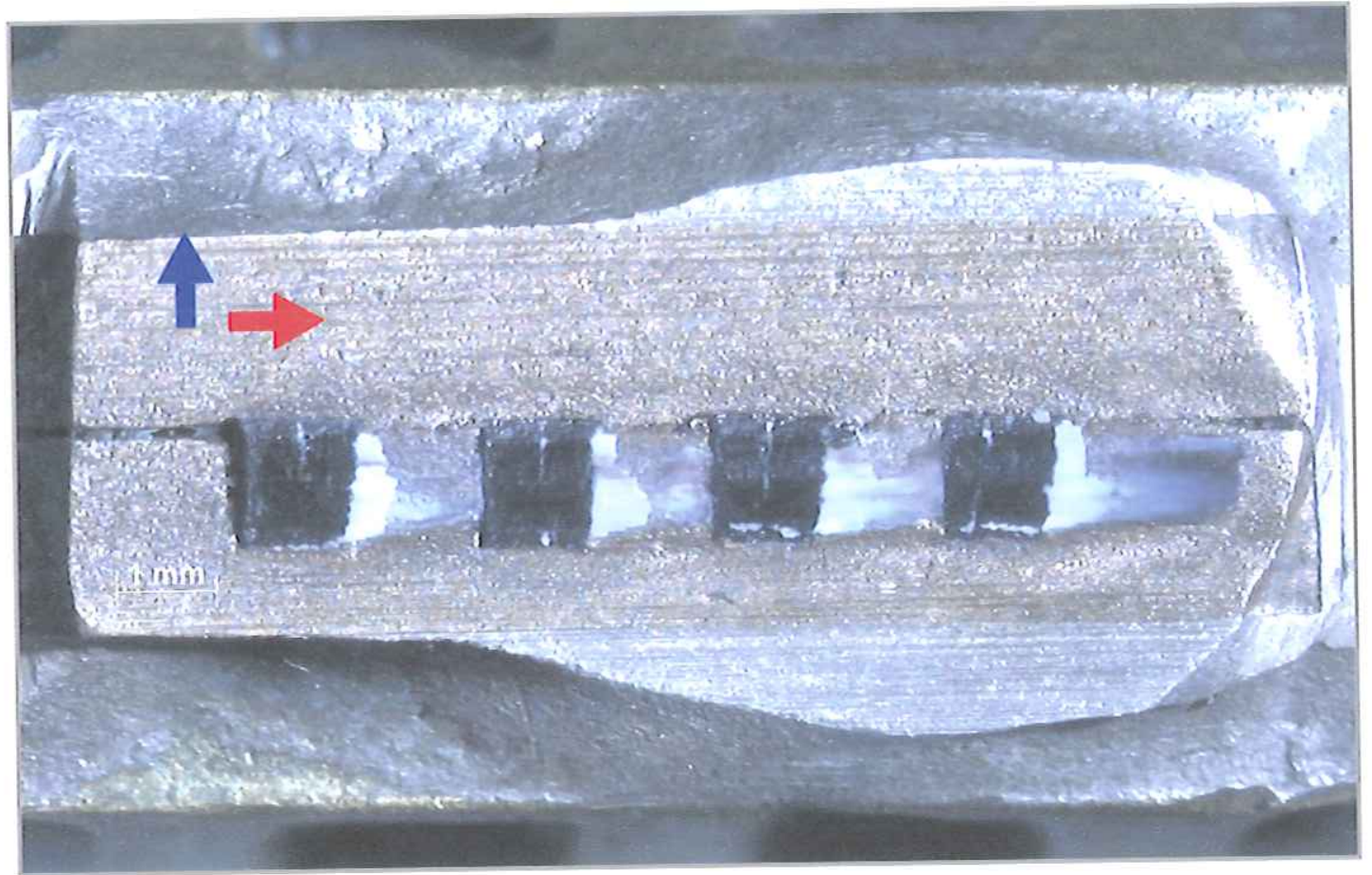

Figura 89: Superfície do dressador após os ensaios (vista de topo).

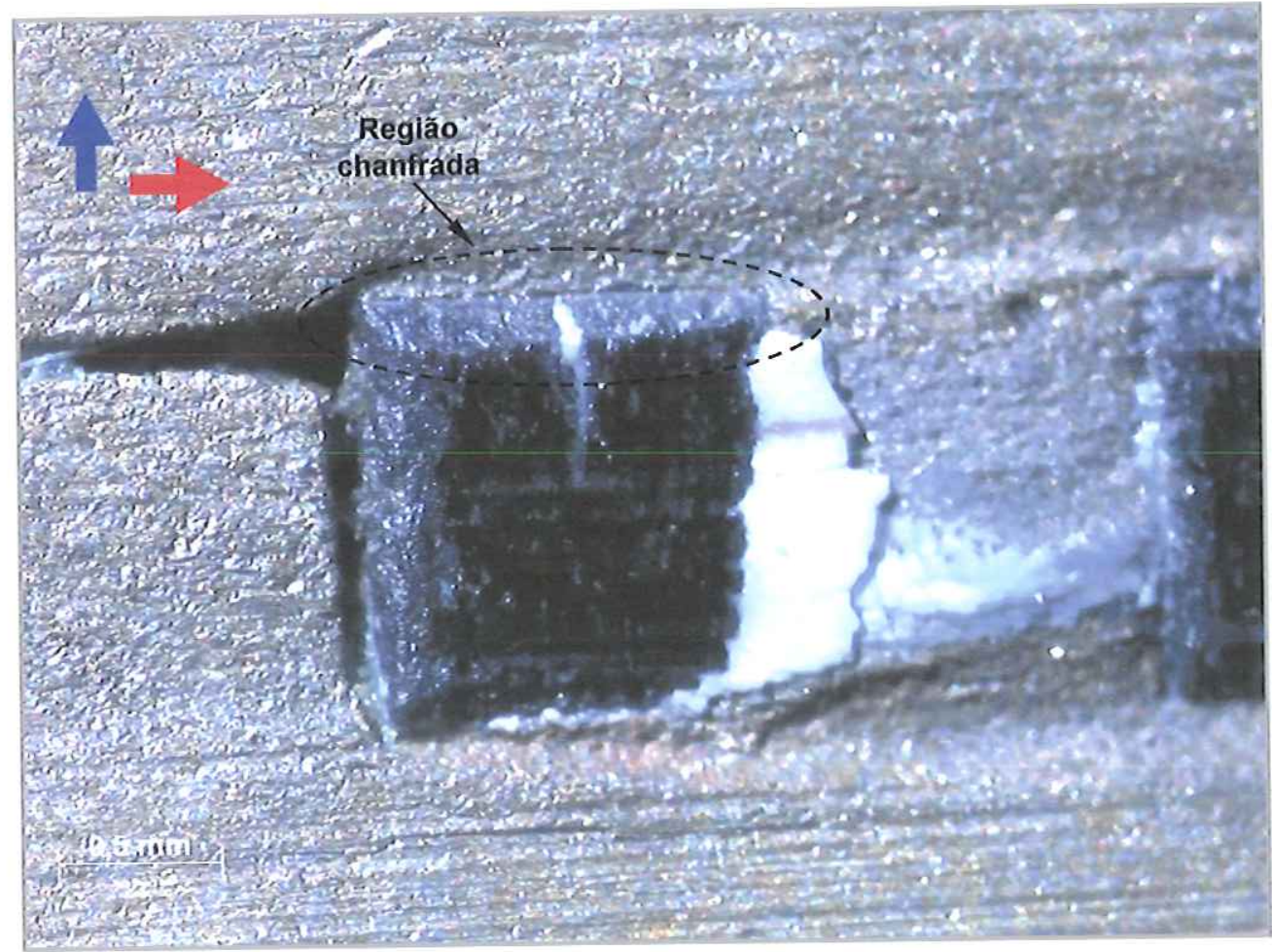

Figura 90: Superfície do primeiro diamante a contactar o rebolo (vista de topo). 


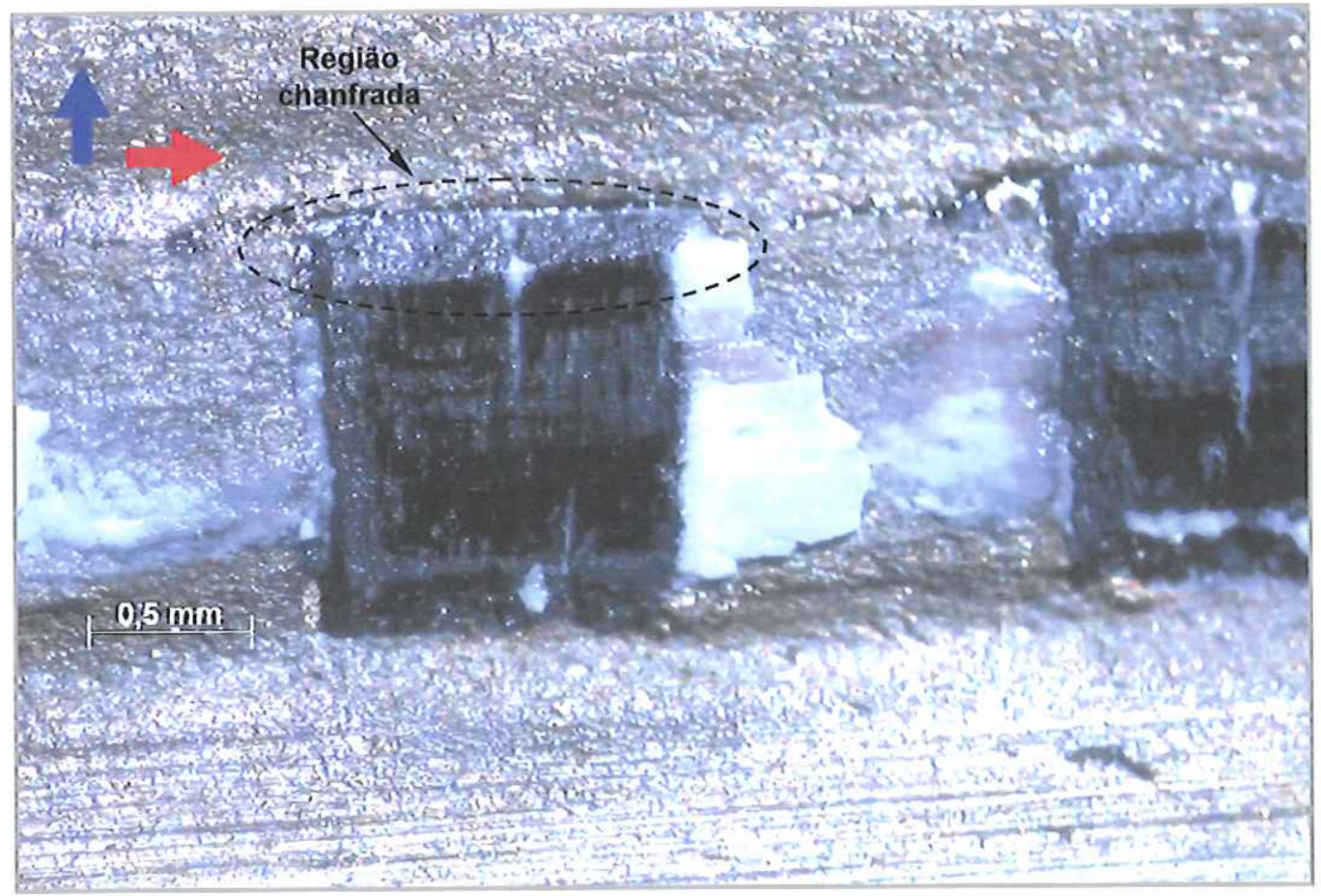

Figura 91: Superfície do segundo diamante a contactar o rebolo (vista de topo).

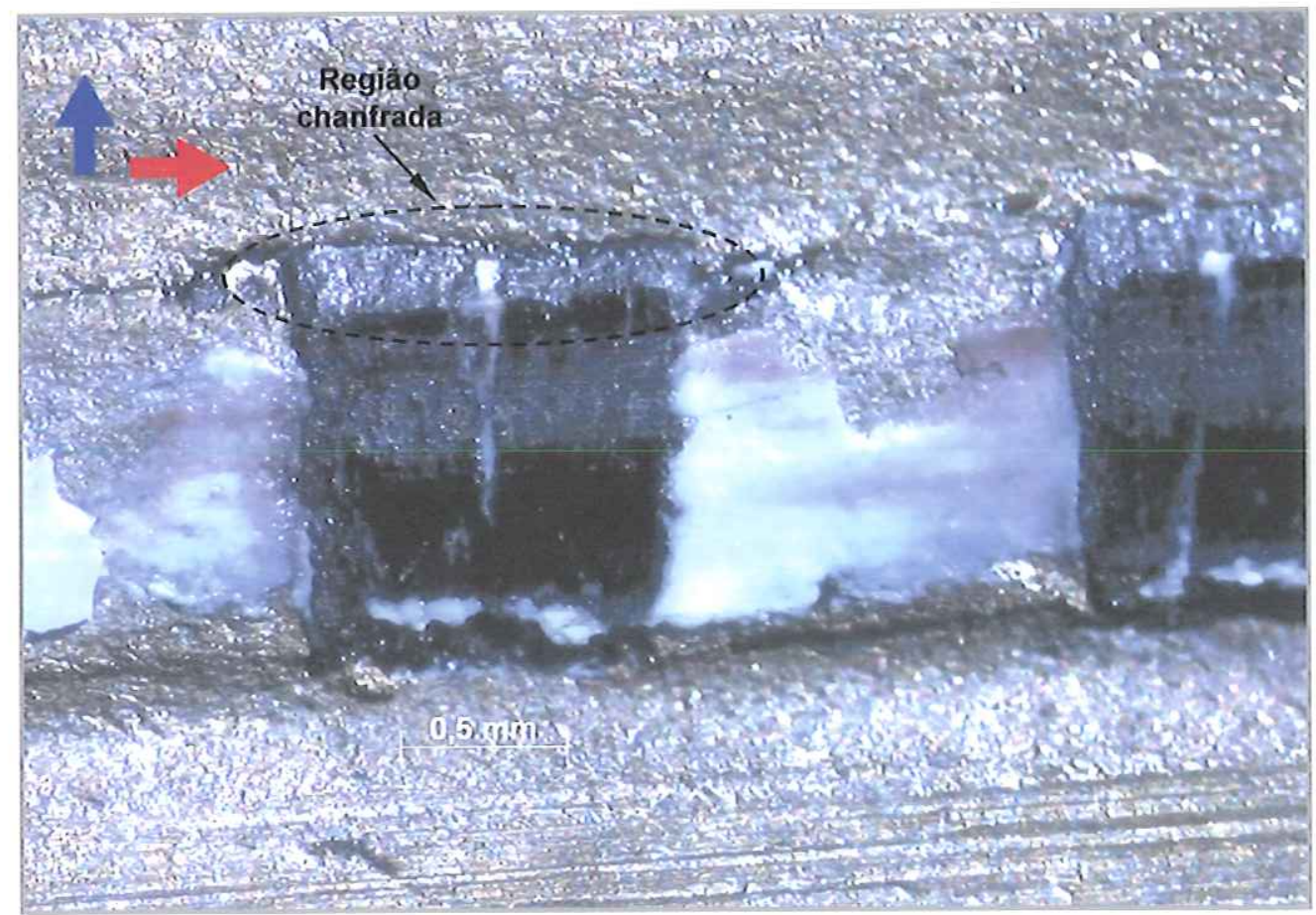

Figura 92: Superfície do terceiro diamante a contactar o rebolo (vista de topo). 


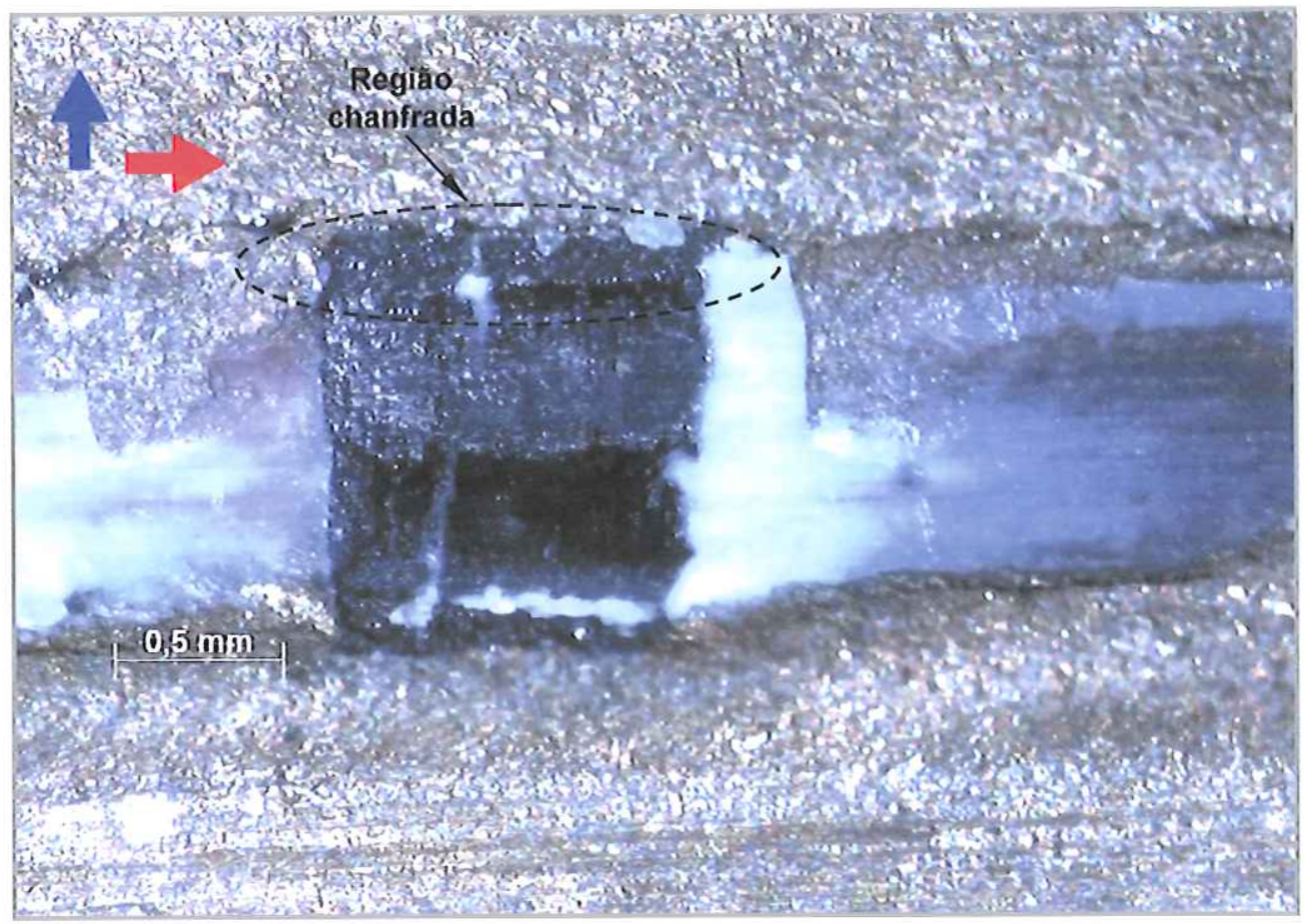

Figura 93: Superfície do quarto diamante a contactar o rebolo (vista de topo).

Após uma observação destas figuras, pode-se perceber na superfície dos diamantes a presença de trincas, possivelmente de origem térmica, resultantes dos ciclos contínuos e intensos de aquecimento/resfriamento aos quais os diamantes foram submetidos nos ensaios.

Nota-se também a existência de uma região "chanfrada" em uma das laterais dos diamantes, conseqüência do desgaste provocado pela operação de dressagem. A formação desta região indica que ela foi a principal responsável pela remoção de material do rebolo. Pode-se supor que, de acordo com as condições de dressagem e de resfriamento empregadas, uma possível situação de evolução do desgaste dos diamantes é a representada pela figura 94 , onde pode-se ver uma situação na qual a região chanfrada vai aumentando progressivamente enquanto a região plana no topo dos diamantes vai diminuindo com o aumento do desgaste dos diamantes. Entretanto, a comprovação deste fato exigiria uma outra estratégia para os ensaios, verificando com maior freqüência o desgaste e utilizando a ferramenta até o final de sua vida útil, o que não foi o caso do presente trabalho. 


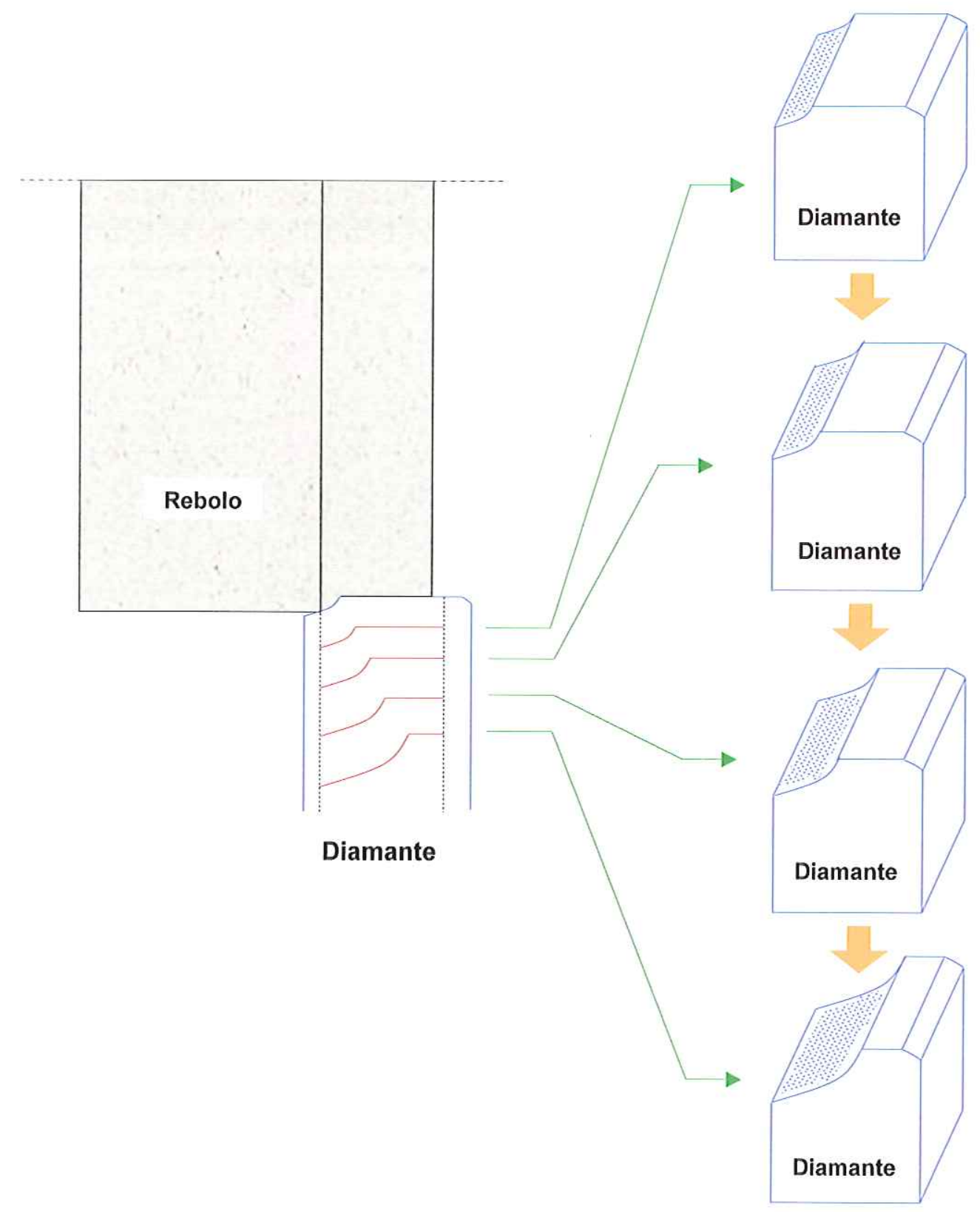

Figura 94: Possível evolução do desgaste dos diamantes do dressador. 


\section{5 - CONCLUSÕES}

Considerando-se as condições dos ensaios realizados e observando-se os resultados obtidos, pode-se chegar às seguintes conclusöes neste trabalho:

- Os níveis de temperaturas obtidos no dressador são influenciados pelos parâmetros considerados nos ensaios, a saber, a profundidade de dressagem $\left(\mathbf{a}_{d}\right)$, o grau de recobrimento de dressagem $\left(\mathbf{U}_{d}\right)$ e a vazão do fluido refrigerante $(\mathbf{Q})$;

- As temperaturas obtidas no dressador nos ensaios onde se variou apenas a profundidade de dressagem $\left(\mathbf{a}_{\mathbf{d}}\right)$ apresentaram uma relação direta com este parâmetro, ou seja, quanto maior o valor de $\mathbf{a}_{\mathbf{d}}$ empregado na dressagem, maiores foram os níveis de temperatura obtidos no dressador;

- Os resultados de temperatura obtidos nos ensaios onde se variou apenas o grau de recobrimento de dressagem $\left(\mathbf{U}_{\mathbf{d}}\right)$ mostraram um comportamento indefinido, impedindo o estabelecimento de uma relação direta entre os níveis de $\mathbf{U}_{d}$ utilizados com os níveis de temperatura obtidos;

- Considerando a vazão do fluido refrigerante (Q), os níveis de temperatura obtidos apresentaram uma diminuição significativa apenas quando se aumentou a vazão para o nível máximo, com um aumento 4 vezes maior em relação à vazão mínima. Pequenas alteraçōes da vazão do fluido refrigerante não produziram efeito significativo na temperatura do dressador dentro dos valores usados neste trabalho; 
- $\quad$ O índice de desgaste (ID) do dressador apresentou uma relação inversa com a profundidade de dressagem $\left(\mathbf{a}_{\mathbf{d}}\right)$, ou seja, quanto maior o valor de $\mathbf{a}_{\mathbf{d}}$, menor o valor de ID obtido, significando uma menor durabilidade do dressador;

- $\quad$ O índice de desgaste (ID) do dressador apresentou uma relação direta com o grau de recobrimento de dressagem $\left(\mathbf{U}_{\mathbf{d}}\right)$. Assim, valores crescentes de $\mathbf{U}_{\mathbf{d}}$ produziram valores igualmente crescentes do índice ID, proporcionando maior durabilidade do dressador;

- Com relação à vazão do fluido refrigerante $(\mathbf{Q})$, a sua variação não foi capaz de influenciar o desgaste do dressador;

- Os resultados obtidos indicam que a simulação foi capaz de representar as temperaturas no dressador com alguma limitação, servindo assim para efeitos comparativos. As temperaturas obtidas na extremidade da ferramenta (região da interface dressador-rebolo) não representam os níveis reais esperados;

- Os valores obtidos pela simulação para o coeficiente médio de transferência de calor por convecção ( $\boldsymbol{h}_{\text {médio }}$ ) nos ensaios onde se variou a vazão do fluido refrigerante foram condizentes com a teoria, ou seja, valores crescentes de vazão originaram valores também crescentes do coeficiente

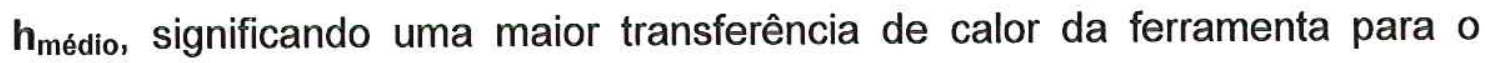
fluido;

- Nos testes de sensibilidade do modelo de elementos finitos empregado a temperatura máxima na região de corte do rebolo apresentou um aumento significativo somente com um aumento de $500 \%$ do fluxo de calor;

- Foram observadas trincas na superfície dos diamantes do dressador, possivelmente de origem térmica, além de uma área "chanfrada" nas laterais dos diamantes que inicialmente tocam o rebolo após o início da dressagem. 


\section{6 - SugestõEs PARA TRABALHOS Futuros}

A partir dos resultados obtidos pode-se fazer algumas sugestões para futuros trabalhos:

- Refinar o modelo proposto para estimar o fluxo de calor pelo diamante (qfí) durante o ensaio com o dressador de ponta única utilizando, por exemplo, um outro material que não acumule calor para isolar este dressador;

- Aumentar o número de termopares inseridos no dressador para buscar uma maior precisão sobre os níveis medidos de temperatura, e para melhorar a posterior comparação com o resultado da simulação por elementos finitos;

- Realizar ensaios com rebolos de granulometrias diferentes para verificar a possível influência desta característica sobre os níveis de temperatura obtidos no dressador;

- Realizar ensaios variando-se o tipo de fluido de refrigeração empregado (experimentar óleo sintético ou então a técnica MQL) para verificar os níveis de temperatura. 


\section{7 - REFERÊNCIAS BIBLIOGRÁFICAS}

ANSYS ${ }^{\circledR}$ ELEMENTS REFERENCE, 1998.

ARONSON, B. (1994). Precision dressing. Manufacturing Engineering, v.113, n. 3, p.45-48, Sept.

ASSAN, A. E. (1999). Método dos elementos finitos - primeiros passos. Campinas, Editora da Unicamp.

BAKON, A., SZYMANSKI, A. (1993). Practical uses of diamond. Ellis Horwood, England.

BARANAUSKAS, V. (2000). O futuro brilhante dos diamantes sintéticos. Ciência Hoje, v.27, n.161, p.40-46, jun.

BEJAN, A. (1996). Transferência de calor. São Paulo, Editora Edgard Blücher.

BIANCHI, E.C. (1992). Ação da geometria teórica do cavaco no desgaste de rebolos de CBN com ligante resinóide. São Carlos. 152p. Tese (Doutorado) Escola de Engenharia de São Carlos, Universidade de São Paulo. 
BIANCHI, E.C. (1990). Ação das condições de dressagem na vida de rebolos na retificação de precisão. São Carlos. 116p. Dissertação (Mestrado) - Escola de Engenharia de São Carlos, Universidade de São Paulo.

BRAGHINI JUNIOR, A. (2002). Metodologia para escolha de fluidos de corte não agressivos ao meio ambiente para aplicações em usinagem de metais. São Carlos. 230p. Tese (Doutorado) - Escola de Engenharia de São Carlos, Universidade de São Paulo.

BRYANT, J. (1999). Efeitos da friabilidade do cristal. Máquinas e Metais, n.406, p.48-59, nov.

CAMPOS, G. P. (1999). Estudo teórico-experimental da distribuição de calor em dressadores sinterizados contendo diamante sintético. São Carlos. 101 p. Dissertação (Mestrado) - Escola de Engenharia de São Carlos, Universidade de São Paulo.

CHEN, X.; ROWE, W.B. (1996). Analysis and simulation of the grinding process. Part I: generation of the grinding wheel surface. International Journal of Machine Tools and Manufacturing, v.36, n.8, p.871-882.

CHIAVERINI, V. (1992). Metalurgia do pó - técnica e produtos, São Paulo, ABM.

CLAPP, D. (1995). Overview of conventional powder metallurgy processing. Advanced Materials \& Processes, v.148, n.2, p.60-61, Aug.

CLARK, I.E.; SEN, P.K. (1998). Advances in the development of ultrahard cutting tool materials. Industrial Diamond Review, v.58, n.577, p.40-44. 
COELHO, R.T. (1999). Experimental and theoretical study of the temperature distribution on diamond dressing tools for precision grinding. In: INTERNATIONAL MACHINING \& GRINDING CONFERENCE, 3rd, Cincinnati, 1999. Proceedings. Ohio, USA, p.481-496.

COELHO, R.T. (1991). Estudo experimental da profundidade de dressagem de rebolos na retificação de precisão usando o método do disco retificado. São Carlos. 106p. Dissertação (Mestrado) - Escola de Engenharia de São Carlos, Universidade de São Paulo.

COELHO, R.T.; OLIVEIRA, J.F.G. (1991). Avaliação experimental da profundidade limite de dressagem na retificação de precisão. In: CONGRESSO BRASILEIRO DE ENGENHARIA MECÂNICA, 11., São Paulo, 1991. Anais. São Paulo, v.3, p.345-348.

COLLINS, J. L. (1999). New cvd diamond products. Industrial Diamond Review, v.59, n.582, p.212.

DAVIES, G. (1984). Diamond. Bristol, Adam Hilger.

DE BEERS INDUSTRIAL DIAMOND DIVISION. Monocrystal: monodie, monodress, monodite. Sunninghill, England. /Catálogo/.

DE HEUS, P.R. (1997). The applications and properties of monocrystal. Industrial Diamond Review. v.57, n.572, p.15-18.

DORNFELD, D. (1992). Application of acoustic emission techniques in manufacturing. NDT \& E International, v.25, n.6, p.259-269.

DORNFELD, D.; CAI, H.G. (1984). An investigation of grinding and wheel loading using acoustic emission. Journal of Engineering for Industry, v.106, n.1, p.28-33, Feb. 
FELIPE JUNIOR, J. (1996). Contribuição para implementação de funções de retificação inteligente (R.I.) utilizando técnicas de monitoramento por emissão acústica. São Carlos. 138p. Tese (Doutorado) - Escola de Engenharia de São Carlos, Universidade de São Paulo.

FIELD, J.E. (1979). The properties of diamond. London, Academic Press Inc.

GENERAL ELECTRIC COMPANY. Formset dresser diamond. Worthington, USA. ICatálogol.

GERMAN, R. M. (1994). Powder metallurgy science, Princeton, USA, Metal Powder Industries Federation.

GOETZEL, C.G. (1984). Infiltration. Metals Handbook, $9^{\text {th }}$ edition, v.7, p.551-552.

HALE, T. E. (1984). Sintering of cemented carbides. Metals Handbook, $9^{\text {th }}$ edition, v.7, p.385-386.

HIGGINS, R.A. (1974). Engineering metallurgy - metallurgical process technology. London, The English Universities Press LTD.

HUEBNER, K. H. (1994). The finite element method for engineers. New York, John Wiley \& Sons.

HIRSCHHORN, J. (1991). Introduction to powder metallurgy, Princeton, USA, American Powder Metallurgy Institute.

INASAKI, I. (1985). Monitoring of dressing and grinding processes with acoustic emission signals. CIRP Annals, v.1, n.34, p.277-280. 
INCROPERA, F.P.; WITT, D.P. (1992). Fundamentos de transferência de calor e de massa. Rio de Janeiro, Editora Guanabara Koogan.

KRAR, S. F.; RATTERMAN, E. (1990). Superabrasives - grinding and machining. New York, Mc Graw-Hill.

KUCHER, K. (2003). Internally cooled dressing tool from a single "casting". Industrial Diamond Review, n. 598, p. 64-65.

LIPTAI, R.G.; HARRIS, D.O.; TATRO, C.A. (1972). An introduction to acoustic emission. ASTM Special Technical Publication 505, p.3-10.

MALKIN, S. (1989) Grinding technology: theory and applications of machining with abrasives, Ellis Worwood.

MARINELLI FILHO, N.; COELHO, R.T.; OLIVEIRA, J.F.G. (1999). Analysis of dressing performance using single crystal diamond dressers. Industrial Diamond Review, n.581, p.133-142.

MARINELLI FILHO, N.; COELHO, R.T.; OLIVEIRA, J.F.G. (1998). Emissão Acústica no monitoramento da dressagem de rebolos de alumina. Máquinas e Metais, n.388, p.56-73, maio.

MARINELLI FILHO, N. (1997). Monitoramento da operação de dressagem de rebolos através da emissão acústica. São Carlos. 113p. Dissertação (Mestrado) - Escola de Engenharia de São Carlos, Universidade de São Paulo.

NAKAYAMA, K.; TAKAGI, J.; IRIE, E.; OKUNO, K. (1980). Sharpness evaluation of grinding wheel face by the grinding of steel ball. CIRP Annals. v.1, n. 29, p. $227-231$. 
NAYAR, H.S. (1984). Production sintering atmospheres. Metals Handbook, $9^{\text {th }}$ edition, v.7, p.339-340.

NUSSBAUM, G. (1988). Rebolos e abrasivos - tecnologia básica. São Paulo, Ícone.

OLIVEIRA, J.F.G. (1999). An innovative system for testing the uniformity of grinding wheel action through high-speed acoustic emission analysis. In: INTERNATIONAL MACHINING \& GRINDING CONFERENCE, 3rd, Cincinnati, 1999. Proceedings. Ohio, USA, p.753-766.

OLIVEIRA, J.F.G.; EIRAS, J.A.; FELIPE JUNIOR, J.; BASSORA, L.A.; VIEIRA JUNIOR, M.; MARINELLI FILHO, N. (1995). Monitoramento do processo de retificação CNC por emissão acústica. In: CONGRESSO ANUAL DA SOBRACON, 2., São Paulo, 1995. Anais. São Paulo.

OLIVEIRA, J.F.G.; DORNFELD, D.; SCHNEIDER, C. (1994a). A otimização da dressagem e a redução do custo de rebolos. Máquinas e Metais, n.340, p.3244, maio.

OLIVEIRA, J.F.G.; DORNFELD, D.A.; WINTER, B. (1994b). Dimensional characterization of grinding wheel surface through acoustic emission. CIRP Annals, v.43, n.1, p.291-294.

OLIVEIRA, J.F.G. (1992). Controle do estado de afiação de rebolos na retificação de precisão. São Carlos. 175p. Tese (Livre Docência) - Escola de Engenharia de São Carlos, Universidade de São Paulo.

OLIVEIRA, J.F.G.; PURQUERIO, B.M.; COELHO, R.T.; BIANCHI, E.C. (1992a). Grinding process dominance by means of the dressing operation. In: INTERNATIONAL MATADOR CONFERENCE, 29., Manchester, 1992. Proceedings. UK, p.547-550. 
OLIVEIRA, J.F.G.; BIANCHI, E.C.; SOUZA, G.F. (1992b). O desempenho de rebolos pode ser controlado pela dressagem. Máquinas e Metais, n.317, p.1225 , jun.

OLIVEIRA, J.F.G.; BIANCHI, E.C.; SOUZA, G.F. (1990). O comportamento da vida de rebolos na retificação: sua importância em máquinas CN/CNC. In: SEMINÁRIO DE COMANDO NUMÉRICO NO BRASIL, 10., São Paulo, 1990. Anais. São Paulo, p.01-21.

OLIVEIRA, J. F. G.; SILVA, G. (1990). Tópicos importantes na retificação de precisão. Máquinas e Metais, n.290, p.46-52, Março.

OLIVEIRA, J. F. G.; PURQUERIO, B. M. (1989). Dressagem controlada: uma solução para os problemas. Máquinas e Metais, n.283, p.60-66.

OLIVEIRA, J.F.G. (1988). Análise da ação do macroefeito de dressagem de rebolos no desempenho do processo de retificação. São Carlos. 272p. Tese (Doutorado) - Escola de Engenharia de São Carlos, Universidade de São Paulo.

PALOSCHI JUNIOR, A., COELHO, R. T. Estudo da Sinterização de Dressadores Usando Ligas de Bronze e Diamantes Sintéticos. In: SIMPÓSIO INTERNACIONAL DE INICIAÇÃO CIENTÍFICA DA UNIVERSIDADE DE SÃO PAULO, 8., São Carlos, São Paulo, 2000.

PARKER, W. J.; JENKINS, R. J.; BUTLER, C. P.; ABBOTT, G. L. (1961). Flash method of determining thermal diffusivity, heat capacity, and thermal conductivity. Journal of Applied Physics, v. 32, n. 9, p. 1679-1684.

POWDER manufacture. http://www.epma.com/process/powder.html (22 Jan. 99). 
PRICKEN, W. (1999). Dressing of vitrified bond wheels with CVDress and Monodress. Industrial Diamond Review, v.59, n.582, p.225-231.

ROWE, W.B.; CHEN, X.; MORGAN, M.N. (1993). The identification of dressing strategies for optimal grinding wheel performance. In: International Matador Conference, 30., Manchester, 1993. Proceedings. UK, p.195-202.

SEN, P.K. (2000). Synthetic diamond dresser logs: serving the future needs of industry. De Beers Industrial Diamonds (UK) - Technical Literature.

SILVA JUNIOR, C. E.; COELHO, R. T. (1998). Dressagem de rebolos para aplicações de precisão. Máquinas e Metais, n.393, p.100-111, out.

SILVA JUNIOR, C.E. (1998). Estudo experimental do desgaste de dressadores sinterizados com perfil de atuação constante. São Carlos. 103 p. Dissertação (Mestrado) - Escola de Engenharia de São Carlos, Universidade de São Paulo.

SPEAR, K.E.; DISMUKES, J.P. (1993). Synthetic diamond: emerging CVD science and technology, John Wiley \& Sons.

SUSSMANN, R.S.; BRANDON, J.R.; COE, S.E.; COLLINS, J.L.; WHITEHEAD, A.J. (1999). A review of the industrial applications of cvd diamond. Industrial Diamond Review, v.61, n.591, p.271-280.

TAEYAERTS, J. (1968). The physical and chemical properties of diamonds: how they affect diamond dressing tools. Cutting Tool Engineering, v.20, n.6, p.17-21, June.

TRENT, E. M. (1984). Metal cutting, Butterworths \& Co Publishers.

VERKERK, J.; PEKELHARING, A. J. (1979). The influence of the dressing operation on productivity in precision grinding. CIRP Annals, v.28, n.2, p.487495. 
VIEIRA JUNIOR, M.; OLIVEIRA, J. F. G. (2000). Método para avaliar a dureza de rebolos em trabalho. Máquinas e Metais, n.415, p.208-221, Agosto.

VIEIRA JUNIOR, M. (1996). Avaliação da dureza de rebolos em trabalho através do uso da emissão acústica na dressagem. São Carlos. 130p. Tese (Doutorado) - Escola de Engenharia de São Carlos, Universidade de São Paulo.

VIGNA, C.M. (1997). Desenvolvimento de dressadores estáticos com perfil de atuação constante. São Carlos. IRelatório Científico EESC - USPI.

WILKS, J., WILKS, E. (1991). Properties and applications of diamond. Butterworth-Heinemann Ltd. 


\section{APÊNDICE A}

\section{Abaixo encontra-se a listagem do programa em linguagem APDL (Ansys Parametric Design Language) desenvolvido para gerar o modelo utilizado nas simulações em elementos finitos.}

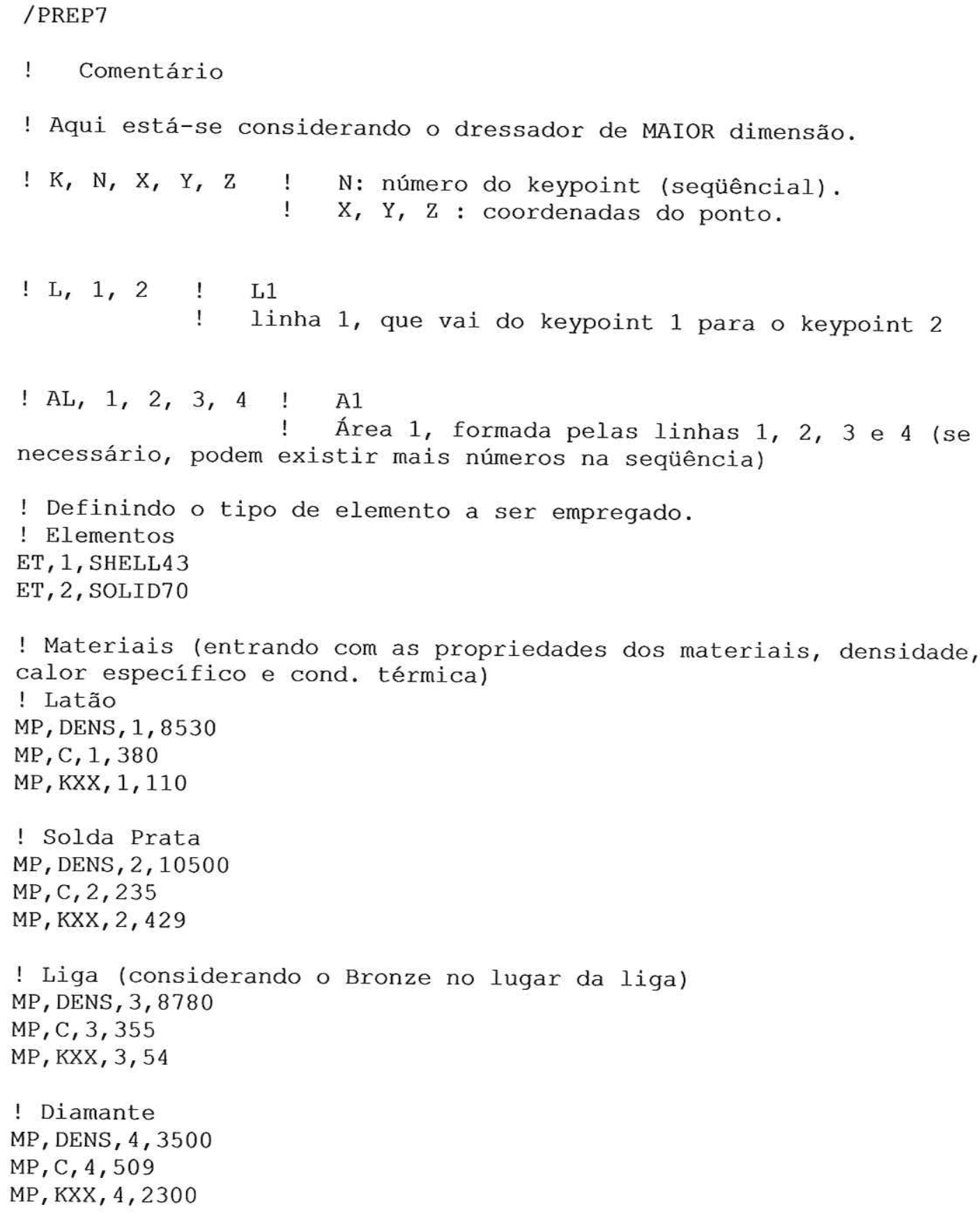


! Coordenadas dos Keypoints em $\mathrm{x}, \mathrm{y}, \mathrm{z}$

$\mathrm{K}, 1,0,0,0 \quad$ ! Keypoint 1 localizado na coordenada

$\mathrm{x}=0, \mathrm{y}=0, \mathrm{z}=0$

$\mathrm{K}, 2,0.65 \mathrm{E}-3,0,0 \quad$ Keypoint 2 localizado nas

coordenadas $\mathrm{x}=0.00065(=0.65 \mathrm{~mm}), \mathrm{y}=0, \mathrm{z}=0$

$\mathrm{K}, 3,1.85 \mathrm{E}-3,0$, 0

$\mathrm{K}, 4,3.15 \mathrm{E}-3,0$, 0

$\mathrm{K}, 5,4.35 \mathrm{E}-3,0$, 0

$\mathrm{K}, 6,7.0 \mathrm{E}-3,0$, 0

$\mathrm{K}, 7,10.0 \mathrm{E}-3,0$, 0

$\mathrm{K}, 8,11.5 \mathrm{E}-3,0$, 0

$\mathrm{K}, 9,0,0.6 \mathrm{E}-3,0$

$\mathrm{K}, 10,0.65 \mathrm{E}-3,0.6 \mathrm{E}-3,0$

$\mathrm{K}, 11,1.85 \mathrm{E}-3,0.6 \mathrm{E}-3,0$

$\mathrm{K}, 12,3.15 \mathrm{E}-3,0.6 \mathrm{E}-3,0$

$\mathrm{K}, 13,4.35 \mathrm{E}-3,0.6 \mathrm{E}-3,0$

$\mathrm{K}, 14,7.0 \mathrm{E}-3,0.6 \mathrm{E}-3,0$

$\mathrm{K}, 15,10.0 \mathrm{E}-3,0.6 \mathrm{E}-3,0$

$\mathrm{K}, 16,11.5 \mathrm{E}-3,1.5 \mathrm{E}-3,0$

$\mathrm{K}, 17,0,2.0 \mathrm{E}-3,0$

$\mathrm{K}, 18,0.65 \mathrm{E}-3,2.0 \mathrm{E}-3,0$

$\mathrm{K}, 19,1.85 \mathrm{E}-3,2.0 \mathrm{E}-3,0$

$\mathrm{K}, 20,3.15 \mathrm{E}-3,2.0 \mathrm{E}-3,0$

$\mathrm{K}, 21,4.35 \mathrm{E}-3,2.0 \mathrm{E}-3,0$

$\mathrm{K}, 22,7.0 \mathrm{E}-3,2.0 \mathrm{E}-3,0$

$\mathrm{K}, 23,10.0 \mathrm{E}-3,2.0 \mathrm{E}-3,0$

$\mathrm{K}, 24,0,2.25 \mathrm{E}-3,0$

$\mathrm{K}, 25,0.65 \mathrm{E}-3,2.25 \mathrm{E}-3,0$

$\mathrm{K}, 26,1.85 \mathrm{E}-3,2.25 \mathrm{E}-3,0$

$\mathrm{K}, 27,3.15 \mathrm{E}-3,2.25 \mathrm{E}-3,0$

$\mathrm{K}, 28,4.35 \mathrm{E}-3,2.25 \mathrm{E}-3,0$

$\mathrm{K}, 29,7.0 \mathrm{E}-3,2.25 \mathrm{E}-3,0$

$\mathrm{K}, 30,10.0 \mathrm{E}-3,2.25 \mathrm{E}-3,0$

$\mathrm{K}, 31,11.5 \mathrm{E}-3,2.25 \mathrm{E}-3,0$

$\mathrm{K}, 32,0,4.0 \mathrm{E}-3,0$

$\mathrm{K}, 33,1.5 \mathrm{E}-3,4.0 \mathrm{E}-3,0$

$\mathrm{K}, 34,4.0 \mathrm{E}-3,4.0 \mathrm{E}-3,0$

$\mathrm{K}, 35,6.5 \mathrm{E}-3,4.0 \mathrm{E}-3,0$

$\mathrm{K}, 36,9.0 \mathrm{E}-3,4.0 \mathrm{E}-3,0$

$\mathrm{K}, 37,11.5 \mathrm{E}-3,4.0 \mathrm{E}-3,0$

! Coordenadas das linhas:

L, 1, 2 ! Linha 1, que vai do KP1 para o KP2 ( a numeração das linhas é feita automaticamente e segue a seqüência)

$L, 2,3$

Linha 2, que vai do KP2 para o KP3

L, 3, 4

Linha 3, que vai do KP3 para O KP4

L, 4,5

Linha $4, \ldots$

Linha $5, \ldots$

Linha $6, \ldots$

Linha $7, \ldots$

L, 6, 7

L, 7, 8

L, 1,9

L, 2, 10

L, 3, 11

L, 4, 12

L, 5, 13

L, 6, 14

L, 7, 15

Linha 8, que vai do KP1 ao KP9

Linha 9, que vai do KP2 ao KP10

Linha 10, que vai do KP3 ao KP11

Linha $11, \ldots$

Linha $12, \ldots$

Linha 13, ...

Linha $14, \ldots$ 


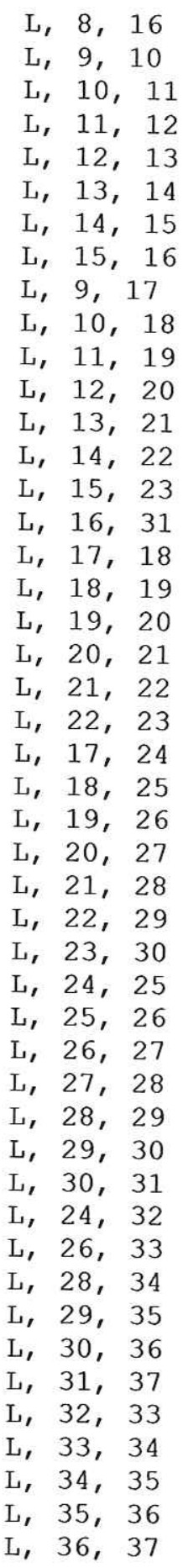

L, 8, 16

$\mathrm{L}, 11,12$

L, 12, 13

L, 13, 14

L, 14, 15

$\mathrm{L}, 15,16$

L, 9, 17

$L, 10,18$

, 11, 19

$\mathrm{L}, 12,20$

$\mathrm{L}, 13,21$

$L, 14,22$

L, 16, 31

$\mathrm{L}, 17,18$

$L, 18,19$

$L, 19,20$

L, 20, 21

L, 21, 22

$L, 22,23$

L, 17, 24

L, 18, 25

$\mathrm{L}, 19,26$

L, 20， 27

L, 21, 28

L, 22, 29

$L, 23,30$

L, 24, 25

$L, 25,26$

L, 26, 27

L, 28,29

L, 29, 30

L, 30, 31

L, 26, 33

$\mathrm{L}, 28,34$

L, 29, 35

$\mathrm{L}, 30,36$

L, 31, 37

$\mathrm{L}, 32,33$

$L, 34,35$

$L, 35,36$

! Divisão das linhas (fornece o número de elementos em que cada linha foi dividida)

LESIZE, $1,1,2$

LESIZE, $2,1,4$

LESIZE, $3,, 3$

LESIZE, $4,, 4$

LESIZE, $5,, 4$

LESIZE, $6,1,4$

LESIZE, $7,, 14$

LESIZE, $8,, 2$

LESIZE, $9,1,2$

LESIZE, $10,, 2$
Linha $15, \ldots$

Linha 16, que vai do KP9 ao KP10

Linha $17, \ldots$

Linha $18, \ldots$

Linha $19, \ldots$

Linha $20, \ldots$

Linha $21, \ldots$.

Linha $22, \ldots$

Linha 23, que vai do KP9 ao KP17

Linha $24, \ldots$

Linha $25, \ldots$

Linha $26, \ldots$

Linha $27, \ldots$

Linha $28, \ldots$

Linha $29, \ldots$.

Linha $30, \ldots$.

Linha 31, que vai do KP17 ao KP18

Linha $32, \ldots$

Linha $33, \ldots$

Linha $34, \ldots$.

Linha $35, \ldots$.

Linha $36, \ldots$.

Linha 37, que vai do KP17 ao KP34

Linha $38, \ldots$

Linha $39, \ldots$

Linha $40, \ldots$

Linha $41, \ldots$.

Linha $42, \ldots$

Linha $43, \ldots$

Linha $44, \ldots$

Linha $45, \ldots$

Linha $46, \ldots$

Linha $47, \ldots$.

Linha $48, \ldots$

Linha $49, \ldots$

Linha $50, \ldots$.

Linha $51, \ldots$

Linha $52, \ldots$

Linha $53, \ldots$

Linha $54, \ldots$

Linha $55, \ldots$

Linha $56, \ldots$

Linha $57, \ldots$

Linha $58, \ldots$.

Linha 59, ...

Linha $60, \ldots$.

Linha $61, \ldots$ 
LESIZE, 11, , 2 LESIZE, 12 , , , 2 LESIZE, 13, , , 2 LESIZE, 14, , , 2 LESIZE, 15, , , 2 LESIZE, 16, , , 2 LESIZE, $17,$, , 4 LESIZE, $18,, 3$ LESIZE, 19, , , 4 LESIZE, 20, , , 4 LESIZE, 21, , , 4 LESIZE, $22,, 4$ LESIZE, 23, , , 3 LESIZE, $24,, 3$ LESIZE, 25, , , 3 LESIZE, 26, , 3 LESIZE, $27,, 13$ LESIZE, $28,, 13$ LESIZE, 29, , 3 LESIZE, 30, , , 4 LESIZE, $31,, 2$ LESIZE, $32,, 4$ LESIZE, 33, , , 3 LESIZE, $34,, 4$ LESIZE, 35, , , 4 LESIZE, $36,1,4$ LESIZE, $37,, 1$ LESIZE, $38,, 1$ LESIZE, $39,, 1$ LESIZE, $40,, 1$ LESIZE, 41, , , 1 LESIZE, $42,, 1$ LESIZE, $43,, 1$ LESIZE, $44,, 2$ LESIZE, $45,, 4$ LESIZE, $46,1,3$ LESIZE, 47, , , 4 LESIZE, 48, , , 4 LESIZE, $49,, 4$ LESIZE, $50,, 4$ LESIZE, 51, , , 4 LESIZE, 52, , , 4 LESIZE, 53, , , 4 LESIZE, $54,, 4$ LESIZE, 55, , , 4 LESIZE, 56, , , 4 LESIZE, 57, , , 6 LESIZE, $58,1,7$ LESIZE, 59, , , 4 LESIZE, $60,, 4$ LESIZE, 61, , 4

! Coordenadas das Áreas definidas por linhas:

$\mathrm{AL}, 1,8,16,9$ Área 1, formada pelas linhas L1, L8, L16 e L9 (a numeração das áreas tbém é automática e segue a seq.)

AL, 2，9，17，10 Área 2, ... $\mathrm{AL}, 3,10,18,11$ Área 3, ... AL, 4, 11, 19, 12 Área $4, \ldots$. 


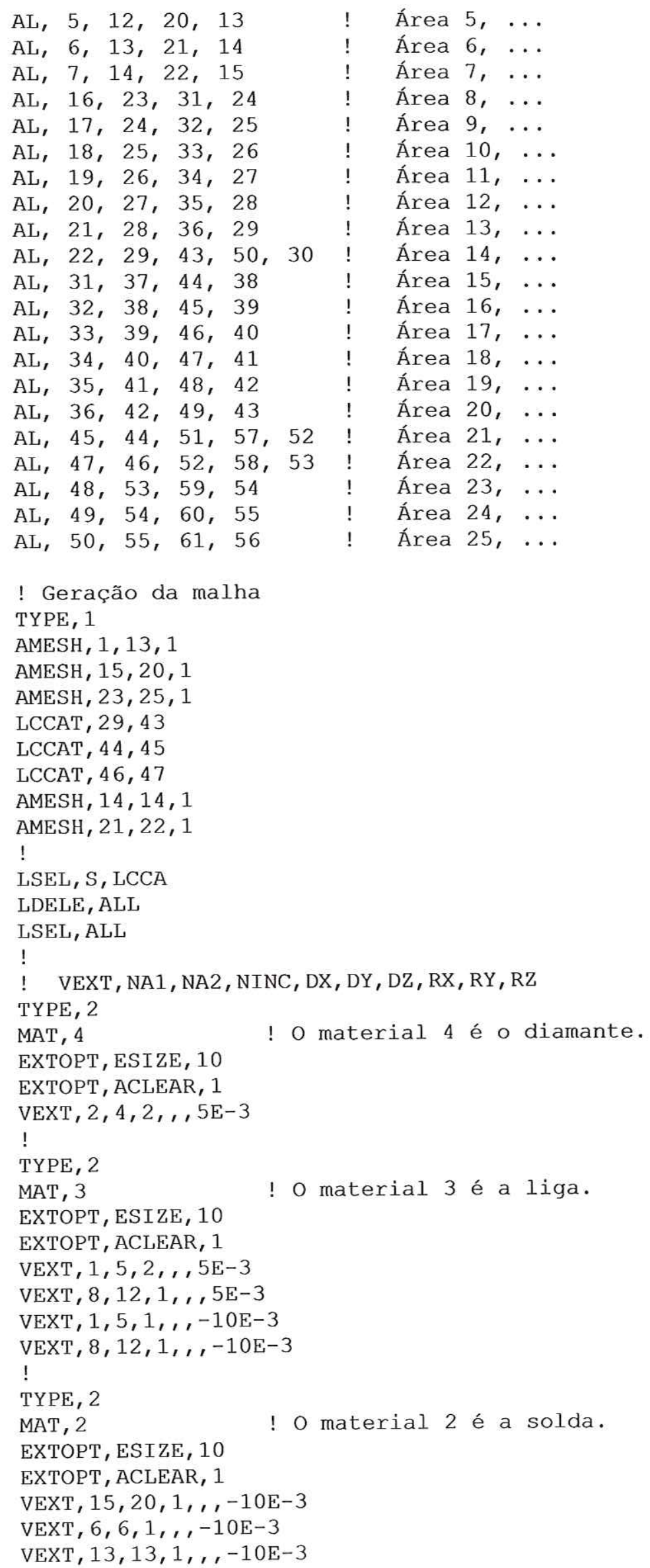

Área 5, ...

Área $6, \ldots$

Área $7, \ldots$

Área $8, \ldots$.

Área 9, ...

Área $10, \ldots$.

Área $11, \ldots$.

Área $12, \ldots$

Área 13, ...

Área $14, \ldots$

Área $15, \ldots$

Área 16, ...

Área $17, \ldots$

Área $18, \ldots$

Área 19, ...

Área 20, ...

Área $21, \ldots$

Área 22, ...

Área 23, ...

Área $24, \ldots$

Área 25, ... 
!

TYPE, 2

MAT, 1

! O material 1 é o latão.

EXTOPT, ESIZE, 10

EXTOPT, ACLEAR, 1

VEXT $, 21,25,1,,,-10 \mathrm{E}-3$

VEXT, 7, 7, 1, , -10E-3

VEXT, $14,14,1,1,-10 \mathrm{E}-3$

!

VEXT, $72,72,1,1,-9 \mathrm{E}-3$

VEXT, $77,93,4,,,-9 \mathrm{E}-3$

VEXT, $98,114,4,1,-9 \mathrm{E}-3$

VEXT, $119,139,4,1,-9 \mathrm{E}-3$

VEXT, $144,144,1,1,-9 \mathrm{E}-3$

VEXT, $149,149,1,1,-9 \mathrm{E}-3$

VEXT, $155,155,1,1,-9$ E-3

VEXT, $160,172,4,1,-9$ E-3

VEXT, $177,177,1,1,-9$ E-3

!

NUMMRG, KP

NUMMRG, NODE

NUMMRG, KP

! 


\section{APÊNDICE B}

Neste apêndice encontram-se todos os gráficos obtidos para as temperaturas medidas pelos termopares 1 (TP1) e 2 (TP2) nos ensaios com o dressador de ponta única para a estimativa do fluxo de calor através do diamante.

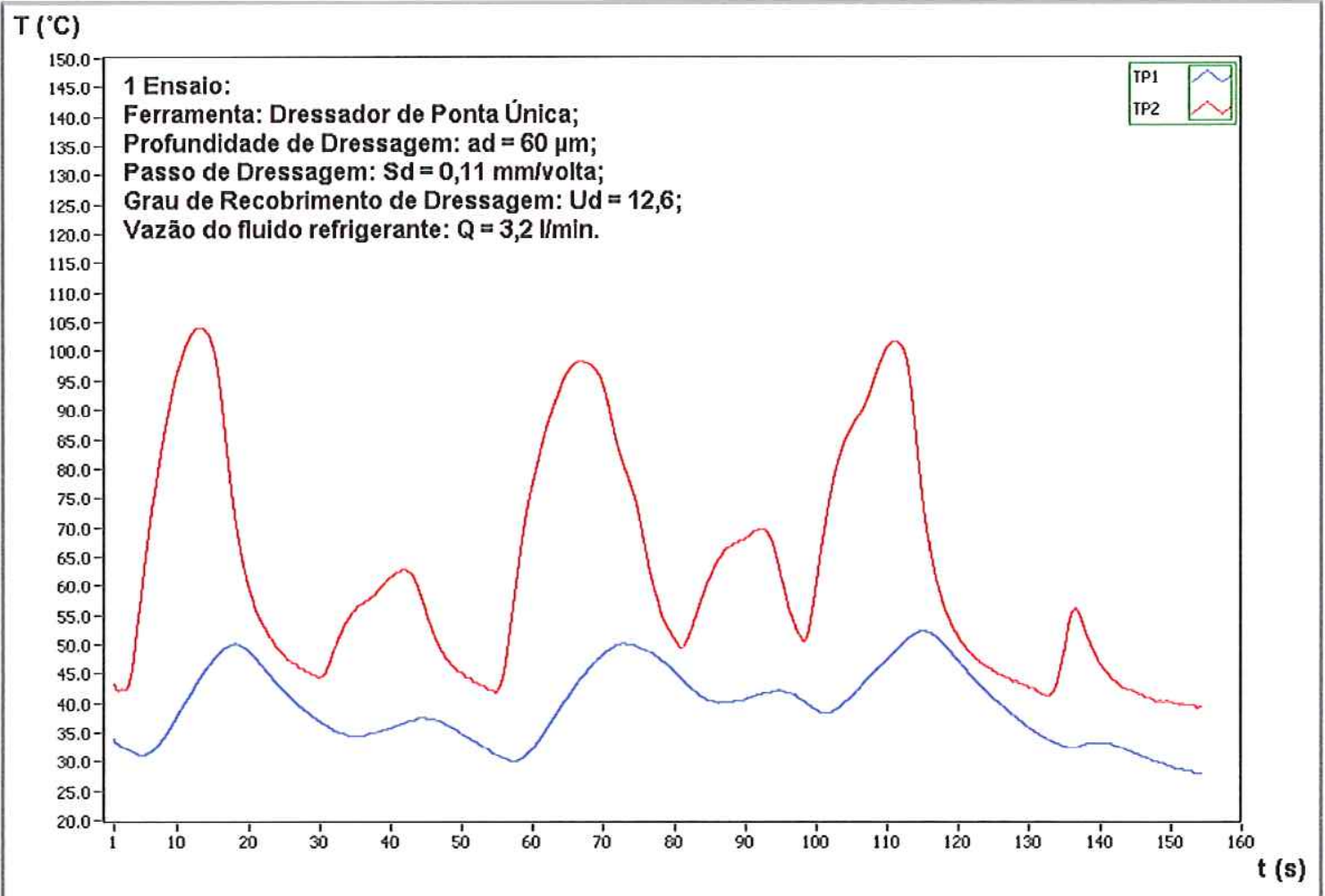

Figura B1: Temperaturas obtidas no $1^{\circ}$ ensaio com o dressador de ponta única. 


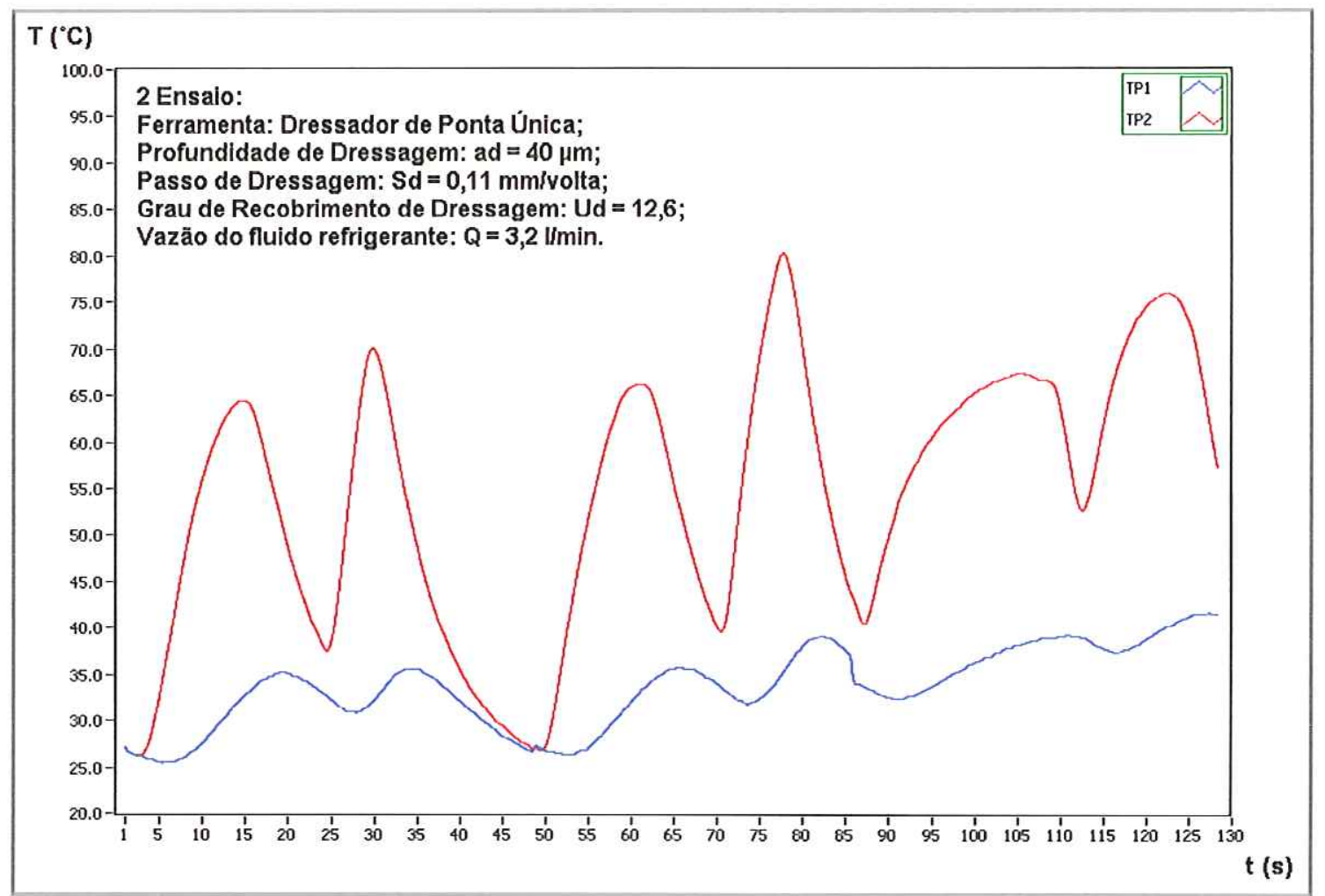

Figura B2: Temperaturas obtidas no $2^{\circ}$ ensaio com o dressador de ponta única.

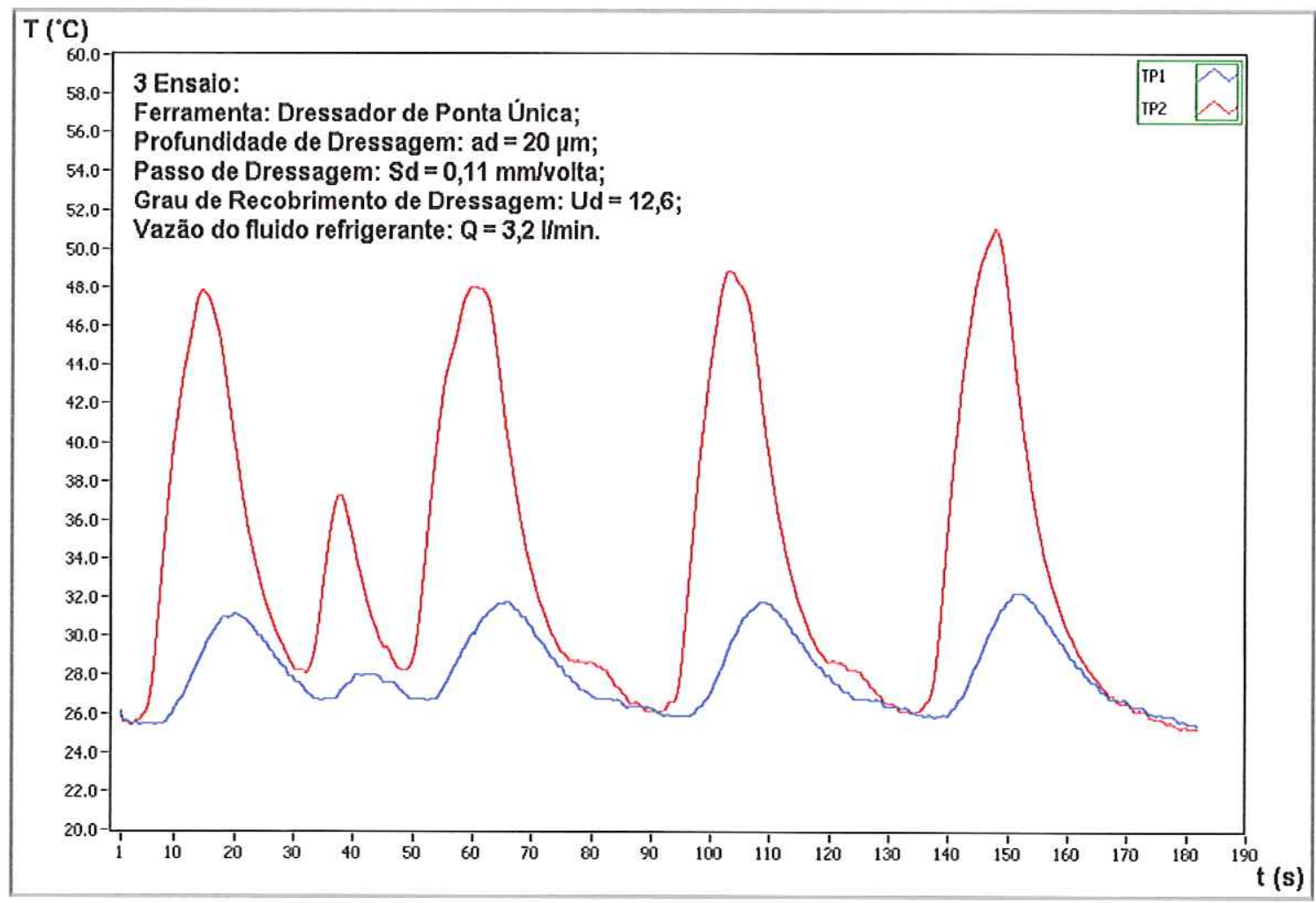

Figura B3: Temperaturas obtidas no $3^{\circ}$ ensaio com o dressador de ponta única. 


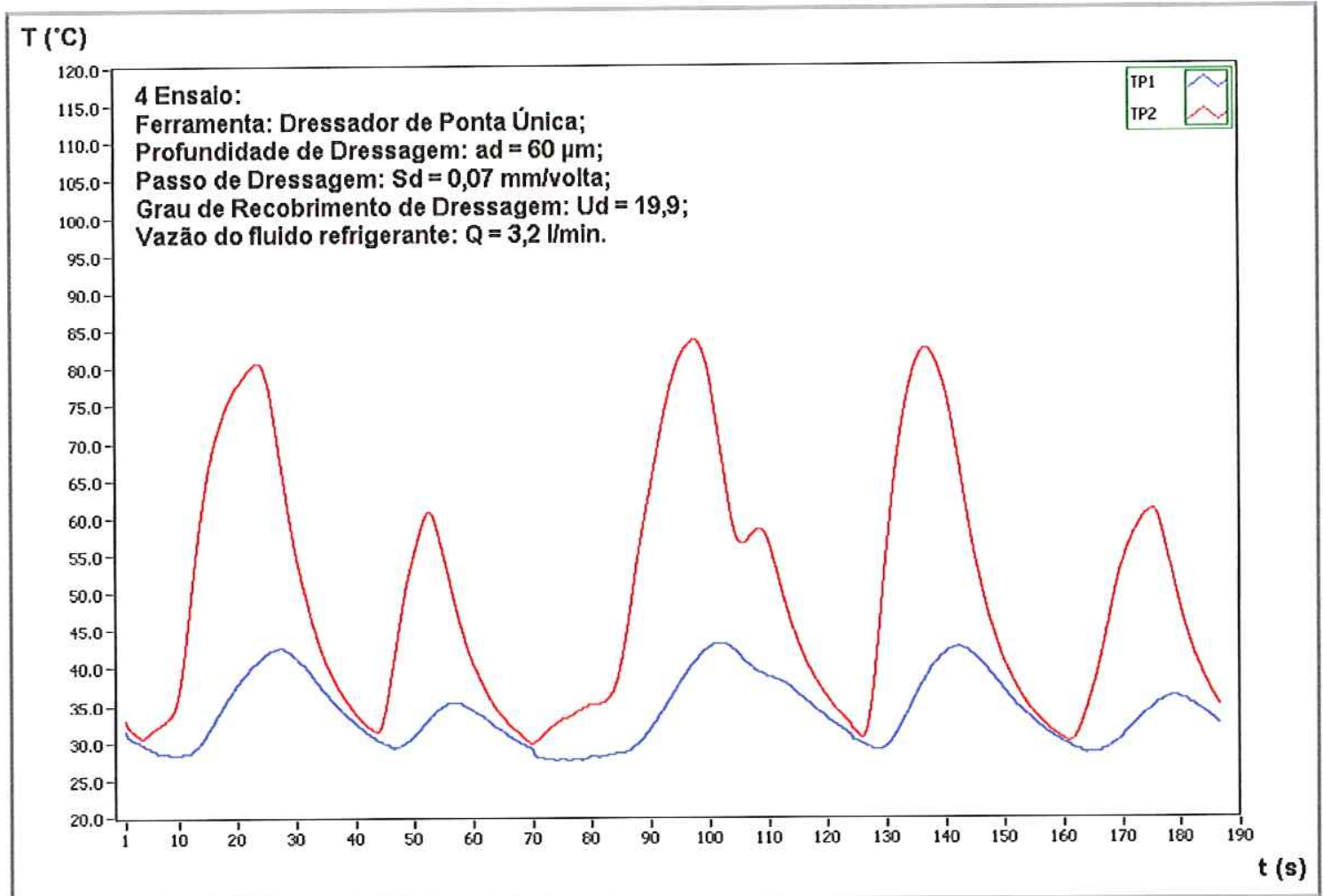

Figura B4: Temperaturas obtidas no $4^{\circ}$ ensaio com o dressador de ponta única.

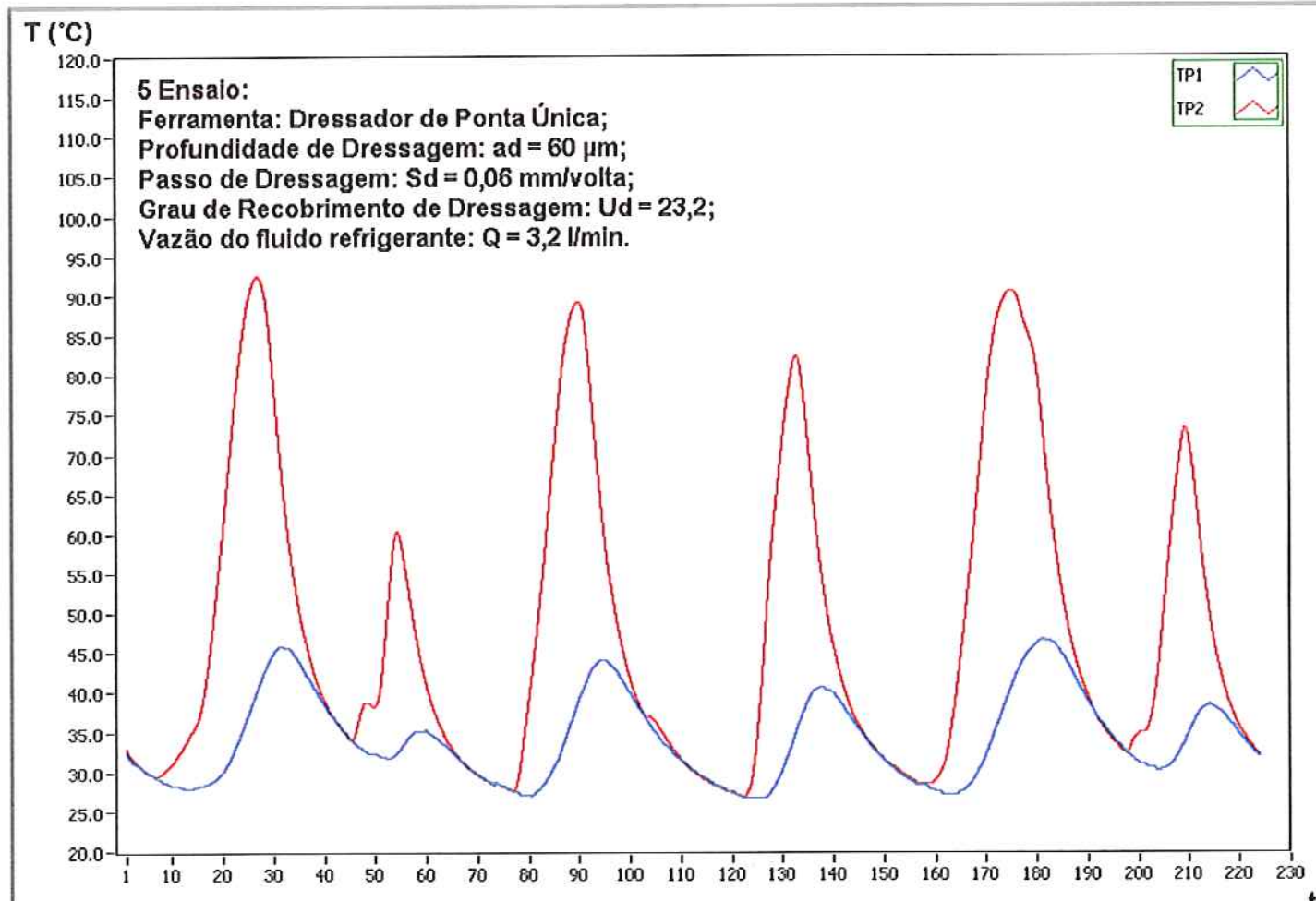

Figura B5: Temperaturas obtidas no $5^{\circ}$ ensaio com o dressador de ponta única. 


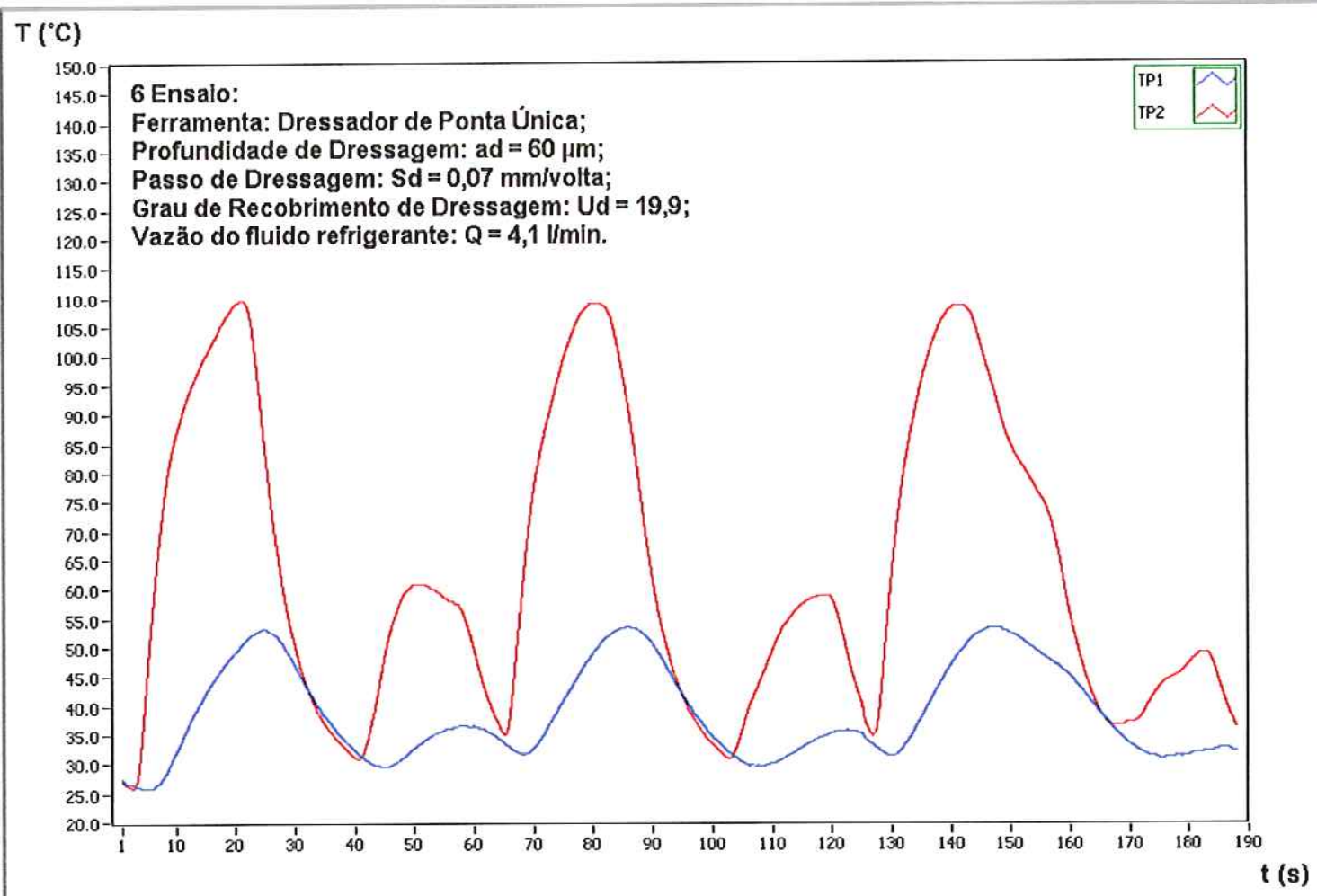

Figura B6: Temperaturas obtidas no $6^{\circ}$ ensaio com o dressador de ponta única.

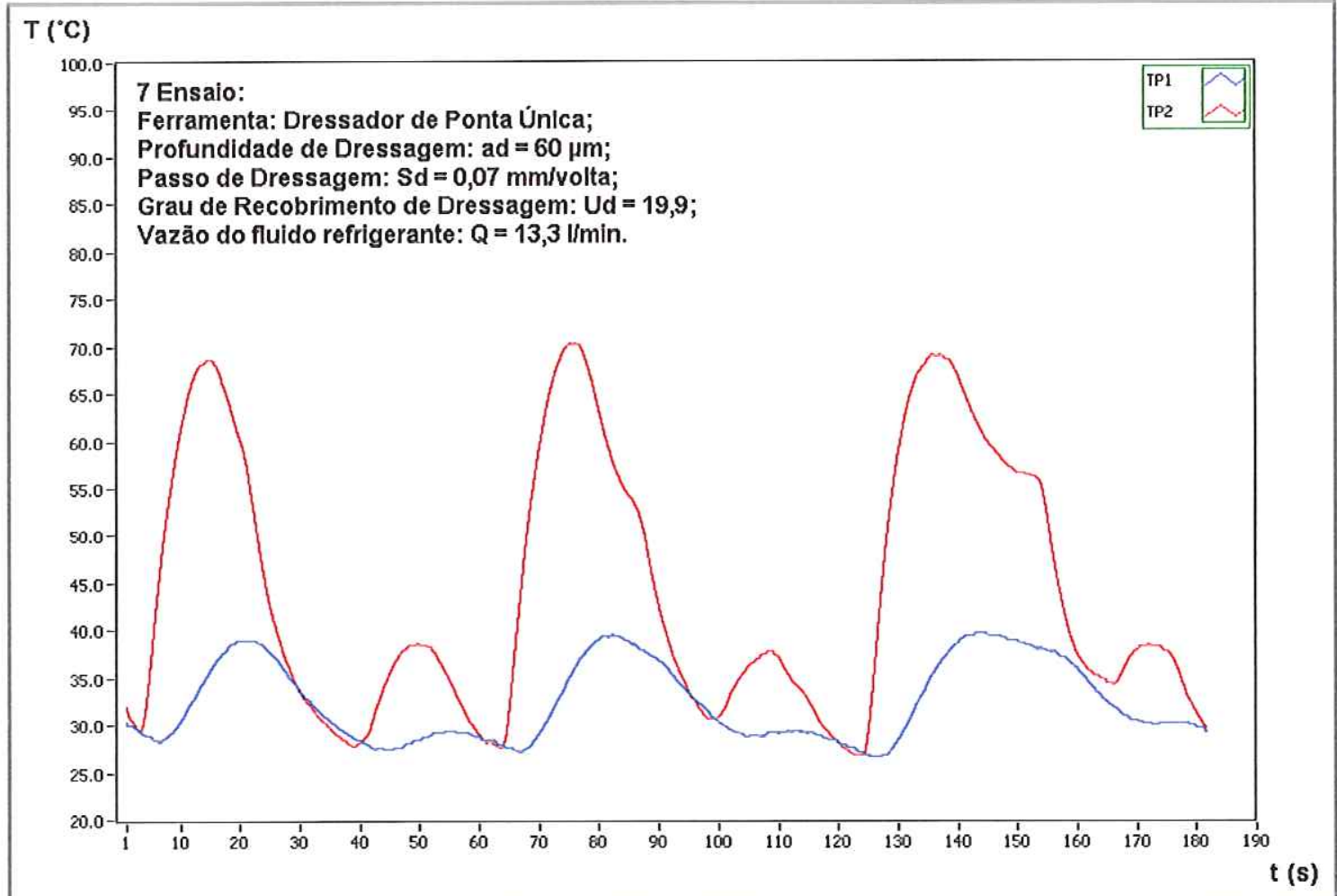

Figura B7: Temperaturas obtidas no $7^{ }$ensaio com o dressador de ponta única. 


\section{APÊNDICE C}

Neste apêndice encontram-se todos os gráficos obtidos na medição das temperaturas pelos termopares 1 (TP1) e 2 (TP2) durante os ensaios com o dressador aletado.

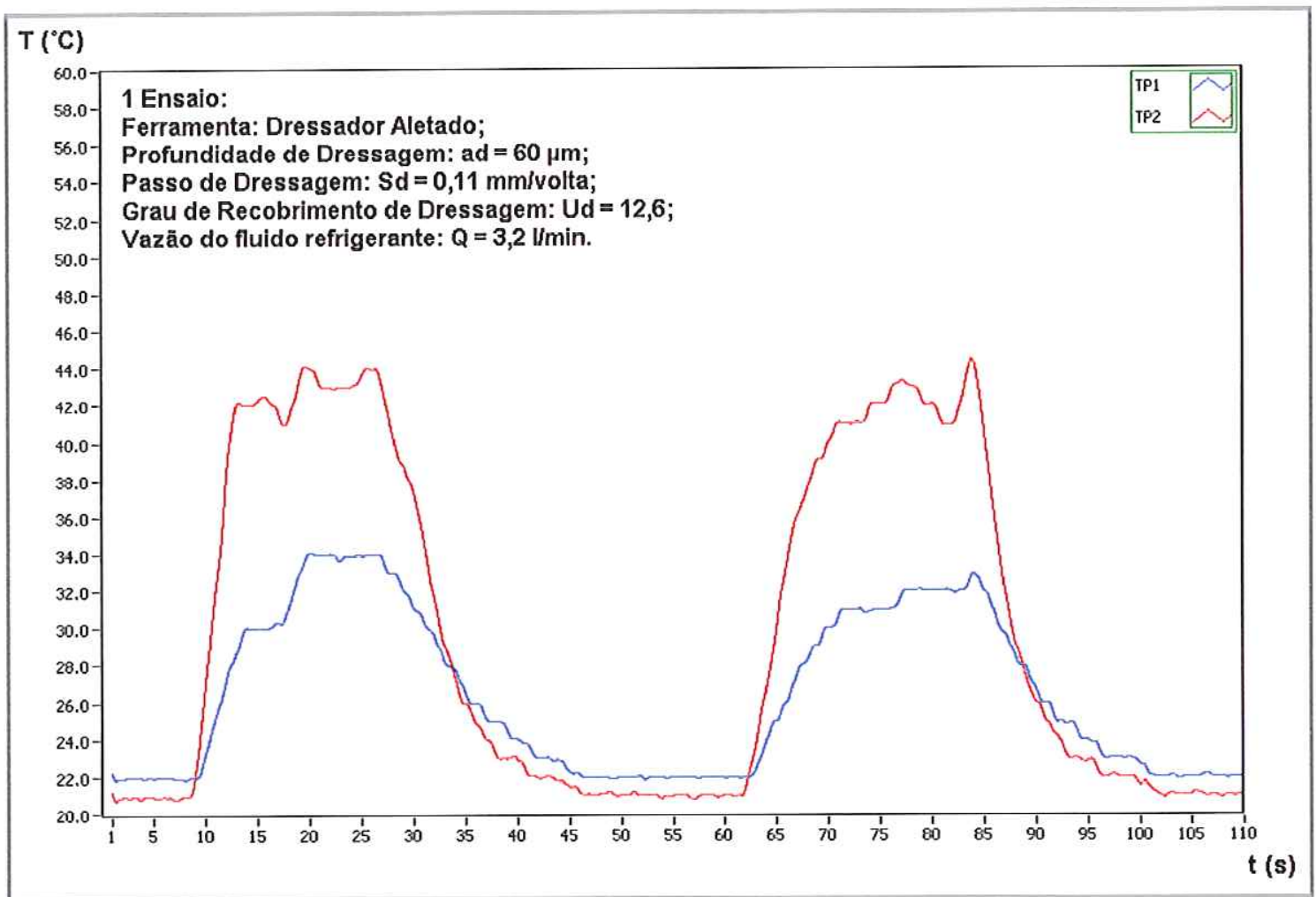

Figura C1: Temperaturas obtidas no $1^{0}$ ensaio com o dressador aletado. 


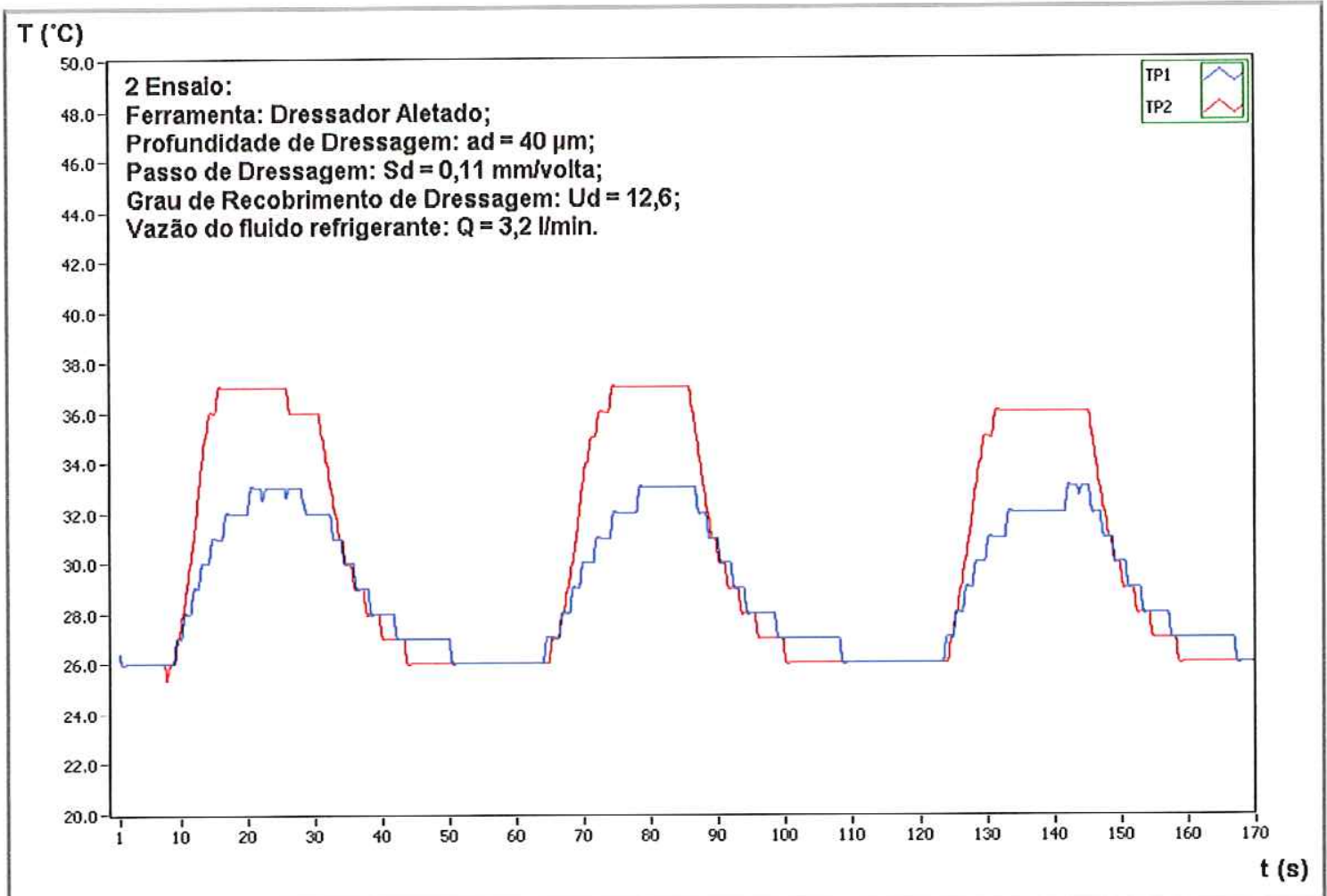

Figura C2: Temperaturas obtidas no $2^{\circ}$ ensaio com o dressador aletado.

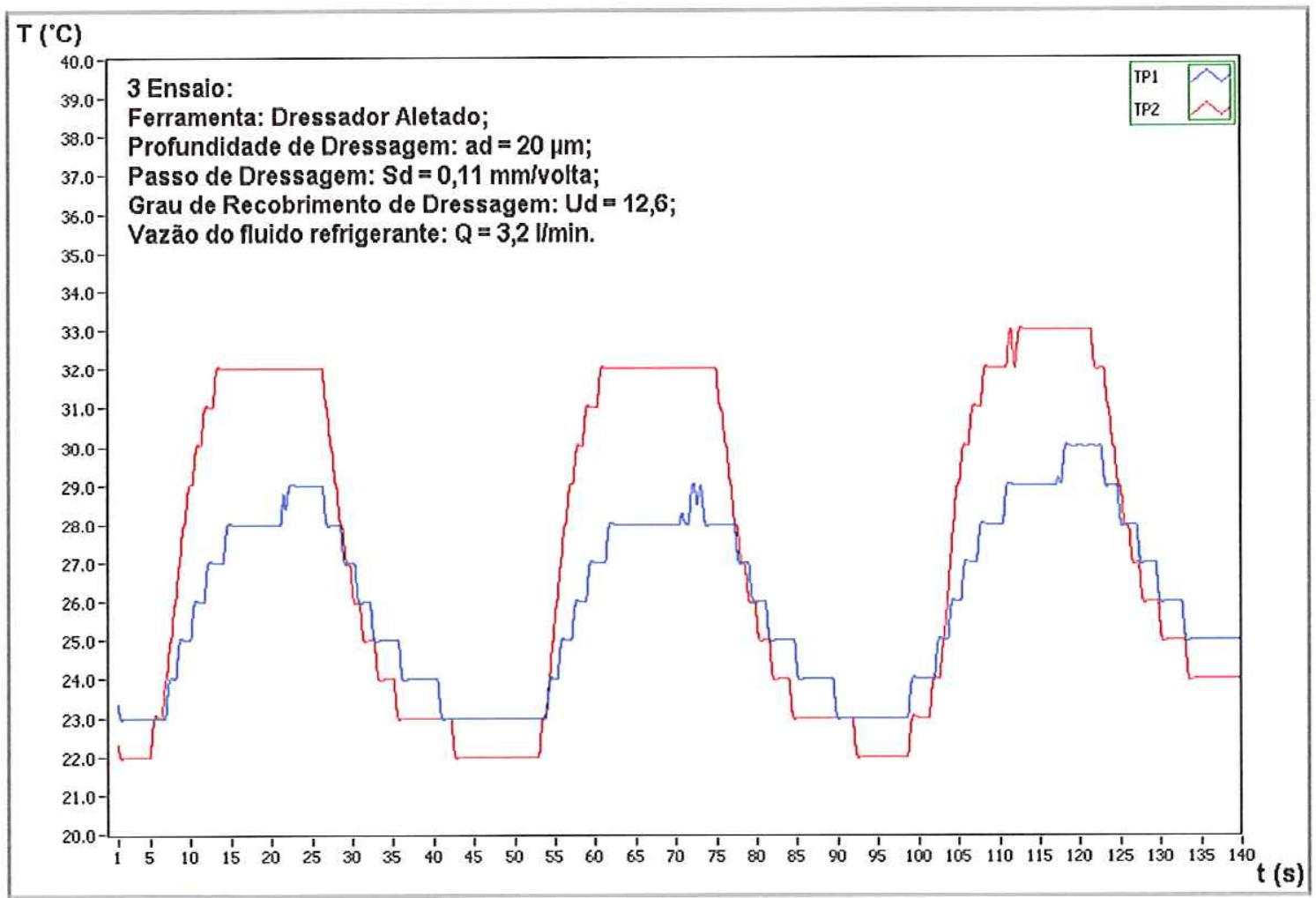

Figura C3: Temperaturas obtidas no $3^{\circ}$ ensaio com o dressador aletado. 


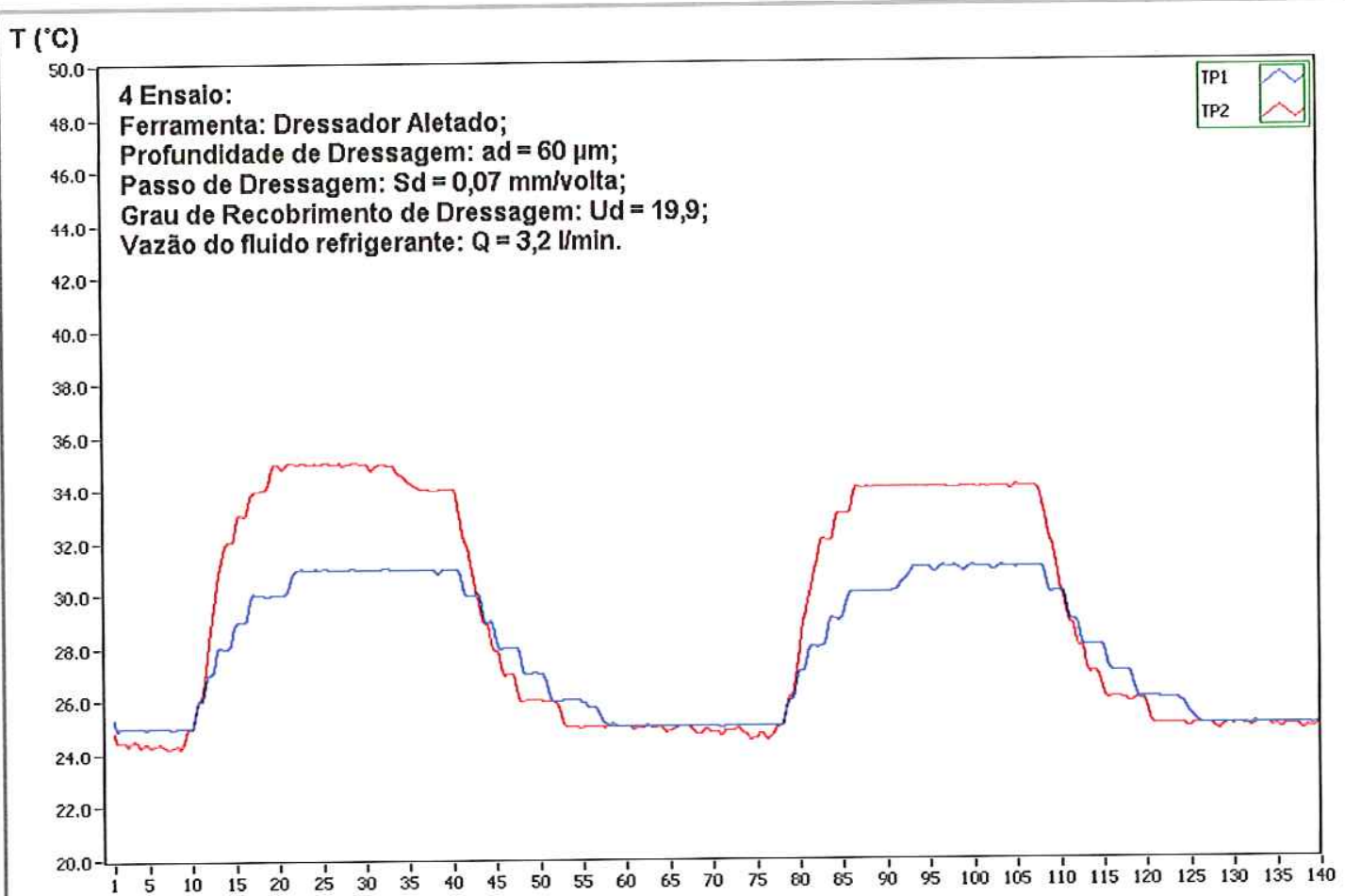

Figura C4: Temperaturas obtidas no $4^{\circ}$ ensaio com o dressador aletado.

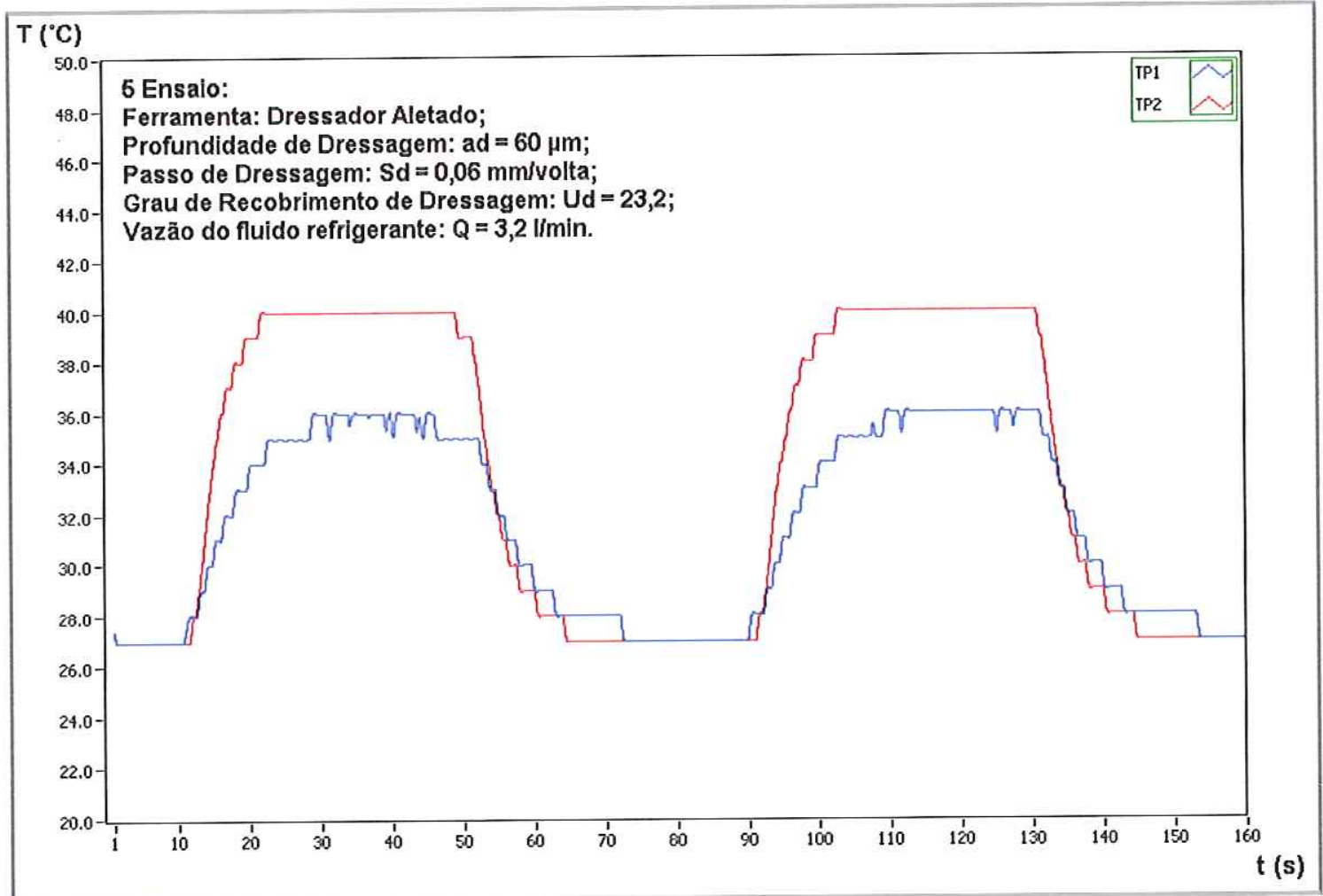

Figura C5: Temperaturas obtidas no $5^{\circ}$ ensaio com o dressador aletado. 


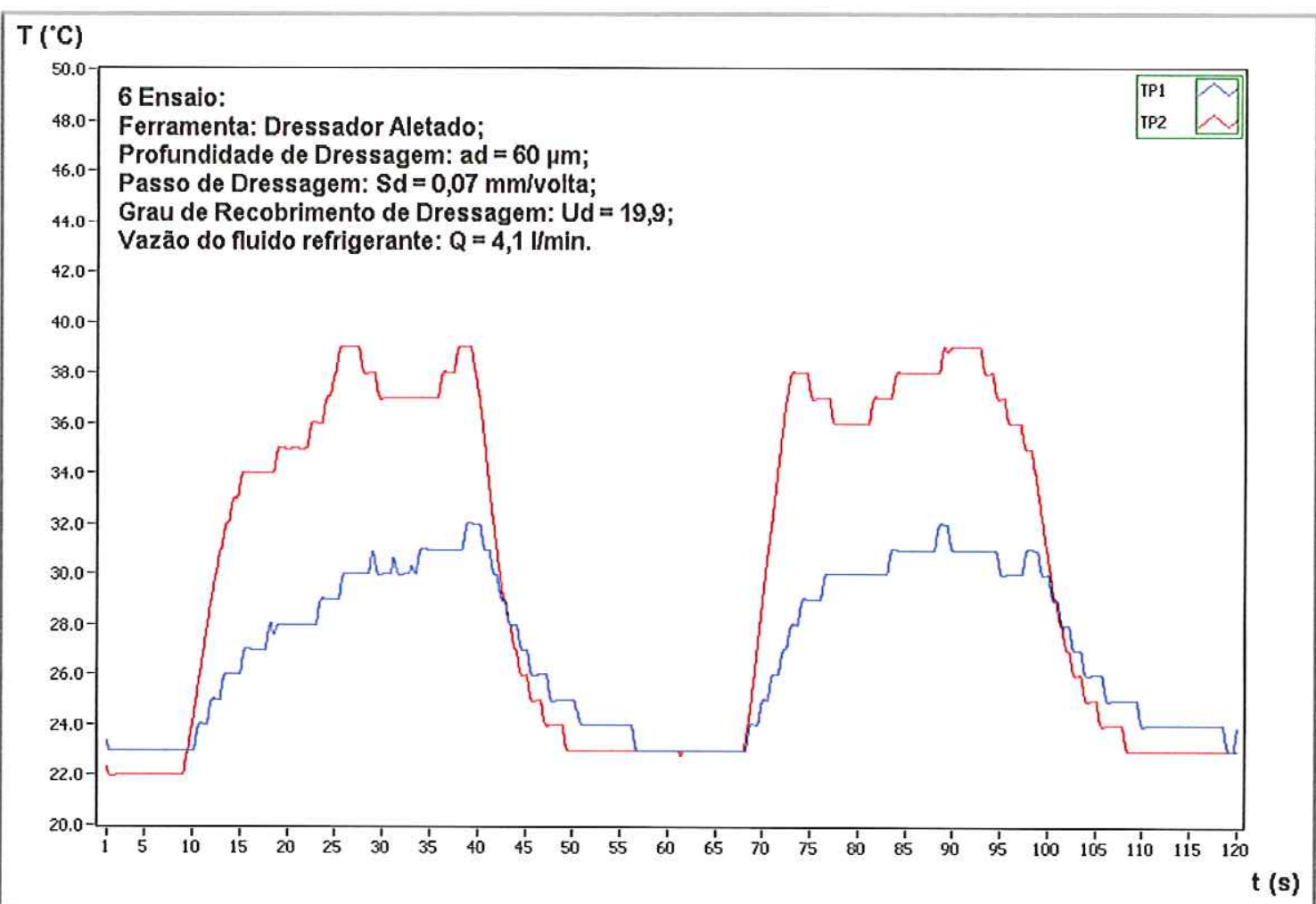

Figura C6: Temperaturas obtidas no $6^{\circ}$ ensaio com o dressador aletado.

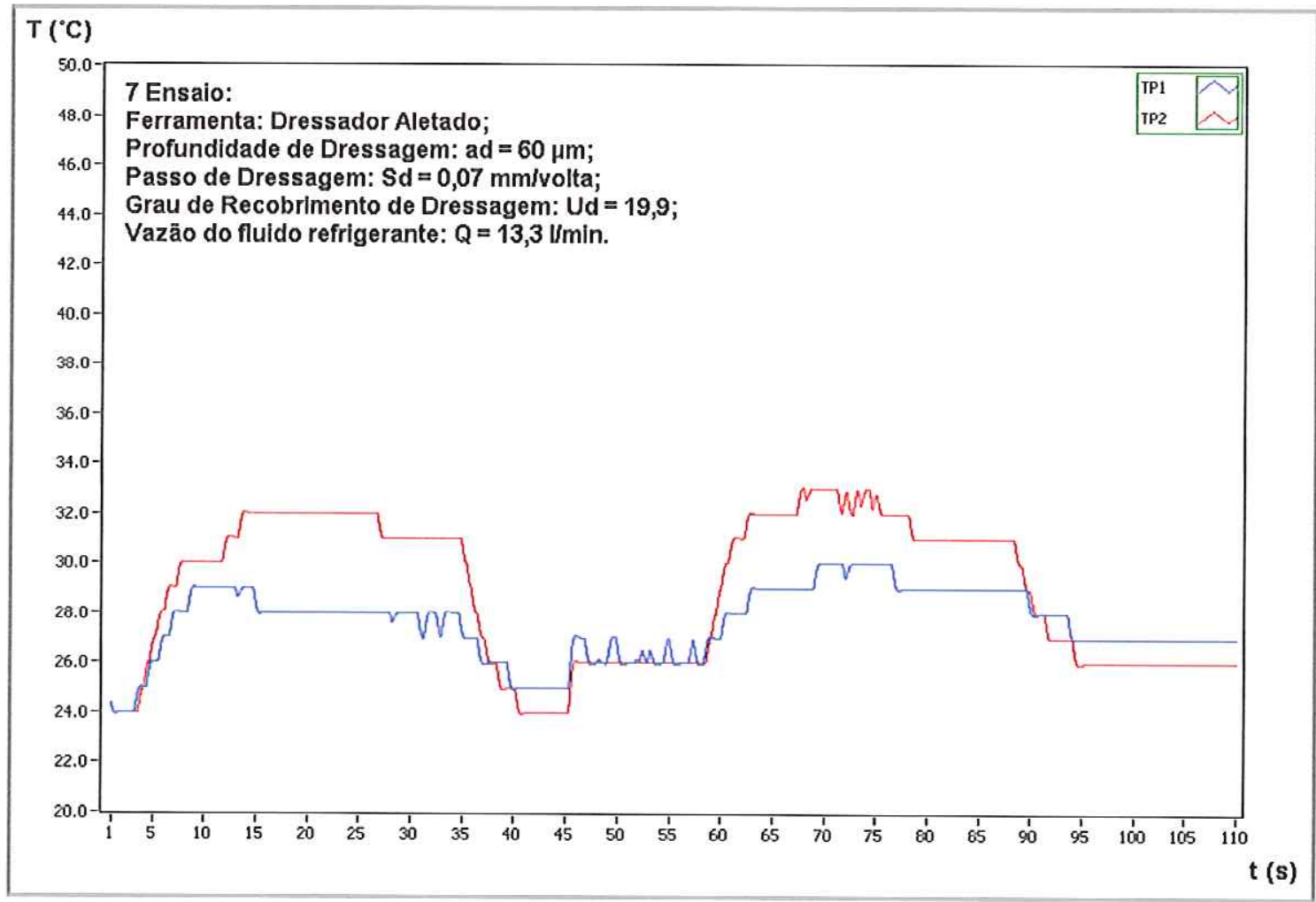

Figura C7: Temperaturas obtidas no $7^{\circ}$ ensaio com o dressador aletado. 